\title{
The hypercoagulable state in patients : determining (hyper)coagulability and the role of thrombin generation
}

Citation for published version (APA):

Dielis, A. W. (2009). The hypercoagulable state in patients : determining (hyper)coagulability and the role of thrombin generation. [Doctoral Thesis, Maastricht University]. Datawyse / Universitaire Pers Maastricht. https://doi.org/10.26481/dis.20090603ad

Document status and date:

Published: 01/01/2009

DOI:

10.26481/dis.20090603ad

Document Version:

Publisher's PDF, also known as Version of record

Please check the document version of this publication:

- A submitted manuscript is the version of the article upon submission and before peer-review. There can be important differences between the submitted version and the official published version of record.

People interested in the research are advised to contact the author for the final version of the publication, or visit the DOI to the publisher's website.

- The final author version and the galley proof are versions of the publication after peer review.

- The final published version features the final layout of the paper including the volume, issue and page numbers.

Link to publication

\footnotetext{
General rights rights.

- You may freely distribute the URL identifying the publication in the public portal. please follow below link for the End User Agreement:

www.umlib.nl/taverne-license

Take down policy

If you believe that this document breaches copyright please contact us at:

repository@maastrichtuniversity.nl

providing details and we will investigate your claim.
}

Copyright and moral rights for the publications made accessible in the public portal are retained by the authors and/or other copyright owners and it is a condition of accessing publications that users recognise and abide by the legal requirements associated with these

- Users may download and print one copy of any publication from the public portal for the purpose of private study or research.

- You may not further distribute the material or use it for any profit-making activity or commercial gain

If the publication is distributed under the terms of Article 25fa of the Dutch Copyright Act, indicated by the "Taverne" license above, 
The hypercoagulable state in patients

Determining (hyper)coagulability and the role of thrombin generation 
(C) Arne W.J.H. Dielis, Maastricht 2009

ISBN $97890 \quad 9024308 \quad 5$

Layout and cover by Arne W.J.H. Dielis

Printed by Datawyse BV | Universitaire Pers Maastricht

All rights reserved. No part of this thesis may be reproduced, stored in a retrieval system or transmitted in any form or by any means, without the permission in writing from the author, or, when appropriate, of the publishers of the publications. 


\title{
The hypercoagulable state in patients
}

\author{
Determining (hyper)coagulability \\ and the role of thrombin generation
}

\section{PROEFSCHRIFT}

ter verkrijging van de graad van doctor aan de Universiteit Maastricht op gezag van de Rector Magnificus, Prof. mr. G.P.M.F. Mols, volgens het besluit van het College van Decanen, in het openbaar te verdedigen op

woensdag 3 juni 2009 om 14:00 uur

door

Arne W.J.H. Dielis

geboren op 15 januari 1980 te Valkenswaard 


\section{Promotores}

Prof. dr. H. ten Cate

Prof. dr. P. de Leeuw

\section{Copromotores}

Dr. H.M.H. Spronk

Dr. K. Hamulyák

\section{Beoordelingscommissie}

Prof. dr. H.A.J. Struijker Boudier (voorzitter)

Prof. dr. M.J.A.P. Daemen

Prof. dr. A.P.M. Gorgels

Prof. dr. J.C. Meijers

Prof. dr. F.R. Rosendaal

Financial support by AstraZeneca, Bayer Schering Pharma, Boehringer Ingelheim, GlaxoSmithKline, Merck Sharp \& Dohme, Pfizer and Schering-Plough for the publication of this thesis is gratefully acknowledged. 
"El destino suele estar a la vuelta de la esquina. (...)

Pero lo que no hace es visitas a domicilio. Hay que ir a por él."

C.R. Zafón 



\section{Contents}

1 General introduction.

9

2 Blood coagulation anno 2009

3 Thrombin generation

3.1 Validation of the Calibrated Automated Thrombogram ..................... 33

3.2 Determinants of thrombin generation ............................................. 39

3.3 The influence of intrinsic coagulation on thrombin generation ............ 55

4 Coagulation-dependent hypercoagulability: Patients with arterial and venous thrombotic disease

4.1 Thrombin generation in patients with a first acute myocardial infarction 73

4.2 Thrombin generation in patients with deep venous thrombosis 91

4.3 Thrombin generation in patients with recurrent deep venous thrombosis

5 Fibrinolysis-dependent hypercoagulability: Patients with hypertension 119

5.1 The hypercoagulable state in hypertension 121

5.2 Correction of the hypertension-induced hypercoagulable state

6 Thrombin generation as a tool to assess prohaemostatic treatment

7 General discussion, summary and conclusions 175

7.1 General discussion, summary and conclusions.

7.2 Algemene discussie, samenvatting en conclusies

Curriculum vitae. 205

Publications 207

Dankwoord 

Chapter 1

General introduction 
Chapter 1 


\section{Coagulation and fibrinolysis - physiology}

Blood coagulation is a critical protective mechanism against bleeding from trauma. In the human body, coagulation (in concert with activated and aggregating platelets and the vessel wall) results in the formation of a stable thrombus when blood coagulation components and platelets come into contact with exposed tissue factor and collagen from damaged vasculature. ${ }^{1-4}$ This physiological response arrests bleeding, and is therefore known as "haemostasis". The importance of coagulation and platelet response can be appreciated from the bleeding diathesis apparent in patients with defects in blood coagulation and/or platelet response (for example coagulation factor deficiencies such as haemophilia A, B and C, or von Willebrand's disease).5,6

After initiation of the extrinsic coagulation cascade through activation of coagulation factor VII (FVII) by tissue factor, several coagulation factors (serine proteases and glycoproteins) are sequentially activated and result in the conversion of prothrombin into thrombin.2,7,8 The thrombin that is formed converts fibrinogen into fibrin, which, under the influence of FXIII activation, polymerizes to form a stable thrombus with platelets. ${ }^{9}$ The haemostatic response is sustained by thrombin, enhancing its own formation through positive feedback loops involving FV, FVIII and FXI, and by inhibiting fibrin degradation through activation of thrombin-activatable fibrinolyis inhibitor. 2,7,8,10-12 Simultaneous activation of anticoagulant proteins by thrombin and FXa (including protein C) and the presence of anticoagulant proteins (antithrombin, tissue factor pathway inhibitor) attenuate the haemostatic response and ensure localization to the site of the vessel injury. ${ }^{13-15}$

Restoration of the blood flow after a thrombus has been formed is accomplished by dissolving the fibrin clot by a mechanism called fibrinolysis. Plasminogen activators convert plasminogen to plasmin upon contact with fibrin molecules, and cross-linked fibrin is degraded to fibrin breakdown products of which D-dimer is a well-known example. ${ }^{16,17}$

While coagulation is a delicate balance between the actions of both pro- and anticoagulant proteins, and fibrinolysis is a balance between pro- and antifibrinolytic proteins, ultimately the quality of the haemostatic response is a balance between both systems. ${ }^{1,18}$

\section{The hypercoagulable state - pathophysiology}

Besides physiological coagulation activity as a response to vessel injury, changes in plasma components (both qualitative and quantitative), vessel wall and blood flow may lead to unfavorable and uncontrolled thrombus formation ("thrombosis"). This triad of domains was supposedly first described by Virchow in 1856. ${ }^{19,20}$ Unfavorable thrombus formation in the arterial system may lead to myocardial infarction and ischemic stroke, 
and deep venous thrombosis and pulmonary embolism in the venous system. Changes towards an increased potential of coagulation are collectively dubbed "hypercoagulability" and lead to a situation that is susceptible for thrombosis - the "hypercoagulable state".

Since changes in any of the domains (blood components, vessel wall, blood flow) can result in a hypercoagulable state, it is obvious that this term is used for a mere myriad of clinical disorders with several underlying mechanisms. ${ }^{21-24}$ Hypercoagulability should therefore be considered as a symptom rather than as a disorder. Two major mechanisms underlying the hypercoagulable state and their complications can be (arbitrarily) distinguished:

\section{Coagulation-dependent hypercoagulability}

A. associated with altered platelet response and vessel wall alterations: atherosclerosis leading to arterial thrombotic disease;

B. associated with blood flow impairment: venous stasis leading to venous thrombotic disease;

\section{Fibrinolysis-dependent hypercoagulability}

associated with vessel wall and blood flow alterations: hypertension leading to arterial thrombotic disease; deep venous thrombosis; diabetes mellitus.

Distinguishing these different hypercoagulable states is important in a clinical setting, since optimal treatment and prevention of thrombotic disease relies on influencing all domains of Virchow's triad involved. In a laboratory setting, the challenge is to objectively measure these hypercoagulable states.

\section{Determination of the hypercoagulable state}

If we consider hypercoagulability a symptom of ongoing disease and if we are able to approach a quantitative measurement of hypercoagulability, we would have a valuable tool to screen patients with an increased risk for thrombosis and to evaluate treatment and prevention strategies.

Established laboratory risk factors and predictors associated with arterial thrombotic disease are increased plasma soluble tissue factor, ${ }^{25}$ FXIIa, ${ }^{26}$ thrombinantithrombin complexes, ${ }^{27}$ prothrombin fragment $1+2^{27}$ and fibrinogen ${ }^{28}$ (coagulation), increased plasminogen activator inhibitor type-1,29,30 low tissue-type plasminogen activator, ${ }^{31,32}$ plasmin-antiplasmin complexes ${ }^{33}$ and persistently increased D-dimer ${ }^{34}$ (fibrinolysis). Associations with venous thrombotic disease are predominantly coagulation-dependent, with plasma risk factors such as high FVIII, ${ }^{35,36}$ low proteins $\mathrm{C}$ and $S,{ }^{37}$ low antithrombin, ${ }^{37}$ as well as FV Leiden ${ }^{38}$ and prothrombin gene mutations ${ }^{39}$ (coagulation), and persistently increased D-dimer after vitamin $\mathrm{K}$ antagonist 
cessation ${ }^{40,41}$ (fibrinolysis). Although associations with thrombotic risk of these markers have been extensively studied in epidemiological studies, their clinical relevance as a risk marker of hypercoagulability in individual patients is limited, and a standardized laboratory method to determine the overall potential of coagulation has been lacking in the past.

The introduction of the thrombin generation assay, in which coagulation in a plasma sample is activated and thrombin formation is followed in real-time, enables measurement of the coagulation potential of plasma. ${ }^{42}$ This assay reflects the balance between pro- and anticoagulant proteins, instead of focusing on a single parameter as in the risk factors described above. Fibrinolytic activity, however, cannot (yet) be probed with this technique.

Several iterations of the thrombin generation assay have been developed and described with a variety of activators, phospholipids and calibrators, but they all present thrombin formation in a thrombin generation curve. This curve does not only provide a quantification of the amount of formed thrombin, but it also gives insight in the contribution of the initiation, propagation and termination phases of coagulation. A typical example of a thrombin generation curve is depicted in Figure 1. Of the techniques available, we validated the Automated Calibrated Thrombogram ${ }^{43}$ (Thrombinoscope BV, Maastricht, The Netherlands) for use in our laboratory.

Figure 1. Thrombin generation curve and derived parameters lag time, endogenous thrombin potential (ETP), peak height, time to peak and slope. Lag time is defined as the time to reach onesixth of the peak height. The ETP corresponds to the area under the curve. Slope is defined as $5 / 6$. peak height / (time to peak - lag time).

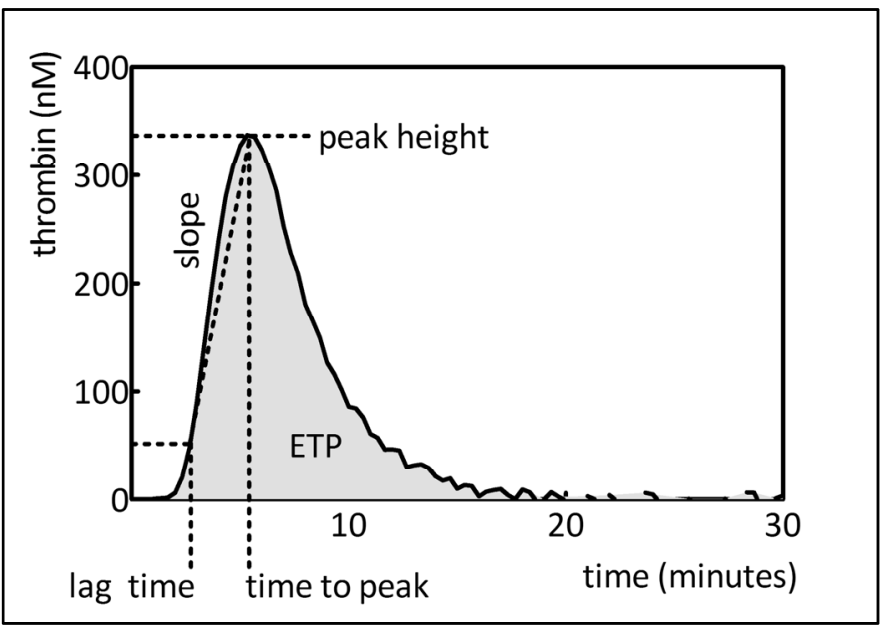




\section{Contents and structure of this thesis}

The research presented in this thesis describes coagulation- and fibrinolysis-dependent hypercoagulability and explores the possibility and clinical relevance of laboratory testing of these hypercoagulable states.

Chapter 2 provides an overview of recent insights in the relationship between coagulation, fibrinolysis and inflammation. Highlighted mechanisms are "contact activation", which seems to be more important for thrombus stabilization and fibrinolysis rather than the initiation of coagulation in vivo, tissue factor pathway inhibitor and the protein $\mathrm{C}$ system that are involved in attenuating inflammation besides their anticoagulant properties, and thrombin-activatable fibrinolysis inhibitor, which has pronounced effects on fibrinolysis. In addition, the central role of thrombin in all of these mechanisms is described.

The implementation and validation of the Calibrated Automated Thrombogram as a technique to measure thrombin generation in a laboratory setting is described in Chapter 3 , including recommendations on reproducibility, standardization and addition of corn trypsin inhibitor to prevent contact activation. Thrombin generation, coagulation factors and the protein $\mathrm{C}$ system were measured in healthy volunteers to establish the determinants of the thrombin generation curve under several test conditions.

Thrombin generation measurements were applied in two groups of patients with coagulation-dependent hypercoagulability: 1. patients with a first acute myocardial infarction, both during the acute phase and during follow-up; 2 . patients followed-up for deep venous thrombosis. In both groups thrombin generation was repeatedly measured in time, and was found to be associated with clinical outcome in these patients (recurrent atherothrombotic disease and cardiovascular death in acute myocardial infarction, and recurrent deep venous thrombosis). Thrombin generation was compared with kwown laboratory risk markers, such as FVIII and D-dimer (Chapter 4).

The fibrinolysis-dependent hypercoagulability that is present in hypertension, in which the renin-angiotensin system plays an important role, is the focus of Chapter 5 . The tight link between the renin-angiotensin system and contact activation is described in more detail. Fibrinolysis-dependent hypercoagulability and the pronounced effects of angiotensin II receptor blocking agents on plasminogen activator inhibitor type-1 and tissue-type plasminogen activator were studied in a cohort of hypertensive patients undergoing renal artery angiography.

The effects of prohaemostatic treatment on thrombin generation measurements (FVIII administration in haemophilia A patients) are presented in Chapter 6. Discrepancies between thrombin generation measurements and plasma FVIII level may reflect inter-individual differences in coagulation activity at comparable FVIII levels.

Chapter 7 concludes this thesis with a general discussion and conclusions. 


\section{References}

1. Spronk HM, Govers-Riemslag JW, ten Cate H. The blood coagulation system as a molecular machine. Bioessays. 2003;25:1220-1228.

2. Lane DA, Philippou H, Huntingon JA. Directing thrombin. Blood. 2005;106:2605-2612.

3. Dahlbäck B. Blood coagulation. Lancet. 2000;355:1627-1632.

4. Furie B, Furie BC. Mechanisms of thrombus formation. N Engl J Med. 2008;359:938-949.

5. Peyvandi F, Jayandharan G, Chandy M, Srivastava A, Nakaya SM, Johnson MJ et al. Genetic diagnosis of haemophilia and other inherited bleeding disorders. Haemophilia. 2006;12:8289.

6. Sadler JE, Mannucci PM, Berntorp E, Bochkov N, Boulyenkov V, Ginsburg D et al. Impact, diagnosis and treatment of von Willebrand disease. Thromb Haemost. 2000;84:160-174.

7. Mann KG, Brummel K, Butenas S. What is all that thrombin for? J Thromb Haemost. 2003;1:1504-1514.

8. Brummel KE, Paradis SG, Butenas S, Mann KG. Thrombin functions during tissue factorinduced blood coagulation. Blood. 2002;100:148-152.

9. Siebenlist KR, Meh DA, Mosesson MW. Protransglutaminase (factor XIII) mediated crosslinking of fibrinogen and fibrin. Thromb Haemost. 2001;86:1221-1228.

10. Østerud B, Rapaport SI. Activation of factor IX by the reaction product of tissue factor and factor VII: additional pathway for initiating blood coagulation. Proc Natl Acad Sci USA. 1977;74:5260-5264.

11. Walsh PN. Roles of platelets and factor XI in the initiation of blood coagulation by thrombin. Thromb Haemost. 2001;86:75-82.

12. Von dem Borne PA, Meijers JC, Bouma BN. Feedback activation of factor XI by thrombin in plasma results in additional formation of thrombin that protects fibrin clots from fibrinolysis. Blood. 1995;86:3035-3042.

13. Hackeng TM, Seré KM, Tans G, Rosing J. Protein S stimulates inhibition of the tissue factor pathway by tissue factor pathway inhibitor. Proc Natl Acad Sci USA. 2006;103:3106-3111.

14. Dahlbäck B, Villoutreix BO. The anticoagulant protein C pathway. FEBS Lett. 2005;579:33103316.

15. Baugh RJ, Broze GJ, Jr., Krishnaswamy S. Regulation of extrinsic pathway factor Xa formation by tissue factor pathway inhibitor. J Biol Chem. 1998;273:4378-4386.

16. Berrettini M, Schleef RR, Espana F, Loskutoff DJ, Griffin HJ. Interaction of type-1 plasminogen activator inhibitor with the enzymes of the contact activation system. J Biol Chem. 1989;264:11738-11743.

17. Loscalzo J, Schafer AI. Thrombosis and Hemorrhage. Boston, Mass: Blackwell Scientific Publications; 1994.

18. Gaffney PJ, Edgell TA, Whitton CM. The haemostatic balance - Astrup revisited. Haemostasis. 1999;29:58-71.

19. Brotman DJ, Deitcher SR, Lip GY, Matzdorff AC. Virchow's triad revisited. South Med J. 2004;97:213-214.

20. Dickson BC. Venous thrombosis: on the history of Virchow's triad. UTMJ. 2004;81:166-171.

21. Kuntz JG, Cheesman JD, Powers RD. Acute thrombotic disorders. Am J Emerg Med. 2006;24:460-467. 


\section{Chapter 1}

22. Zwicker JI, Furie BC, Furie B. Cancer-associated thrombosis. Crit Rev Oncol Hematol. 2007;62:126-136.

23. Schafer AI, Levine MN, Konkle BA, Kearon C. Thrombotic disorders: diagnosis and treatment. Hematology Am Soc Hematol Educ Program. 2003:520-539.

24. Nachman RL, Silverstein R. Hypercoagulable states. Ann Intern Med. 1993;119:819-827.

25. Seljeflot I, Hurlen M, Hole T, Arnesen H. Soluble tissue factor as predictor of futute events in patients with acute myocardial infarction. Thromb Res. 2003;111:369-372.

26. Govers-Riemslag JW, Smid M, Cooper JA, Bauer KA, Rosenberg RD, Hack E et al. The plasma kallikrein-kinin system and risk of cardiovascular disease in men. J Thromb Haemost. 2007;5:1896-1903.

27. Van der Putten RF, Glatz JF, Hermens WT. Plasma markers of activated hemostasis in the early diagnosis of acute coronary syndromes. Clin Chim Acta. 2006;371:37-54.

28. Danesh J, Wheeler JG, Hirschfield GM, Eda S, Eiriksdottir G, Rumley A. C-reactive protein and other circulating markers of inflammation in the prediction of coronary heart disease. $N$ Engl J Med. 2004;350:1387-1397.

29. Binder BR, Christ G, Gruber F, Grubic N, Hufnagl P, Krebs M, Mihaly J, Prager GW. Plasminogen activator inhibitor 1: physiological and pathophysiological roles. News Physiol Sci. 2002;17:56-61.

30. Corsetti JP, Ryan D, Moss AJ, Rainwater DL, Zareba W, Sparks CE. Plasminogen activator inhibitor-1 polymorphism (4G/5G) predicts recurrence in nonhyperlipidemic postinfarction patients. Arterioscler Thromb Vasc Biol. 2008;28:548-554.

31. Johansson L, Jansson JH, Boman K, Nilsson TK, Stegmayr B, Hallmans G. Tissue plasminogen activator, plasminogen activator inhibitor-1, and tissue plasminogen activator/plasminogen activator inhibitor-1 complex as risk factors for the development of a first stroke. Stroke. 2000;31:26-32.

32. Jansson JH, Olofssen BO, Nilsson TK. Predictive value of tissue plasminogen activator mass concentration on long-term mortality in patients with coronary artery disease. A 7-year follow-up. Circulation. 1993;88:2030-2034.

33. Cushman M, Lemaitre RN, Kuller LH, Psaty BM, Macy EM, Sharrett AR et al. Fibrinolytic activation markers predict myocardial infarction in the elderly. The Cardiovascular Health Study. Arterioscler Thromb Vasc Biol. 1999;19:493-498.

34. Danesh J, Whincup P, Walker M, Lennon L, Thomson A, Appleby P et al. Fibrin D-dimer and coronary heart disease: prospective study and meta-analysis. Circulation. 2001;103:23232327.

35. Kyrle PA, Minar E, Hirschl M, Bialonczyk C, Stain M, Schneider B et al. High plasma levels of factor VIII and the risk of recurrent venous thromboembolism. N Engl J Med. 2000;343:457462.

36. Legnani C, Cini M, Cosmi B, Poggi M, Boggian O, Palareti G. Risk of deep vein thrombosis: interaction between oral contraceptives and high factor VIII levels. Haematologica. 2004;89:1347-1351.

37. Dahlbäck B. Advances in understanding pathogenic mechanisms of thrombophilic disorders. Blood. 2008;112:19-27.

38. Castoldi E, Rosing J. Factor V Leiden: a disorder of factor V anticoagulant function. Curr Opin Hematol. 2004;11:176-181. 
39. Chinthammitr Y, Vos HL, Rosendaal FR, Doggen CJ. The association of prothrombin A19911G polymorphism with plasma prothrombin activity and venous thrombosis: results of the MEGA study, a large population-based case-control study. J Thromb Haemost. 2006;4:25872592.

40. Palareti G, Legnani C, Cosmi B, Guazzaloca G, Pancani C, Coccheri S. Risk of venous thromboembolism recurrence: high negative predictive value of $\mathrm{D}$-dimer performed after oral anticoagulation is stopped. Thromb Haemost. 2002;87:7-12.

41. Palareti G, Legnani C, Cosmi B, Valdre L, Lunghi B, Bernardi F et al. Predictive value of Ddimer test for recurrent venous thromboembolism after anticoagulation withdrawal in subjects with a previous idiopathic event and in carriers of congenital thrombophilia. Circulation. 2003;108:313-318.

42. Hemker HC, Al Dieri R, de Smedt E, Béguin S. Thrombin generation, a function test of the haemostatic-thrombotic system. Thromb Haemost. 2006;96:553-561.

43. Hemker HC, Giesen P, Al Dieri R, Regnault V, de Smedt E, Wagenvoord R et al. The Calibrated Automated Thrombogram (CAT): a universal routine test for hyper- and hypocoagulability. Pathophysiol Haemost Thromb. 2002;32:249-253. 



\section{Chapter 2}

\section{Blood coagulation anno 2009}

Advancing insights in the in vivo mechanisms of coagulation.

Adapted from:

Voortschrijdend inzicht in de werking van de bloedstolling in vivo.

Löwenberg EC ${ }^{1}$, Dielis AWJH², Meijers JC ${ }^{1}$, ten Cate $\mathrm{H}^{2}$, Levi M¹.

1 Inwendige Geneeskunde/Vasculaire Geneeskunde, Academisch Medisch Centrum, Universiteit van Amsterdam, Amsterdam, The Netherlands;

2 Interne Geneeskunde, Laboratorium voor Klinische Trombose en Haemostase, Cardiovascular Research Institute Maastricht, Maastricht University Medical Center, Maastricht, The Netherlands.

Nederlands Tijdschrift voor Geneeskunde. 2009;153:30-37. 
Chapter 2

\section{Abstract}

New knowledge about the mechanism of blood coagulation and the many ways in which coagulation, fibrinolysis and inflammation interact in vivo, has changed our current thinking about these processes and related medical conditions substantially. This article deals with the functional interactions between these systems and the key role of some regulatory proteins (such as thrombin, thrombin-activatable fibrinolysis inhibitor, and several physiological anticoagulants). 


\section{Introduction}

In the last few years, new insights in the mechanisms of physiological and pathological coagulation have been gained. The "classic" distinction between intrinsic and extrinsic coagulation has been shown to be false as initiation of coagulation in vivo is exclusively dependent on tissue factor (TF). This was reported previously in this journal. ${ }^{1}$

In this article we will provide a short overview of recent developments in coagulation, reviewing three current subjects: the mutual relationship between coagulation and inflammation; new insights in the "old" intrinsic coagulation; and thrombin-activatable fibrinolysis inhibitor (TAFI), a relatively novel factor that links coagulation and fibrinolysis.

\section{Coagulation and inflammation; a strong mutual relationship}

The activation of both coagulation and inflammation plays an important role in several vascular disorders, including thrombosis and atherosclerosis. It has become increasingly evident that a strong mutual relationship is present between these two processes. ${ }^{2}$

\section{Inflammation-mediated activation of coagulation}

The activation of coagulation, resulting in fibrin formation, as a result of inflammation is a physiological protective mechanism attenuating invasive micro-organisms and the subsequent inflammatory response. In a situation of uncontrolled inflammation and related excessive coagulation activity this fibrin formation itself may lead to disease. Hypercoagulability, or the increased susceptibility for thrombosis, associated with severe infections such as sepsis contributes to microvascular obstruction and organ failure. This general activation of coagulation can result in diffuse intravascular coagulation (DIC). ${ }^{3}$

$\mathrm{TF}$ plays an essential role in the initiation of coagulation by inflammation. In experimental endotoxinaemia and bacteriaemia blocking of TF activity fully prohibits thrombin formation. ${ }^{4,5}$ Normally, TF can only be detected in tissues that are not in direct contact with blood, for example the adventitia of large blood vessels. Proinflammatory cytokines are able to induce increased TF expression in activated mononuclear cells that are present in the circulation and in endothelial cells when coagulation is activated by an inflammatory response. ${ }^{6}$ When in direct contact with blood, TF complexes with activated coagulation factor VII (TF/FVIIa complex) and this complex converts FX into $\mathrm{FXa}$, which then generates small amounts of thrombin. The thrombin that is formed activates platelets and essential cofactors V and VIII. The procoagulant surface of 
activated platelets enhances thrombin formation through direct FX activation by the TF/FVIIa complex, and through indirect FXa generation via activation of FIX. FXa, in turn, forms the prothrombinase complex together with cofactor Va in the presence of calcium ions, and catalyzes the conversion of prothrombin into thrombin. The formation of thrombin, one of the key players in coagulation, leads to fibrin deposition (Figure 1). Platelets express P-selectin on their membrane after being activated by thrombin, and thereby increase thrombocyte adhesion to endothelium and leukocytes, and TF expression on monocytes. ${ }^{6}$

Inflammation is also capable of influencing coagulation through inhibition of physiological anticoagulants, of which antithrombin, tissue factor pathway inhibitor (TFPI) and the protein $\mathrm{C}$ system are the most important regulators. The major inhibitor of thrombin and FXa, antithrombin, is vastly decreased during inflammation because of a diminished synthesis, an increased degradation by activated neutrophil-derived elastase and an increased comsumption due to enhanced thrombin formation. ${ }^{7,8}$ In addition, the function of antithrombin is impaired due to a decrease in the amount of glycosaminoglycans on the endothelium, including heparan sulphates. ${ }^{9}$

TFPI is the major inhibitor of the TF/FVIIa complex. Administration of recombinant TFPI in supraphysiological concentrations in experimental endotoxaemia was found to block inflammation-induced formation of thrombin. ${ }^{10}$ Moreover, recombinant TFPI attenuates the activation of coagulation in patients with severe sepsis, although this did not result in a lower mortality in these patients. ${ }^{11}$

The protein $\mathrm{C}$ system, comprised of protein $\mathrm{C}$, thrombomodulin and the endothelial protein $\mathrm{C}$ receptor (EPCR), is also involved in the regulation of coagulation activity (Figure 2). Activation of protein $\mathrm{C}$ is catalyzed by thrombomodulin-bound thrombin and increased in the presence of EPCR. ${ }^{12}$ Furthermore, when bound to thrombomodulin, less thrombin is available and this limits thrombin-mediated fibrin formation and the binding of thrombin to activated platelets and inflammatory cells. The activity of the protein $\mathrm{C}$ system is lower during inflammation, mainly because cytokines induce a decrease in thrombomodulin and EPCR on the endothelial cell surface. ${ }^{13}$ In conclusion, mediators of inflammation inhibit several important physiological anticoagulants and sustain the hypercoagulable state that is associated with inflammation.

\section{Coagulation-mediated inflammation}

As stated above, inflammatory cells are able to activate coagulation but, inversely, coagulation can also influence inflammation. Protease-activatable receptors (PARs) play an essential role in coagulation-mediated inflammation. These receptors are present on the surface of endothelial cells, mononuclear cells and platelets. ${ }^{14}$ Coagulation proteins like thrombin, FXa and FVIIa activate PARs through proteolytic cleaving of the terminal part of the receptor leading to autoactivation by the neoterminus. This activation results 
in transmembrane signaling that induces cytokine and growth factor production.

The aforementioned protein $\mathrm{C}$ system (including thrombomodulin, protein $\mathrm{C}$ and EPCR) possesses inflammation-influencing properties (Figure 2). Thrombomodulin stimulates the activation of TAFI, which inhibits imflammation by inactivating complement factor $\mathrm{C} 5 \mathrm{a} .{ }^{15}$ Activated protein $\mathrm{C}$ (APC) attenuates inflammation through inhibition of endotoxin-induced cytokine production, ${ }^{16}$ particularly when bound to EPCR. ${ }^{17}$ Recombinant human APC (rh-APC) has been shown to have inflammationmodulating properties in addition to its anticoagulant function and is therefore used in the treatment of patients with severe sepsis.

The fibrinolytic system enhances the inflammatory response since both fibrinogen and fibrin stimulate the production of inflammatory mediators, ${ }^{18}$ and because fibrinolytic proteins enhance adhesion and migration of inflammatory cells, in particular urokinase-type plasminogen activator ( $\mathrm{u}-\mathrm{PA}$ ) and its receptor (u-PAR).

\section{Advancing insights in the functions of factor XII: from intrinsic coagulation to inflammation, fibrinolysis and thrombus stabilization}

In the last decade it has become clear that the "contact system" (the FXII-dependent pathway of coagulation) does not seem to play an important role in (intrinsic) coagulation in vivo, but instead is involved in fibrinolysis, vascular permeability, inflammation (through activation of the complement system) and thrombus stabilization. ${ }^{19}$ The contact system is involved in fibrinolysis with FXII that induces the conversion of plasminogen into plasmin, ${ }^{20}$ and with prekallikrein, which activates u-PA. The bradykinin that is subsequently formed releases tissue-type plasminogen activator (t-PA) (Chapter 5.1). ${ }^{20}$ Figure 3 schematically summarizes the functions of the contact system.

Although the contact system seems to be less important for in vivo coagulation, recent studies show that FXII-deficient mice have an increased tendency to form nonocclusive thrombi. This is probably caused by instability of these thrombi and a decreased adherence to the vessel wall. This observation indicates that FXII does not play a role in in vivo initiation of coagulation, but rather in thrombus stabilization. ${ }^{21}$ This is in agreement with studies in humans that show an association between low (activated) FXII and an increased risk of cardiovascular death, coronary artery disease and cerebrovascular accident. ${ }^{22}$ A possible explanation for this association is an increase in the risk of embolization of these non-occlusive thrombi. A recent case study in FXII-deficient patients, however, reported that FXII did not increase the risk of arterial thrombosis in the presence of classic risk factors such as smoking, hypertension and dyslipidaemia. ${ }^{23}$ 
Figure 1. Thrombin regulates coagulation, fibrinolysis and inflammation.

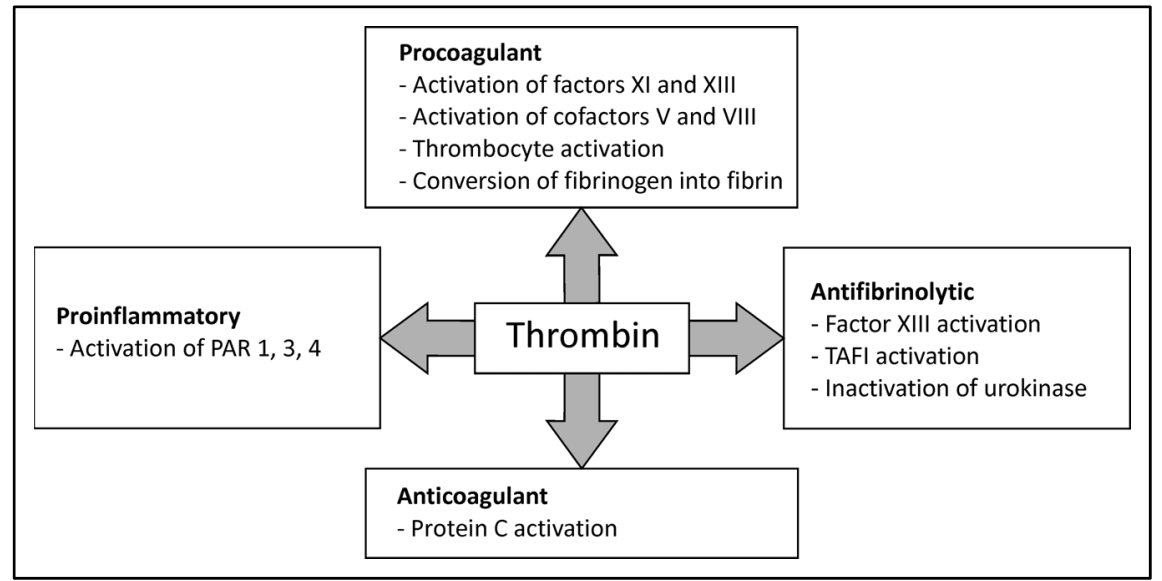

Thrombin possesses both procoagulant (activation of coagulation factors XI and XIII, cofactors V and VIII, thrombocytes, and the conversion of fibrinogen into fibrin) and anticoagulant properties (activation of protein C). In addition, thrombin has antifibrinolytic properties through the ability to activate FXIII and TAFI and inhibition of urokinase, and proinflammatory properties through activation of protease-activatable receptors type 1,2 and 4 .

\section{Thrombin-activatable fibrinolysis inhibitor, an important link between coagulation and fibrinolysis}

Thrombus stability is dependent on the balance between coagulation and fibrinolysis. The thrombin that is formed during coagulation plays a central role in the continuation of this balance (see Figure 1) by converting fibrinogen into fibrin and by activating coagulation factor XIII, which enhances thrombus stability through "cross-linking" of fibrin monomers. Thrombin is also involved in fibrinolysis through inactivation of urokinase and a more recently discovered protein: TAFI.

TAFI is a circulating inactive pro-enzyme in the blood, and is activated after proteolytic cleaving by thrombin. TAFI interacts with fibrin to inhibit fibrinolysis. Efficient activation of fibrinolysis is dependent on the binding of plasminogen and t-PA to $\mathrm{C}$-terminal lysine residues on fibrin molecules since these enhance plasmin formation. Activated TAFI (TAFIa) blocks this positive feedback loop by removing the necessary lysine residues, negatively affecting both plasmin formation and fibrinolysis.

TAFIa is an unstable and temperature-sensitive enzyme with a half-life of approximately 10 minutes at body temperature. The inactivation of TAFIa is predominantly the result of spontaneous changes in conformation rather than specific proteolytic breakdown. ${ }^{24}$ The function of TAFIa seems to be dependent on the level in 
Figure 2. The protein $\mathrm{C}$ system regulates coagulation, fibrinolysis and inflammation.

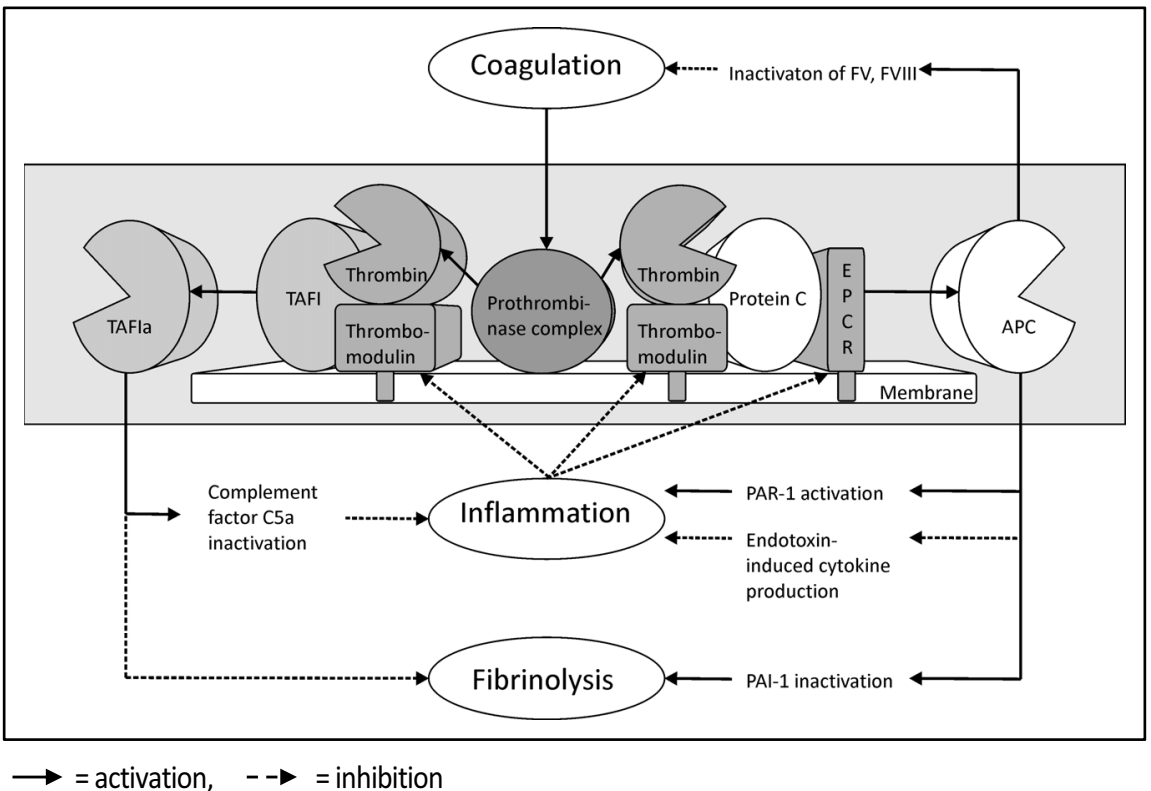

The prothrombinase complex, consisting of factor $\mathrm{Xa}$ and cofactor $\mathrm{Va}$, converts prothrombin into thrombin. Thrombin binds to thrombomodulin and, together with protein $\mathrm{C}$ and the endothelial protein $\mathrm{C}$ receptor (EPCR), acts as the protein $\mathrm{C}$ system. Thrombomodulin-bound thrombin activates both protein $\mathrm{C}$ and thrombin-activatable fibrinolysis activator (TAFI). Protein $\mathrm{C}$ activation is enhanced by binding of protein $C$ to EPCR. Activated protein $C$ (APC) has several distint functions and is able to inhibit coagulation (by inactivating cofactors $\mathrm{V}$ and $\mathrm{VIII}$ ), stimulate fibrinolysis (by inactivating plasminogen activator inhibitor type-1), and both activate and inhibit inflammation. Activated protein C suppresses endotoxin-induced cytokine production (anti-inflammatory), but it also activates protease-activatable receptor type-1 (PAR-1) that induces cytokine and growth factor production (proinflammatory). Inflammatory mediators reduce the expression of thrombomodulin and EPCR on the endothelial surface and give cause to an impaired protein $C$ system. Activation of TAFI by thrombomodulin-bound thrombin results in inhibition of fibrinolysis and inflammation (by inactivation of complement factor $\mathrm{C5a}$ ).

which it is present: only when the TAFIa concentration is above a certain threshold it is able to inhibit fibrinolysis. ${ }^{25}$ Thus, the duration of TAFIa acitivity is mostly dependent on both the plasma concentration and the level of inactivation. This mechanism is important for the development of TAFI-modulating medication because influencing the stability of the enzyme could have a more pronounced effect than merely changing its concentration.

Patients with bleeding disorders such as haemophilia A (FVIII deficiency), 
haemophilia B (FIX deficiency) and haemophilia C (FXI deficiency) predominantly present with late bleedings (ranging from hours to days after the injury) in tissues with locally high fibrinolytic activity (urinary tract, nasal and oral cavities) at normal plasma concentrations of FVII and FX. These characteristics suggest a defect in the TAFIamediated inhibition of fibrinolysis in addition to a defective fibrin formation. Tranexamic acid prevents the binding of plasminogen to fibrin, and administration to haemophilia patients undergoing dental extraction completely prevented bleedings that would typically occure three to five days after the intervention. ${ }^{26}$ Because haemophilia patients cannot produce sufficient amounts of thrombin there is not only a defect in the formation of thrombi, but also in the activation of TAFI. Therefore, the thrombus that is formed is less protected against degradation, leading to an increased bleeding tendency. Inversely, high TAFI levels increase thrombotic risk. ${ }^{27-29}$

\section{Conclusion}

Recent insights in the function of factors that are involved in coagulation, fibrinolysis and inflammation in vivo have changed our thinking about "classic" systems of these processes. There are important links between coagulation, fibrinolysis and inflammation on several levels, and the proteins that are involved have multiple effects on these processes, that may even seem contradictory at times.

Coagulation factor XII, regarded as the initiator of "intrinsic coagulation" for a long time, seems to be important for in vivo thrombus stabilization, fibrinolysis and regulation of vascular permeability and inflammation. Thrombin is involved in all these processes and has anticoagulant, procoagulant, proinflammatory and antifibrinolytic properties. TAFI inhibits both fibrinolytic and inflammatory activity (through inactivation of complement factor $\mathrm{C} 5 \mathrm{a}$ ). Activated protein $\mathrm{C}$ is simililarly involved in all processes.

Further research on mutual pathways involved in physiology and pathophysiology of coagulation, fibrinolysis and inflammation and their proteins is important for the development of thrombosis- and inflammation-modulating therapies. 
Figure 3. Functions of FXII.

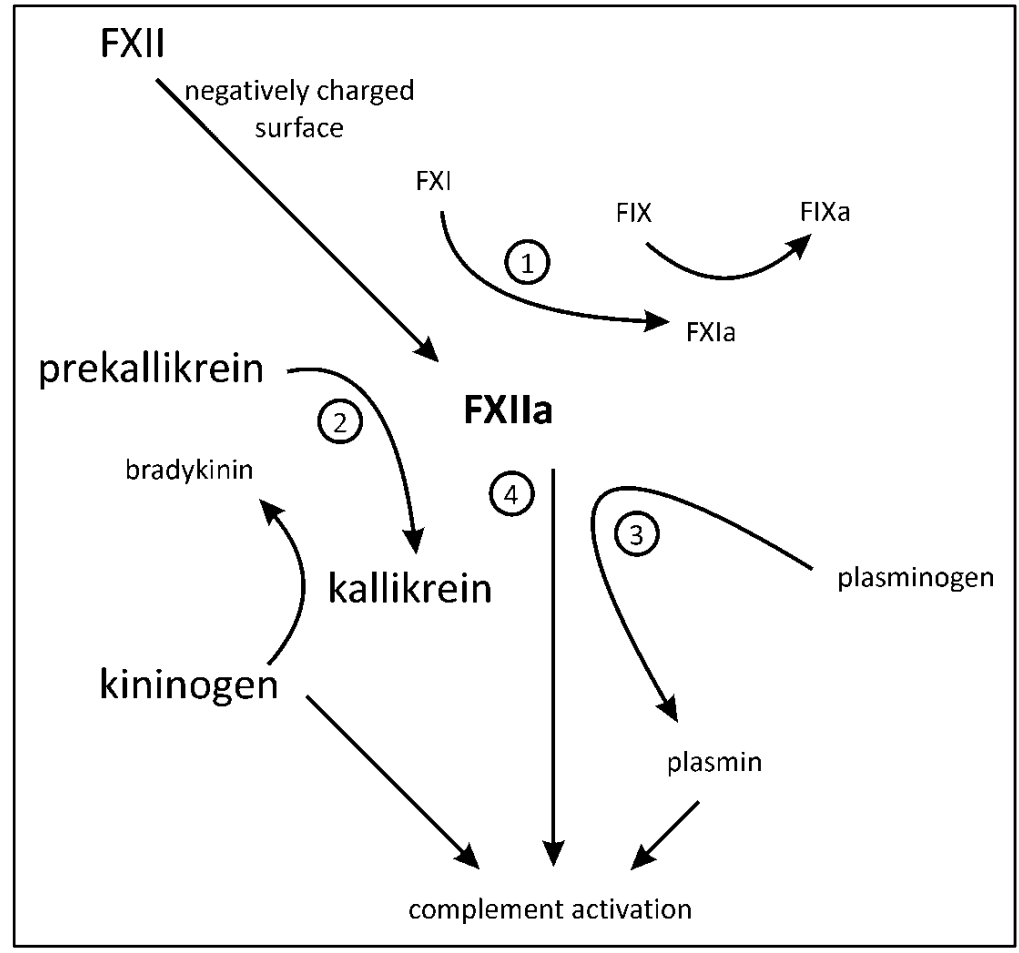

1. FXIla activates FXI, resulting in the formation of thrombin (intrinsic coagulation). This occurs in vitro, but does not seem to be relevant in vivo; 2 . FXIla influences vascular permeability via activation of prekallikrein to kallikrein and subsequent formation of bradykinin from high molecular weight kininogen; 3. FXIla activates fibrinolysis by generating plasmin; 4. FXIla activates the complement system both directly and indirectly via plasmin and kininogen. 


\section{References}

1. Ten Cate $H$, Levi $M$, Hack CE. Nieuwe inzichten en hypothese ten aanzien van de bloedstolling in vivo. Ned Tijdschr Geneeskd. 1993;137:282-287.

2. Levi M, van der Poll T. Two-way interactions between inflammation and coagulation. Trends Cardiovasc Med. 2005;15:254-259.

3. Levi M, ten Cate H. Disseminated intravascular coagulation. N Engl J Med. 1999;341:586592.

4. Taylor FB, Chang A, Ruf W, Morrissey JH, Hinshaw L, Catlett R et al. Lethal E. coli septic shock is prevented by blocking tissue factor with monoclonal antibody. Circ Shock. 1991;33:127134.

5. Levi M, ten Cate H, Bauer KA, van der Poll T, Edgington TS, Büller HR et al. Inhibition of endotoxin-induced activation of coagulation and fibrinolysis by pentoxifylline or by a monoclonal anti-tissue factor antibody in chimpanzees. J Clin Invest. 1994;93:114-120.

6. Shebuski RJ, Kilgore KS. Role of inflammatory mediators in thrombogenesis. J Pharmacol Exp Ther. 2002;300:729-735.

7. Vary TC, Kimball SR. Regulation of hepatic protein synthesis in chronic inflammation and sepsis. Am J Physiol. 1992;262:C445-C452.

8. Seitz R, Wolf M, Egbring R, Havemann K. The disturbance of hemostasis in septic shock: role of neutrophil elastase and thrombin, effects of antithrombin III and plasma substitution. Eur J Haematol. 1989;43:22-28.

9. Adachi T, Yamazaki N, Tasaki H, Toyokawa T, Yamashita K, Hirano K. Changes in the heparin affinity of extracellular superoxide dismutase in patients with coronary artery atherosclerosis. Biol Pharm Bull. 1998;21:1090-1093.

10. De Jonge E, Dekkers PE, Creasy AA, Hack CE, Paulson SK, Karim A et al. Tissue factor pathway inhibitor dose-dependantly inhibits coagulation activation without influencing the fibrinolytic and cytokine response during human endotoxemia. Blood. 2000;95:1124-1129.

11. Abraham E, Reinhart K, Opal S, Demeyer I, Doig C, Rodriguez AL et al. Efficacy and safety of tifacogin (recombinant tissue factor pathway inhibitor) in severe sepsis: a randomized controlled trial. JAMA. 2003;290:238-247.

12. Schouten M, Wiersinga WJ, Levi M, van der Poll T. Inflammation, endothelium, and coagulation in sepsis. J Leukoc Biol. 2008;83:536-545.

13. Faust SN, Levin M, Harrison OB, Goldin RD, Lockhart MS, Kondaveeti S et al. Dysfunction of endothelial protein $\mathrm{C}$ activation in severe meningococcal sepsis. $N$ Engl $\mathrm{J}$ Med. 2001;345:408-416.

14. Coughlin SR. Thrombin signalling and protease-activated receptors. Nature. 2000;407:258264.

15. Campbell W, Okada N, Okada H. Carboxypeptidase R is an inactivator of complementderived inflammatory peptides and an inhibitor of fibrinolysis. Immunol Rev. 2001;180:162167.

16. Murakami K, Okajima K, Uchiba M, Johno M, Nakagaki T, Okabe H et al. Activated protein C prevents LPS-induced pulmonary vascular injury by inhibiting cytokine production. Am J Physiol. 1997; 272:L197-L202.

17. Esmon CT. New mechanisms for vascular control of inflammation mediated by natural 
anticoagulant proteins. J Exp Med. 2002;196:561-564.

18. Szaba FM, Smiley ST. Roles for thrombin and fibrin(ogen) in cytokine/chemokine production and macrophage adhesion in vivo. Blood. 2002;99:1053-1059.

19. Colman RW, Schmaier AH. Contact system: a vascular biology modulator with anticoagulant, profibrinolytic, antiadhesive, and proinflammatory attributes. Blood. 1997;90:3819-3843.

20. Dielis AW, Smid M, Spronk HM, Hamulyák K, Kroon AA, ten Cate H et al. The prothrombotic paradox of hypertension. Role of the renin-angiotensin and kallikrein-kinin systems. Hypertension. 2005;46:1236-1242.

21. Kleinschnitz C, Stoll G, Bendszus M, Schuh K, Pauer HU, Burfeind P et al. Targeting coagulation factor XII provides protection from pathological thrombosis in cerebral ischemia without interfering with hemostasis. J Exp Med. 2006;203:513-518.

22. Govers-Riemslag JW, Smid M, Cooper JA, Bauer KA, Rosenberg RD, Hack CE et al. The plasma kallikrein-kinin system and risk of cardiovascular disease in men. J Thromb Haemost. 2007;5:1896-1903.

23. Girolami A, Morello M, Girolami B, Lombardi AM, Bertolo C. Myocardial infarction and arterial thrombosis in severe (homozygous) FXII deficiency: no apparent causative relation. Clin Appl Thromb Hemost. 2005;11:49-53.

24. Marx PF, Hackeng TM, Dawson PE, Griffin JH, Meijers JC, Bouma BN. Inactivation of active thrombin-activable fibrinolysis inhibitor takes place by a process that involves conformational instability rather than proteolytic cleavage. J Biol Chem. 2000;275:1241012415.

25. Leurs J, Nerme V, Sim Y, Hendriks D. Carboxypeptidase U (TAFIa) prevents lysis from proceeding into the propagation phase through a threshold-dependent mechanism. $J$ Thromb Haemost. 2004;2:416-423.

26. Walsh PN, Rizza CR, Matthews JM, Eipe J, Kernoff PB, Coles MD et al. Epsilon-Aminocaproic acid therapy for dental extractions in haemophilia and Christmas disease: a double blind controlled trial. Br J Haematol. 1971;20:463-475.

27. Van Tilburg NH, Rosendaal FR, Bertina RM. Thrombin activatable fibrinolysis inhibitor and the risk for deep vein thrombosis. Blood. 2000;95:2855-2859.

28. Eichinger S, Schonauer V, Weltermann A, Minar E, Bialonczyk C, Hirschl M. Thrombinactivatable fibrinolysis inhibitor and the risk for recurrent venous thromboembolism. Blood. 2004;103:3773-3776.

29. Silveira A, Schatteman KA, Goossens F, Moor E, Scharpé SS, Strömqvist M. Plasma procarboxypeptidase $U$ in men with symptomatic coronary artery disease. J Thromb Haemost. 2000;84:364-368. 



\section{Chapter 3}

Thrombin generation 
Chapter 3 


\title{
Validation of the Calibrated Automated Thrombogram
}

\begin{abstract}
Assessment of thrombin generation II: Validation of the Calibrated Automated Thrombogram in platelet-poor plasma in a clinical laboratory.
\end{abstract}

Spronk $\mathrm{HMH}^{1}$, Dielis AWJH ${ }^{1}$, de Smedt E ${ }^{2}$, van Oerle $\mathrm{R}^{1}$, Fens $\mathrm{D}^{1}$, Prins $\mathrm{MH}^{3}$, Hamulyák $\mathrm{K}^{4}$, ten Cate $\mathrm{H}^{1}$.

1 Department of Internal Medicine, Laboratory for Clinical Thrombosis and Haemostasis, Cardiovascular Research Institute Maastricht, Maastricht University Medical Center, Maastricht, The Netherlands;

2 Synapse BV, Cardiovascular Research Institute Maastricht, Maastricht University, Maastricht, The Netherlands;

3 Department of Epidemiology, Maastricht University, Maastricht, The Netherlands;

4 Department of Internal Medicine, Division of Haematology, Maastricht University Medical Center, Maastricht, The Netherlands.

Thrombosis and Haemostasis. 2008;100:362-364. 
Chapter 3.1 
Dear Sir,

Thrombin is one of the central enzymes in blood coagulation and both the rate of thrombin formation and the total amount of thrombin formed can be considered to be a reflection of the potential coagulation activity in plasma. ${ }^{1}$ This thrombin potential in plasma can be assessed by several methods, of which the Calibrated Automated Thrombogram (Thrombinoscope BV, Maastricht, The Netherlands) is one example. In this method a calibration factor is measured in a plasma sample identical to that in which thrombin generation is being determined and the course of the calibration factor is assessed during the entire experiment. ${ }^{1}$ In order to allow more extensive application of this thrombin generation methodology, we defined reproducibility, quality control, age and sex effects, and plasma collection at various time intervals in two cohorts of healthy individuals. The following groups of volunteers were used in this study: 1) individual plasmas from 139 healthy volunteers ( 72 females, 67 males) with a mean age of 54 years (range 20-90); 2) individual plasmas from 33 healthy volunteers (18 females, 15 males) with a mean age of 51 years at baseline, six weeks, 12 weeks, and one year. Normal pool plasma (NPP) from 80-90 healthy volunteers was used as reference plasma. Women using oral contraceptives and volunteers on anticoagulation therapy were not recruited. The study protocol was approved by the Medical Ethics Committee of the University Hospital Maastricht, The Netherlands, and informed consent was obtained from all participants. 3.2\% Citrated platelet-poor plasmas were prepared by two-step centrifugation: first, at $4000 \mathrm{~g}$ for 15 minutes followed by centrifugation at $10000 \mathrm{~g}$ for five minutes. All aliquots were snap frozen in liquid nitrogen, stored at $-80^{\circ} \mathrm{C}$ until use and thawed at $37^{\circ} \mathrm{C}$ for 15 minutes before analysis.

Thrombin generation was assessed according to the manufacturer's instructions (Thrombinoscope BV) in a 96-well plate fluorometer (Ascent Reader, Thermo Labsystems OY, Helsinki, Finland) equipped with a 390/460 filter set and a dispenser as previously described (Chapter 3.2). ${ }^{2}$ Final concentrations were 5 pM recombinant relipidated tissue factor (rTF) and $4 \mu \mathrm{M}$ phosphatidylserine / phosphatidylcholine / phosphatidylethanolamine vesicles in HEPES-buffered saline.

The intra-assay variations of the parameters derived from the thrombin generation curve were all below $6 \%$, whereas the inter-assay variations were all below $10 \%$ (over a one month period). Repeated analysis of NPP over a period of more than one year, however, revealed a decrease in thrombin generation for this control sample after approximately five months, as indicated by a decrease in endogenous thrombin potential (ETP) and peak height (Figure 1A). Four months later (at the nine-month interval) both ETP and peak height were restored to baseline levels, suggesting an influence of differences in reagent batches instead of plasma stability at $-80^{\circ} \mathrm{C}$. Also, thrombin generation, as indicated by decreased ETP and peak height (Figure 1B, E), was decreased after re-analysis of the platelet-poor plasmas from the 139 volunteers with an interval of five months, again suggesting one or more unstable reagents and 
supporting the need for normalization. It is unlikely that the observed differences were due to instability of frozen plasma since the decrease in thrombin generation was observed for both NPP collected in 2004 (Figure 1A, D) and 2005 (data not shown). Furthermore, for unknown reasons thrombin generation within the same samples was restored to baseline levels nine months after the first observed decrease. For normalization, ETP-values and peak heights of test samples were divided by the NPP value in the same run, and the ratios of $\mathrm{ETP}_{\text {patient }} / \mathrm{ETP}_{\mathrm{NPP}}$ and peak height $\mathrm{patient}_{\text {peak }}$ height $_{\mathrm{NPP}}$ of the 139 platelet-poor plasmas from healthy volunteers determined at baseline and after nine months showed no differences (Figure 1C, F), supporting the relevance of normalization. Due to this normalization it is not possible to define an actual reference range, but values should be given as percentage of the NPP.

There were significant differences in peak height and time to tail between females and males in the group of 139 healthy volunteers (peak height: males $0.97 \pm 0.16$ and females $1.04 \pm 0.17$ [95\%CI: 0.01 to 0.12 ], time to tail: males $1.07 \pm 0.13$ and females $1.03 \pm 0.09$ [95\%CI: -0.08 to -0.01 ), whereas the lag time, ETP, and time to peak were comparable between the two genders (data not shown).

Although the thrombin generation parameters ETP and peak height correlated with age $\left(R^{2}=0.0548, \quad P<0.01\right.$ and $R^{2}=0.0328, \quad P<0.05$, respectively), the calculated correlations were too weak to be of importance. For example, an increase of 10 years in age would predict an increase in ETP of 2.3 nM.min. Age has been reported, however, to be a determinant of thrombin generation; Haidl and colleagues showed strong correlations (ETP: $R=0.702$, peak height: $R=0.533, P<0.05$ ) between thrombin generation and age. ${ }^{3}$ Differences in observed correlations could be the result of variation in study cohorts since Haidl et al. included subjects with an age of 20 years and younger $(n=141)$, whereas our cohort consisted of subjects aged 22 to 90 years.

Thrombin generation in platelet-poor plasma from the 33 healthy volunteers collected at four different time points $(0,6,12$, and 52 weeks) was analyzed by repeated measures ANOVA. Both the ETP and peak height showed a quadratic trend with highest values at six weeks $(P<0.02$ and $P<0.05$, respectively). An increase in ETP between baseline and six weeks, followed by a subsequent decrease at 12 weeks is very unlikely in plasmas of 33 volunteers. It is, however, very likely that the observed differences were due to confounding since plotting the coefficient of variance (CV) of ETP against the average ETP showed scattering around the mean predictor within the $95 \%$ confidence interval for most of the analysis (data not shown).

We conclude that thrombin generation measurement can be well adopted in general laboratory settings using platelet-poor plasma samples obtained by routine vacuum blood collection. Internal calibration is required to correct for intra-assay variation while normalization against normal plasma corrects for significant temporal variation, and will be needed in order to compare plasmas from populations within and between institutes. 
Figure 1. Quality control and normalization of the Calibrated Automated Thrombogram. Panels A and C) Control platelet-poor plasma (NPP) was analyzed repeatedly within a time period of nine months. The first $\mathbf{3 0}$ analyses (black circles) of NPP were used to calculate mean and SD (solid and dotted lines, respectively) for ETP (A) and peak height (D). Panels B and E) Platelet-poor plasma from 139 volunteers was analyzed twice with an interval of nine months (Panels $C$ and F). The ETP of a given sample (ETP patient $_{\text {t }}$ ) was expressed as ratio of the ETP of the control platelet-poor plasma (ETP ${ }_{\text {NPP }}$ ) analyzed within the same 96-wells plate.

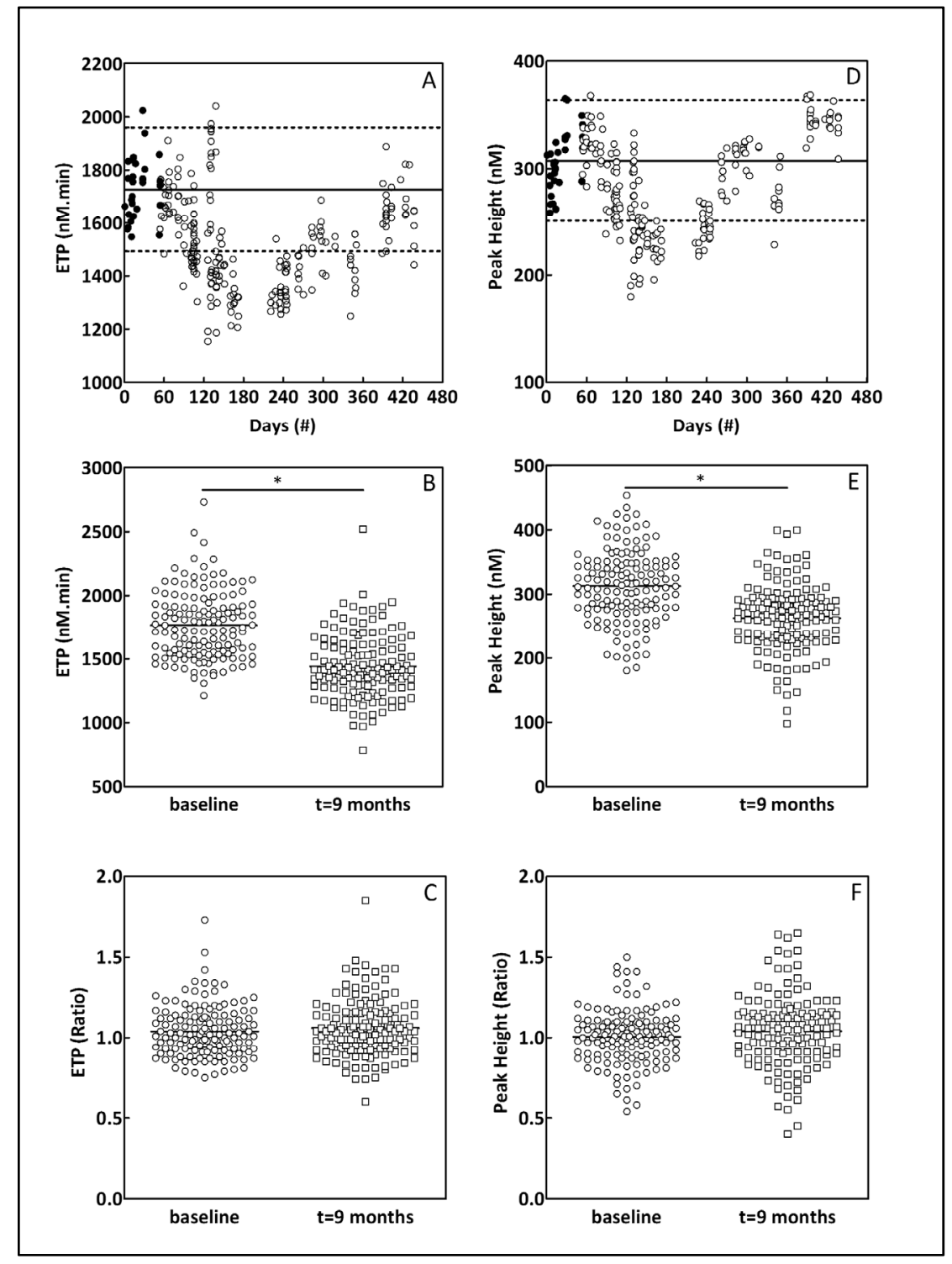

* denotes $P<0.05$. 
Chapter 3.1

\section{References}

1. Hemker HC, Giesen P, Al Dieri R, Regnault V, de Smedt E, Wagenvoord R et al. The Calibrated Automated Thrombogram (CAT): a universal routine test for hyper- and hypocoagulability. Pathophysiol Haemost Thromb. 2002;32:249-253.

2. Dielis AW, Castoldi E, Spronk HM, van Oerle R, Hamulyák K, ten Cate H et al. Coagulation factors and the protein $\mathrm{C}$ system as determinants of thrombin generation in a normal population. J Thromb Haemost. 2008;6:125-131.

3. Haidl H, Cimenti C, Leschnik B, Zach D, Muntean W. Age-dependency of thrombin generation measured by means of calibrated automated thrombography (CAT). Thromb Haemost. 2006;95:772-775. 


\section{Determinants of thrombin generation}

Coagulation factors and the protein $\mathrm{C}$ system as determinants of thrombin generation in a normal population.

Dielis AWJH ${ }^{1}$, Castoldi E2 , Spronk $\mathrm{HMH}^{1}$, van Oerle R ${ }^{3}$, Hamulyák $\mathrm{K}^{3}$, ten Cate $\mathrm{H}^{1}$, Rosing $\mathrm{J}^{2}$.

1 Department of Internal Medicine, Laboratory for Clinical Thrombosis and Haemostasis, Cardiovascular Research Institute Maastricht, Maastricht University Medical Center, Maastricht, The Netherlands;

2 Department of Biochemistry, Cardiovascular Research Institute Maastricht, Maastricht University, Maastricht, The Netherlands;

3 Department of Internal Medicine, Division of Haematology, Maastricht University Medical Center, Maastricht, The Netherlands.

Journal of Thrombosis and Haemostasis. 2008;6:125-131. 


\section{Summary}

Background: Thrombin generation is a powerful tool to probe overall plasma coagulability.

Objective: To determine which plasma factors influence the various parameters of the thrombin generation curve, for example lag time, peak height and endogenous thrombin potential (ETP), under different experimental conditions.

Patients and methods: Plasma levels of coagulation factors and inhibitors, as well as thrombin generation at $1 \mathrm{pM}$ tissue factor $(\mathrm{TF}) \pm$ thrombomodulin $(\mathrm{TM})$ and at $13.6 \mathrm{pM}$ $\mathrm{TF} \pm$ activated protein $\mathrm{C}$ (APC), were determined in plasma from 140 healthy individuals. Data were analyzed by multiple regression models.

Results: Thrombin generation increased with age and was higher in females than in males. Under all conditions, the lag time was mainly dependent on the levels of free tissue factor pathway inhibitor (TFPI), free protein S (PS), FVII, FIX and fibrinogen. The major determinants of thrombin generation (ETP and peak height) at $1 \mathrm{pM}$ TF were fibrinogen, FXII (despite inhibition of contact activation), free TFPI and antithrombin (AT), both in the absence and in the presence of TM. Thrombin generation in the presence of TM was also dependent on protein $\mathrm{C}$ levels. At $13.6 \mathrm{pM} \mathrm{TF}$, thrombin generation was determined by prothrombin, AT, fibrinogen, free TFPI and FV levels in the absence of APC, and by free TFPI, free PS and FX levels in the presence of APC.

Conclusions: The lag time, ETP and peak height of thrombin generation depend on the levels of multiple coagulation factors and inhibitors. The specific assay determinants vary with the experimental conditions. 


\section{Introduction}

Thrombin, the central enzyme in blood coagulation, ${ }^{1}$ is the end-product of the coagulation cascade which is initiated after the exposure of tissue factor (TF) on the sub-endothelium. Binding of circulating activated factor VII (FVIIa) to TF leads to the sequential activation of coagulation factors, eventually resulting in the conversion of prothrombin to thrombin. Once formed, thrombin converts fibrinogen into fibrin, activates platelets and stimulates the generation of more thrombin by enhancing upstream reactions by positive feedback loops (e.g. activation of coagulation FV, FVIII and FXI). After binding to thrombomodulin (TM) at the endothelial cell surface, thrombin also initiates the anticoagulant pathway by activating protein $\mathrm{C}$. Activated protein C (APC) and its cofactor protein S (PS) inhibit thrombin formation by proteolytically inactivating $\mathrm{FVa}$ and FVIIIa. $^{2}$ Thrombin generation is further downregulated by the tissue factor pathway inhibitor (TFPI)/PS system, which inhibits FXa and the TF/FVIIa complex, ${ }^{3,4}$ and by antithrombin (AT) which irreversibly blocks FXa and thrombin. ${ }^{5}$

Given the central role of thrombin in blood clotting, the tendency of a plasma sample to generate thrombin might contain useful information about thrombotic or haemorrhagic risk. Recently, an automated method (Calibrated Automated Thrombogram, CAT) has become available to follow in vitro thrombin generation in plasma after activation of coagulation with $\mathrm{TF}$, phospholipids and $\mathrm{CaCl}_{2 \cdot} 6,7$ The thrombin generation curve is characterized by a lag phase (initiation), followed by a thrombin burst (propagation) which is eventually completely inhibited by plasma protease inhibitors (termination). The area under the curve, known as the endogenous thrombin potential (ETP), represents the total amount of active thrombin formed.

Several studies have shown that the ETP is a good overall indicator of prothrombotic 7-12 and haemorrhagic tendency. ${ }^{7,13-16}$ However, despite sporadic attempts to elucidate the effects of single coagulation factors on thrombin generation, ${ }^{17-19}$ it remains unclear how the levels of coagulation factors and inhibitors influence the various parameters of the thrombin generation curve (lag time, ETP and peak height). To address this issue, we have used multiple regression analysis to dissect the effect of individual coagulation factors and inhibitors on thrombin generation parameters measured under different experimental conditions in a population of healthy individuals. 


\section{Materials and methods}

\section{Study population}

Blood samples were collected from 140 healthy volunteers (67 males, 47.9\%, and 73 females, 52.1\%). Mean age was 54 years (range 22-90 years). Women using oral contraceptives and individuals on anticoagulation therapy were not included. Six of the 140 individuals (4.3\%, four males and two females) were found to carry the factor $\mathrm{V}$ Leiden mutation ${ }^{20}$ and were subsequently excluded from the analysis.

\section{Blood collection and plasma preparation}

Venous blood was collected in $3.2 \%$ citrate $(\mathrm{w} / \mathrm{v})$. Platelet-poor plasma was prepared by two centrifugation steps: the first at $2000 \mathrm{~g}$ for 15 minutes and the second at 11000 $g$ for five minutes. Plasma aliquots were snap-frozen, stored at $-80^{\circ} \mathrm{C}$ and thawed at $37^{\circ} \mathrm{C}$ before analysis.

\section{Thrombin generation measurements}

Thrombin generation in platelet-poor plasma was measured with the CAT method, ${ }^{6}$ which employs a low affinity fluorogenic substrate for thrombin (Z-Gly-Gly-Arg-AMC) to continuously monitor thrombin activity in clotting plasma. According to the manufacturer's instructions, measurements were conducted on $80 \mu \mathrm{L}$ full plasma in a total volume of $120 \mu \mathrm{L}$ and in the presence of $416 \mu \mathrm{M}$ fluorogenic substrate and $16 \mathrm{mM}$ added $\mathrm{CaCl}_{2}$. In order to correct for inner-filter effects and substrate consumption, each thrombin generation measurement was calibrated against the fluorescence curve obtained in the same plasma with a fixed amount of thrombin- $\alpha_{2}$-macroglobulin complex (thrombin calibrator, Thrombinoscope BV, Maastricht, The Netherlands). Fluorescence was read in a Fluoroskan Ascent reader (Thermo Labsystems OY, Helsinki, Finland) equipped with a 390/460 filter set and thrombin generation curves were calculated with the Thrombinoscope software (Thrombinoscope BV). Three parameters were derived from the thrombin generation curves: lag time (min), ETP (nM.min) and peak height (nM).

Thrombin generation was determined under the following experimental conditions (final plasma concentrations): $1 \mathrm{pM}$ TF and $4 \mu \mathrm{M}$ phospholipids in the absence and presence of $1.5 \mathrm{nM}$ recombinant soluble TM (Asahi Kasei Pharma Corporation, Tagata, Japan); and $13.6 \mathrm{pM}$ TF and $20 \mu \mathrm{M}$ phospholipids in the absence and presence of $12 \mathrm{nM}$ plasma-derived human APC (Kordia Life Sciences, Leiden, The Netherlands). The $1 \mathrm{pM}$ TF trigger was a commercial product (PPP Reagent Low; Thrombinoscope BV, Maastricht, The Netherlands), while the $13.6 \mathrm{pM}$ trigger was prepared in-house by 
mixing recombinant TF (Hemoliance RecombiPlastin; Instrumentation Laboratory, Breda, The Netherlands) and a phospholipid emulsion containing phosphatidylserine, phosphatidylcholine and sphingomyelin (TGT-lipids; Rossix, Mölndal, Sweden). The concentrations of TM and APC were chosen such as to inhibit thrombin generation in normal plasma by $70 \%$ and $90 \%$, respectively. To prevent contact activation, the measurements at low TF ( $1 \mathrm{pM})$ were performed in the presence of $33 \mu \mathrm{g} \mathrm{mL}^{-1}$ corn trypsin inhibitor (CTI; Haematologic Technologies Inc, Essex Junction, VT, USA), a specific inhibitor of FXIIa. In control experiments, this CTI concentration was found to completely abolish thrombin generation in plasma spiked with phospholipids only (no TF) and to reduce the ETP and thrombin peak height by $30-40 \%$ in plasma triggered with $1 \mathrm{pM}$ TF (data not shown).

A TM ratio was calculated by dividing the ETP obtained in the presence of TM by the ETP in the absence of TM, both measured at 1 pM TF. Similarly, a normalized APC sensitivity ratio (nAPCsr) was calculated by dividing the ETP obtained in the presence of APC by the ETP in the absence of APC, both measured at $13.6 \mathrm{pM} \mathrm{TF}$, and by normalizing this ratio by the ETP ratio of normal plasma in the same run.

\section{Measurement of plasma factor levels}

Plasma fibrinogen levels were measured with the Clauss method. All other coagulation factor levels were determined by one-stage PT-based (prothrombin, FV, FVII, FX) or aPTT-based (FVIII, FIX, FXI, FXII) clotting assays. AT levels (FXa inhibitory activity) and protein C levels (amidolytic activity after activation with Protac) were measured chromogenically. All assays were performed on a Sysmex CA-7000 Automated Coagulation Analyzer with reagents obtained from Dade Behring (Liederbach, Germany). Total PS was measured by a home-made ELISA, as described. ${ }^{21}$ Free PS and free TFPI antigen levels were determined with the respective Asserachrom ELISA kits (Diagnostica Stago, Asnières sur Seine, France), and TFPI activity with the Actichrome TFPI activity assay (American Diagnostica, Stamford, CT, USA). Factor levels are expressed as $\mathrm{U} \mathrm{dL}^{-1}$, except for fibrinogen (expressed as $\mathrm{mg} \mathrm{mL}^{-1}$ ) and free TFPI antigen and activity (expressed as $\mathrm{ng} \mathrm{mL}^{-1}$ ). All plasma factor level measurements employed commercially available standards (Dade Behring) calibrated to WHO standards.

\section{Statistical analysis}

Data are expressed as mean \pm standard deviation (SD). Differences between parameters of the different thrombin generation measurements $(1 \mathrm{pM}$ and $13.6 \mathrm{pM}$ TF with and without added TM or APC) were analyzed using paired Student's $t$-test, whereas differences between genders were analyzed using Student's $t$-test. Correlations were expressed as Pearson's coefficients. A two-tailed probability value $P<0.05$ was 
considered statistically significant.

To assess the determinants of thrombin generation parameters, multiple linear regression analysis was performed with lag time, ETP and peak height as dependent variables and plasma levels of coagulation factors and inhibitors as independent variables, as previously described. ${ }^{22}$ For each model, the adjusted $R^{2}$ and the standardized regression coefficients (beta) of the independent variables were calculated. The beta indicates the change of the dependent variable, expressed in SD, when the independent variable increases one SD and all other variables in the model remain unchanged. The higher the beta, the larger the effect of the particular plasma factor on thrombin generation for variations of that factor level within its physiological range.

Statistics were computed using SPSS for Windows, version 12.0 (SPSS Inc., Chicago, IL, USA). 


\section{Results}

\section{Thrombin generation parameters}

After exclusion of FV Leiden carriers $(n=6)$, there were 134 individuals available for analysis. Thrombin generation parameters determined at $1 \mathrm{pM}$ TF with and without added TM, and at 13.6 pM TF with and without added APC are presented in Table 1.

Thrombin generation curves measured at $1 \mathrm{pM}$ TF showed longer lag times and lower ETPs and peaks than at $13.6 \mathrm{pM}$ TF $(P<0.001)$. Addition of TM to the $1 \mathrm{pM}$ TF assay resulted in a significant decrease of the ETP and peak height $(P<0.001)$, and in a small but significant reduction of the lag time $(P<0.001)$. Addition of APC to the $13.6 \mathrm{pM}$ TF measurement prolonged the lag time and decreased both the ETP and peak height $(P<0.001)$.

Lag times, ETPs and peak heights obtained at $1 \mathrm{pM}$ TF with and without TM and at $13.6 \mathrm{pM}$ TF without APC showed a positive correlation with age ( $R$ between 0.23 and $0.39, P<0.01)$. When thrombin generation parameters were analyzed according to gender, females showed shorter lag times $(P=0.002)$ and higher ETPs and peak heights $(P<0.001)$ than males in the $13.6 \mathrm{pM}$ TF assay with APC.

\section{Correlations between lag time, ETP and peak height}

At $1 \mathrm{pM}$ TF, ETP and peak height were strongly correlated $(R=0.92, P<0.001)$, while the lag time showed a weak inverse correlation with the ETP $(R=-0.24, P<0.01)$. The same trend was observed at $13.6 \mathrm{pM}$ TF, with a strong correlation between ETP and peak height $(R=0.80, P<0.001)$ and a weak correlation between lag time and ETP $(R=0.22$, $P=0.01)$.

All thrombin generation parameters measured at $1 \mathrm{pM}$ TF in the presence of TM showed a positive correlation with the corresponding parameters determined in the absence of TM ( $R$ between 0.88 and $0.95, P<0.001)$. At $13.6 \mathrm{pM} \mathrm{TF}$, only the lag time and peak height in the presence of APC correlated with the corresponding parameters without APC $(R=0.55, P<0.001$ and $R=0.36, P<0.001$, respectively $)$, whereas the ETPs determined in the absence and presence of APC did not correlate with each other.

\section{Effects of age and sex on the levels of coagulation factors and inhibitors}

The levels of coagulation and inhibitors in the population under study $(n=134, F V$ Leiden carriers excluded) are presented in Table 2. Females had higher levels of fibrinogen, FVII, FX, FXI, AT and protein C, but lower levels of free PS, than males.

The levels of fibrinogen, FV, FVII, FVIII, FIX, FX, FXI, protein C, total PS and free TFPI 
Table 1. Parameters of thrombin generation determined at $1 \mathrm{pM}$ tissue factor (TF) in the absence and presence of thrombomodulin (TM), and at $13.6 \mathrm{pM}$ TF in the absence and presence of activated protein $\mathrm{C}$ (APC).

\begin{tabular}{|c|c|c|c|}
\hline & $\begin{array}{l}\text { Lag time } \\
\text { (min) }\end{array}$ & $\begin{array}{l}\text { ETP } \\
\text { (nM.min) }\end{array}$ & $\begin{array}{l}\text { Peak height } \\
(\mathrm{nM})\end{array}$ \\
\hline \multicolumn{4}{|l|}{ All samples ( $n=134$ ) } \\
\hline $1 \mathrm{pM} \mathrm{TF}$ & $5.84 \pm 1.65$ & $995 \pm 289$ & $116 \pm 50.8$ \\
\hline $1 \mathrm{pM} \mathrm{TF}+\mathrm{TM}$ & $5.57 \pm 1.85$ & $299 \pm 143$ & $59.6 \pm 34.2$ \\
\hline $13.6 \mathrm{pM}$ TF & $2.67 \pm 0.38$ & $1490 \pm 224$ & $335 \pm 40.7$ \\
\hline 13.6 pM TF + APC & $4.34 \pm 0.88$ & $152 \pm 107$ & $31.8 \pm 27.1$ \\
\hline \multicolumn{4}{|l|}{ Males (n=63) } \\
\hline $1 \mathrm{pM} \mathrm{TF}$ & $6.06 \pm 1.52$ & $948 \pm 300$ & $113 \pm 55.2$ \\
\hline $1 \mathrm{pM} \mathrm{TF}+\mathrm{TM}$ & $5.81 \pm 1.79$ & $280 \pm 150$ & $56.1 \pm 36.4$ \\
\hline $13.6 \mathrm{pM}$ TF & $2.72 \pm 0.39$ & $1480 \pm 239$ & $328 \pm 38.0$ \\
\hline $13.6 \mathrm{pM} \mathrm{TF}+\mathrm{APC}$ & $4.62 \pm 1.01$ & $99.9 \pm 73.9$ & $18.9 \pm 17.8$ \\
\hline \multicolumn{4}{|l|}{ Females ( $n=71)$} \\
\hline $1 \mathrm{pM} \mathrm{TF}$ & $5.66 \pm 1.74$ & $1030 \pm 277$ & $119 \pm 47.3$ \\
\hline $1 \mathrm{pM} \mathrm{TF}+\mathrm{TM}$ & $5.38 \pm 1.89$ & $315 \pm 137$ & $62.5 \pm 32.2$ \\
\hline $13.6 \mathrm{pM}$ TF & $2.62 \pm 0.36$ & $1490 \pm 212$ & $342 \pm 42.1^{*}$ \\
\hline $13.6 \mathrm{pM} \mathrm{TF}+\mathrm{APC}$ & $4.11 \pm 0.69 *$ & $194 \pm 111^{*}$ & $42.2 \pm 28.9 *$ \\
\hline
\end{tabular}

Data are expressed as mean \pm SD. ${ }^{*}$ denotes $P<0.05$ compared with males.

showed a positive correlation with age ( $R$ between 0.19 and $0.50, P<0.05)$, whereas AT levels tended to decrease with age $(R=-0.16, P=0.066)$.

\section{Dependence of thrombin generation parameters on coagulation factors and inhibitors}

Standardized regression coefficients of the candidate determinants and adjusted $R^{2}$ of the linear regression models for the $1 \mathrm{pM}$ TF and $13.6 \mathrm{pM}$ TF measurements are reported in Tables 3 and 4, respectively.

At $1 \mathrm{pM}$ TF (Table 3), the lag time of thrombin generation was mainly determined by the levels of free TFPI, free PS, FIX and fibrinogen, both in the absence and presence of TM. Differently, the ETP and peak height were mainly dependent on fibrinogen and FXII levels (positive determinants), and free TFPI and AT levels (negative determinants). In the presence of TM, protein $\mathrm{C}$ was an additional negative determinant of the ETP and 
peak height.

At $13.6 \mathrm{pM}$ TF (Table 4), the lag time of thrombin generation was dependent on the levels of fibrinogen, FVII and free TFPI, both in the absence and presence of APC. However, the major predictors of the lag time measured in the presence of APC were FV and FIX levels. The ETP and peak height were mainly determined by fibrinogen, prothrombin, AT, free TFPI, and FV levels in the absence of APC, and by free PS, free TFPI and FX levels in the presence of APC.

The TM ratio showed an excellent correlation with the ETPs obtained both in the absence $(R=0.61, P<0.001)$ and presence $(R=0.89, P<0.001)$ of TM. Differently, the nAPCsr correlated only with the ETP measured in the presence of APC $(R=0.97$, $P<0.001)$. The determinants of the TM ratio and nAPCsr largely overlapped with those of the underlying ETPs (Tables 3 and 4).

Table 2. Coagulation factor and inhibitor levels.

\begin{tabular}{|c|c|c|c|}
\hline & All samples ( $n=134)$ & Males (n=63) & Females $(n=71)$ \\
\hline & Mean \pm SD & Mean $\pm S D$ & Mean \pm SD \\
\hline Fibrinogen $\left(\mathrm{mg} \mathrm{mL}^{-1}\right)$ & $3.23 \pm 0.54$ & $3.10 \pm 0.55$ & $334 \pm 0.49 *$ \\
\hline Prothrombin $\left(\mathrm{U} \mathrm{dL}^{-1}\right)$ & $119 \pm 18.2$ & $117 \pm 16.5$ & $121 \pm 19.5$ \\
\hline $\mathrm{FV}\left(\mathrm{U} \mathrm{dL}^{-1}\right)$ & $108 \pm 18.6$ & $105 \pm 19.3$ & $111 \pm 17.7$ \\
\hline $\mathrm{FVII}\left(\mathrm{U} \mathrm{dL}^{-1}\right)$ & $122 \pm 22.6$ & $116 \pm 21.3$ & $127 \pm 22.7^{*}$ \\
\hline FVIII $\left(\mathrm{U} \mathrm{dL}^{-1}\right)$ & $96.7 \pm 20.0$ & $93.6 \pm 19.2$ & $99.6 \pm 20.4$ \\
\hline $\mathrm{FIX}\left(\mathrm{U} \mathrm{dL}^{-1}\right)$ & $101 \pm 11.5$ & $100 \pm 11.0$ & $102 \pm 11.9$ \\
\hline $\mathrm{FX}\left(\mathrm{UdL}^{-1}\right)$ & $126 \pm 15.5$ & $123 \pm 16.6$ & $129 \pm 13.9 *$ \\
\hline $\mathrm{FXI}\left(\mathrm{U} \mathrm{dL}^{-1}\right)$ & $94.1 \pm 12.2$ & $90.7 \pm 13.2$ & $96.9 \pm 10.6^{*}$ \\
\hline FXII $\left(\mathrm{U} \mathrm{dL}^{-1}\right)$ & $90.9 \pm 20.2$ & $89.3 \pm 19.0$ & $92.3 \pm 21.3$ \\
\hline AT $\left(\mathrm{UdL}^{-1}\right)$ & $118 \pm 10.1$ & $116 \pm 8.81$ & $120 \pm 10.9 *$ \\
\hline Protein $\mathrm{C}\left(\mathrm{U} \mathrm{dL}^{-1}\right)$ & $109 \pm 19.8$ & $103 \pm 13.5$ & $114 \pm 22.9 *$ \\
\hline Free PS $\left(\mathrm{U} \mathrm{dL}^{-1}\right)$ & $95.9 \pm 17.4$ & $101 \pm 17.6$ & $91.0 \pm 15.9 *$ \\
\hline Total PS (U dL $\left.{ }^{-1}\right)$ & $114 \pm 14.9$ & $113 \pm 14.9$ & $114 \pm 15.1$ \\
\hline TFPI activity (ng mL ${ }^{-1}$ ) & $49.4 \pm 22.6$ & $50.4 \pm 21.3$ & $48.5 \pm 23.8$ \\
\hline Free TFPI antigen ( $\mathrm{ng} \mathrm{mL}^{-1}$ ) & $11.2 \pm 3.05$ & $11.5 \pm 2.51$ & $10.9 \pm 3.45$ \\
\hline
\end{tabular}

TFPI, tissue factor pathway inhibitor; PS, protein $\mathrm{S} .{ }^{*}$ denotes $P<0.05$ compared with males. 
Table 3. Determinants of thrombin generation at $1 \mathrm{pM}$ tissue factor (TF) [in the absence and presence of thrombomodulin (TM)] and of the TM ratio.

\begin{tabular}{|c|c|c|c|c|c|c|c|c|}
\hline \multirow[b]{2}{*}{ Dep. variable } & & \multicolumn{3}{|l|}{$1 \mathrm{pM}$ TF } & \multicolumn{3}{|c|}{$1 \mathrm{pM} \mathrm{TF}+\mathrm{TM}$} & \multirow{2}{*}{$\begin{array}{l}1 \mathrm{pM} \text { TF } \\
\pm \mathrm{TM} \text { ratio }\end{array}$} \\
\hline & & Lag time & ETP & Peak height & Lag time & ETP & Peak height & \\
\hline Mean $\pm S D$ & & $5.84 \pm 1.65$ & $995 \pm 290$ & $116 \pm 50.8$ & $5.57 \pm 1.85$ & $299 \pm 143$ & $59.6 \pm 34.2$ & $0.29 \pm 0.08$ \\
\hline Determinant & SD & Beta & Beta & Beta & Beta & Beta & Beta & Beta \\
\hline (Adjusted $R^{2}$ ) & & $(0.430)$ & $(0.408)$ & $(0.421)$ & $(0.436)$ & $(0.409)$ & $(0.412)$ & $(0.647)$ \\
\hline Fibrinogen & 0.54 & $0.197^{*}$ & $0.400^{*}$ & $0.368^{*}$ & $0.270^{*}$ & $0.258^{*}$ & $0.273^{*}$ & 0.068 \\
\hline Prothrombin & 18.2 & 0.063 & -0.001 & -0.181 & 0.002 & -0.166 & $-0.224^{*}$ & $-0.301^{*}$ \\
\hline FV & 18.6 & 0.109 & 0.116 & 0.134 & 0.108 & $0.241^{*}$ & $0.243^{*}$ & $0.301^{*}$ \\
\hline FVII & 22.6 & $-0.232 *$ & 0.129 & 0.122 & -0.161 & 0.062 & 0.062 & 0.048 \\
\hline FVIII & 20.0 & 0.102 & -0.013 & 0.119 & 0.129 & 0.099 & 0.146 & 0.114 \\
\hline FIX & 11.5 & $-0.409 *$ & 0.041 & 0.091 & $-0.414^{*}$ & 0.125 & 0.111 & 0.173 \\
\hline FX & 15.5 & 0.090 & 0.125 & 0.097 & 0.083 & 0.099 & 0.093 & 0.118 \\
\hline FXI & 12.2 & 0.165 & -0.153 & -0.127 & 0.088 & -0.201 & -0.176 & -0.169 \\
\hline FXII & 20.2 & -0.002 & $0.302^{*}$ & $0.317^{*}$ & 0.100 & $0.317^{*}$ & $0.328 *$ & $0.230^{*}$ \\
\hline AT & 10.1 & -0.092 & $-0.311^{*}$ & $-0.240 *$ & -0.091 & $-0.247^{*}$ & $-0.205^{*}$ & -0.121 \\
\hline Protein C & 19.8 & 0.115 & -0.044 & -0.066 & 0.093 & $-0.229 *$ & $-0.193^{*}$ & $-0.331^{*}$ \\
\hline Free PS & 17.4 & $0.295^{*}$ & -0.101 & 0.012 & $0.355^{*}$ & -0.142 & -0.073 & -0.192 \\
\hline Total PS & 14.9 & -0.047 & 0.227 & 0.191 & -0.074 & $0.335^{*}$ & 0.292 & 0.284 \\
\hline TFPI activity & 22.6 & -0.012 & 0.062 & 0.032 & 0.071 & 0.061 & 0.065 & 0.060 \\
\hline Free TFPI & 3.05 & $0.536 *$ & $-0.399 *$ & $-0.280^{*}$ & $0.479 *$ & $-0.391^{*}$ & $-0.332 *$ & $-0.283^{*}$ \\
\hline
\end{tabular}

TFPI, tissue factor pathway inhibitor; PS, protein S. Data are presented as standardized regression coefficients (beta). * denotes $P<0.05$. 
Table 4. Determinants of thrombin generation at $13.6 \mathrm{pM}$ tissue factor (TF) [in the absence and presence of activated protein $C(A P C)$ ] and of the normalized APC sensitivity ratio (nAPCsr).

\begin{tabular}{|c|c|c|c|c|c|c|c|c|}
\hline \multirow[b]{2}{*}{ Dep. variable } & & \multicolumn{3}{|c|}{$13.6 \mathrm{pM} \mathrm{TF}$} & \multicolumn{3}{|c|}{$13.6 \mathrm{pM} \mathrm{TF}+\mathrm{APC}$} & \multirow{2}{*}{$\begin{array}{l}13.6 \mathrm{pM} \text { TF } \\
\text { nAPCsr }\end{array}$} \\
\hline & & Lag time & ETP & Peak height & Lag time & ETP & Peak height & \\
\hline Mean $\pm S D$ & & $2.67 \pm 0.38$ & $1490 \pm 224$ & $335 \pm 40.7$ & $4.34 \pm 0.88$ & $152 \pm 107$ & $31.8 \pm 27.1$ & $1.06 \pm 0.75$ \\
\hline Determinant & SD & Beta & Beta & Beta & Beta & Beta & Beta & Beta \\
\hline (Adjusted $R^{2}$ ) & & $(0.427)$ & $(0.471)$ & $(0.334)$ & $(0.235)$ & $(0.439)$ & $(0.402)$ & $(0.713)$ \\
\hline Fibrinogen & 0.54 & $0.292 *$ & $0.280^{*}$ & $0.280^{*}$ & $0.250^{*}$ & -0.031 & -0.093 & -0.072 \\
\hline Prothrombin & 18.2 & -0.077 & $0.420^{*}$ & 0.121 & -0.171 & -0.036 & -0.066 & -0.123 \\
\hline FV & 18.6 & 0.115 & $-0.224^{*}$ & $-0.366^{*}$ & $0.344^{*}$ & -0.168 & -0.112 & -0.120 \\
\hline FVII & 22.6 & $-0.287^{*}$ & 0.048 & 0.074 & $-0.406^{*}$ & 0.104 & 0.003 & 0.041 \\
\hline FVIII & 20.0 & -0.031 & -0.113 & -0.060 & 0.093 & -0.036 & -0.016 & 0.002 \\
\hline FIX & 11.5 & -0.100 & 0.224 & $0.368^{*}$ & $-0.411^{*}$ & 0.243 & 0.186 & 0.178 \\
\hline FX & 15.5 & -0.010 & 0.100 & 0.199 & -0.060 & $0.286^{*}$ & $0.296^{*}$ & $0.219^{*}$ \\
\hline FXI & 12.2 & 0.209 & -0.070 & -0.144 & 0.062 & -0.046 & -0.040 & -0.010 \\
\hline FXII & 20.2 & -0.004 & 0.074 & 0.087 & 0.186 & 0.011 & 0.038 & 0.031 \\
\hline AT & 10.1 & 0.041 & $-0.455^{*}$ & $-0.221^{*}$ & -0.011 & 0.073 & 0.105 & 0.165 \\
\hline Protein C & 19.8 & -0.033 & 0.156 & 0.111 & 0.014 & -0.043 & -0.029 & -0.042 \\
\hline Free PS & 17.4 & $0.331^{*}$ & 0.026 & $-0.262^{*}$ & 0.120 & $-0.470^{*}$ & $-0.536^{*}$ & $-0.475^{*}$ \\
\hline Total PS & 14.9 & 0.142 & 0.101 & 0.098 & 0.096 & -0.130 & -0.108 & -0.168 \\
\hline TFPI activity & 22.6 & 0.017 & -0.029 & 0.014 & 0.044 & 0.020 & 0.039 & 0.058 \\
\hline Free TFPI & 3.05 & $0.254^{*}$ & $-0.216^{*}$ & $-0.297^{*}$ & $0.265^{*}$ & $-0.393^{*}$ & $-0.311^{*}$ & $-0.318^{*}$ \\
\hline
\end{tabular}

TFPI, tissue factor pathway inhibitor; PS, protein S. Data are presented as standardized regression coefficients (beta). * denotes $P<0.05$. 


\section{Discussion}

Since the introduction of the CAT technique, ${ }^{6}$ which has made the measurement of thrombin generation in plasma straightforward and amenable to high-throughput, thrombin generation assays have become increasingly popular in clinical laboratories. ${ }^{23}$ Although several studies support the value of thrombin generation in detecting hyperand hypocoagulable states, ${ }^{7-16}$ the dependence of thrombin generation on the levels of individual coagulation factors and inhibitors has not been studied in detail. Therefore, we have used multiple regression analysis to dissect the contribution of individual plasma factors to thrombin generation parameters (lag time, ETP and peak height) measured under different experimental conditions in a population of healthy individuals. Thrombin generation was initiated with a commercial trigger (1 pM TF and $4 \mu \mathrm{M}$ phospholipids) in the absence and presence of soluble $\mathrm{TM}$, or with a home-made trigger (13.6 pM TF and $20 \mu \mathrm{M}$ phospholipids) in the absence and presence of APC. Under each condition, the lag time reflects the initiation phase of thrombin generation, while the peak height and the ETP (which are highly correlated) probe the propagation and termination phases of coagulation.

In the absence of TM or APC, thrombin generation curves obtained at $13.6 \mathrm{pM} \mathrm{TF}$ were faster and higher than those obtained at 1 pM TF (Table 1), as expected from the relative trigger strengths. In accordance with a recent report, ${ }^{24}$ thrombin generation increased with age, which is largely explained by age-dependent changes in the levels of coagulation factors and inhibitors (data not shown). Moreover, plasma from females was more "procoagulant" than that of males, as indicated by the tendency towards shorter lag times and higher ETPs and thrombin peaks, especially when thrombin generation was measured in the presence of TM or APC.

Irrespective of the trigger, the lag time of thrombin generation was determined by essentially the same plasma variables, for example (i) FVII, in line with the notion that the coagulation cascade is initiated by binding of TF to FVII(a); (ii) FIX (at 1 pM TF \pm TM and at $13.6 \mathrm{pM} \mathrm{TF}+\mathrm{APC}$ ), probably due to direct activation of FIX by the TF/FVIIa complex at low procoagulant stimuli; 25 (iii) free TFPI and PS, reflecting inhibition of the TF/FVIIa complex by the TFPI/PS system; ${ }^{4}$ and d) fibrinogen (Tables 3 and 4). The prolongation of the lag time at high fibrinogen levels is supported by the comparison between thrombin generation curves measured in full and defibrinated plasma ${ }^{7}$ and is attributable to the ability of fibrin(ogen), particularly $\gamma^{\prime}$-fibrinogen, to bind to thrombin exosite II and to inhibit thrombin-mediated FVIII activation. ${ }^{26,27}$

The most consistent determinants of the amount of thrombin formed, as quantified by ETP and peak height, were fibrinogen (positive determinant, because of the ability of fibrin to protect thrombin from inhibition by $\mathrm{AT}^{28}$ ), and AT and free TFPI levels (negative determinants). Despite the addition of CTI to prevent contact activation, FXII levels were also a major determinant of ETP and peak height in the measurements 
performed at low TF (1 pM), both in the absence and in the presence of TM, suggesting that some FXII might have been already activated prior to the thrombin generation measurement ${ }^{29}$ and/or that it might have eluded inhibition by CTI. Although such minimal contact activation of coagulation may not be sufficient to exceed the threshold required for detectable thrombin generation in the absence of $\mathrm{TF}$, it may well be amplified by feedback reactions from the extrinsic pathway, thereby contributing to thrombin generation at low $\mathrm{TF}$ concentrations.

Prothrombin level was a determinant of the ETP and peak height at $13.6 \mathrm{pM}$ TF but not at $1 \mathrm{pM} \mathrm{TF}$, possibly because only a fraction of the prothrombin present in plasma is activated at low TF. Surprisingly, FVIII level was never a determinant of the ETP, not even at $1 \mathrm{pM}$ TF. In this respect it should be noted that most individuals in the population under study had normal FVIII levels and that the ETP is hardly affected by variations of FVIII levels within the normal range, as demonstrated by FVIII titrations in FVIII-deficient plasma (data not shown and ref. ${ }^{16}$ ). Presently, we do not have a good explanation for the negative effect of FV on thrombin generation in the absence of APC, but it cannot be excluded that FV acts a surrogate marker for a different factor that was not included in the multiple regression analysis.

When the protein C pathway was challenged by adding TM or APC to plasma, thrombin generation (ETP and peak height) was markedly reduced. The measurement at $1 \mathrm{pM}$ TF in the presence of TM showed an excellent correlation with the measurement in the absence of TM. Accordingly, the two measurements were dependent on essentially the same plasma variables, with the notable exception of protein $\mathrm{C}$ which was a determinant only in the presence of TM (Table 3). Contrary to the expectations, free PS was not a determinant of the ETP or peak height in the measurement with TM. This may be due to the low phospholipid concentration $(4 \mu \mathrm{M}$ final) in the $1 \mathrm{pM}$ trigger, which might be insufficient for full expression of the highly lipid-dependent APC-cofactor activity of PS. ${ }^{30}$ The inverse relationship between prothrombin levels and thrombin generation in the presence of TM might result from increased protein $\mathrm{C}$ activation by the thrombin/TM complex at high prothrombin levels. Thrombin generation measured at $13.6 \mathrm{pM}$ TF in the presence of added APC showed no correlation (ETP) or only a weak correlation (peak) with the corresponding measurement in the absence of APC. The most important determinant of the measurement with APC was gender, females yielding shorter lag times and higher ETPs and peak heights than males (Table 1). Accordingly, free TFPI and PS levels, which are notably lower in females (Table 2), had the largest effects on ETP and peak height measured in the presence of APC (Tables 3 and 4). FX, which in activated form binds to and protects FVa from APC-mediated inactivation, ${ }^{31}$ was also an important determinant of thrombin generation in the presence of APC.

The TM ratio and the nAPCsr were highly correlated with the ETPs measured in the presence of TM and APC, respectively, and were determined by virtually the same plasma variables as these ETPs (Tables 3 and 4). In the case of the nAPCsr, strong 
dependence on free TFPI and free PS levels, as well as on FX levels, is in good agreement with a recent study ${ }^{22}$ on the determinants of the thrombin generation-based nAPCsr as measured with the end point method. ${ }^{32}$

Possible limitations of the present study are the relatively small population size and the use of a healthy population, in which all factors levels are in the normal range. Different (or additional) determinants may be identified in patient populations with factor levels far below or above the normal range ( $c f$. for example ref. ${ }^{13}$ ).

In conclusion, this study represents the first attempt to define the determinants of thrombin generation parameters in a healthy population. We show that these determinants vary with the experimental conditions, making it possible to develop of thrombin generation assay variants targeted to specific diagnostic purposes.

\section{Acknowledgements}

A.W.J.H. Dielis is a Kootstra fellow from Maastricht University. E. Castoldi was supported by a VIDI grant (nr. 917-76-312) from the Dutch Organisation for Scientific Research (NWO).

\section{Disclosure of conflict of interests}

The authors state that they have no conflict of interest. 


\section{References}

1. Lane DA, Philippou H, Huntington JA. Directing thrombin. Blood. 2005;106:2605-2612.

2. Dahlbäck B, Villoutreix BO. The anticoagulant protein C pathway. FEBS Lett. 2005;579:33103316.

3. Baugh RJ, Broze GJ, Jr., Krishnaswamy S. Regulation of extrinsic pathway factor Xa formation by tissue factor pathway inhibitor. J Biol Chem. 1998;273:4378-4386.

4. Hackeng TM, Seré KM, Tans G, Rosing J. Protein S stimulates inhibition of the tissue factor pathway by tissue factor pathway inhibitor. Proc Natl Acad Sci USA. 2006;103:3106-3111.

5. Pike RN, Buckle AM, le Bonniec BF, Church FC. Control of the coagulation system by serpins. Getting by with a little help from glycosaminoglycans. FEBS J. 2005;272:4842-4851.

6. Hemker HC, Giesen P, Al Dieri R, Regnault V, de Smedt E, Wagenvoord R et al. The Calibrated Automated Thrombogram (CAT): a universal routine test for hyper- and hypocoagulability. Pathophysiol Haemost Thromb. 2002;32:249-253.

7. Hemker HC, Al Dieri R, de Smedt E, Béguin S. Thrombin generation, a function test of the haemostatic-thrombotic system. Thromb Haemost. 2006;96:553-561.

8. Simioni P, Castoldi E, Lunghi B, Tormene D, Rosing J, Bernardi F. An underestimated combination of opposites resulting in enhanced thrombotic tendency. Blood. 2005;106:2363-2365.

9. Dargaud Y, Trzeciak MC, Bordet JC, Ninet J, Negrier C. Use of calibrated automated thrombinography +/- thrombomodulin to recognise the prothrombotic phenotype. Thromb Haemost. 2006;96:562-567.

10. Hron G, Kollars M, Binder BR, Eichinger S, Kyrle PA. Identification of patients at low risk for recurrent venous thromboembolism by measuring thrombin generation. JAMA. 2006;296:397-402.

11. Brandts A, van Hylckama Vlieg A, Rosing J, Baglin TP, Rosendaal FR. The risk of venous thrombosis associated with a high endogenous thrombin potential in the absence and presence of activated protein C. J Thromb Haemost. 2007;5:416-418.

12. Tripodi A, Martinelli I, Chantarangkul V, Battaglioli T, Clerici M, Mannucci PM. The endogenous thrombin potential and the risk of venous thromboembolism. Thromb Res. 2007; in press.

13. Al Dieri R, Peyvandi F, Santagostino E, Giansily M, Mannucci PM, Schved JF et al. The thrombogram in rare inherited coagulation disorders: its relation to clinical bleeding. Thromb Haemost. 2002;88:576-582.

14. Castoldi E, Govers-Riemslag JW, Pinotti M, Bindini D, Tans G, Berrettini M et al. Coinheritance of Factor V (FV) Leiden enhances thrombin formation and is associated with a mild bleeding phenotype in patients homozygous for the FVII 9726+5G>A (FVII Lazio) mutation. Blood. 2003;102:4014-4020.

15. Dargaud Y, Béguin S, Lienhart A, Al Dieri R, Trzeciak C, Bordet JC et al. Evaluation of thrombin generating capacity in plasma from patients with haemophilia A and B. Thromb Haemost. 2005;93:475-480.

16. Beltrán-Miranda CP, Khan A, Jaloma-Cruz AR, Laffan MA. Thrombin generation and phenotypic correlation in haemophilia A. Haemophilia. 2005;11:326-334.

17. Allen GA, Wolberg AS, Oliver JA, Hoffman M, Roberts HR, Monroe DM. Impact of 
procoagulant concentration on rate, peak and total thrombin generation in a model system. $J$ Thromb Haemost. 2004;2:402-413.

18. Brugge JM, Tans G, Rosing J, Castoldi E. Protein S levels modulate the activated protein C resistance phenotype induced by elevated prothrombin levels. Thromb Haemost. 2006; 95:236-242.

19. Hézard N, Bouaziz-Borgi L, Remy MG, Nguyen P. Utility of thrombin generation assay in the screening of factor V G1691A (Leiden) and prothrombin G20210A mutations and protein S deficiency. Clin Chem. 2006;52:665-670.

20. Bertina RM, Koeleman BP, Koster T, Rosendaal FR, Dirven RJ, de Ronde H et al. Mutation in blood coagulation factor $\mathrm{V}$ associated with resistance to activated protein C. Nature. 1994;369:64-67.

21. Koenen RR, Thomassen MC, Tans G, Rosing J, Hackeng TM. Effect of oral contraceptives on the anticoagulant activity of protein S in plasma. Thromb Haemost. 2005;93:853-859.

22. De Visser MC, van Hylckama Vlieg A, Tans G, Rosing J, Dahm AE, Sandset PM et al. Determinants of the APTT- and ETP-based APC sensitivity tests. J Thromb Haemost. 2005;3:1488-1494.

23. Baglin T. The measurement and application of thrombin generation. Br J Haematol. 2005;130:653-661.

24. Haidl H, Cimenti C, Leschnik B, Zach D, Muntean W. Age-dependency of thrombin generation measured by means of calibrated automated thrombography (CAT). Thromb Haemost. 2006;95:772-775.

25. Østerud B, Rapaport SI. Activation of factor IX by the reaction product of tissue factor and factor VII: additional pathway for initiating blood coagulation. Proc Natl Acad Sci USA. 1977;74:5260-5264.

26. Farrell DH, Lovely RS, Boshkov LK. Inhibition of thrombin cleavage of factor VIII by fibrinogen $\gamma^{\prime}$ chain carboxyl terminus. Blood. 2005;106:1957 [abstract].

27. Mosesson MW. Update on antithrombin I (fibrin). Thromb Haemost. 2007;98:105-108.

28. Weitz JI, Hudoba M, Massel D, Maraganore J, Hirsh J. Clot-bound thrombin is protected from inhibition by heparin-antithrombin III but is susceptible to inactivation by antithrombin IIIindependent inhibitors. J Clin Invest. 1990;86:385-391.

29. Luddington R, Baglin T. Clinical measurement of thrombin generation by calibrated automated thrombography requires contact factor inhibition. J Thromb Haemost. 2004;2:1954-1959.

30. Norstrøm EA, Steen M, Tran S, Dahlbäck B. Importance of protein S and phospholipid for activated protein C-mediated cleavages in factor Va.J Biol Chem. 2003;278:24904-24911.

31. Rosing J, Hoekema L, Nicolaes GA, Thomassen MC, Hemker HC, Váradi K et al. Effects of protein $\mathrm{S}$ and factor Xa on peptide bond cleavages during inactivation of factor Va and factor VaR506Q by activated protein C. J Biol Chem. 1995;270:27852-27858.

32. Nicolaes GA, Thomassen MC, Tans G, Rosing J, Hemker HC. Effect of activated protein C on thrombin generation and on the thrombin potential in plasma of normal and APC-resistant individuals. Blood Coagul Fibrinolysis. 1997;8:28-38. 
Chapter 3.3

\section{The influence of intrinsic coagulation on thrombin generation}

Monitoring thrombin generation: Is addition of corn trypsin inhibitor needed?

Spronk $\mathrm{HMH}^{1}$, Dielis $A W \mathrm{H}^{1}$, Panova-Noeva $\mathrm{M}^{2}$, van Oerle $\mathrm{R}^{1}$, Govers-Riemslag JWP ${ }^{1}$, Hamulyák K${ }^{3}$, Falanga $A^{2}$, ten Cate $\mathrm{H}^{1}$.

1 Department of Internal Medicine, Laboratory for Clinical Thrombosis and Haemostasis, Cardiovascular Research Institute Maastricht, Maastricht University Medical Center, Maastricht, The Netherlands;

2 Haemostasis and Thrombosis Unit, Division of Immunohematology and Transfusion Medicine, Ospedali Riuniti di Bergamo, Bergamo, Italy;

3 Department of Internal Medicine, Division of Haematology, Maastricht University Medical Center, Maastricht, The Netherlands.

Thrombosis and Haemostasis. Accepted for publication, 2009. 


\section{Abstract}

Background: Thrombin generation monitoring has the potential to be used as a clinical diagnostic tool in the near future. However, robust pre-analytical conditions may be required and one factor that has been reported is in vitro contact activation that might influence in vitro measurements of thrombin generation and thereby act as an unpredictable pre-analytical variable. The aim of the current study was to investigate the influence of contact activation and the necessity of corn trypsin inhibitor (CTI) to abolish contact activation in thrombin generation measurements at low tissue factor (TF) concentrations.

Methods: Thrombin generation was performed using the Calibrated Automated Thrombogram (CAT), thereby determining the endogenous thrombin potential (ETP), peak height, and the lag time, in plasma obtained from healthy volunteers.

Results: Addition of CTI after plasma preparation had no significant influence on thrombin generation triggered with $0.5 \mathrm{pM}$ TF or higher, as demonstrated by unaltered ETP and lag time values between analyses with and without CTI. Addition of CTI before blood collection reduced thrombin generation triggered with $0.5 \mathrm{pM}$ TF: both the ETP and peak height were significantly reduced compared to no CTI addition. In contrast, thrombin generation remained unaltered at a $1 \mathrm{pM}$ TF trigger or above.

Conclusion: This study demonstrates that addition of CTI after plasma separation is not necessary when triggering with $\mathrm{TF}$ concentrations of $0.5 \mathrm{pM}$ and higher. Furthermore, it was demonstrated that it is not needed to pre-fill blood collecting tubes with CTI when measuring with TF concentrations of $1 \mathrm{pM}$ and higher. 


\section{Introduction}

Thrombin is an essential enzyme in the coagulation cascade, ${ }^{1}$ and determines one of the final steps in haemostasis: the conversion of soluble fibrinogen to the insoluble and rigid fibrin clot. Activation of the coagulation cascade in vivo is thought to predominantly occur through complex formation of circulating (activated) factor VII (FVIIa) and vessel wall exposed tissue factor (TF) (reviewed in ref. ${ }^{2}$ ), whereas a second pathway, the so-called "contact activation" route, occurs in vitro when factor XII (FXII) gets exposed to artificial anionic or negatively charged surfaces and may play an amplifying role in vivo (reviewed in ref. ${ }^{3}$ ). The classic laboratory methods to determine coagulation defects in both pathways, e.g. the prothrombin time (PT) for the TF/FVIIa route and the activated partial thromboplastin time (aPTT) for contact activation, are more applicable to detect clinically relevant bleeding disorders rather then hypercoagulability. Since thrombin is considered as the central enzyme in coagulation and increased thrombin production could contribute to a prothrombotic state, a new assay was developed to assess thrombin generation in individual plasmas. ${ }^{4}$ Information on the production and inhibition of thrombin in plasma has been shown to be useful in evaluating thrombotic or haemorrhagic conditions in patients (Chapter 4.2)..$^{5-10}$ One of the more commonly used methods is the Calibrated Automated Thrombogram (CAT, Thrombinoscope BV, Maastricht, The Netherlands). This method uses a low affinity fluorogenic substrate (Z-Gly-Gly-Arg-AMC), which is converted into a fluorogenic signal by thrombin. The activity of thrombin is thus continuously registered over time, resulting in a characteristic thrombin generation curve.

Over the past years this method was validated for pre-analytical conditions (Chapter $3.1)^{11-13}$ and shown to exert good reproducibility and stability. One problem, however, might be the activation of FXII during blood drawing and/or during analysis. Recently, Van Veen and Dargaud demonstrated the contribution of contact activation to thrombin generation analyses, especially at low concentrations of $\mathrm{TF}, 11,13$ thereby introducing an unpredictable pre-analytical variable which increased inaccuracy and imprecision. ${ }^{14}$ The use of the specific FXIIa inhibitor corn trypsin inhibitor (CTI) attenuated the effects of contact activation observed during thrombin generation. The consequences of contact activation for clinical practice are considerable: addition of CTI to blood collection tubes increases the costs and requires an additional tube besides the commonly used vacutainer.

Since contact activation can occur during venipuncture or in the thrombin generation analysis itself, we hypothesized that the blood collection procedure and the used reagents for thrombin generation are key determinants in in vitro activation of FXII. In order to verify the previous results of Van Veen and Dargaud, as well as to determine the effects of blood collection and used reagents, we analyzed thrombin generation under well defined conditions with and without CTI. 


\section{Methods}

\section{Experimental design}

1: Effects of blood collection method. Venous blood from four healthy volunteers was simultaneously collected using a standard 21-gauge needle (BD, Plymouth, United Kingdom) for the right arm and a Winged Infusion Set or "butterfly" needle equipped with a $30 \mathrm{~cm}$ long tubing (Push Button Blood Collection Set, BD) for the left arm.

2: Effects of CTI addition to plasma. Venous blood from 12 healthy volunteers was collected in $3.2 \%(\mathrm{w} / \mathrm{v})$ citrate using a 21-gauge needle and plasma was prepared as described below. Just before thrombin generation analysis CTI was added to the plasmas to obtain final concentrations of 25 or $50 \mu \mathrm{g} \mathrm{mL}^{-1}$. Thrombin generation was analyzed using $0.5,1,2$ or $5 \mathrm{pM}$ TF as trigger.

3: Effects of CTI addition to venous blood. Venous blood from 12 healthy volunteers was collected in $3.2 \%\left(\mathrm{w} / \mathrm{v}\right.$ ) citrate containing CTI (final concentration of $40 \mu \mathrm{g} \mathrm{mL}^{-1}$ in plasma) using a 21-gauge needle. Thrombin generation was analyzed using $0.5,1,2$ or 5 pM TF as trigger.

\section{Blood collection and plasma preparation}

Venous blood from the left and right arm of four healthy volunteers was collected in $3.2 \%(\mathrm{w} / \mathrm{v})$ citrate using a 21-gauge needle (BD) or a Winged Infusion Set (BD) through venipuncture. The first $10 \mathrm{~mL}$ of venous blood were discarded. Platelet-poor plasma was prepared by two centrifugation steps: the first at $2000 \mathrm{~g}$ for 15 minutes and the second at $11000 \mathrm{~g}$ for 10 minutes. Plasma aliquots were snap-frozen in liquid nitrogen and stored at $-80^{\circ} \mathrm{C}$ until use. All samples were thawed at $37^{\circ} \mathrm{C}$ for 15 minutes before analysis and analyzed batch-wise. CTI was obtained from Haematologic Technologies, Inc. (Essex Junction, VT, USA) and added to the 3.2\% (w/v) citrate collection tubes to obtain a final concentration of $40 \mu \mathrm{g} \mathrm{mL}^{-1}$ in plasma. To study the effect of CTI addition during thrombin generation, CTI was added to plasma before analysis to obtain final concentrations of 25 or $50 \mu \mathrm{g} \mathrm{mL} \mathrm{m}^{-1}$. Kaolin was added to $3.2 \%(\mathrm{w} / \mathrm{v})$ citrate tubes to obtain a final concentration of $1 \mathrm{mg} \mathrm{mL}^{-1}$ after plasma collection.

\section{Pooled normal plasma and FXII-deficient plasmas}

Pooled normal plasma was prepared at the Departments of Haematology and Clinical Chemistry of the Maastricht University Medical Center, Maastricht, The Netherlands, by pooling plasma from 85 healthy volunteers not using any medication. FXII-deficient plasma was either obtained from the Maastricht University Medical Center (indicated as FXII-deficient plasma [1]) or George King Bio-Medical, Inc. (Overland Park, KS, USA; 
indicated as FXII-deficient plasma [2]) and were both from patients with a congenital FXII-deficiency. FXI-deficient plasma was obtained from George King Bio-Medical, Inc.

\section{Thrombin generation}

Thrombin generation in TF-triggered platelet-poor plasma was measured by means of the CAT method as described previously (Chapter 3.2), ${ }^{15}$ which makes use of a low affinity fluorogenic substrate for thrombin (Z-Gly-Gly-Arg-AMC) to continuously monitor thrombin activity in clotting plasma. In order to correct for inner-filter effects and substrate consumption, each thrombin generation measurement was calibrated against the fluorescence curve obtained in the same plasma with a fixed amount of thrombin- $\alpha_{2}$-macroglobulin complex (Thrombin Calibrator, Thrombinoscope BV), as recommended by the manufacturer. Fluorescence was read in an Ascent Reader (Thermo Labsystems OY, Helsinki, Finland) equipped with a 390/460 filter set, and thrombin generation curves were calculated with the Thrombinoscope software (Thrombinoscope BV).

Unless stated otherwise, thrombin generation was determined under several experimental conditions (final plasma concentrations): $0.5,1,2$ or $5 \mathrm{pM}$ TF and $4 \mu \mathrm{M}$ phospholipids. The TF triggers and phospholipids were obtained from Thrombinoscope BV. Three parameters were derived from the thrombin generation curves: lag time, peak height and endogenous thrombin potential (ETP; area under the curve).

\section{FXIIa-C1-esterase inhibitor complex measurement}

Complexes of FXIIa and FXIa with their natural inhibitor C1-esterase inhibitor, respectively, were measured with enzyme-linked immunosorbent assays (ELISAs), using monoclonal antibodies (mAb) and as described previously. ${ }^{16}$ In brief, mAb F3 was used to recognize FXII, mAb XI-5 to FXI, and mAb KOK 12 specific for complexed C1esterase inhibitor. Appropriate secondary antibodies were biotinylated using EZLink Nhydroxysuccinimide ester-biotin according to instructions from the manufacturer (Pierce, Rockford, IL, USA). Absorbance was read at $450 \mathrm{~nm}$ on an EL 808 Ultra microplate reader (Bio-tek Instruments Inc., Winooski, VT, USA). Results were expressed as a percentage of activated pooled normal plasma.

Pooled EDTA normal plasma was maximally activated at $37^{\circ} \mathrm{C}$ by incubation with an equal volume of $0.2 \mathrm{mg} \mathrm{mL}^{-1}$ dextran sulfate (Mr 500 000; Sigma Chemical Co., St Louis, MO, USA) to obtain reference curves for the FXIIa-C1-esterase inhibitor ELISA, whereas kaolin (final concentration $5 \mathrm{mg} \mathrm{mL}^{-1}$ )-activated EDTA plasma was used for the FXIaC1-esterase inhibitor ELISA. Activation was stopped by adding three volumes of phosphate-buffered saline (PBS) containing $0.1 \mathrm{mg} \mathrm{mL} \mathrm{m}^{-1}$ soybean trypsin inhibitor (Sigma Chemical Co.) and $0.05 \%$ (w/v) polybrene (Sigma Chemical Co.). Kaolin was 
Chapter 3.3

removed by centrifuging the reaction mixture for five minutes at $13000 \mathrm{~g}$. No signal was detected in ELISAs performed on activated FXII- or FXI-deficient plasmas.

\section{Statistical analysis}

The data obtained for the thrombin generation are expressed as median (interquartile range; IQR). Differences in thrombin generation parameters between the groups treated with or without CTI were calculated with a non-parametric paired test (Wilcoxon's signed rank test). A two-tailed probability value $P<0.05$ was considered statistically significant.

Statistical analysis was performed using Prism for Windows 5.00 (GraphPad Software, San Diego, CA, USA). 


\section{Results}

\section{Effects of blood collection method}

Inter-laboratory variations in thrombin generation results can be the result of differences in equipment (including filter settings and temperature), reagent batches, as well as pre-analytical variables such as the method used for venous blood drawing. Using two different needle systems venous blood was simultaneously obtained from four healthy volunteers. Thrombin generation triggered with $5 \mathrm{pM}$ TF in the prepared platelet-poor plasma was not different between the two collection methods. For the needle system (21-gauge needle) a median ETP of 1171 nM.min (IQR: 1158-1321) was observed whereas for the Winged Infusion Set the ETP was 1219 nM.min (IQR: 11791352), differences not significant. Also, the peak height and lag time did not differ between the two systems (data not shown).

For the 1 pM TF trigger, however, both the ETP and peak height were significantly increased for plasmas obtained with the Winged Infusion Set compared to the needle system (Figure 1). On average, the ETP increased by almost $15 \%$ or 151 nM.min whereas the peak height gained up to $24 \%$ more thrombin ( $38 \mathrm{nM}$ ) by using a low $\mathrm{TF}$ trigger in the thrombin generation assay.

\section{Effects of CTI addition to plasma}

The differences between the two blood drawing systems are most likely due to enhanced contact activation induced by the $30 \mathrm{~cm}$ long tubing in the Winges Infusion Set. In order to find out whether CTI selectively inhibits FXIIa and no other enzymes of the coagulation cascade, 0,25 or $50 \mu \mathrm{g} \mathrm{mL}^{-1} \mathrm{CTI}$ was added to pooled normal plasma and FXII-deficient plasmas. Subsequently, thrombin generation was triggered with 1 or $5 \mathrm{pM}$ TF. No differences in thrombin generation curves were observed for both triggers in the absence or presence of 25 or $50 \mu \mathrm{g} \mathrm{mL}-1$ CTI, suggesting selectivity of CTI for

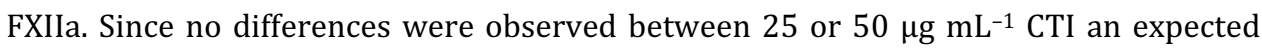
sufficient concentration of $40 \mu \mathrm{g} \mathrm{mL} \mathrm{m}^{-1} \mathrm{CTI}$ was chosen for all further experiments.

In order to demonstrate whether CTI addition to plasma influenced thrombin generation under conditions using the standard TF-triggers, CTI was added to plasmas from 12 healthy volunteers and thrombin generation was triggered with 0.5, 1, 2 and 5 pM TF. For all TF triggers the measurement with CTI added to plasma was in accordance with the analysis without CTI. Overall, ETP and peak height on average increased with increasing concentration TF trigger and were not different between analyses with or without CTI. ETP values in the absence of CTI were 1126 nM.min (IQR: 731-1464), 1281 nM.min (IQR: 904-1570), 1369 nM.min (IQR: 1015-1663), and 1602 nM.min (IQR: 1214-1823) for 0.5, 1, 2 and 5 pM TF, respectively. 
Figure 1. Effect of blood collection method on thrombin generation. Venous blood was collected with a 21-gauge needle (Needle) or with a Winged Infusion Set equipped with a $30 \mathrm{~cm}$ long tubing (Butterfly). Thrombin generation was analyzed using 1 pM TF as trigger. Panel A: lag time in minutes; panel B: ETP in nM.min thrombin; panel C: peak height in nM thrombin.

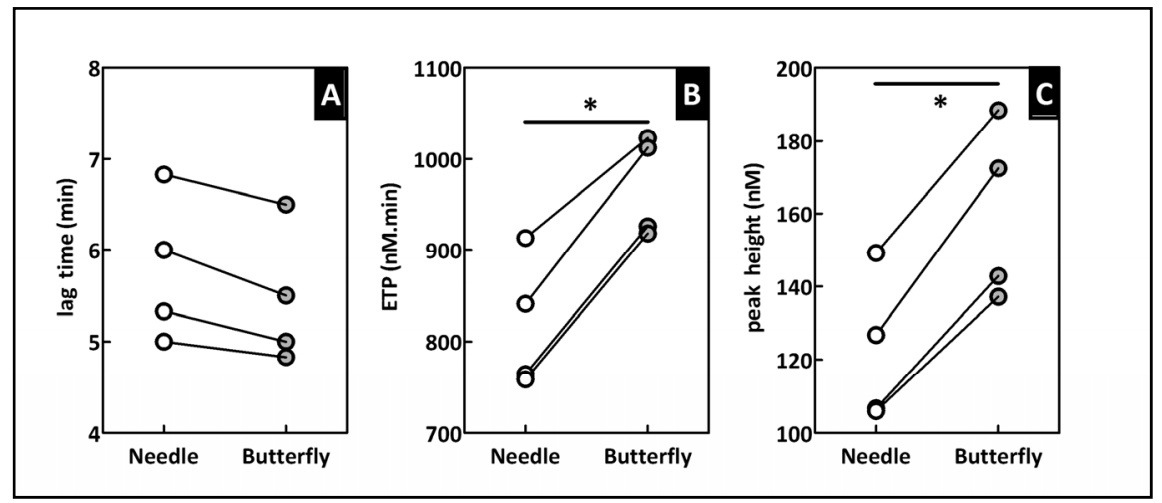

* denotes $P<0.05$.

For analyses with CTI added the ETP values obtained were 1132 nM.min (IQR: 7391517), 1358 nM.min (IQR: 971-1646), 1417 nM.min (IQR: 1093-1688), and 1585 nM.min (IQR: 1200-1821). Peak height values obtained in analyses with and without the addition of CTI followed the same pattern as for ETP, with increasing maximum thrombin formation with increasing TF concentrations and no differences between measurements in the absence or presence of CTI (data not shown). For intra-individual comparison of analyses without or with CTI, an acceptable within individual range of $10 \%$ was arbitrarily chosen based on inter-assay variations published previously. ${ }^{12,15}$ Both the ETP and peak height from thrombin generation with CTI were within this $10 \%$ range of the values obtained without CTI (Figure 2).

\section{Effects of CTI addition to venous blood}

To demonstrate that the presence of CTI in a venous blood collection tube effectively inhibits FXIIa, kaolin ( $1 \mathrm{mg} \mathrm{mL}^{-1}$ ) was added to the tubes in order to activate FXII and thrombin generation was recorded subsequently. Kaolin was found to be a strong initiator of thrombin generation since the lag times shifted from 10.3 minutes (IQR: 8.112.2) towards 2.6 minutes (IQR: $2.4-2.9, P<0.01$ ). The ETP and peak height increased as well upon addition of kaolin to venous blood collection tubes. The ETP increased by almost 16\% from 1386 nM.min (IQR: 1109-1448) to 1603 nM.min (IQR: 1386-1764) upon kaolin addition. The effect was even stronger for the peak height with an increase of $40 \%$ from $297 \mathrm{nM}$ (IQR: 226-354) to $415 \mathrm{nM}$ (IQR: 403-442). Combined addition of kaolin and CTI to the blood collection tubes reduced thrombin generation to a level 
Figure 2. Influence of CTI addition to $3.2 \%(w / v)$ citrate blood collection tubes on thrombin generation triggered with $0.5,1,2$ or $5 \mathrm{pM}$ TF (from left to right) for 12 healthy individuals. Upper panel: ETP in nM.min thrombin; lower panel: peak height in $\mathrm{nM}$ thrombin. Diamonds denote thrombin generation analyses in the absence of CTI and circles indicate measurements in the presence of $40 \mu \mathrm{g} \mathrm{mL}^{-1} \mathrm{CTI}$ added to $3.2 \%$ (w/v) citrate blood collection tubes. Error bars: individual ranges of $10 \%$.

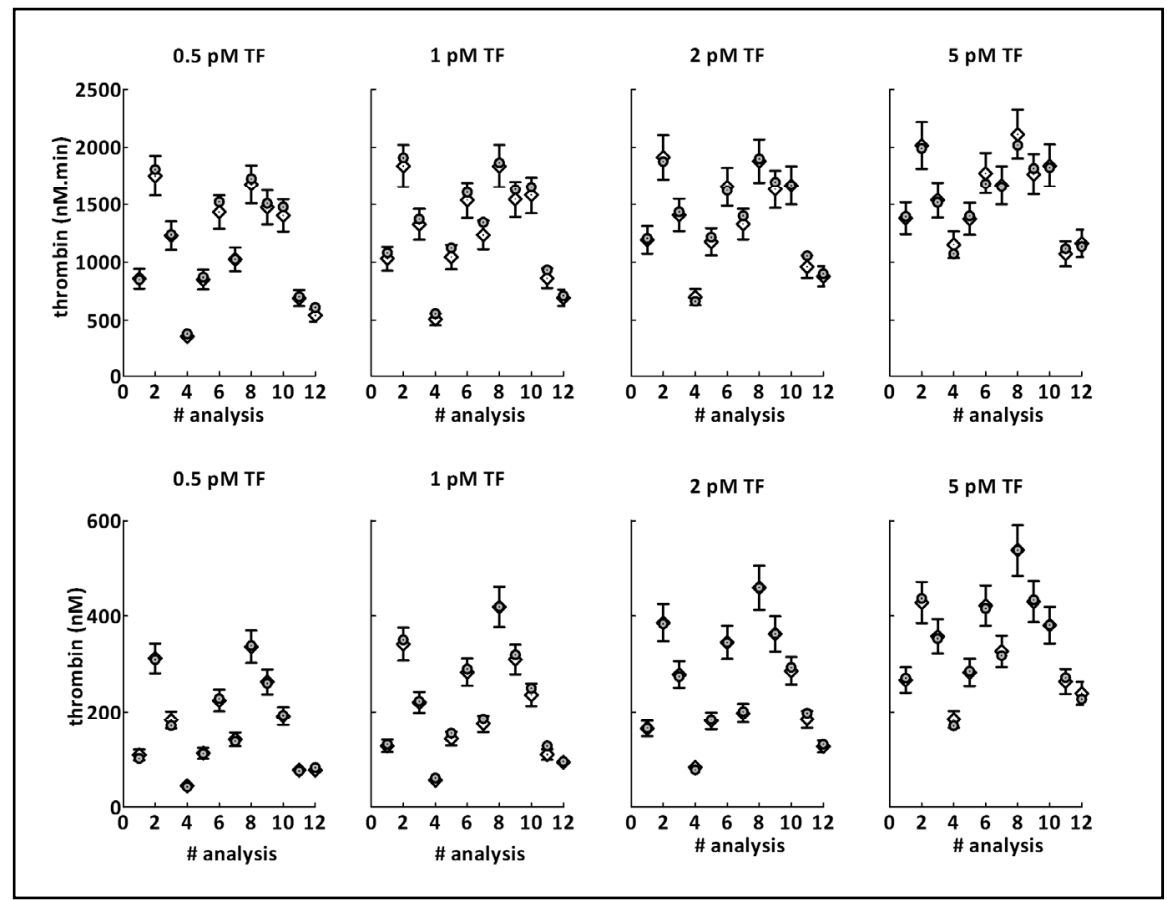

observed for citrated plasma alone. The lag time prolonged to 8.3 minutes $(8.0-13.6)$ and both ETP and peak height reduced to 1490 nM.min (IQR: 1129-1590, $P<0.01$ compared to kaolin) and $326 \mathrm{nM}$ (IQR: 209-365, $P<0.01$ compared to kaolin), respectively.

Since the presence of CTI during blood collection could efficiently inhibit contact activation, the influences of CTI on thrombin generation under conditions of the default TF triggers were studied. CTI $\left(40 \mu \mathrm{g} \mathrm{mL}^{-1}\right)$ was added to $3.2 \%(\mathrm{w} / \mathrm{v})$ citrate blood collection tubes and plasma was obtained from 12 healthy volunteers. Thrombin generation was triggered with $0.5,1,2$ or $5 \mathrm{pM}$ TF and compared between plasmas derived from collection tubes with and without CTI. For the higher TF concentrations thrombin generation was comparable between the two collection tubes. As described above, ETP values in the absence of CTI were 1281 nM.min (IQR: 904-1570), 1369 nM.min (IQR: 1015-1663), and 1602 nM.min (IQR: 1214-1823) for 1, 2 and 5 pM TF, respectively. Addition of CTI to blood collection tubes hardly altered these values: 1259 
nM.min (IQR: 885-1620), 1333 nM.min (IQR: 1036-1693), and 1662 nM.min (IQR: 1241-1873) for 1, 2 and $5 \mathrm{pM} \mathrm{TF}$, respectively, differences not statistically significant. For the 0.5 pM TF analysis, however, eight out of 12 analyses showed a lower ETP and peak height for thrombin generation in plasmas derived from collection tubes containing CTI (Figure 3). On average the ETP at $0.5 \mathrm{pM}$ TF reduced with $28 \%$ from 1126 nM.min (IQR: 731-1464) to 808 nM.min (IQR: 367-1414) upon addition of CTI to the collection tube. Whereas the peak height for the 1, 2 and $5 \mathrm{pM}$ TF analyses followed the same pattern as the ETP, peak height measured at $0.5 \mathrm{pM}$ TF trigger showed a reduction of 55\% from $162 \mathrm{nM}$ (IQR: 85-253) to $74 \mathrm{nM}$ (IQR: 29-182) when CTI was present during blood drawing.

\section{Activation of FXII during blood collection}

To demonstrate activation of FXII during collection of blood the contact activation complexes FXIIa-C1-esterase inhibitor and FXIa-C1-esterase inhibitor were analyzed in plasmas obtained from blood collected in $3.2 \%(\mathrm{w} / \mathrm{v})$ citrate blood collection tubes with and without $40 \mu \mathrm{g} \mathrm{mL} \mathrm{m}^{-1}$ CTI. Plasma collected without CTI from 12 healthy volunteers contained $0.16 \%$ (IQR: 0.14-0.16) FXIIa-C1-esterase inhibitor complexes and this level was comparable to the concentrations in plasmas collected in the presence of CTI (0.16\%, IQR: $0.14-0.18)$. FXIa-C1-esterase inhibitor complexes, however, were decreased in plasmas containing CTI (0.17\%, IQR: $0.14-0.29$ vs $0.27 \%$, IQR: $0.22-0.33$, $P=0.01$ ) (Figure 4). 
Figure 3. Influence of CTI addition to $3.2 \%(w / v)$ citrate blood collection tubes on thrombin generation triggered with $0.5,1,2$ or 5 pM TF (from left to right) for 12 healthy individuals. Upper panel: ETP in nM.min thrombin; lower panel: peak height in $\mathrm{nM}$ thrombin. Diamonds denote thrombin generation analyses in the absence of CTI and circles indicate measurements in the presence of $40 \mu \mathrm{g} \mathrm{mL}^{-1} \mathrm{CTI}$ added to $3.2 \%$ (w/v) citrate blood collection tubes. Error bars: individual ranges of $10 \%$.

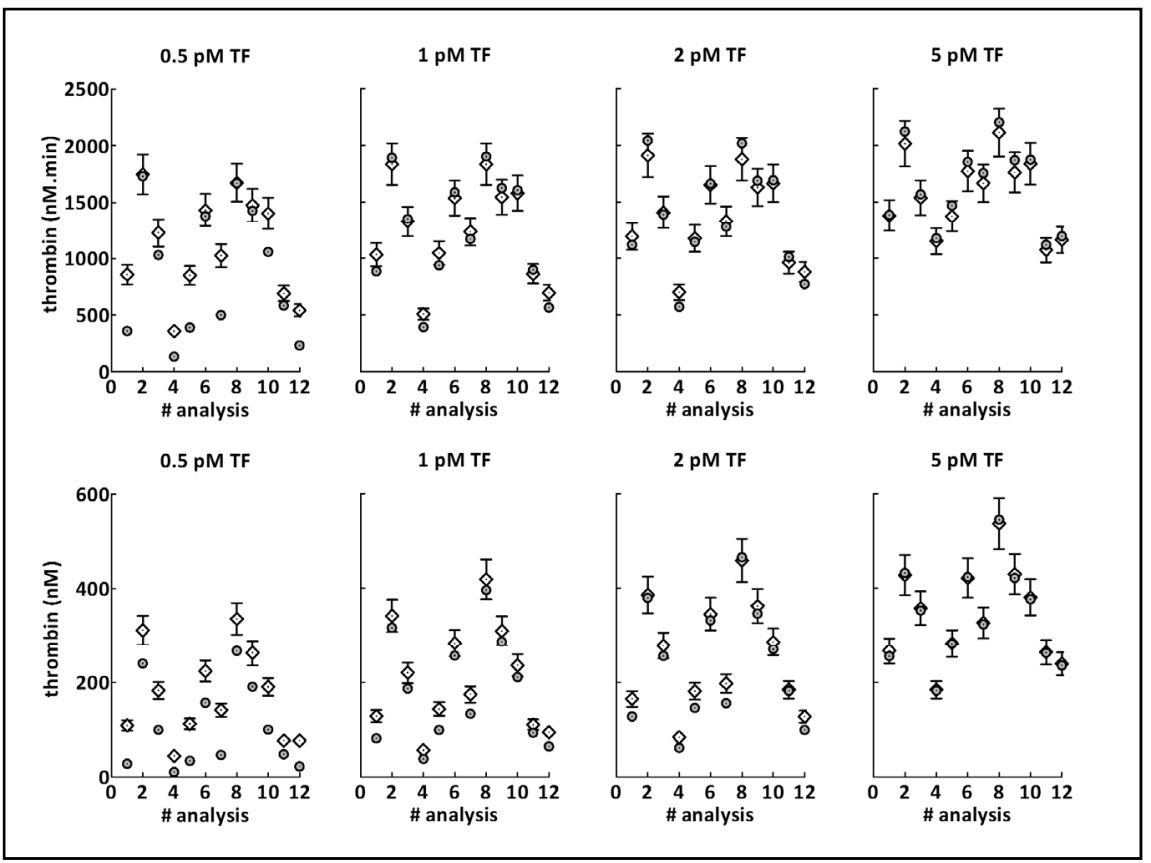

Figure 4. Activation of FXII and FXI during blood drawing. FXIla- and FXla-C1-esterase inhibitor complexes were analyzed in plasma prepared from blood collected without CTI (-CTI) or with $\mathbf{4 0}$ $\mu \mathrm{g} \mathrm{mL}^{-1}$ CTI present during blood drawing (+CTI). The FXIla-C1-esterase inhibitor complexes are depicted in the left panel, whereas the FXIa-C1-esterase inhibitor complexes are shown in the right panel.

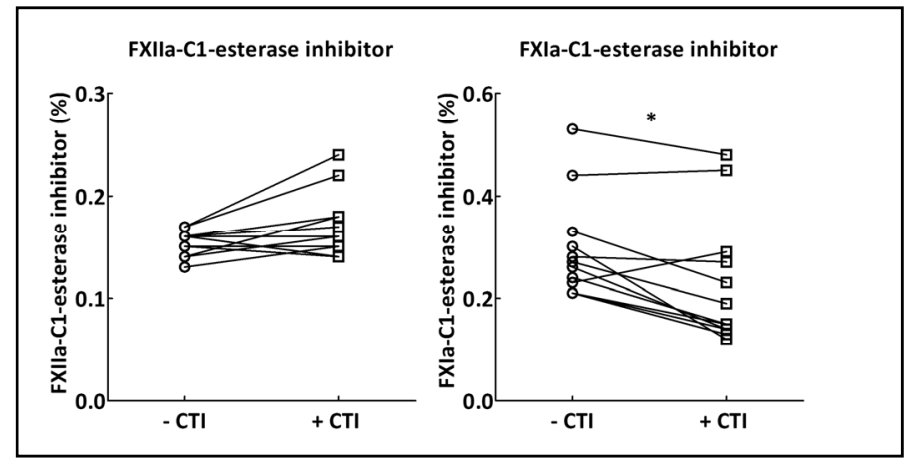




\section{Conclusions}

In recent literature it has been argued that CTI can abrogate the influences of in vitro contact activation on thrombin generation. ${ }^{11,13,14}$ In this study the addition of CTI to a sample after plasma preparation had no influence on thrombin generation, whereas the presence of CTI during blood collection only altered thrombin generation triggered at TF concentrations below $1 \mathrm{pM}$.

In the first part of this study the use of a Winged Infusion Set for blood collection resulted in markedly increased thrombin generation. This was surprising because this needle system had been previously used assuming that it would provide a rather "atraumatic" sampling condition. Especially thrombin generation conducted at $1 \mathrm{pM}$ TF was altered when blood was collected using the Winged Infusion Set. Due to the presence of a $30 \mathrm{~cm}$ long tubing between the collecting and delivering needle activation of blood coagulation FXII is likely to occur. As reported previously, one of the potential problems with the thrombin generation test in routine clinical practice will be the interference of the contact system. ${ }^{17}$ In the past, the influence of contact activation during blood collection was minimized through the use of a free-flowing and tourniquet-free method. ${ }^{4}$ This method is, however, only suited for research purposes since application in a hospital and clinical laboratory is impossible due to the large numbers of venipunctures performed daily. Therefore, the use of the standard needles used for vacuum blood collection is preferred over other systems with a long physical distance between vein and collection tube or those making logistics too complicated.

The occurrence of contact activation during blood collection was confirmed through analysis of complexes of FXIIa and FXIa with their natural inhibitor C1-esterase inhibitor, respectively. The presence of the specific FXIIa inhibitor, CTI, in the blood collection tubes had no influence on the levels of FXIIa-C1-esterase inhibitor, whereas the FXIa-C1-esterase inhibitor complexes were reduced. Elevated levels of FXIa-C1esterase inhibitor complexes suggest contact activation. Absence of differences in FXIIaC1-esterase inhibitor complexes were most likely due to insensitivity of the assay to detect very small changes at baseline: low levels of FXIIa a re sufficient to trigger coagulation.

Addition of CTI to plasma has been shown to reduce or overcome the influence of contact activation on thrombin generation. ${ }^{11,13,14}$ Using 5 pM TF as trigger, Luddington and Baglin observed an almost two-fold reduction in ETP upon addition of CTI to the blood collection tube. ${ }^{14}$ This effect abolished at a TF concentration of $15 \mathrm{pM}$, suggesting a larger influence of contact activation at lower TF levels. Furthermore, Van Veen and colleagues observed an average reduction in ETP of 343 nM.min upon addition of CTI to plasma, using a trigger of 1 pM. ${ }^{13}$ Even the use of a higher TF trigger ( $\left.5 \mathrm{pM}\right)$ did not completely attenuate the effects of contact activation on thrombin generation. And last, Dargaud and colleagues used the addition of CTI to plasma to reduce the inter- 
laboratory variations in thrombin generation. In their study, addition of CTI to the collection tubes reduced the ETP on average with $178 \mathrm{nM}$.min at a $1.5 \mathrm{pM}$ TF trigger.11 Again, the use of pre-filled CTI/citrate tubes is feasible under research conditions, but major drawbacks exist for application in a hospital laboratory. First of all, currently most hospitals use 3.2 or $3.8 \%(\mathrm{w} / \mathrm{v})$ citrate vacutainer blood collection tubes for coagulation assays. Second, there is a significant cost issue. Currently, CTI is sold at a list price of around $€ 100$ (approximately $\$ 150$ or $£ 70$ ) for $1 \mathrm{mg}$. Pre-filling $4.5 \mathrm{~mL}$ tubes to a final plasma concentration of $40 \mu \mathrm{g} \mathrm{mL}^{-1}$ (used in this paper) will cost around $€ 15$ (approximately $\$ 22$ or $£ 12$ ) per tube. In conclusion, the use of pre-filled CTI blood collection tubes is not preferred given the major logistic and financial consequences.

In contrast to the described inhibition of contact activation through addition of CTI and the beneficial effects on thrombin generation,11,13,14 no influence on thrombin generation was observed when CTI was added to plasma. Using blood collection tubes pre-filled with CTI, however, thrombin generation triggered with low TF (0.5 pM) was reduced, but this reduction was negligible or absent at higher TF concentrations. These data suggest that the extrinsic pathway can overrule the contact activation pathway in thrombin generation when triggered with $1 \mathrm{pM}$ TF or higher.

The differences between our results and the data reported by Van Veen and Dargaud might stem from differences in the used plasma preparations and reagents used for thrombin generation. One striking difference is the centrifugation protocol: in one paper plasma was obtained through double centrifugation at $2000 \mathrm{~g}$ for 10 minutes at room temperature ${ }^{13}$ and in another by double centrifugation at $3000 \mathrm{~g}$ for 15 minutes at room temperature.11 Within our laboratory blood is first centrifuged at $2000 \mathrm{~g}$ for 15 minutes and the obtained plasma is centrifuged a second time at $11000 \mathrm{~g}$ for 10 minutes (both at room temperature). The second step at a higher speed appears to be essential to remove remaining microparticles that possibly facilitate activation of FXII (Trappenburg, Onze Lieve Vrouwe Gasthuis, Amsterdam, The Netherlands, personal communication). Secondly, the source of phospholipids and TF to trigger thrombin generation could be major determinants of variations in thrombin generation. We therefore agree with Van Veen and colleagues ${ }^{13}$ and with Dargaud and colleagues ${ }^{11}$ that there is a lack of standard conditions among different groups in studies on thrombin generation, which needs to be solved. Standardization without the introduction of prefilled CTI blood collection tubes is preferred since additional tubes will lead towards increasing costs and more complicated logistics in a clinical setting.

Our study showed that there is no significant influence of contact activation on thrombin generation by means of the Calibrated Automated Thrombogram at a TF trigger of $1 \mathrm{pM}$ or above. On the basis of these results and previous data (Chapter 3.1),12 we propose that a standard thrombin generation protocol should include the following: 1. no addition of CTI during or after blood drawing; 2. venipuncture through a 21-gauge needle and blood collection using 3.2\% (w/v) citrate vacutainer (with the first $10 \mathrm{~mL}$ of venous blood discarded); 3. uniform plasma preparation at high speed centrifugation; 4 . 


\section{Chapter 3.3}

uniform reagents; and 5. normalization against an international reference plasma. 


\section{References}

1. Spronk HM, Govers-Riemslag JW, ten Cate H. The blood coagulation system as a molecular machine. Bioessays. 2003;25:1220-1228.

2. Mackman N. Role of tissue factor in hemostasis, thrombosis, and vascular development. Arterioscler Thromb Vasc Biol. 2004;24:1015-1022.

3. Gailani D, Renne T. Intrinsic pathway of coagulation and arterial thrombosis. Arterioscler Thromb Vasc Biol. 2007;27:2507-2513.

4. Hemker HC, Giesen P, Al Dieri R, Regnault V, de Smedt E, Wagenvoord R et al. Calibrated automated thrombin generation measurement in clotting plasma. Pathophysiol Haemost Thromb. 2003;33:4-15.

5. Ten Cate-Hoek AJ, Dielis AW, Spronk HM, van Oerle R, Hamulyák K, Prins MH et al. Thrombin generation in patients after acute deep-vein thrombosis. Thromb Haemost. 2008;100:240245.

6. Hron G, Kollars M, Binder BR, Eichinger S, Kyrle PA et al. Identification of patients at low risk for recurrent venous thromboembolism by measuring thrombin generation. JAMA. 2006;296:397-402.

7. Regnault V, Hemker HC, Wahl D, Lecompte T. Phenotyping the haemostatic system by thrombography-potential for the estimation of thrombotic risk. Thromb Res. 2004;114:539545.

8. Dargaud Y, Béguin S, Lienhart A, Al Dieri R, Trzeciak C, Bordet JC et al. Evaluation of thrombin generating capacity in plasma from patients with haemophilia A and B. Thromb Haemost. 2005;93:475-480.

9. Dielis AW, Balliël WM, van Oerle R, Hermens WT, Spronk HM, ten Cate $\mathrm{H}$ et al. Thrombomodulin-modified thrombin generation after in vivo recombinant factor VIII treatment in severe haemophilia A. Haematologica. 2008;93:1351-1357.

10. Siegemund T, Petros S, Siegemund A, Scholz U, Engelmann L. Thrombin generation in severe haemophilia A and B: the endogenous thrombin potential in platelet-rich plasma. Thromb Haemost. 2003;90:781-786.

11. Dargaud Y, Luddington R, Gray E, Negrier C, Lecompte T, Petros S et al. Effect of standardization and normalization on imprecision of calibrated automated thrombography: an international multicentre study. Br J Haematol. 2007;139:303-309.

12. Spronk HM, Dielis AW, de Smedt E, van Oerle R, Fens D, Prins MH et al. Assessment of thrombin generation II: Validation of the Calibrated Automated Thrombogram in plateletpoor plasma in a clinical laboratory. Thromb Haemost. 2008;100:362-364.

13. Van Veen JJ, Gatt A, Cooper PC, Kitchen S, Bowyer AE, Makris M. Corn trypsin inhibitor in fluorogenic thrombin-generation measurements is only necessary at low tissue factor concentrations and influences the relationship between factor VIII coagulant activity and thrombogram parameters. Blood Coagul Fibrinolysis. 2008;19:183-189.

14. Luddington R, Baglin T. Clinical measurement of thrombin generation by calibrated automated thrombography requires contact factor inhibition. J Thromb Haemost. 2004;2:1954-1959.

15. Dielis AW, Castoldi E, Spronk HM, van Oerle R, Hamulyák K, ten Cate H. Coagulation factors and the protein $\mathrm{C}$ system as determinants of thrombin generation in a normal population. $J$ 
Chapter 3.3

Thromb Haemost. 2008;6:125-131.

16. Govers-Riemslag JW, Smid M, Cooper JA, Bauer KA, Rosenberg RD, Hack CE et al. The plasma kallikrein-kinin system and risk of cardiovascular disease in men. J Thromb Haemost. 2007;5:1896-1903.

17. Rand MD, Lock JB, van 't Veer C, Gaffney DP, Mann KG. Blood clotting in minimally altered whole blood. Blood. 1996;88:3432-3445. 
Chapter 4

Coagulation-dependent hypercoagulability: Patients with arterial and venous thrombotic disease 
Chapter 4 


\section{Thrombin generation in patients with a first acute myocardial infarction}

Thrombin generation is a risk predictor of clinical outcome after acute myocardial infarction.

Dielis AWJH' $\mathrm{H}^{1}$, Winkens $\mathrm{M}^{2}$, Spronk $\mathrm{HMH}^{1}$, Wijers-Holys $\mathrm{PA}^{3}$, van Oerle $\mathrm{R}^{1}$, Hamulyák $\mathrm{K}^{3}$, Prins $\mathrm{MH}^{4}$, Rosing $\mathrm{J}^{5}$, Waltenberger $\mathrm{JL}^{2}$, ten Cate $\mathrm{H}^{1}$.

1 Department of Internal Medicine, Laboratory for Clinical Thrombosis and Haemostasis, Cardiovascular Research Institute Maastricht, Maastricht University Medical Center, Maastricht, The Netherlands;

2 Department of Cardiology, Maastricht University Medical Center, Maastricht, The Netherlands;

3 Department of Internal Medicine, Division of Haematology, Maastricht University Medical Center, Maastricht, The Netherlands;

4 Department of Epidemiology, Maastricht University, Maastricht, The Netherlands;

5 Department of Biochemistry, Cardiovascular Research Institute Maastricht, Maastricht University, Maastricht, The Netherlands. 


\section{Abstract}

Background: Hypercoagulability is considered to play an important role in the pathogenesis of acute myocardial infarction. Established biochemical risk markers of this "hypercoagulable state" include D-dimer, C-reactive protein, tissue-type plasminogen activator and fibrinogen, and these have been found to be associated with the occurrence of (recurrent) acute myocardial infarction. Thrombin generation, in contrast to the aforementioned markers, provides a more general overview of coagulation, and might be a better predictor of clinical outcome.

Objective: To determine the value of thrombin generation as risk estimator of clinical outcome.

Patients and methods: Thrombin generation at 1 and $5 \mathrm{pM}$ tissue factor (TF), D-dimer and prothrombin fragment $1+2(\mathrm{~F} 1+2)$ were determined in patients with acute myocardial infarction, on admission and during follow-up for six months. Clinical outcome was recorded during follow-up for one year, with a combined end point of cardiovascular death, recurrent myocardial infarction, cerebrovascular accident and chest pain requiring hospitalization and intervention.

Results: On admission, thrombin generation was increased compared to a genderand age-matched reference population in both the $1 \mathrm{pM} \mathrm{TF}$ (endogenous thrombin potential; ETP: 147.4 vs $102.6 \%, P<0.05$; peak height: 215.3 vs $109.6 \%, P<0.05$ ) and 5 pM TF assays (ETP: 112.8 vs $102.9 \%, P<0.05$; peak height: 131.6 vs $101.8 \%, P<0.05$ ). During follow-up for six months, peak heights were persistently increased in patients compared to the reference population. A total of 32 patients reached an end point. ETP at $5 \mathrm{pM}$ TF was significantly lower in patients with an end point compared to patients that did not reach an end point (103.3 vs $115.2 \%, P=0.03)$. Low ETP and high D-dimer were associated with the occurrence of end points, $\mathrm{OR}=3.7(1.2-11.5)$ and $\mathrm{OR}=5.2$ (1.715.6), respectively.

Conclusions: ETP measaured at $5 \mathrm{pM}$ TF during the acute phase of myocardial infarction is an inverse independent risk predictor, while D-dimer is a positive risk predictor of clinical outcome. 


\section{Introduction}

Acute myocardial infarction is the result of thrombus formation upon the exposure of tissue factor (TF) and collagen from a ruptured atherosclerotic plaque to circulating factor VII (FVII) and platelets, respectively. ${ }^{1,2}$ This leads to activation of haemostasis, thereby arresting blood flow in one or more coronary arteries. TF and activated FVII (FVIIa) complex formation results in the formation of thrombin and the conversion of fibrinogen to fibrin, accelerated by concurrent platelet activation. ${ }^{3-5}$ During this process, and probably also before and after, a "hypercoagulable state" is present in the plasma, a situation that is characterized by an increased coagulation potential.6-8 Despite treatment and secondary prevention (e.g. percutaneous coronary intervention (PCI), stenting, dual platelet inhibition, treatment of risk factors) acute myocardial infarction remains associated with short-term as well as long-term recurrent thrombotic complications (in-hospital 3.6\%, six-month outcome 4.8\%) and mortality (both inhospital and six-month mortality around 4.6\%, combined deaths), while congestive heart failure is the leading cause of in-hospital morbidity (11\%).9,10 This may indicate an ongoing hypercoagulable state that is not treated optimally. Stratification of patients according to their thrombotic risk and subsequent specific antithrombotic treatment strategies in these high-risk individuals can potentially improve outcome and secondary prevention of atherothrombotic disease. ${ }^{9}$

Markers of hypercoagulability, including high D-dimer (a reflection of fibrin degradation), ${ }^{11,12}$ C-reactive protein (CRP; reflection of a general response to tissue injury), ${ }^{13}$ tissue-type plasminogen activator (t-PA; an inhibitor of fibrinolysis) (Chapter $5.1)^{14}$ and fibrinogen ${ }^{15}$ have been shown to be independent risk factors for (recurrent) cardiovascular disease.

A relatively novel technique in measuring hypercoagulability is the thrombin generation assay. ${ }^{16,17}$ Thrombin is the central enzyme in blood coagulation, ${ }^{3,18}$ and the rate in which it is formed and the total amount produced can be considered a marker of the coagulation potential of plasma. This general assay takes all plasma components in consideration, providing a more general overview of coagulation activity than the aforementioned individual markers.

We hypothesize that thrombin generation as a measurement of hypercoagulability is a useful predictor of clinical outcome after a first acute myocardial infarction. In this study, we used the Calibrated Automated Thrombogram (CAT; Thrombinoscope BV, Maastricht, The Netherlands) to assess coagulation potential in plasma from patients during the acute phase of a first acute myocardial infarction and during follow-up, and we studied the value of thrombin generation as a risk estimator of clinical outcome. In addition, we compared thrombin generation measurements, as a reflection of coagulation potential, to established markers D-dimer and prothrombin fragment $1+2$ $(\mathrm{F} 1+2)$, as a reflection of occurred coagulation. 


\section{Design and methods}

\section{Patients and reference population}

Consecutive patients with a first acute myocardial infarction were recruited at the Department of Cardiology of the Maastricht University Medical Center, The Netherlands. All patients fulfilled the following inclusion criteria: chest pain lasting longer than 30 minutes but not exceeding 24 hours, ST-segment elevation $>1 \mathrm{~mm}$ on electrocardiography, and (in the absence of ST-segment elevation) elevated creatine phosphokinase (CK) and troponin T plasma levels. Exclusion criteria were a positive medical history of acute myocardial infarction or stroke, the use of previously prescribed anticoagulant medication (heparin, low molecular weight heparin (LMWH) and vitamin $\mathrm{K}$ antagonists) and a referral site outside of the Maastricht University Medical Center region.

To overcome the absence of a clearly defined reference range for thrombin generation parameters, blood samples were drawn from a group of 68 healthy individuals matched for gender and age and originating from the same region of The Netherlands, referred to as "reference population" in the thrombin generation results section.

\section{Study design}

After inclusion, blood samples were drawn at the Cardiology Emergency Unit (day 0), and after four days, three and six months. Patients were followed up for use of medication and clinical outcome after four days, three, six and 12 months. Clinical outcome recorded consisted of cardiovascular death and recurrent myocardial infarction (primary end points), and cerebrovascular accident (CVA) and chest pain requiring hospitalization and intervention (angiography, PCI with or without stenting and coronary artery bypass graft (CABG) (secondary end points).

The study protocol was approved by the Medical Ethics Committee of the Maastricht University Medical Center, The Netherlands. Informed consent was obtained from all patients.

\section{Pooled normal plasma}

Pooled normal plasma was prepared at the Departments of Haematology and Clinical Chemistry of the Maastricht University Medical Center, The Netherlands, by pooling plasma from 85 healthy volunteers not using any medication. 


\section{Blood collection and preparation}

Venous blood was collected in $3.2 \%(\mathrm{w} / \mathrm{v})$ citrated tubes. Platelet-poor plasma was prepared by two-step centrifugation: first at $2000 \mathrm{~g}$ for 15 minutes followed by centrifugation at $11000 \mathrm{~g}$ for 10 minutes. Plasma aliquots were stored at $-80^{\circ} \mathrm{C}$ until use and thawed at $37^{\circ} \mathrm{C}$ for 15 minutes before analysis.

\section{Thrombin generation measurements}

Thrombin generation in tissue factor (TF)-triggered platelet-poor plasma was measured by means of the CAT method (Thrombinoscope BV), which employs a low affinity fluorogenic substrate for thrombin (Z-Gly-Gly-Arg-AMC) to continuously monitor thrombin activity in clotting plasma. According to the manufacturer's instructions, measurements were conducted on $80 \mu \mathrm{L}$ platelet-poor plasma in a total volume of 120 $\mu \mathrm{L}$ and in the presence of $416 \mu \mathrm{M}$ fluorogenic substrate. In order to correct for innerfilter effects and substrate consumption, each thrombin generation measurement was calibrated against the fluorescence curve obtained in the sample plasma with a fixed amount of thrombin- $\alpha_{2}$-macroglobulin complex (Thrombin Calibrator, Thrombinoscope BV). Fluorescence was read in a Fluoroskan Ascent reader (Thermo Labsystems OY, Helsinki, Finland) equipped with a 390/460 filter set and thrombin generation curves were calculated with the Thrombinoscope software (Thrombinoscope BV). Five parameters were derived from the thrombin generation curves: lag time (initiation phase of coagulation), endogenous thrombin potential (ETP; area under the thrombin generation curve), peak height, time to peak and slope (propagation phase of coagulation). Lag time was defined as the time to reach one-sixth of the peak height. Slope was calculated by dividing five-sixth of the peak height by the time to peak minus the lag time.

Thrombin generation was determined at final plasma concentrations of both 1 and 5 pM TF (PPP Reagent, PPP Reagent Low, Thrombinoscope BV) in the presence of $4 \mu \mathrm{M}$ phospholipids (phosphatidylserine / phosphatidylcholine / phosphatidylethanolamine vesicles in HEPES-buffered saline).

Validation of the CAT method in our laboratory showed normalization of timeindependent parameters (ETP and peak height) to be mandatory to obtain acceptable inter-assay variations (Chapter 3.1). ${ }^{19}$ Intra-assay variations for normalized parameters are typically below 6\%, inter-assay variations below $8 \%$. Therefore, each thrombin generation measurement includes pooled normal plasma and both the ETP and peak

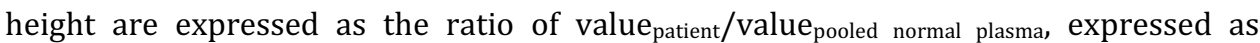
percentages. The slope was calculated from normalized peak height data. This method yields comparable data to slope calculated from non-normalized peak height data $(R=0.997, P<0.0001$, data not shown). 


\section{D-dimer and F1+2 measurements}

D-dimer measurements in platelet-poor plasma were performed using the D-dimer Plus test (Dade Behring Inc., Liederbach, Germany) according to the manufacturer's instructions. F1+2 was quantified by ELISA according to the manufacturer's instructions (Dade Behring Inc.).

\section{Statistical analysis}

Data are expressed as mean (95\% confidence interval) or median [interquartile range], according to group size and data normality. Differences over time in thrombin generation parameters, D-dimer and F1+2 were analyzed using paired Student's $t$-test or Wilcoxon's signed rank test when appropriate. Differences between patients and the reference population were assessed using Student's $t$-test or Mann Whitney U-test as appropriate. Correlations are expressed as Pearson's coefficients. The associations between thrombin generation parameters, D-dimer and F1+2 and outcome were assessed using Pearson's chi-square test, and are expressed with corresponding odds ratios.

If a significant association was found further analysis was performed using binary logistic regression to adjust for potential confounding factors (gender, age in quartiles, hypertension, smoking, diabetes and hypercholesterolemia). Survival was analyzed using Kaplan-Meier log rank test, expressed as Mantel-Cox chi-square. A two-tailed probability value $P<0.05$ was considered statistically significant.

Statistics were computed using SPSS for Windows, version 12.0 (SPSS Inc., Chicago, IL, USA) and Prism for Windows 5.00 (GraphPad Software Inc., San Diego, CA, USA). 


\section{Results}

\section{Patients and reference population}

A total of 135 consecutive patients (100 males, $74.1 \%$ and 35 females, $25.9 \%$ ) with a first acute myocardial infarction were included. Mean age on admission was 60.6 years, 59.9 (range: 28.0-82.8) for males and 62.5 (range: 33.8-88.2) for females, difference

Table 1. Baseline characteristics of the study population.

\begin{tabular}{lllllll}
\hline & \multicolumn{2}{l}{ Total group } & \multicolumn{2}{l}{ Males } & \multicolumn{2}{l}{ Females } \\
\hline $\mathrm{n}$ (percentage) & 135 & $(100.0)$ & 100 & $(74.1)$ & 35 & (25.9)
\end{tabular}

Risk factors (number (percentage))

$\begin{array}{lllllll}\text { Age (years; mean (SD)) } & 60.6 & (12.6) & 59.9 & (12.2) & 62.5 & (13.8) \\ \text { Hypertension } & 38 & (28.1) & 28 & (28.0) & 10 & (28.6) \\ \text { Smoking } & 72 & (53.3) & 51 & (51.0) & 21 & (60.0) \\ \text { Diabetes } & 8 & (5.9) & 6 & (6.0) & 2 & (5.7) \\ \text { Hypercholesterolemia } & 29 & (21.5) & 21 & (21.0) & 8 & (22.9)\end{array}$

Localization of infarction (number (percentage))

$\begin{array}{lllllll}\text { inferior involved } & 74 & (54.8) & 58 & (58.0) & 16 & (45.7) \\ \text { anterior involved } & 53 & (39.3) & 36 & (36.0) & 17 & (48.6) \\ \text { posterior involved } & 59 & (43.7) & 43 & (43.0) & 16 & (45.7) \\ \text { lateral involved } & 35 & (25.9) & 27 & (27.0) & 8 & (22.9) \\ \text { inferoposterior } & 57 & (42.2) & 42 & (42.0) & 15 & (42.9) \\ \text { anterolateral } & 19 & (14.1) & 14 & (14.0) & 5 & (14.3)\end{array}$

Enzymes on admission (median [interquartile range])

Troponin $\mathrm{T}\left(\mathrm{ng} \mathrm{mL}^{-1}\right) \quad 0.10 \quad[0.03-0.36] \quad 0.11 \quad[0.04-0.34] \quad 0.06 \quad[0.02-0.99]$

Creatine kinase $\left(\mathrm{UL}^{-1}\right) \quad 128.0 \quad[81.0-231.0] \quad 145.5 \quad$ [95.8-246.3] $\quad 81.0 * \quad[57.0-163.0]$

$\begin{array}{lllll}\text { Lactate dehydrogenase }\left(\mathrm{UL}^{-1}\right) & 389.0 & {[330.8-478.8]} & 385.0 & \text { [331.0-476.0] } 392.0 \\ \text { [330.0-581.0] }\end{array}$

Enzymes during hospitalization, peak levels (median [interquartile range])

$\begin{array}{lllllll}\text { Troponin } \mathrm{T}\left(\mathrm{ng} \mathrm{mL} \mathrm{L}^{-1}\right) & 2.76 & {[1.03-6.67]} & 2.83 & {[1.14-7.16]} & 1.99 & {[0.63-5.24]} \\ \text { Creatine kinase }\left(\mathrm{UL}^{-1}\right) & 1113 & {[485-2594]} & 1190 & {[489.3-3107]} & 783.0 & {[259.0-1741]} \\ \text { Lactate dehydrogenase }\left(\mathrm{U} \mathrm{L}^{-1}\right) & 823.0 & {[539.0-1389]} & 838.5 & {[540.5-1555]} & 769.0 & {[518.0-1243]}\end{array}$

* denotes $P<0.05$ compared to males. 
not significant. Baseline characteristics, localization of infarction and cardiac enzymes on admission and peak levels during hospitalization of the patients are presented in Table 1. The distribution of classic risk factors for arterial disease did not differ significantly between genders. On admission, females had significantly lower creatine kinase than males ( 81.0 vs $145.5 \mathrm{U} \mathrm{L}^{-1}$ ). The most frequent localization of infarction was inferoposterior, present in $42.2 \%$ of patients. Of all patients, $16(11.9 \%)$ did not reach the one-year follow-up (three vascular deaths, indicated as end points; one patient moved outside of the study region; 12 patients withdrew participation throughout the study or could not be contacted).

The reference population for thrombin generation consisted of 50 males $(73.5 \%)$ and 18 females (26.5\%), with a mean age of 58.2 years (57.2 for males, 62.4 for females), comparable to the patient population.

\section{Thrombin generation and anti-FXa activity}

During their hospital stay, most patients were treated with LMWH and this markedly influenced thrombin generation measurements at day four. Anti-FXa activity was used as a means to determine the influence of low molecular weight heparin treatment. In the $1 \mathrm{pM}$ TF assay, the ETP was inversely correlated with anti-FXa activity $(R=-0.86$,

Figure 1. Correlations between ETP at $1 \mathrm{pM}$ TF and anti-FXa activity at day 4. Data are presented as Pearson's $R$.

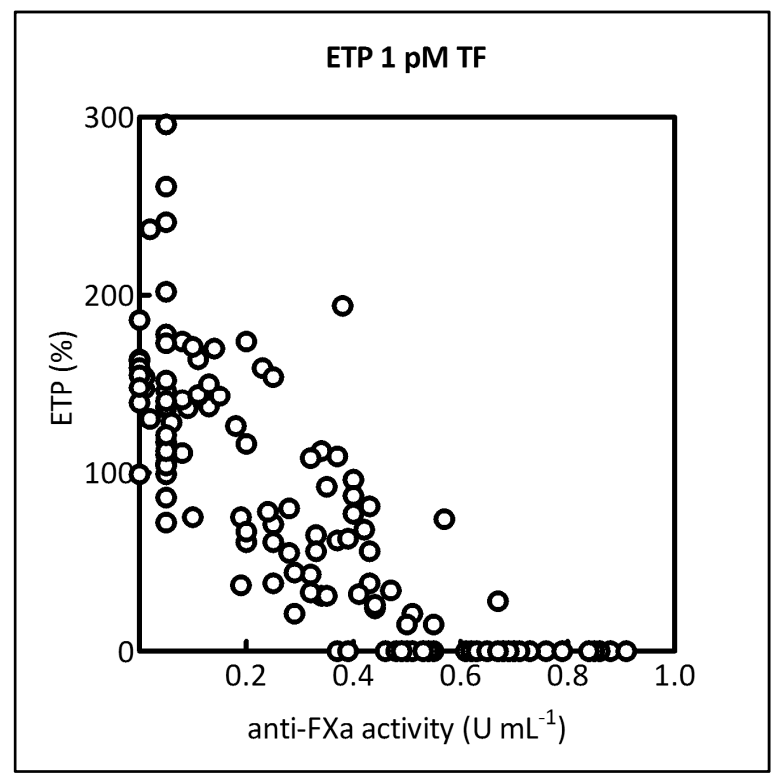

$R=-0.86, P<0.05$. 
$P<0.05$ ) (Figure 1). At anti-FXa activity above $0.5 \mathrm{U} \mathrm{mL}^{-1}$ the Thrombinoscope software was unable to calculate a thrombin generation curve in most of the patients, resulting in ETPs with an arbitrary value of 0 . In the 5 pM TF assay, the ETP was inversely correlated with anti-FXa activity $(R=-0.76, P<0.05)$, although a smaller proportion of thrombin generation curves could not be calculated at higher anti-FXa activity levels.

To correct for this technical limitation, we (arbitrarily) decided to exclude all thrombin generation measurements at day four in plasma samples with anti-FXa activity above $0.5 \mathrm{U} \mathrm{mL}^{-1}$ (23.7\% of patients).

\section{Thrombin generation, D-dimer and F1+2 measurements}

Thrombin generation measurements in patients and the reference population are presented in Table 2A. Figure 2 depicts ETP and peak height at 1 and $5 \mathrm{pM}$ TF in the reference population and patients. D-dimer and F1+2 measurements in patients are presented in Table 2B.

On admission, thrombin generation was increased compared to the reference population, with increased ETP, peak height and slope. This was most pronounced in the 1 pM TF assay (ETP 147.4\%, peak height 215.3\%), although variations were wider in the $1 \mathrm{pM}$ TF assay than in the $5 \mathrm{pM}$ TF assay. After four days, thrombin generation significantly decreased compared to $0 \mathrm{~d}$ (correlated to treatment with low molecular weight heparin, see Figures 1), reflected in a strong decrease in the peak height and ETP, although all were still above $100 \%$, except the peak height in the $5 \mathrm{pM}$ TF assay. During follow-up at three and six months, the ETP in both the 1 and 5 pM TF assays was more comparable to the reference population, although the ETP in the $1 \mathrm{pM}$ TF assay at three months was still increased. Peak height and slope, however, remained significantly higher in patients than in the reference group throughout the entire followup period, indicating an ongoing increase in coagulation potential.

In the $5 \mathrm{pM}$ TF assay, the time to peak in patients was shortened after three and six months compared to the reference group, while lag time showed no significant differences. In contrast, the lag time and time to peak were significantly prolonged in patients at all time points. The ETP and peak height in the $5 \mathrm{pM}$ TF assay negatively correlated with age $(R=-0.34, P=0.001$ and $R=-0.25, P=0.02$, respectively). In the $1 \mathrm{pM}$ TF assay, the ETP was negatively correlated with age: $R=-0.24, \mathrm{P}=0.03$.

Median D-dimer on admission was $370 \mathrm{ng} \mathrm{mL}^{-1}$ with a wide range $(<100-8700 \mathrm{ng}$

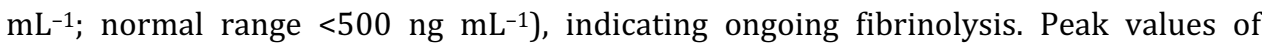
D-dimer were reached on day four. During follow-up, median D-dimer was below 500 ng $\mathrm{mL}^{-1}$ although a subgroup of patients had persistently increased D-dimer levels after six months. D-dimer correlated with age: $R=0.34, P=0.001$, but not with thrombin generation parameters.

$\mathrm{F} 1+2$ levels on admission were $214 \mathrm{nM} \mathrm{mL}^{-1}$ and remained unchanged throughout 
Table 2. Thrombin generation measurements at 1 and $5 \mathrm{pM}$ TF in the reference population and acute myocardial infarction patients on admission (0d) and during follow-up for 4 days ( $4 \mathrm{~d}), 3$ and 6 months (3m, $6 \mathrm{~m})(\mathrm{A})$, and D-dimer and $\mathrm{F} 1+2$ in patients (B).

\begin{tabular}{lllll}
\hline $\begin{array}{l}\text { Reference } \\
\text { population }\end{array}$ & $\begin{array}{l}\text { Patients } \\
\text { Od }\end{array}$ & $4 \mathrm{~d}$ & $3 \mathrm{~m}$ & $6 \mathrm{~m}$ \\
\hline
\end{tabular}

A

\section{Thrombin generation $1 \mathrm{pM}$ TF}

\begin{tabular}{|c|c|c|c|c|c|c|c|c|c|c|}
\hline Lag time (min) & 3.9 & [3.7-4.3] & $5.8^{\dagger}$ & [4.9-7.4] & $10.0^{*+}$ & [7.5-14.2] & $7.0^{*+}$ & [5.6-8.5] & $6.6^{*+}$ & [5.6-8.2] \\
\hline ETP (\%) & 102.6 & [89.9-115.6] & $147.4^{\dagger}$ & [121.0-174.9] & ] $112.4^{*}$ & [66.2-152.9] & $118.5^{*+}$ & [101.1-140.6] & ]110.8* & [87.9-133.3] \\
\hline Peak height (\%) & 109.6 & [63.2-126.5] & $215.3^{+}$ & [155.1-281.4] & ]119.1* & [59.6-182.8] & $136.8^{*+}$ & [108.3-182.1] & $120.2^{*+}$ & [89.7-169.0] \\
\hline \multicolumn{11}{|c|}{ Time to peak (min) } \\
\hline & 8.2 & {$[7.7-8.9]$} & $9.6^{+}$ & [8.6-11.3] & $14.6^{* \dagger}$ & {$[11.5-20.1]$} & $11.2^{*+}$ & {$[9.9-13.0]$} & $11.1^{*+}$ & [9.9-12.6] \\
\hline Slope $\left(\% \min ^{-1}\right)$ & 19.0 & {$[12.4-26.8]$} & $50.2^{+}$ & [30.4-77.4] & $23.2^{*+}$ & {$[10.0-37.8]$} & $27.3^{* \dagger}$ & [19.7-38.3] & $23.3^{*+}$ & [15.3-33.8] \\
\hline
\end{tabular}

\section{Thrombin generation $5 \mathrm{pM}$ TF}

\begin{tabular}{|c|c|c|c|c|c|c|c|c|c|c|}
\hline Lag time (min) & 2.6 & [2.3-2.9] & 2.6 & [2.0-3.3] & $3.8^{*+}$ & {$[3.0-5.0]$} & 2.3 & {$[2.0-3.0]$} & 2.3 & {$[2.0-3.0]$} \\
\hline ETP (\%) & 102.9 & [93.2-115.0] & $112.8^{+}$ & [97.8-127.7] & $100.7^{*}$ & [67.6-125.3] & $99.4^{*}$ & [90.0-113.4] & $101.1^{*}$ & [91.5-113.5] \\
\hline Peak height (\%) & 101.8 & [90.4-109.4] & $131.6^{\dagger}$ & [95.7-154.7] & $85.4^{*+}$ & [38.9-119.9] & $108.8^{*+}$ & [90.8-126.1] & $110.3^{*+}$ & [90.9-123.7] \\
\hline \multicolumn{11}{|c|}{ Time to peak (min) } \\
\hline & 8.2 & {$[7.7-8.9]$} & 5.3 & [4.5-6.3] & $7.3^{* \dagger}$ & [5.5-9.5] & $5.3^{\dagger}$ & [4.3-6.1] & $5.3^{\dagger}$ & {$[4.5-6.0]$} \\
\hline Slope $\left(\%\right.$ min $\left.^{-1}\right)$ & 29.8 & [24.0-32.9] & $45.9+$ & [25.9-55.8] & $21.5^{*+}$ & [8.6-40.4] & $35.3^{*+}$ & [24.9-44.2] & $34.2^{*+}$ & [25.4-45.4] \\
\hline
\end{tabular}

B

\begin{tabular}{llllllllll} 
D-dimer $\left(\mathrm{ng} \mathrm{mL}^{-1}\right)-$ & - & 370 & {$[260-710]$} & $600^{*}$ & {$[335-965]$} & 410 & {$[270-700]$} & 405 & {$[250-700]$} \\
$\mathrm{F} 1+2\left(\mathrm{nM} \mathrm{mL}^{-1}\right)$ & - & 214 & {$[165-298]$} & 218 & {$[159-325]$} & 223 & {$[166-304]$} & 194 & {$[174-332]$} \\
\hline
\end{tabular}

Data are presented as median [interquartile range]. ${ }^{*}$ denotes $P<0.05$ compared to $0 \mathrm{~d}$; $\dagger$ denotes $P<0.05$ compared to the reference population.

the study period. $\mathrm{F} 1+2$ on admission weakly correlated with age $(R=0.28, P=0.01)$. Except for day four, F1+2 correlated with D-dimer $\left(R^{\prime}\right.$ s $\left.0.38-0.52, P<0.001\right)$. F1+2 on day four correlated weakly with parameters of thrombin generation at $1 \mathrm{pM} \mathrm{TF}$, except for the slope (lag time: $R=-0.25, P=0.04$; ETP: $R=0.24, P<0.05$; peak height: $R=0.24$, $P=0.05$; time to peak: $R=-0.34, P=0.004$ ).

Thrombin generation parameters did not show significant differences between patients stratified for gender, or the presence of smoking, hypertension, diabetes and hypercholesterolemia. Female patients and patients with hypertension had significantly higher median D-dimer concentrations (female vs male: 660 vs $360 \mathrm{ng} \mathrm{mL}^{-1}, P=0.001$; hypertension vs no hypertension: 595 vs $\left.360 \mathrm{ng} \mathrm{mL}^{-1}, P=0.02\right)$. Female patients had significantly higher F1+2 levels at all time points (female vs male on admission: 244 vs $191 \mathrm{nM} \mathrm{mL}^{-1}, P=0.004$, other data not shown). None of these parameters were associated nor correlated with cardiac enzymes measured on admission and during 
hospitalization, or the localization of infarction.

\section{Predictors of clinical outcome}

A total of 32 patients reached an end point within 12 months after the acute myocardial infarction, of which one-third (10 cases) occurred in the first four days after onset, including all vascular deaths (three cases). Recurrence of myocardial infarction was recorded in three patients (one within four days, three and six months after onset of infarction). The most frequent end point was chest pain requiring hospitalization and intervention ( 25 cases). One patient suffered from a cerebrovascular accident within the first four days. Risk factors (gender, hypertension, smoking, diabetes and hypercholesterolemia) were equally distributed in patients with and without an end point during follow-up, although patients reaching an end point were of older age $(66.2$ vs 58.1 years).

Figure 2. ETP at 1 and $5 \mathrm{pM}$ TF (panels $A$ and $B$ ) and peak height at 1 and $5 \mathrm{pM}$ TF (panels $C$ and $D$ ) in the reference population (white circles) and patients (black circles) on admission ( $0 \mathrm{~d})$ and during follow-up for 4 days $(4 \mathrm{~d}), 3$ and 6 months $(3 \mathrm{~m}, 6 \mathrm{~m})$. Data are presented as median [interquartile range].

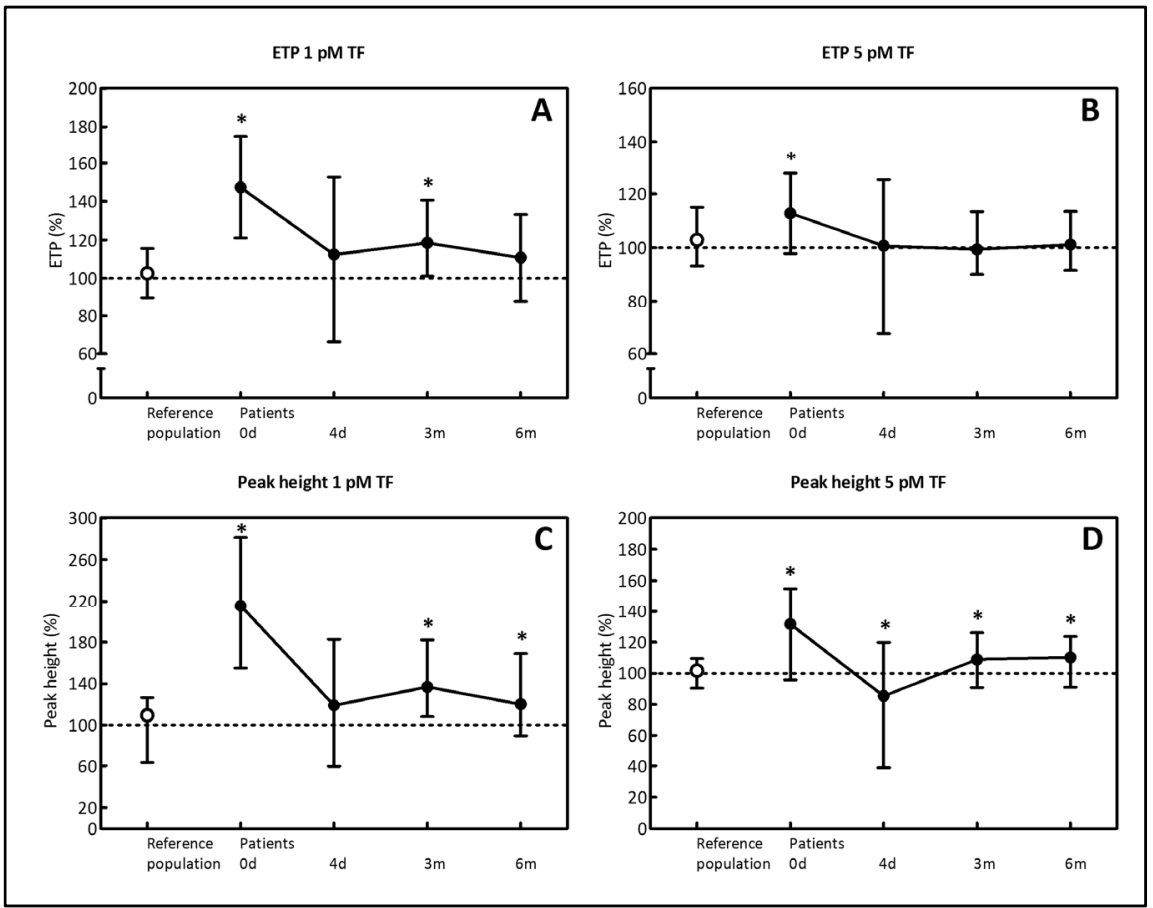

* denotes $P<0.05$ compared to the reference population. 
In patients that reached an end point during follow-up, the ETP at $5 \mathrm{pM}$ TF on admission was significantly lower than in patients without an end point during follow-up (103.3 vs $115.2 \%, P=0.03$ ), while D-dimer on admission was significantly higher in patients with an event during follow-up (560 vs $360 \mathrm{ng} \mathrm{mL}^{-1}, P=0.02$ ). F1+2 was not up (103.3 vs $115.2 \%, P=0.03$ ), while D-dimer on admission was significantly higher in different between patients with and without an end point during follow-up (243 vs $208 \mathrm{nM} \mathrm{mL}^{-}$ 1). Upon dichotomizing admission ETP and D-dimer to "low" (< total group median) and "high" ( $\geq$ total group median), low ETP was significantly associated with the occurrence of end points (chi-square=5.7, $P=0.02$ ) with an odds ratio of $3.7(1.2-11.5)$ for low compared to high ETP. In contrast, high admission D-dimer was significantly associated with the occurrence of end points (chi-square $=9.7, P=0.002$ ) with an odds ratio of 5.2 (1.7-15.6) for high compared to low D-dimer. Although binary logistic regression showed an association with age (beta $=0.48, P=0.03$ ), baseline ETP at $5 \mathrm{pM}$ TF remained an independent predictor of outcome (beta=-1.7, $P=0.003$ ). $F 1+2$ on admission was not significantly correlated with the occurrence of end points.

Kaplan-Meier survival analysis yielded comparable results, with a significant shorter mean end point free survival in patients with low vs patients with high ETP (270 vs 331 days, $\log$ rank=6.2, $P=0.01$ ), and a shorter mean end point-free survival in patients with high vs patients with low D-dimer (255 vs 330 days, log rank=9.7, $P=0.002$ ). No differences in survival were found between low and high F1+2 (low vs high F1+2: 324 vs 284 days, difference not significant). Differences in survival between the groups already occurred within the first four days, after which the survival curves showed a comparable decrease in time (see Figure 3).

A low admission ETP and high admission D-dimer coincided in $27.6 \%$ of patients, indicating a low association between the two parameters. When the association analysis was repeated and patients with both low ETP and high D-dimer were compared to the remaining patients, the combined parameters yielded a higher significant odds ratio than in separate analyses, odds ratio=5.8 (1.9-17.2), chi-square=11.2, $P=0.001$. 
Figure 3. End point-free survival in patients with low $(<112.8 \%$, solid line) and high ( $\geq 112.8 \%$, dotted line) admission ETP at 5 pM TF. Data are presented as mean (SEM).

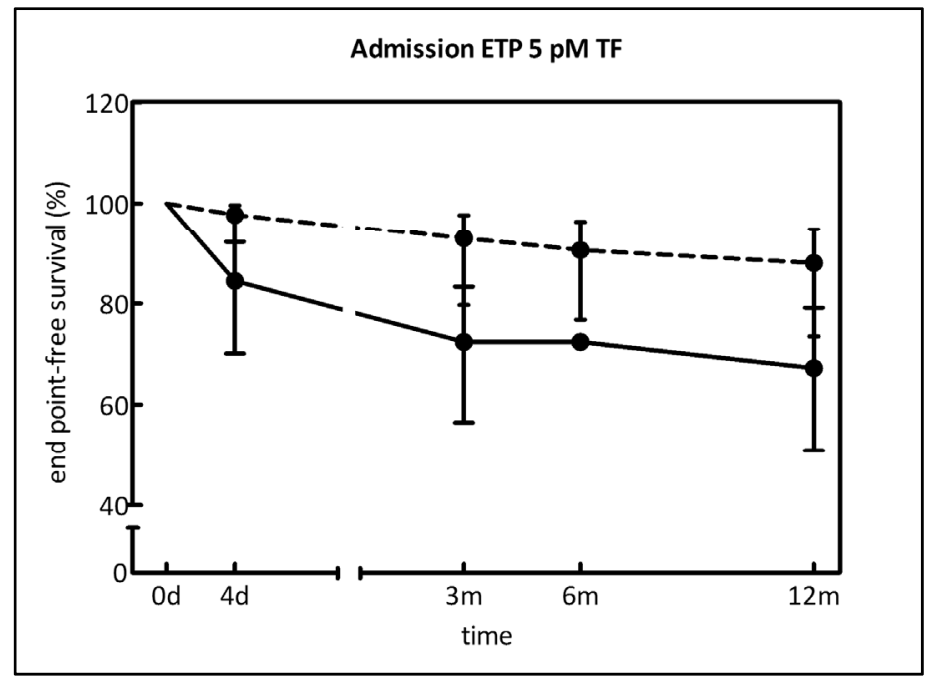

Od, admission; $4 d$, 4 days; $3 m, 3$ months; $6 \mathrm{~m}, 6$ months; $12 \mathrm{~m}, 12$ months. 


\section{Discussion}

In the presented study we measured overall thrombin generation in plasma from patients with a first acute myocardial infarction both during the acute phase and during follow-up for six months and assessed the significance of thrombin generation as a risk predictor of clinical outcome.

During the acute phase of myocardial infarction, thrombin potential was increased in both the 1 and 5 pM TF assays. This effect was particularly pronounced in the $1 \mathrm{pM}$ TF assay with the ETP reaching $147.4 \%$, a peak height of $215.3 \%$ and a slope of $50.2 \%$ $\mathrm{min}^{-1}$. We were not able to demonstrate increased thrombin formation by measuring $\mathrm{F} 1+2$, with values in the normal range on admission. This lack in F1+2 changes could be caused by the short in vivo half-life of F1+2 of approximately one hour, and although we included patients within the acute timeframe, the actual blood sampling may have occurred several hours after onset of the infarction. Moreover, coagulation in myocardial infarction is a localized, relatively small process that may not generate sufficient amounts of thrombin to be reflected in F1+2 level changes. In this regard, it should be noted that while thrombin generation analysis reveals the underlying potential to generate thrombin, F1+2 analysis provides a single time point reflection of clotting, which may explain the apparent discrepancy between the two test outcomes.

All thrombin generation parameters were strongly influenced by the installed treatment during the first four days, with a strong correlation between ETP and antiFXa activity as a measure of low molecular weight heparin treatment. After four days, ETP and peak height were considerably lower than on admission, with levels comparable to or lower than the reference population, and vastly prolonged timedependent parameters. The inability to accurately calculate a proportion of samples from patients while on LMWH may have resulted in a relative overestimation of the thrombin potential on day four.

After follow-up for three and six months the peak height and slope in the patient group were persistently increased compared to the age- and gender-matched reference population suggesting that a hypercoagulable state is still present and inherent to these patients. This hypercoagulability does not seem to generate thrombin in a continuous manner since F1+2 levels were all within the normal reference range throughout the entire follow-up period. It does, however, indicate an increased potential to form thrombin after coagulation initiation, and we hypothesize that this is a relevant mechanism in relation to long-term outcome in these patients.

To assess the value of thrombin generation as a predictor of clinical outcome we dichotomized admission ETP and determined the association with clinical outcome, defined as a combination of both primary and secondary end points. Surprisingly, admission ETP at $5 \mathrm{pM}$ TF was inversely associated with clinical outcome, meaning that patients with a low ETP on admission were at the highest risk of reaching an end point 
during follow-up. ETP was associated with age, but admission ETP remained an independent risk predictor after correction for age and other risk factors. In contrast, admission D-dimer was positively associated with clinical outcome as expected. ${ }^{20,21}$

Although this study does not provide a mechanism for the observed findings, we must speculate about possible explanations for the inverse association between ETP and clinical outcome. A first explanation may be derived from the functions of endogenously generated thrombin. The thrombin that is formed during coagulation has both procoagulant (amplifying intrinsic coagulation and generating fibrin) and anticoagulant (through protein $\mathrm{C}$ activation) properties, and at a low thrombin generation potential the anticoagulant properties of thrombin may be insufficient, while these low levels of thrombin are able to further enhance coagulation. Recently we showed that only upon addition of thrombomodulin to low TF-triggered thrombin generation protein $\mathrm{C}$ was a determinant of the ETP and peak height (Chapter 3.2).22 In addition, in vivo the concentration of vascular thrombomodulin may be a rate-limiting factor in generating thrombin-dependent protein $\mathrm{C}$ activation. In atherosclerosis, thrombomodulin and the endothelial protein $\mathrm{C}$ receptor are known to be diminished and together relatively low levels of thrombin and low concentrations of the critical cofactor thrombomodulin may impair the generation of sufficient activated protein C. ${ }^{23}$ Unfortunately, direct assessment of activated protein $\mathrm{C}$ in plasma is difficult due to the presence of inhibitors. The direct assessment of activated protein $\mathrm{C}$ in complex with protein $\mathrm{C}$ inhibitor has been carried out in plasma from patients with an acute myocardial infarction. ${ }^{24}$ In that study, elevated complex levels were reported in the acute phase of myocardial infarction; however, the capacity to attenuate prothrombotic activity may still be insufficient.

A second scenario may be that in patients with intrinsic low thrombin generation potential the primary component of their hypercoagulability is more in the cellular part (platelets) than in the plasma component (coagulation proteins), a scenario that is compatible with the general notion that arterial thrombi are cell-rich and fibrin-poor (white thrombi). Still, it remains puzzling that the plasma determination of thrombin generation would then predict an increased risk of arterial thrombosis, since platelets are not present. A third option in which increased consumption of clotting factors would explain the outcome prediction was apparently not present since the levels of F1+2 were not different among patients with and without recurrent events and were in the normal reference range.

A third mechanism that may be involved is upregulation of antithrombotic proteins, besides actual increased thrombin generation in our patient group, resulting in a decreased net measured thrombin generation. Tissue factor pathway inhibitor is a particular strong suppressor of thrombin generation (Chapter 3.2) 22 and tissue factor pathway inhibitor has been shown to be released by endothelial cells in the presence of thrombin (at least in vitro). ${ }^{25}$ These possible mechanisms, however, should be verified in future studies. 
A limitation of the present study is the relatively low percentage of primary end points, and the relatively large proportion of early events. This can partly be explained by only including patients with a first episode of acute myocardial infarction, and without indications for oral anticoagulant treatment. This may have led to selection of relatively healthy low-risk patients. The low number of hard end points neither allowed for distinguishing between primary and secondary end points, distinguishing between early and late outcome, nor for application of a more dose-effect-based analysis (with ETP divided into tertiles or quartiles for example). Thrombin generation measured at 1 pM TF seems to be more sensitive to detect hypercoagulability during follow-up than the $5 \mathrm{pM}$ TF assay. It has been suggested that the contact activation system (involving FXII) can be involved at low TF triggers and that the addition of corn trypsin inhibitor to either the blood sampling tubes or the assay is mandatory to abolish this effect. Although a contribution of the contact activation system is unlikely, as we previously described no relevant influence of corn trypsin inhibitor addition to thrombin generation assays with TF triggers of $1 \mathrm{pM}$ and above (Chapter 3.3), this was only studied in healthy individuals, not in patients. Furthermore, one may question the relevance of an admission ETP measured during the acute phase of myocardial infarction as a predictor of outcome during 12 months, but from our survival analysis it can be appreciated that the largest effect (difference in end point-free survival) already occurs within the first four days after infarction, and that this effect is merely sustained throughout a longer follow-up period (illustrated in Figure 3).

In conclusion, we established plasma thrombin generation levels during and after the acute phase of myocardial infarction, and we showed that ETP is an inverse independent risk predictor of clinical outcome, while D-dimer is a positive risk predictor of clinical outcome. The combination of such tests, which have distinct predictive power, may eventually support clinical risk stratification and adjustment of antithrombotic therapy.

\section{Acknowledgements}

Elizabeth Prins and Lex Ruiters, MD, were involved in the initial part of this study. A.W.J.H. Dielis is a Kootstra fellow from Maastricht University. This study was funded by the Profileringsfonds of the Maastricht University Medical Center and an unrestricted grant from Pfizer. 


\section{References}

1. Falk E, Shah PK, Fuster V. Coronary plaque disruption. Circulation. 1995;92:657-671.

2. Davies MJ, Thomas AC, Knapman PA, Hangartner JR. Intramyocardial platelet aggregation in patients with unstable angina suffering sudden ischemic cardiac death. Circulation. 1986;73:418-427.

3. Lane DA, Philippou H, Huntington JA. Directing thrombin. Blood. 2005;106:2605-2612.

4. Mann KG, Brummel K, Butenas S. What is all that thrombin for? J Thromb Haemost. 2003;1:1504-1514.

5. Brummel KE, Paradis SG, Butenas S, Mann KG. Thrombin functions during tissue factorinduced blood coagulation. Blood. 2002;100:148-152.

6. Orbe J, Zudaire M, Serrano R, Coma-Canella I, Martínez de Sizarrondo S, Rodríguez JA et al. Increased thrombin generation after acute versus chronic coronary disease as assessed by the thrombin generation test. Thromb Haemost. 2008;99:382-387.

7. Ardissino D, Merlini PA, Bauer KA, Galvani M, Ottani F, Franchi F. Coagulation activation and long-term outcome in acute coronary syndromes. Blood. 2003;102:2731-2735.

8. Merlini PA, Bauer KA, Oltrona L, Ardissino D, Cattaneo M, Belli C et al. Circulation. 1994;90:61-68.

9. White HD, Chew DP. Acute myocardial infarction. Lancet. 2008;372:570-584.

10. Fox KA, Steg PG, Eagle KA, Goodman SG, Anderson Jr. FA, Granger CB. Decline in rates of death and heart failure in acute coronary syndromes, 1999-2006. JAMA. 2007;297:18921900.

11. Lowe GD. Circulating inflammatory markers and risks of cardiovascular and noncardiovascular disease. J Thromb Haemost. 2005;3:1618-1627.

12. Danesh J, Whincup P, Walker M, Lennon L, Thomson A, Appleby P et al. Fibrin D-dimer and coronary heart disease: prospective study and meta-analysis. Circulation. 2001;103:23232327.

13. Danesh J, Wheeler JG, Hirschfield GM, Eda S, Eiriksdottir G, Rumley A. C-reactive protein and other circulating markers of inflammation in the prediction of coronary heart disease. $N$ Engl J Med. 2004;350:1387-1397.

14. Dielis AW, Smid M, Spronk HM, Hamulyák K, Kroon AA, ten Cate H et al. The prothrombotic paradox of hypertension. Role of the renin-angiotensin and kallikrein-kinin systems. Hypertension. 2005;46:1236-1242.

15. Danesh J, Collins R, Appleby P, Peto R. Association of fibrinogen, C-reactive protein, albumin, or leukocyte count with coronary heart disease. Meta-analyses of prospective studies. JAMA. 1998;279:1477-1482.

16. Hemker HC, Giesen P, Al Dieri R, Regnault V. de Smedt E, Wagenvoord R et al. The Calibrated Automated Thrombogram (CAT): a universal routine test for hyper- and hypocoagulability. Pathophysiol Haemost Thromb. 2002;32:249-253.

17. Hemker HC, Al Dieri R, de Smedt E, Béguin S. Thrombin generation, a function test of the haemostatic-thrombotic system. Thromb Haemost. 2006;96:553-561.

18. Crawley JT, Zanardelli S, Chion CK, Lane DA. The central role of thrombin in haemostasis. J Thromb Haemost. 2007;5:95-101.

19. Spronk HM, Dielis AW, de Smedt E, van Oerle R, Fens D, Prins MH et al. Assessment of 
thrombin generation II: Validation of the Calibrated Automated Thrombogram in plateletpoor plasma in a clinical laboratory. Thromb Haemost. 2008;100:362-364.

20. Fiotti N, Di Chiara A, Altamura N, Miccio M, Fioretti P, Guarnieri G et al. Coagulation indicators in chronic stable effort angina and unstable angina: relationship with acute phase reactants and clinical outcome. Blood Coagul Fibrinolysis. 2002;13:247-255.

21. Oldgren J, Linder R, Grip L, Siegbahn A, Wallentin L. Coagulation activity and clinical outcome in unstable coronary artery disease. Arterioscler Thromb Vasc Biol. 2001;21:10591064.

22. Dielis AW, Castoldi E, Spronk HM, van Oerle R, Hamulyák K, ten Cate H et al. Coagulation factors and the protein $\mathrm{C}$ system as determinants of thrombin generation in a normal population. J Thromb Haemost. 2008;6:125-131.

23. Laszik ZG, Zhou XJ, Ferrell GL, Silva FG, Esmon CT. Down-regulation of endothelial expression of endothelial protein $\mathrm{C}$ receptor and thrombomodulin in coronary atherosclerosis. Am J Pathol. 2001;159:797-802.

24. Bhiladvala P, Strandberg K, Stenflo J, Holm J. Early identification of acute myocardial infarction by activated protein C-protein C inhibitor complex. Thromb Res. 2006;118:213219.

25. Crawley JT, Lane DA. The haemostatic role of tissue factor pathway inhibitor. Arterioscler Thromb Vasc Biol. 2008;28:233-242. 
Chapter 4.2

\section{Thrombin generation in patients with deep venous thrombosis}

Thrombin generation in patients after acute deep-vein thrombosis.

Ten Cate-Hoek AJ ${ }^{1,2}$, Dielis $A W J H^{3}$, Spronk $\mathrm{HMH}^{3}$, van Oerle $\mathrm{R}^{1}$, Hamulyák $\mathrm{K}^{1}$, Prins $\mathrm{MH}^{2}$, ten Cate $\mathrm{H}^{3}$.

1 Department of Internal Medicine, Division of Haematology, Maastricht University Medical Center, Maastricht, The Netherlands;

2 Department of Epidemiology, Maastricht University, Maastricht, The Netherlands;

3 Department of Internal Medicine, Laboratory for Clinical Thrombosis and Haemostasis, Cardiovascular Research Institute Maastricht, Maastricht University Medical Center, Maastricht, The Netherlands.

Thrombosis and Haemostasis. 2008;100:240-245. 


\section{Summary}

Thrombin generation measurement may be of value for assessing the risk of venous thromboembolism, but its long-term profile has not been assessed in patients. We evaluated thrombin generation by Calibrated Automated Thrombogram (CAT) in plasma during follow up of 104 consecutive patients after an acute episode of deep venous thrombosis. Blood was drawn three times over the course of 24 months. Thrombin generation was measured in absence and presence of thrombomodulin and compared to a reference range derived from thrombin generation curves in 137 healthy volunteers. Thrombin generation of patients showed significantly higher endogenous thrombin potential (ETP) and peak height compared to the reference population. Differences were more pronounced in assays triggered with $1 \mathrm{pM}$ TF. Inhibition by thrombomodulin was attenuated in patients off anticoagulants as compared to the reference population ( 21 vs $42.2 \%, P<0.0001$ ); inhibition in patients on anticoagulant treatment was less pronounced $(9.7 \%, P<0.0001)$. Protein $\mathrm{C}$ activity, protein $\mathrm{S}$ antigen as well as free protein S showed highly negative correlation with ETP in all patients. A significant negative relation was found between factor VIII levels and thrombomodulininduced reduction of ETP and peak height. In conclusion, thrombin generation by CAT reflects changes in coagulation status in patients following a thromboembolic event and is most sensitive at CAT analysis triggered with $1 \mathrm{pM}$ TF. A role for factor VIII as an important attributable cause of hypercoagulability is reflected by the reduced inhibitory effect of thrombomodulin at high factor VIII levels. 


\section{Introduction}

Prevention of a recurrent event is the main objective of anticoagulant treatment for an acute thromboembolic process. The optimal duration of anticoagulant treatment remains a subject of debate ${ }^{1}$ due to the inability to account for individual risk factors for recurrent thromboembolism. Several strategies can be employed to estimate risk of recurrence, including assessment of amount of residual thrombosis, ${ }^{2,3}$ as well as coagulation activity after cessation of antithrombotic therapy by means of laboratory tests such as for D-dimer ${ }^{4,5}$ or factor VIII (FVIII) levels. ${ }^{6-8}$ However, these laboratory assays reflect ongoing fibrinolysis rather than coagulation (D-dimer), while FVIII levels only provide one element of the complex coagulation network. Similarly, determination of FXI, FIX and prothrombin could be utilized as risk indicators, since the levels of these proteins are also associated with risk of venous thrombosis.9,10

Intuitively, a more global coagulation test that integrates the information retrieved from separate coagulation tests could potentially improve patient management. It has indeed been demonstrated that a global coagulation test such as the thrombin generation assay performed at one point in time can predict an increased risk of a first episode of deep venous thrombosis (DVT) in persons with an increased endogenous thrombin potential (ETP), an increased risk of recurrence based on a high ETP, however, was not found.11 On the other hand, a low chance of recurrence was found in patients after acute DVT with low ETP. ${ }^{12}$ In addition, thrombin generation has been utilized to screen for thrombophilic defects. ${ }^{13-15}$ Given these observations, thrombin generation measurement may be a good candidate for the management of individual anticoagulant treatment in the secondary prevention of recurrent thrombosis in patients following an acute thrombotic event. Since the risk of recurrent thrombosis is not stable in time, we were interested to study the variation in time of thrombin generation in patients after a DVT as compared to healthy individuals. In addition, we compared on and off anticoagulant treatment on thrombin generation with and without the addition of thrombomodulin (TM). 


\section{Methods}

\section{Patients and reference population}

Over the course of three years, 104 patients with acute DVT were identified and followed over time at the outpatient thrombosis clinic of the University Hospital Maastricht, Maastricht, The Netherlands. Patients were followed up for a period of 24 months following their diagnosis.

The inclusion of patients was consecutive and irrespective of the fact whether an event was a first event or a recurrent event and whether this event was idiopathic or provoked. In all patients DVT was confirmed by ultrasound at the first visit. The study was approved by the local ethics board and written informed consent was obtained for additional blood collection in order to test thrombin generation.

Anticoagulant treatment was installed according to ACCP (American College of Chest Physicians) guidelines. ${ }^{16}$ For a number of patients treatment was tailored individually. Blood was drawn one month after cessation of treatment in 72 patients, for patients with provoked thrombosis this meant that blood was drawn at month four and for patients with idiopathic thrombosis blood was drawn at month seven (B1: 4-7 months). The second round of laboratory tests was performed for the entire group off anticoagulant treatment (65 patients) at 12 months (B2) and the third at 24 months in 40 patients (B3). While the study was and is still ongoing at the moment of analysis not all of the patients had reached the end of the two year follow-up period. The thrombin generation assay was performed in March 2007 on all available samples to the date of 12 December 2006 (only half-way during the third year of follow-up).

For patients on prolonged anticoagulant treatment the blood was also drawn at three points in time. The first blood draw took place at six months (32 patients) after the acute event, the second blood draw at 12 months (18 patients) and the final draw at 24 months (eight patients).

The reference laboratory values were derived from a group of 137 healthy individuals recruited from the community, frequency matched for sex and age and originating from the same region of The Netherlands. Healthy individuals on anticoagulant medication or on antiplatelet drugs were excluded as were pregnant women and women on oral contraceptives. Blood for the reference laboratory values was drawn at two separate occasions that were 12 months apart.

\section{Normal pooled plasma}

Normal pooled plasma used for normalization of samples was prepared within the Departments of Haematology and Clinical Chemistry of the University Hospital Maastricht, The Netherlands, by pooling plasma from 80-90 apparently healthy 
volunteers.

\section{Blood collection and plasma preparation}

Venous blood was collected in $3.2 \%$ citrate $(\mathrm{w} / \mathrm{v})$. Blood was drawn three times over the course of a two year follow-up period in all patients. Platelet-poor plasma was prepared by two centrifugation steps: the first at $2000 \mathrm{~g}$ for 15 minutes and the second at $11000 \mathrm{~g}$ for five minutes. Plasma aliquots were snap-frozen in liquid nitrogen, stored at $-80^{\circ} \mathrm{C}$ until use. All samples were thawed at $37^{\circ} \mathrm{C}$ for 15 minutes before analysis and analyzed batch wise.

\section{Thrombin generation measurements}

Thrombin generation in tissue factor (TF)-triggered platelet-poor plasma was measured by means of the Calibrated Automated Thrombogram (CAT) method (Thrombinoscope BV, Maastricht, The Netherlands), which makes use of a low affinity fluorogenic substrate for thrombin (Z-Gly-Gly-Arg-AMC) to continuously monitor thrombin activity in clotting plasma. In order to correct for inner-filter effects and substrate consumption, each thrombin generation measurement was calibrated against the fluorescence curve obtained in the same plasma with a fixed amount of thrombin- $\alpha_{2}$-macroglobulin complex (Thrombin Calibrator, Thrombinoscope BV), as recommended by the manufacturer. Fluorescence was read in an Ascent Reader (Thermo Labsystems OY, Helsinki, Finland) equipped with a 390/460 filter set, and thrombin generation curves were calculated with the Thrombinoscope software (Thrombinoscope BV).

All samples were tested at the same occasion and thrombin generation was determined under three experimental conditions (final plasma concentrations): $1 \mathrm{pM}$ $\mathrm{TF}$ and $4 \mu \mathrm{M}$ phospholipids in the absence and presence of $2 \mathrm{nM}$ soluble thrombomodulin (TM), and $5 \mathrm{pM}$ TF and $4 \mu \mathrm{M}$ phospholipids. The TF triggers and phospholipids were obtained from Thrombinoscope BV; TM was kindly donated by Prof. Coen Hemker, Maastricht. No corn trypsin inhibitor (CTI) to inhibit contact activation was included in our samples, although several authors reported reduced variability by means of contact factor inhibition using CTI. ${ }^{17,18}$ Contact activation was extensively assessed at previous occasions in our laboratory by analyzing thrombin generation in the absence of $\mathrm{TF}$ and was never observed in plasma obtained and prepared according to the described protocol.

Three parameters were derived from the thrombin generation curves: lag time, peak height and ETP (area under the curve). Data for these parameters were normalized towards and given as ratio to normal pooled plasma, analyzed on each plate.

The intra-assay variation of the thrombin generation curve parameters was determined using platelet-poor plasma from three different subjects assayed in 21 
replicates per sample in one run. None of the concentration-dependent parameters (ETP and peak) had a coefficient of variation (CV) $>5 \%$. The lag time had a CV of $4-6 \%$, for the other time-dependent parameters CV was $<4 \%$. The intra-assay with TM for all derived parameters was below $10 \%$.

For determination of the inter-assay variation, two lots of normal pooled plasma were analyzed in 21 independent runs over a period of one month using one lot of PPP Reagent, three different batches FluCa and substrate, and two lots of calibrator. For the concentration-dependent parameters the $\mathrm{CV}$ was $7-8 \%$, for the time-dependent parameters $5-8 \%$. For the analysis with $1 \mathrm{pM}$ TF and TM, the overall coefficients of variation are $5.93 \%, 14.68 \%$ and $15.44 \%$ for lag time, ETP, and peak height, respectively.

In order to test the inhibitory potential of the protein $\mathrm{C}$ pathway on thrombin generation, TM was titrated to inhibit ETP by approximately $50 \%$ in normal pooled plasma triggered with $1 \mathrm{pM} \mathrm{TF}$.

Protein $S$ (total) levels were measured with a home-made assay, containing Dako (ITK) antibodies, and validated in an external quality control program (ECAT, Leiden, The Netherlands). Free protein $\mathrm{S}$ levels were measured with the Asserachrom free protein S assay (Stago Diagnostics, Asnieres, France). The FV Leiden mutation was determined with a commercial kit (Roche Diagnostics, Basel, Switzerland) on a Light Cycler instrument (Roche Diagnostics). FVIII activity, APC resistance and protein C activity assays were performed on a CA7000 Coagulation instrument (Dade-Behring, Eschborn, Germany) according to the manufacturer's instruction.

FVIII activity was measured with a one-stage clotting assay (Dade-Behring). Activated protein C (APC) resistance was measured with a ProC AC R kit (Dade-Behring) and protein $\mathrm{C}$ activity was measured with the Behrichrom protein $\mathrm{C}$ kit (Dade-Behring).

\section{Statistical analysis}

Data are expressed as mean [95\% confidence interval; $95 \% \mathrm{CI}$ ], unless otherwise specified. Differences between parameters of the different thrombin generation analyses (1 pM TF (with and without added TM) and 5 pM TF) were analyzed using paired Student's $t$-test, whereas the differences between genders were analyzed using Student's $t$-test. Correlations were expressed as Pearson's coefficients. A two-tailed probability value $P<0.05$ was considered statistically significant.

Statistics were computed using SPSS for Windows, version 12.0 (SPSS Inc., Chicago, IL, USA). 


\section{Results}

A total of 104 consecutive patients were included in the study. They had a mean age of 55.8 years (range: $26-83$ ) and 53 (46.9\%) were male. Of these patients $19 \%$ had a previous episode of DVT (and 24\% a positive family history of venous thrombosis). Thrombin generation curves were measured for these patients and compared to a reference range derived from thrombin generation curves in 137 healthy volunteers. The mean age in the reference group was 53.7 years (22-90) and the number of males in this group was 67 (48.2\%). During follow-up a number of patients remained on anticoagulant treatment for various reasons e.g. the presence of two or more previous thromboembolic events, substantial residual thrombosis on ultrasound, known combined or severe thrombophilic defects. (A total of 32 patients continued to be on anticoagulant therapy at six months, 18 at 12 months and eight at 24 months.)

Initial CAT analyses were performed at $5 \mathrm{pM} \mathrm{TF}$ as indicated by the manufacturer. At these conditions patients without anticoagulant treatment showed significantly higher ETP at B2 and B3 and peak height at all time points compared to the reference ETP and peak height values. The lag times, however, did not differ significantly (Table 1). Furthermore, measurements of thrombin generation and peak height increased significantly over the course of one year and thereafter remaining stable in the patient population without anticoagulant treatment; in the reference population thrombin generation and peak height did not change within the observed period of one year (data not shown).

The observed differences in ETP and peak height for patients after cessation of anticoagulant treatment and the entire reference population were even more pronounced in assays triggered with $1 \mathrm{pM} \mathrm{TF}$, suggesting an increased sensitivity compared to the $5 \mathrm{pM}$ TF trigger.

As expected, at $1 \mathrm{pM}$ TF the ETP of patients was significantly higher after cessation of anticoagulant treatment (-OAC) compared to the ETP in patients still on treatment (162.6 vs $65.8 \%, P<0.0001)$. Patients on anticoagulant treatment (+OAC) showed decreased ETP also compared to those of a reference population (65.8 vs $102.7 \%$, $P<0.0001 ;-36.9 \%$ ) (Figure 1).

Furthermore, patients on anticoagulant treatment had a prolonged lag time (9.9 vs 4.0 minutes, $P<0.0001 ;+147.5 \%)$ and a decreased peak height (109.8 vs $99.1 \%$, $P<0.0001 ;+10.8 \%$ ) compared to the reference group.

We observed a marked reduction in the inhibitory potential of TM on the ETP in the patients off anticoagulant treatment as compared to the reference group (21 vs $42.2 \%$, $P<0.0001$ ) (Table 1, Figure 2). The inhibition of ETP after addition of TM in patients on anticoagulant treatment $(+\mathrm{OAC})$ was even less pronounced $(9.7 \%, P<0.0001)$ (Figure 2 ). We estimated that protein $\mathrm{C}$ activity is responsible for $40 \%\left(R^{2}=0.4\right)$ of the TM-induced reduction in patients on anticoagulant treatment, while in patients without 
anticoagulant treatment this is only $20 \%$. The effect of TM remained unchanged after removal of the patients with a FV Leiden mutation (data not shown).

After addition of TM, protein $\mathrm{C}$ activity, protein $\mathrm{S}$ antigen and free protein $\mathrm{S}$ each showed a highly significant negative correlation with ETP in all patients both with and without anticoagulant treatment. Only after excluding patients diagnosed with a FV Leiden mutation, a significant negative correlation was found between FVIII levels and induced reduction of ETP and peak height by the addition of TM in our patient population. No significant differences were found in lag time in any of the groups (Table 2).

Table 1. Thrombin generation measurements at $1 \mathrm{pM} \mathrm{TF}, 5 \mathrm{pM}$ TF and effect of TM at $1 \mathrm{pM}$ TF in patients during follow-up compared to healthy individuals. Data are presented as normalized mean [ $95 \%$ confidence interval].

\begin{tabular}{|c|c|c|c|c|c|c|c|c|c|c|c|}
\hline & \multicolumn{11}{|c|}{ Healthy individualsPatients } \\
\hline & \multirow{2}{*}{\multicolumn{2}{|c|}{$\begin{array}{l}\mathrm{HI} \\
(\mathrm{n}=137)\end{array}$}} & \multirow{2}{*}{\multicolumn{2}{|c|}{$\begin{array}{l}\text { B1 } \\
(n=72)\end{array}$}} & \multirow{2}{*}{\multicolumn{3}{|c|}{$\begin{array}{c}\mathrm{B} 2 \\
P(\mathrm{~B} 1-\mathrm{HI})(\mathrm{n}=65)\end{array}$}} & \multirow{2}{*}{\multicolumn{3}{|c|}{$P(\mathrm{~B} 2-1)(\mathrm{n}=40)$}} & \multirow[b]{2}{*}{$P($ B3-1) } \\
\hline & & & & & & & & & & & \\
\hline \multicolumn{12}{|l|}{$5 \mathrm{pM} \mathrm{TF}$} \\
\hline Lag time & 2.6 & {$[2.4-2.8]$} & 2.4 & {$[2.1-2.7]$} & NS & 2.4 & {$[2.1-2.5]$} & NS & 2.1 & {$[1.9-2.2]$} & NS \\
\hline ETP & 102.9 & [96.6-109.2] & 112.3 & [103.1-121.6] & ] NS & 121.2 & {$[112.7-129.7$} & ] $<0.05$ & 119.0 & [109.8-128.2] & ] $<0.0001$ \\
\hline Peak height & 93.6 & {$[89.7-97.5]$} & 121.2 & [111.4-131.1] & ]$<0.01$ & 128.3 & {$[119.5-137.1$} & ] $<0.05$ & 130.5 & {$[122.4-138.6]$} & ] $<0.01$ \\
\hline \multicolumn{12}{|l|}{$1 \mathrm{pM} \mathrm{TF}$} \\
\hline Lag time & 4.0 & [3.9-4.1] & 5.6 & {$[4.8-6.3]$} & $<0.0001$ & 5.3 & {$[4.6-5.9]$} & NS & 4.8 & {$[4.0-5.6]$} & NS \\
\hline ETP & 102.7 & [99.0-106.3] & 162.6 & [147.7-177.5] & ]$<0.0001$ & 174.2 & {$[158.6-189.8$} & 3] $<0.05$ & 169.7 & {$[153.3-186.0]$} & ]$<0.05$ \\
\hline Peak height & 99.1 & {$[92.7-105.5]$} & 248.9 & [223.4-274.5] & ] $<0.0001$ & 272.8 & {$[244.0-301.6$} & ; $<0.05$ & 267.1 & [237.5-296.8] & NS \\
\hline \multicolumn{12}{|c|}{1 pM TF: difference after addition of TM (\%) } \\
\hline Lag time & -0.13 & {$[-0.8-0.5]$} & 1.0 & {$[0.1-2.0]$} & $<0.05$ & 0.1 & {$[-1.2-1.4]$} & - & 0.2 & {$[-0.7-1.1]$} & - \\
\hline ETP & -42.2 & {$[-44.0--40.3]$} & ] -21.0 & {$[-23.7--18.3]$} & $<0.0001$ & -18.8 & {$[-21.4--16.3]$} & - & -18.4 & {$[-22.1--14.7]$} & - \\
\hline Peak height & -20.4 & [-22.1--18.7] & ] -3.1 & {$[-4.7--1.5]$} & $<0.0001$ & -1.7 & {$[-3.8-0.3]$} & - & -2.0 & {$[-3.7--0.3]$} & - \\
\hline
\end{tabular}

$\overline{T F}$, tissue factor; ETP, endogenous thrombin potential; TM, thrombomodulin. Lag time is presented in minutes, ETP and peak height are presented as percentage of normal pooled plasma. $\mathrm{HI}$, healthy individuals. B1=one month after cessation of anticoagulant treatment, B2=12 months after the event in patients without anticoagulant treatment, B3=24 months after the event in patients without anticoagulant treatment. Results from paired $t$-test between healthy individuals and patients at one month after cessation of treatment $=P(\mathrm{~B} 1$ $\mathrm{HI})$. Results from paired $t$-tests within patients $=P(\mathrm{~B} 2-1)$ and $P(\mathrm{~B} 3-1)$. 
Table 2. Correlations of TM reduction at $1 \mathrm{pM}$ TF with FVIII, protein C (PC) activity, free protein S (PS) and total protein S. Data are presented as Pearson's $R$.

\begin{tabular}{lllll}
\hline & FVIII & PC activity & Free PS & Total PS \\
\hline Reference range & & & & \\
Lag time TM difference & 0.118 & $-0.198^{*}$ & $-0.247^{\dagger}$ & -0.060 \\
ETP TM difference & $0.171^{*}$ & $-0.354^{\dagger}$ & $-0.515^{\dagger}$ & $-0.267^{\dagger}$ \\
Peak height TM difference & 0.106 & $-0.346^{\dagger}$ & $-0.465^{\dagger}$ & $-0.186^{\dagger}$ \\
& & & & \\
+ OAC & & & & \\
Lag time TM difference & 0.057 & 0.012 & -0.093 & -0.062 \\
ETP TM difference & $-0.443^{*}$ & $-0.767^{\dagger}$ & $-0.652^{\dagger}$ & $-0.613^{\dagger}$ \\
Peak height TM difference & -0.374 & -0.332 & -0.169 & -0.179 \\
& & & & \\
- OAC & & & & \\
Lag time TM difference & -0.060 & 0.220 & 0.164 & 0.082 \\
ETP TM difference & $0.297^{*}$ & $-0.465^{\dagger}$ & $-0.402^{\dagger}$ & $-0.358^{\dagger}$ \\
Peak height TM difference & 0.244 & $-0.395^{\dagger}$ & -0.122 & -0.114 \\
\hline
\end{tabular}

TM, thrombomodulin. * denotes $P<0.01 ; \dagger$ denotes $P<0.001$. 
Figure 1. Thrombin generation in the reference group and DVT patients. ETP is expressed as \% compared to normal pooled plasma. Lines represent means.

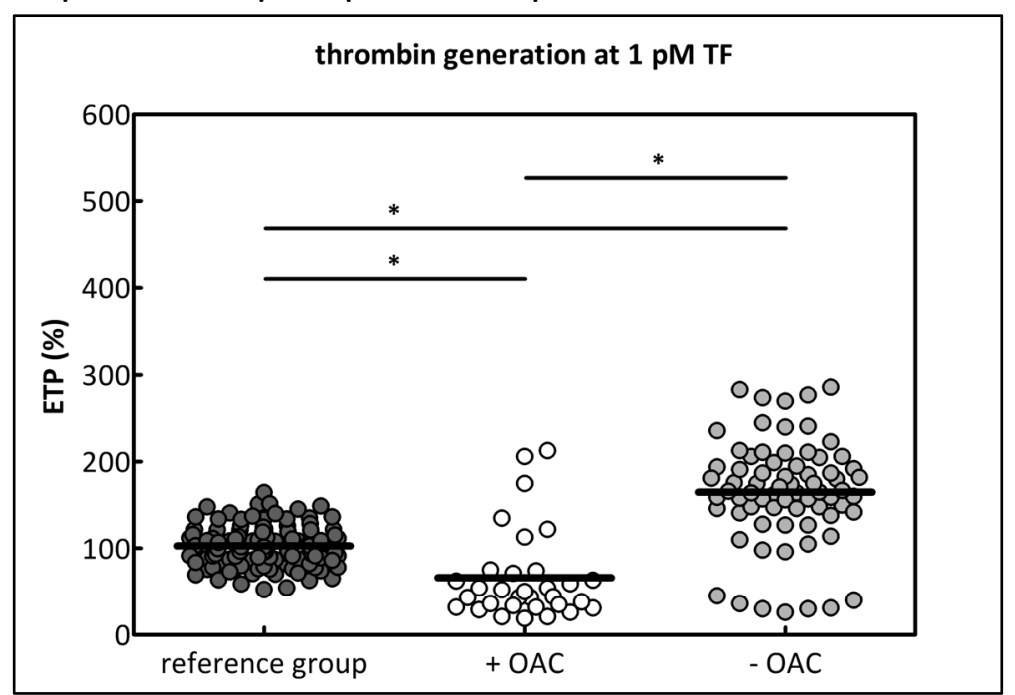

+OAC, patients on vitamin K antagonists; $-\mathrm{OAC}$, patients off vitamin $\mathrm{K}$ antagonists. ${ }^{*}$ denotes $P<0.05$.

Figure 2. Difference in thrombin generation upon TM addition in the reference group and DVT patients. ETP is expressed as \% compared to normal pooled plasma. Lines represent means.

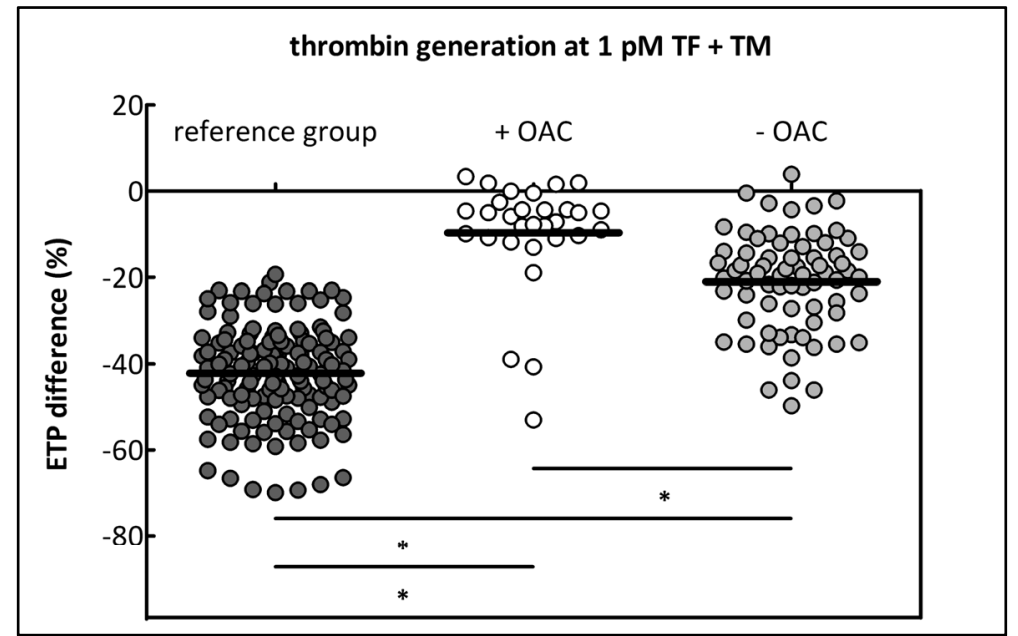

+OAC, patients on vitamin $\mathrm{K}$ antagonists; $-\mathrm{OAC}$, patients off vitamin $\mathrm{K}$ antagonists. * denotes $P<0.05$. 


\section{Discussion}

Our data show that thrombin generation is significantly higher in patients after recent DVT compared to thrombin generation in a reference population of healthy individuals. This elevation of the thrombin generating potential most likely reflects a hypercoagulable state in these patients.

This assumption is confirmed by our observations during follow-up. Thrombin generation varied in time in patients, while thrombin generation remained stable in the reference population suggesting that levels of thrombin generation are related to the preceding thromboembolic event.

Relatively low ETP and peak height were found one month after cessation of anticoagulant treatment increasing to a significantly higher level after one year of follow-up. Although half-life times of coumarins lay between 48 and 72 hours, this phenomenon may be explained by a prolonged anticoagulant effect of the coumarins after cessation of treatment that is not yet established in other tests.

Secondly, we found more pronounced differences in thrombin generation responses between patients without anticoagulant treatment and the reference population after plasma stimulation with lower amounts of TF, 1 pM TF instead of 5 pM TF.

This effect is most likely caused by the increased sensitivity to subtle differences in endogenous plasma components at low TF stimulation as compared to the rather robust stimulation with $5 \mathrm{pM}$ TF. At low TF concentrations, the interplay between mechanisms of activation and inhibition becomes more sensitive for the cofactor function of protein $\mathrm{S}$ in relation to tissue factor pathway inhibitor. ${ }^{19}$

In our study we furthermore observed that addition of TM lowers thrombin generation less efficiently in patients after a recent event of DVT as compared to thrombin generation in a reference population. This finding is in agreement with previously published work from Dargaud et al., who tested the effect of TM at the higher $5 \mathrm{pM}$ TF concentration. ${ }^{20}$ The lack of significant differences found in the lag time upon TM addition in any of the groups is obviously due to the fact that inhibition only takes place in the propagation phase after thrombin is activated.

Our data indicate that, as expected, proteins $\mathrm{C}$ and $\mathrm{S}$ are determinants of the effect of TM in all patients. Proteins $\mathrm{C}$ and $\mathrm{S}$ were contributing more strongly to the inhibition induced by TM in patients still on coumarin treatment. This can be explained by the fact that ETP is lowered by TM in an APC/protein S-dependent manner and since treatment with vitamin $\mathrm{K}$ antagonists lowers levels of active protein $\mathrm{C}$ and $\mathrm{S},{ }^{21}$ the residual protein $\mathrm{C}$ activity is rendered closer to the rate limiting amount of active protein $\mathrm{C}$ in these patients. The decrease in ETP following the addition of TM is therefore mainly dependent on the amount of residual protein $\mathrm{C}$ activity.

Finally we observed a significant negative correlation between FVIII levels and TM reduction in our patient population, after excluding patients diagnosed with a factor $\mathrm{V}$ 
Leiden mutation from the analysis. That the effect of TM remained unchanged after removal of the patients with a FV Leiden mutation does not imply that FV is no determinant in TM-induced inhibition of thrombin generation, but the contributory effect of FV may be too small to be noted at the test conditions used, where FVIII may be a slightly dominant cofactor. The observed negative correlation between FVIII and TM reduction can be explained by an enhanced feedback mechanism through thrombindependent FVIII activation at increased levels of FVIII, thus counteracting the influence of TM on ETP and peak height (acquired APC-resistance). FVIII is not dependent on vitamin $\mathrm{K}$ antagonist treatment and is already known as a risk factor for recurrent DVT.7,8 The relation of FVIII with a reduced TM effect on ETP may explain some of the prothrombotic influence of elevated FVIII concentrations in relation to recurrent DVT.

The contributions of other endogenous determinants of this TM "resistance" remain to be established. We are aware of the limitations of our findings for as our patient group is a non-selected heterogeneous group and comprises patients with various preexisting thrombosis risk factors (active malignancy, congestive heart failure, positive family history, previous episodes of venous thromboembolism).

In conclusion, our findings show a clear difference in thrombin generation in patients following an acute episode of DVT as compared to a reference group of healthy individuals. This difference was most pronounced when the CAT was started with a low, 1 pM TF concentration. Hence, this lower TF concentration may be more suitable to detect a hypercoagulable state in patients at risk of (recurrent) thrombosis. Thrombin generation with and without addition of TM provides information regarding several steps in the coagulation cascade including initiation and propagation. As demonstrated, FVIII is a determinant of reduced inhibition of thrombin generation after addition of TM and may explain part of the prothrombotic influence of elevated FVIII concentrations. The added information derived from an endogenous thrombin generation curve is that the overall rest capacity of thrombin generation, even under anticoagulant treatment, can be assessed.

This study was not performed to establish the clinical utility of the CAT assay. Future research should be aimed at unraveling the mechanism of impaired TM inhibition as a possible focus for improving management decisions regarding the duration of anticoagulant treatment in individual patients and ideally relate levels of endogenous thrombin generation over time to risk of recurrent thrombotic events. 


\section{References}

1. Kearon C. Long-term management of patients after venous thromboembolism. Circulation. 2004;110:I10- I18.

2. Piovella F, Crippa L, Barone M, Vigano D'Angelo S, Serafini S, Galli L et al. Normalization rates of compression ultrasonography in patients with a first episode of deep vein thrombosis of the lower limbs: association with recurrence and new thrombosis. Haematologica. 2002;87:515-522.

3. Prandoni P, Lensing AW, Prins MH, Bernardi E, Marchiori A, Bagatella P et al. Residual venous thrombosis as a predictive factor of recurrent venous thromboembolism. Ann Intern Med. 2002;137:955-960. Summary for patients in: Ann Intern Med. 2002;137:I32.

4. Palareti G, Legnani C, Cosmi B, Guazzaloca G, Pancani C, Coccheri S. Risk of venous thromboembolism recurrence: high negative predictive value of $\mathrm{D}$-dimer performed after oral anticoagulation is stopped. Thromb Haemost. 2002;87:7-12.

5. Palareti G, Legnani C, Cosmi B, Valdre L, Lunghi B, Bernardi F et al. Predictive value of Ddimer test for recurrent venous thromboembolism after anticoagulation withdrawal in subjects with a previous idiopathic event and in carriers of congenital thrombophilia. Circulation. 2003;108:313-318.

6. Kyrle PA, Minar E, Hirschl M, Bialonczyk C, Stain M, Schneider B et al. High plasma levels of factor VIII and the risk of recurrent venous thromboembolism. N Engl J Med. 2000;343:457462.

7. Legnani C, Cini M, Cosmi B, Poggi M, Boggian O, Palareti G. Risk of deep vein thrombosis: interaction between oral contraceptives and high factor VIII levels. Haematologica. 2004;89:1347-1351.

8. Kreuz W, Stoll M, Junker R, Heinecke A, Schobess R, Kurnik K et al. Familial elevated factor VIII in children with symptomatic venous thrombosis and postthrombotic syndrome: results of a multicenter study. Arterioscler Thromb Vasc Biol. 2006;26:1901-1906.

9. Meijers JC, Tekelenburg WL, Bouma BN, Bertina RM, Rosendaal FR. High levels of coagulation factor XI as a risk factor for venous thrombosis. N Engl J Med. 2000;342:696701.

10. Van Hylckama Vlieg A, van der Linden IK, Bertina RM, Rosendaal FR. High levels of factor IX increase the risk of venous thrombosis. Blood. 2000;95:3678-3682.

11. Van Hylckama Vlieg A, Christiansen SC, Luddington R, Cannegieter SC, Rosendaal FR, Baglin TP. Elevated endogenous thrombin potential is associated with an increased risk of a first deep venous thrombosis but not with the risk of recurrence. Brit J Haematology. 2007;138:769-774.

12. Hron G, Kollars M, Binder BR, Eichinger S, Kyrle PA. Identification of patients at low risk for recurrent venous thromboembolism by measuring thrombin generation. JAMA. 2006;296:397-402.

13. Couturaud F, Duchemin J, Leroyer C, Delahousse B, Abgrall JF, Mottier D; Groupe d'Etude de la Thrombose de Bretagne Occidentale (G.E.T.B.O). Thrombin generation in first-degree relatives of patients with venous thromboembolism who have factor V Leiden. A pilot study. Thromb Haemost. 2008;99:223-228.

14. Gatt A, van Veen JJ, Cooper P, Kitchen S, Makris M. Protein C deficiency screening using a 
thrombin generation assay - an upgrade. Thromb Haemost. 2007;98:691-692.

15. Lincz LF, Lonergan A, Scorgie FE, Rowlings P, Gibson R, Lawrie A et al. Endogenous thrombin potential for predicting risk of venous thromboembolism in carriers of factor $\mathrm{V}$ Leiden. Pathophysiol Haemost Thromb. 2006;35:435-439.

16. Geerts WH, Pineo GF, Heit JA, Bergqvist D, Lassen MR, Colwell CW et al. Prevention of venous thromboembolism: the Seventh ACCP Conference on Antithrombotic and Thrombolytic Therapy. Chest. 2004;126:338S-400S.

17. Van Veen JJ, Gatt A, Cooper PC, Kitchen S, Bowyer AE, Makris M. Corn trypsin inhibitor in fluorogenic thrombin generation measurements is only necessary at low tissue factor concentrations and influences the relationship between factor VIII coagulant activity and thrombogram parameters. Blood Coagul Fibrinolysis. 2008;19:183-189.

18. Dargaud Y, Luddington R, Baglin TP. Elimination of contact factor activation improves measurement of platelet-dependent thrombin generation by calibrated automated thrombography at low-concentration tissue factor. J Thromb Haemost. 2006;4:1160-1161.

19. Hackeng TM, Seré KM, Tans G, Rosing J. Protein S stimulates inhibition of the tissue factor pathway by tissue factor pathway inhibitor. Proc Natl Acad Sci USA. 2006;103:3106-3111.

20. Dargaud Y, Trzeciak MC, Bordet JC, Ninet J, Negrier C. Use of calibrated automated thrombinography +/- thrombomodulin to recognise the prothrombotic phenotype. Thromb Haemost. 2006;96:562-567.

21. Penning-van Beest FJ, Gómez García EB, van der Meer FJ, van Meegen E, Rosendaal FR, Stricker BH. Levels of vitamin K-dependent procoagulant and anticoagulant proteins in overanticoagulated patients. Blood Coagul Fibrinolysis. 2002;13:733-739. 
Chapter 4.3

\section{Thrombin generation in patients with recurrent deep venous thrombosis}

High levels of thrombin generation in relation to increased risk of recurrent thrombosis.

Ten Cate-Hoek AJ ${ }^{1,2}$, Dielis AWJH ${ }^{3}$, Schouten $\mathrm{G}^{3}$, Spronk $\mathrm{HMH}^{3}$, van Oerle $\mathrm{R}^{3}$, Hamulyák $\mathrm{K}^{1}$, Prins $\mathrm{MH}^{2}$, ten Cate $\mathrm{H}^{3}$.

1 Department of Internal Medicine, Division of Haematology, Maastricht University Medical Center, Maastricht, The Netherlands;

2 Department of Epidemiology, Maastricht University, Maastricht, The Netherlands;

3 Department of Internal Medicine, Laboratory for Clinical Thrombosis and Haemostasis, Cardiovascular Research Institute Maastricht, Maastricht University Medical Center, Maastricht, The Netherlands. 


\section{Abstract}

Background: Recent studies suggest that thrombin generation may be able to distinguish between a low and a high risk for recurrence in patients.

Objective: To study the possible relation between recurrent thrombosis and levels of thrombin generation, with and without thrombomodulin (TM), at different points in time between patients with and patients without a recurrent event.

Patients: 125 consecutive patients with confirmed proximal deep venous thrombosis (venous thromboembolism; VTE) at the outpatient clinic of the Maastricht University Medical Center, Maastricht, The Netherlands.

Methods: Thrombin generation was determined under two experimental conditions (final plasma concentrations): $1 \mathrm{pM}$ tissue factor (TF) and $4 \mu \mathrm{M}$ phospholipids in the absence and presence of $2 \mathrm{nM}$ soluble TM. Differences between parameters of thrombin generation in the absence and presence of TM were analyzed between patients with and without a recurrent event. Furthermore, the association between thrombin generation and established risk indicators for VTE was assessed.

Results: Blood was obtained from 108 patients; seven (5.6\%) patients had an objectively documented recurrent event within the follow-up period. Significant differences were found between thrombin generation determined in the last sample before the recurrent event compared to blood sampled one month after cessation of anticoagulant treatment as well as in samples at one year after the event in patients without a recurrent event. Upon addition of $\mathrm{TM}$, the endogenous thrombin potential (ETP) showed a significantly reduced inhibition between patients with a recurrent event and those without a recurrent event (-9.5\% vs $-19.5 \%)$. Significant associations were found between risk factors for VTE and thrombin generation. In particular lag time was associated with a number of variables that also determine risk of recurrent thrombosis, including residual thrombosis, previous thrombosis and age. FV Leiden and gender are of influence for ETP and peak height. Upon addition of TM, however, none of the indices of thrombin generation are influenced anymore by known risk factors.

Conclusion: The assessment of thrombin generation in the presence of TM may therefore be practically useful. The observed changes in TM responsiveness between patients with and those without recurrence may provide the opportunity to utilize this test to assess the risk in patients while still on anticoagulant therapy. 


\section{Introduction}

The optimal duration of secondary prophylaxis for an acute thromboembolic process remains subject of research. Over the course of time many transient and permanent (genetic or acquired) risk factors have been identified.1-10 The risk of a recurrent event lies around 3\% per year for patients with a provoked event, $10 \%$ per year for idiopathic venous thromboembolism (VTE). The eight year cumulative incidence for recurrent VTE is about $30 \%$. $^{11}$

Currently, there are two major drawbacks to risk identification in patients after an acute event of VTE. One is the inability to determine all risk factors present through the use of one single test. The other disadvantage is the uncertainty of the relative weight of each of the separate risk factors in the disturbance of the haemostatic balance. The quest for a global coagulation assay that reflects the balance between the pro- and anticoagulant factors involved in the risk for (recurrent) thrombosis is therefore widely held.

It has been suggested that thrombin generation performed at one point in time is different between persons with and without an increased risk of a first episode of deep venous thrombosis (DVT). ${ }^{12}$ A low chance of recurrence was found after acute DVT in patients with low endogenous thrombin potential (ETP). ${ }^{13}$ More recently, high thrombin generation measured in the presence of thrombomodulin (TM) was associated with an increased risk of recurrent thrombosis. ${ }^{14}$

We previously documented that thrombin generation is not stable in time but has relatively low values one month after cessation of anticoagulant therapy, and increases in the course of one year following the acute event of thrombosis (Chapter 4.2). ${ }^{15}$ We were therefore interested to study the possible relation between levels of thrombin generation and recurrent thrombosis at different points in time after cessation of anticoagulant therapy.

We furthermore studied the influence of TM on thrombin generation in patients with, as compared to those without recurrent thrombosis. 


\section{Methods}

\section{Patients}

Consecutive patients with confirmed proximal DVT were followed for a period of two years after the acute event as part of routine patient care at the outpatient clinic of the Maastricht University Medical Center, Maastricht, The Netherlands, between July 2003 and December 2006.

The study was approved by the local ethics board and written informed consent was obtained for additional blood collection in order to test thrombin generation. The inclusion of patients was consecutive and irrespective of the fact whether an event was a first event or a recurrent event and whether this event was idiopathic or provoked.

Anticoagulant treatment was installed according to international guidelines and was individually tailored when necessary. ${ }^{16}$ Patients with provoked thrombosis were treated with anticoagulant medication for three months. Before cessation of therapy ultrasound examination of the afflicted leg was repeated to assess whether or not residual thrombosis was present. In case residual thrombosis was present, anticoagulant therapy was continued for another three months. ${ }^{17}$

For patients with a first event of idiopathic thrombosis initial anticoagulant therapy was installed for a period of six months. When residual thrombosis was found at ultrasound examination one week before planned cessation, patients would receive an additional six months of anticoagulant therapy.

Patients with previous events of VTE were treated for at least 12 months or indefinitely.

\section{Blood collection}

Blood was drawn one month after cessation of treatment. In effect, blood was drawn at month four in patients with provoked thrombosis, and at month seven in patients with idiopathic thrombosis (B1: 4-7 months).

The second round of laboratory tests was performed for the entire group off anticoagulant treatment at 12 months (B2), and the third at 24 months (B3).

\section{Normal pooled plasma}

Normal pooled plasma used for normalization of samples was prepared within the Departments of Haematology and Clinical Chemistry of the Maastricht University Medical Center, Maastricht, The Netherlands, by pooling plasma from 80-90 apparently healthy volunteers. 


\section{Blood collection and plasma preparation}

Venous blood was collected in $3.2 \%$ citrate $(\mathrm{w} / \mathrm{v})$. Blood was drawn three times over the course of a two year follow-up period in all patients. Platelet-poor plasma was prepared by two centrifugation steps: the first at $2000 \mathrm{~g}$ for 15 minutes and the second at $11000 \mathrm{~g}$ for five minutes, both at room temperature. Plasma aliquots were snapfrozen in liquid nitrogen, stored at $-80^{\circ} \mathrm{C}$ until use. All samples were thawed at $37^{\circ} \mathrm{C}$ for 15 minutes before analysis and analyzed batch wise.

\section{Thrombin generation and additional measurements}

Thrombin generation in tissue factor (TF)-triggered platelet poor plasma was measured by means of the Calibrated Automated Thrombogram (CAT) method (Thrombinoscope BV, Maastricht, The Netherlands), which makes use of a low affinity fluorogenic substrate for thrombin (Z-Gly-Gly-Arg-AMC) to continuously monitor thrombin activity in clotting plasma. In order to correct for inner-filter effects and substrate consumption, each thrombin generation measurement was calibrated against the fluorescence curve obtained in the same plasma with a fixed amount of thrombin- $\alpha_{2}$-macroglobulin complex (Thrombin Calibrator, Thrombinoscope BV), as recommended by the manufacturer. Fluorescence was read in an Ascent Reader (Thermo Labsystems OY, Helsinki, Finland) equipped with a 390/460 filter set, and thrombin generation curves were calculated with the Thrombinoscope software (Thrombinoscope BV).

Thrombin generation was determined under two experimental conditions (final plasma concentrations): $1 \mathrm{pM}$ TF and $4 \mu \mathrm{M}$ phospholipids in the absence and presence of $2 \mathrm{nM}$ soluble TM. The TF triggers and phospholipids were obtained from Thrombinoscope BV; TM was kindly donated by Prof. Coen Hemker, Maastricht, The Netherlands.

No corn trypsin inhibitor (CTI) to inhibit contact activation was included in our samples, although several authors reported reduced variability by means of contact factor inhibition using CTI. ${ }^{18,19}$ Contact activation was extensively assessed at previous occasions in our laboratory by analyzing thrombin generation in the absence of TF (Chapter 3.3).

Three parameters were derived from the thrombin generation curves: lag time, ETP (area under the curve) and peak height. Data for these parameters were normalized towards and given as ratio to normal pool plasma, analyzed on each plate, as described (Chapter 3.1). ${ }^{20}$

In order to test the inhibitory potential of the protein $C$ pathway on thrombin generation TM was titrated to inhibit the ETP by approximately $50 \%$ in normal pooled plasma triggered with $1 \mathrm{pM}$ TF.

The FV Leiden mutation was determined with a commercial kit (Roche Diagnostics, 
Basel, Switzerland) on a Light Cycler instrument (Roche Diagnostics).

FVIII activity and activated protein C (APC) resistance were performed on a CA7000 Coagulation instrument (Dade-Behring, Eschborn, Germany) according to the manufacturer's instruction. FVIII activity was measured with a one-stage clotting assay (Dade-Behring). APC resistance was measured with a ProC AC R kit (Dade-Behring).

\section{Statistical analysis}

Descriptive statistics were computed for baseline characteristics, and data are expressed as mean (95\% confidence interval), unless otherwise specified. Descriptive statistics were computed for D-dimer levels and FVIII levels in the cohort for two different points in time, B1 and B2, and data are expressed as median [interquartile range].

Differences between parameters of thrombin generation measurements (the $1 \mathrm{pM}$ $\mathrm{TF}$ assay in the absence and presence of TM) within patients were analyzed with Student's $t$-test or Mann Whitney U as appropriate. Differences between patients with and without recurrence were analyzed using paired Student's $t$-test or Wilcoxon's signed rank test as appropriate.

To test the association between thrombin generation and established risk indicators for VTE; lag time, ETP and peak height with and without TM were divided around the median of the cohort. Pearson's chi-square (expressed with the corresponding odds ratio; OR) was used to assess the following variables: previous VTE, varicositas/venous insufficiency, obesity (BMI>26 $\mathrm{kg} \mathrm{m}^{2-1}$ ), age over 70, gender, duration of anticoagulant therapy, residual thrombosis, levels of normal/abnormal D-dimer, levels of low/high FVIII, FV Leiden and malignancy. In subsequent multivariate logistic regression analyses all variables that generated a $P$ value of $\leq 0.05$ on the chi-square test were entered.

A two-tailed probability value $P<0.05$ was considered statistically significant. Statistics were computed using SPSS for Windows, version 15.0 (SPSS Inc., Chicago, IL, USA). 


\section{Results}

\section{Patients}

All 125 patients who visited the outpatient clinic for the follow-up of an acute DVT consented to participate in the study and were included in the analysis. The baseline characteristics for these patients are shown in Table 1. The values of D-dimer levels and FVIII levels are presented in Table 2.

Table 1. Patient characteristics.

\begin{tabular}{|c|c|c|c|c|}
\hline Characteristics & $n$ & $(\%)$ & & \\
\hline \multicolumn{5}{|l|}{$n=125$} \\
\hline Men; women & 51 & (40.8); & 74 & $(59.2)$ \\
\hline Age in years (SD; range) & 55.8 & $(1.48 ; 17-82)$ & & \\
\hline $\mathrm{BMI}>26$ & 65 & $(52)$ & & \\
\hline \multicolumn{5}{|l|}{ Risk factors VTE } \\
\hline \multicolumn{5}{|l|}{$n=125$} \\
\hline Recent trauma $\leq 2$ months & 26 & $(20.8)$ & & \\
\hline Recent surgery $\leq 2$ months & 26 & $(20.8)$ & & \\
\hline Malignancy & 5 & $(4.0)$ & & \\
\hline Hormonal therapy & 26 & $(20.8)$ & & \\
\hline Pregnancy/puerperum & 1 & $(0.8)$ & & \\
\hline FV Leiden ( $n=87$ ) & 21 & $(20.8)$ & & \\
\hline Varicositas/venous insufficiency & 14 & $(11.2)$ & & \\
\hline Travel $>10$ hours & 8 & $(6.4)$ & & \\
\hline Previous VTE & 27 & $(21.6)$ & & \\
\hline Residual thrombosis & 42 & $(35.6)$ & & \\
\hline \multicolumn{5}{|l|}{ Treatment duration } \\
\hline \multicolumn{5}{|l|}{$n=125$} \\
\hline 3 months & 25 & (20) & & \\
\hline 6 months & 61 & $(48.8)$ & & \\
\hline 12 months & 16 & $(12.8)$ & & \\
\hline 24 months or indefinite & 21 & $(16.8)$ & & \\
\hline
\end{tabular}

$\mathrm{BMI}$, body mass index; VTE, venous thromboembolism. 
Table 2. Differences in thrombin generation, D-dimer and FVIII levels between patients with and without recurrent venous thromboembolism (VTE). Data are presented as median [interquartile range].

\begin{tabular}{|c|c|c|c|c|c|c|c|c|}
\hline \multirow[b]{3}{*}{ FVIII (\%) } & \multicolumn{4}{|c|}{ No recurrent VTE $(n=103)$} & \multicolumn{4}{|c|}{ Recurrent VTE $(n=5)$} \\
\hline & \multicolumn{2}{|l|}{ B1 } & \multicolumn{2}{|l|}{ B2 } & \multicolumn{2}{|l|}{ B1 } & \multicolumn{2}{|l|}{ PREC } \\
\hline & 184.5 & {$[150.5-218.0]$} & 181.0 & {$[149.5-225.3]$} & 171.5 & {$[135.8-255.5]$} & 187.0 & {$[146.3-222.5]$} \\
\hline D-dimer (ng mL ${ }^{-1}$ ) & 340.0 & {$[125.0-510.0]$} & 380.0 & {$[242.5-665.0]$} & 540.0 & {$[212.5-770.0]$} & 445.0 & {$[210.0-1237.5]$} \\
\hline \multicolumn{9}{|c|}{ Thrombin generation $1 \mathrm{pM}$ TF -TM } \\
\hline Lag time (min) & 5.0 & {$[4.0-8.8]$} & 5.0 & {$[4.0-6.5]$} & 5.6 & {$[4.2-8.0]$} & 4.0 & {$[3.7-5.2]$} \\
\hline ETP (\%) & 148.0 & [54.0-187.0] & 171.0 & [121.6-171.0] & 148.0 & [93.0-244.0] & $212.0^{*+}$ & {$[193.5-259.0]$} \\
\hline Peak height (\%) & 222.0 & {$[100.0-303.0]$} & 262.4 & {$[144.5-323.0]$} & 191.0 & {$[104.0-427.5]$} & $358.0^{*}+$ & {$[310.0-464.0]$} \\
\hline \multicolumn{9}{|c|}{ Thrombin generation $1 \mathrm{pM}$ TF +TM } \\
\hline Lag time diff. (\%) & 0.0 & {$[0.0-0.0]$} & 0.0 & {$[0.0-0.0]$} & 0.0 & {$[-0.90-3.78]$} & 0.0 & {$[0.0-0.0]$} \\
\hline ETP diff. (\%) & -19.5 & {$[-24.5--17.5]$} & -16.0 & {$[-25.2--7.0]$} & -15.0 & {$[-35.5--10.5]$} & $-9.0^{*}$ & {$[-14.0--5.5]$} \\
\hline Peak height diff. (\%) & -3.8 & {$[-6.4--2.2]$} & -26.9 & {$[-34.9--16.5]$} & -6.0 & {$[-6.1--2.7]$} & -25.2 & {$[-33.2--4.7]$} \\
\hline
\end{tabular}

PREC, last sample before recurrent event; diff., difference between thrombin generation in the presence (+TM) and absence (-TM) of thrombomodulin. * denotes $P<0.05$ compared to $\mathrm{B} 1$, $\dagger$ denotes $P<0.05$ compared to B2.

\section{Clinical events}

Of the 125 patients who were followed, complete follow-up was available for 102 patients; blood was obtained from 108 patients. Twenty-one patients (16.8\%) were lost to follow-up in the course of the two year follow-up period; two patients missed the visit at six months, two additional patients missed the 12 month visit, and 17 only missed the final visit. Of these 21 patients, six patients had moved away, three could not be followed due to substance abuse, three elderly patients had transportation difficulties, and one patient suffered a recurrent event and visited another hospital closer to her home while for the remaining eight patients no particular reason for their lack of compliance could be identified.

\section{Recurrence and death}

Seven $(5.6 \%)$ patients had an objectively documented recurrent event within the follow-up period; blood was obtained from five of these patients. In addition, four (3.2\%) patients died during the follow-up period (two male, two female; three of them died from metastasized malignancies (gastric, breast and lung) and there was one case of sudden death at home). 


\section{Analysis}

\section{Thrombin generation and recurrent events}

Differences between parameters of thrombin generation measurements (the $1 \mathrm{pM}$ TF assay in the absence and presence of TM) between patients with and without recurrence are given in Table 2 .

The first comparison was done between levels of lag time, ETP and peak height with and without TM, for patients with and without a recurrent event at one month after cessation of anticoagulant treatment (B1). No statistical difference was found for any of the tested variables.

When the same parameters were determined in the last sample before the recurrent event (PREC) as compared to blood sampled one month after cessation of anticoagulant treatment in patients without a recurrent event (B1), both ETP and peak height were significantly different between patients with a recurrent event and those without.

Upon addition of TM, only the ETP showed a significantly reduced inhibition in patients with a recurrent event versus those without a recurrent event ( -9.5 vs $-19.5 \%)$.

Significant differences were found for both ETP and peak height when levels of lag time, ETP and peak height with and without TM were compared for the last sample before the recurrent event (PREC) versus the sample at one year (B2) in patients without recurrence. When TM was added no significant differences were found.

\section{Thrombin generation and risk factors for VTE}

The outcomes on the chi-square test for the associations between lag time and clinical risk factors show that lag time is associated with residual thrombosis $(P<0.001,0 R=4.7$ (1.8-12.2)), previous VTE $(P=0.024,0 R=3.8(1.1-13.1))$, estrogen use $(P=0.005,0 R=0.2$ $(0.1-0.6))$ and age $>70(P=0.013,0 R=3.0(1.2-7.3))$.

Patients with high ETP are more often female $(P=0.043,0 R=0.4(0.2-0.9))$, and have significantly less often the FV Leiden mutation $(P=0.013,0 R=0.2(0.1-0.7))$. None of the other variables tested were significantly different.

Women have significantly lower peak heights $(P=0.043,0 \mathrm{R}=0.4(0.2-0.9))$, as do patients with FV Leiden $(P=0.013,0 R=0.2(0.1-0.8))$.

In the subsequent multivariate logistic regression analysis of the variables associated with lag time, gender and estrogen use were not significant anymore, while residual thrombosis $(P=0.004,0 R=4.6(1.6-12.9))$, previous VTE $(P=0.036,0 R=4.6(1.1-19.1))$ and age $>70(P=0.046,0 R=3.4(1.0-11.3))$ were still associated. Both variables associated with ETP remained significant (female gender: $P=0.041,0 \mathrm{R}=0.4(0.2-0.9)$; FV Leiden mutation: $P=0.013,0 R=0.2(0.0-0.7))$. For peak height both gender $(P=0.041$, 


\section{Chapter 4.3}

$\mathrm{OR}=0.4(0.2-0.9))$ and FV Leiden $(P=0.013, \mathrm{OR}=0.2(0.0-0.7))$ remained significant.

In the presence of TM, ETP and peak height did not show any associations with risk factors for VTE. Lag time, however, was associated with previous VTE $(P=0.044,0 R=4.7$ (0.9-23.4)).

In the multivariate logistic regression analysis of the variables associated with lag time in the presence of TM, none of the associations were present anymore. 


\section{Discussion}

The results of our study suggest that in general thrombin generation has the potential to be suitable for global assessment of the risk of recurrent VTE in unselected patients.

In accordance with Tripodi et al. ${ }^{14}$, our data show that levels of lag time and ETP were not significantly different in samples taken at one month after cessation of anticoagulant therapy between patients with and without a recurrent event. In disagreement with the results of the aforementioned study, we observed no differences in peak height. Upon addition of TM we did not observe differences between thrombin generation of patients with and patients without a recurrent event. This may be due to the small number of recurrent events available for testing.

Timing of blood collection with regard to the optimal usefulness of the assay may be more important than currently appreciated. Closer towards the recurrent event the potential to detect a procoagulant effect may be increased. This was manifested when the last measurements available before the recurrent event were compared to the samples of one month after cessation of therapy in patients without a recurrent event; statistically significant differences in thrombin generation indices were observed. This was also the case for the comparison with samples from patients without a recurrent event taken at a later point in time after cessation of anticoagulant therapy.

The fact that no statistically significant differences were found at one month after cessation of anticoagulant medication may, besides the lack of power, also be attributed to the relatively low levels of thrombin generation at that point in time compared to the significantly higher levels of thrombin generation at one year after the event (Chapter 4.2). ${ }^{15}$

Futhermore, it is of interest that associations were found between risk factors for VTE and thrombin generation. In particular lag time was associated with a number of variables that also determine risk of recurrent thrombosis, including residual thrombosis, previous thrombosis and age. FV Leiden and gender are of influence for ETP and peak height. Upon addition of TM, however, none of the indices of thrombin generation are influenced anymore by known risk factors.

The best practical usefulness for thrombin generation therefore lies in the assessment of thrombin generation in the presence of TM. We have shown earlier that under anticoagulant therapy inhibition with TM is significantly different in patients as opposed to healthy individuals (Chapter 4.2). ${ }^{15}$ It would be interesting to study whether TM has different levels of inhibition during anticoagulant therapy between patients with a recurrent event and patients without. The most attractive management strategy may be to test the inhibitory potential of thrombin generation at different points in time during anticoagulant treatment.

Finally, it must be stressed that the character of this study is exploratory and that, given the few events observed, no firm conclusions can be drawn as of yet. In spite of 
such limitations the present data provide important new information regarding the dynamics of the pre-thrombotic state. This may add to improved diagnostic options in patients at risk of recurrent DVT. In addition, and in accordance with the data from Tripodi and colleagues, ${ }^{14}$ the observed change in TM responsiveness between patients with versus those without recurrence may provide the opportunity to utilize this test to assess the risk in patients while still on anticoagulant therapy.

Further studies are needed to assess the optimal point in time for determination of the risk of recurrence and in order to derive the mechanisms involved in the changes in thrombin generation towards the time of the recurrent thrombotic event. 


\section{References}

1. Kearon C. Long-term management of patients after venous thromboembolism. Circulation. 2004;110:I10-I18.

2. Piovella F, Crippa L, Barone M, Vigano D'Angelo S, Serafini S, Galli L et al. Normalization rates of compression ultrasonography in patients with a first episode of deep vein thrombosis of the lower limbs: association with recurrence and new thrombosis. Haematologica. 2002;87:515-522.

3. Prandoni P, Lensing AW, Prins MH, Bernardi E, Marchiori A, Bagatella P et al. Residual venous thrombosis as a predictive factor of recurrent venous thromboembolism. Ann Intern Med. 2002;137:955-960. Summary for patients in: Ann Intern Med. 2002;137:I32.

4. Palareti G, Legnani C, Cosmi B, Guazzaloca G, Pancani C, Coccheri S. Risk of venous thromboembolism recurrence: high negative predictive value of D-dimer performed after oral anticoagulation is stopped. Thromb Haemost. 2002;87:7-12.

5. Palareti G, Legnani C, Cosmi B, Valdre L, Lunghi B, Bernardi F et al. Predictive value of Ddimer test for recurrent venous thromboembolism after anticoagulation withdrawal in subjects with a previous idiopathic event and in carriers of congenital thrombophilia. Circulation. 2003;108:313-318.

6. Kyrle PA, Minar E, Hirschl M, Bialonczyk C, Stain M, Schneider B et al. High plasma levels of factor VIII and the risk of recurrent venous thromboembolism. N Engl J Med. 2000;343:457462.

7. Legnani C, Cini M, Cosmi B, Poggi M, Boggian O, Palareti G. Risk of deep vein thrombosis: interaction between oral contraceptives and high factor VIII levels. Haematologica. 2004;89:1347-1351.

8. Kreuz W, Stoll M, Junker R, Heinecke A, Schobess R, Kurnik K et al. Familial elevated factor VIII in children with symptomatic venous thrombosis and post-thrombotic syndrome: results of a multicenter study. Arterioscler Thromb Vasc Biol. 2006;26:1901-1906.

9. Meijers JC, Tekelenburg WL, Bouma BN, Bertina RM, Rosendaal FR. High levels of coagulation factor XI as a risk factor for venous thrombosis. N Engl J Med. 2000;342:696701.

10. Van Hylckama Vlieg A, van der Linden IK, Bertina RM, Rosendaal FR. High levels of factor IX increase the risk of venous thrombosis. Blood. 2000;95:3678-3682.

11. Prandoni P, Lensing AW, Cogo A, Cuppini S, Villalta S, Carta M et al. The long-term clinical course of acute deep venous thrombosis. Ann Intern Med. 1996;125:1-7.

12. Van Hylckama Vlieg A, Christiansen SC, Luddington R, Cannegieter SC, Rosendaal FR, Baglin TP. Elevated endogenous thrombin potential is associated with an increased risk of a first deep venous thrombosis but not with the risk of recurrence. Brit J Haematology. 2007;138:769-774.

13. Hron G, Kollars M, Binder BR, Eichinger S, Kyrle PA. Identification of patients at low risk for recurrent venous thromboembolism by measuring thrombin generation. JAMA. 2006;296:397-402.

14. Tripodi A, Legnani C, Chantarangkul V, Cosmi B, Palareti G, Mannucci PM. High thrombin generation measured in the presence of thrombomodulin is associated with an increased risk of recurrent venous thromboembolism. J Thromb Haemost. 2008;6:1327-1333. 
15. Ten Cate-Hoek AJ, Dielis AW, Spronk HM, van Oerle R, Hamulyák K, Prins MH et al. Thrombin generation in patients after acute deep-vein thrombosis. Thromb Haemost. 2008;100:240245.

16. Geerts WH, Pineo GF, Heit JA, Bergqvist D, Lassen MR, Colwell CW et al. Prevention of venous thromboembolism: the Seventh ACCP Conference on Antithrombotic and Thrombolytic Therapy. Chest. 2004;126:338S-400S.

17. Prandoni P, Lensing AW, Prins MH, Bernardi E, Marchiori A, Bagatella P et al. Residual venous thrombosis as a predictive factor of recurrent venous thromboembolism. Ann Intern Med. 2002;137:955-960.

18. Van Veen JJ, Gatt A, Cooper PC, Kitchen S, Bowyer AE, Makris M. Corn trypsin inhibitor in fluorogenic thrombin generation measurements is only necessary at low tissue factor concentrations and influences the relationship between factor VIII coagulant activity and thrombogram parameters. Blood Coagul Fibrinolysis. 2008;19:183-189.

19. Dargaud Y, Luddington R, Baglin TP. Elimination of contact factor activation improves measurement of platelet-dependent thrombin generation by calibrated automated thrombography at low-concentration tissue factor. J Thromb Haemost. 2006;4:1160-1161.

20. Spronk HM, Dielis AW, de Smedt E, van Oerle R, Fens D, Prins MH et al. Assessment of thrombin generation II: Validation of the Calibrated Automated Thrombogram in plateletpoor plasma in a clinical laboratory. Thromb Haemost. 2008;100:362-364. 
Chapter 5

Fibrinolysis-dependent hypercoagulability: Patients with hypertension 
Chapter 5 


\section{The hypercoagulable state in hypertension}

The prothrombotic paradox of hypertension. Role of the reninangiotensin and kallikrein-kinin systems.

Dielis AWJH1ㄴ, Smid $\mathrm{M}^{1}$, Spronk HMH ${ }^{1}$, Hamulyák $\mathrm{K}^{2}$, Kroon $\mathrm{AA}^{3}$, ten Cate $\mathrm{H}^{1}$, de Leeuw $\mathrm{PW}^{3}$.

1 Department of Internal Medicine, Laboratory for Clinical Thrombosis and Haemostasis, Cardiovascular Research Institute Maastricht, Maastricht University Medical Center, Maastricht, The Netherlands;

2 Department of Internal Medicine, Division of Haematology, Maastricht University Medical Center, Maastricht, The Netherlands;

3 Department of Internal Medicine, Maastricht University Medical Center, Maastricht, The Netherlands.

Hypertension. 2005;46:1236-1242. 


\section{Abstract}

Despite increased pulsatile stress, thrombotic rather than haemorrhagic events represent a major complication of hypertension. The pathophysiology of thrombosis in hypertension involves the interaction among vascular endothelium and particularly the renin-angiotensin and kallikrein-kinin systems. Because hypertension is often associated with some degree of inflammation, the combination of chronic inflammation and chronic shear stress may convert the normal anticoagulant endothelium into a procoagulant surface, expressing tissue factor. Activation of the renin-angiotensin system leads to activation of nuclear factor $\mathrm{kB}$-dependent proinflammatory genes, also accelerating the expression of tissue factor. Renin-angiotensin and kallikrein-kinin systems interact at several levels to modulate coagulation, fibrinolysis, and vasodilatation in such a way that these 2 systems could have a major influence on the occurrence of thrombotic complications. Treatment with angiotensin-converting enzyme inhibitors and angiotensin II type-1 receptor antagonists may favorably influence the balance between the renin-angiotensin and kallikrein-kinin axis, regulating blood pressure as well as reducing the risk of thrombosis, which may explain part of the clinical efficacy of these drugs. 


\section{Introduction}

Although hypertension exposes blood vessels to increased pulsatile stress, thrombotic rather than haemorrhagic events represent a major complication in hypertensive patients. This apparent contradiction is known as the thrombotic paradox of hypertension or "Birmingham paradox."1,2 Nevertheless, in hypertension, several thrombogenic abnormalities occur and evidence is emerging that the condition confers a "prothrombotic state." Just as is the case in venous thrombosis, abnormalities in the vessel wall, blood constituents (such as haemostatic and fibrinolytic factors and platelets), and blood flow can precipitate and explain most thrombotic complications.

All of the components of this arterial variant of Virchow's triad are dependent on endothelial function. Indeed, vascular endothelium maintains blood fluidity, modulates blood coagulation, promotes or prevents vascular growth, modulates inflammation, and regulates vasomotor tone. ${ }^{3}$ The renin-angiotensin and the kallikrein-kinin systems are powerful regulators of these processes. Therefore, in this brief review, we discuss the possible endothelial origin of the prothrombotic state in hypertension in relation to these two regulatory systems. As a PubMed search strategy, we selected relevant articles by entering as key words hypertension, renin-angiotensin, aldosterone, kallikrein, (brady)kinin, coagulation, fibrinolysis, and their various combinations.

\section{Endothelial function and blood fluidity}

Under physiological conditions, balanced coagulation and fibrinolysis ensure blood fluidity. In most patients with hypertension, a certain degree of atherosclerotic vascular disease is present that is associated with increased plasma concentrations of C-reactive protein. These elevated $\mathrm{C}$-reactive protein concentrations may activate inflammation as well as coagulation. ${ }^{4}$ Increased activity of proinflammatory mediators potentially activates vascular endothelial cells to generate tissue factor (TF) and plasminogen activator inhibitor-1 (PAI-1), among a range of other proteins. ${ }^{5} \mathrm{TF}$ is an integral membrane protein that is present in adventitial mesenchymal cells of blood vessels.

Normally, endothelial cells contain little or no $\mathrm{TF}, 6,7$ but various stimuli can activate these cells to produce this protein. When expressed, TF binds to activated factor VII (FVIIa). 8,9 The catalytic TF-FVIIa complex may directly activate factor X (FX) as well as factor IX (FIX), leading to thrombin generation, although at least physiologically, the activation of FIX is the dominant pathway. ${ }^{10}$ Under thrombotic conditions, the engagement of activated platelets and the cofactors FVa and FVIIIa accelerate the rate of thrombin formation dramatically, ultimately leading to clot formation. TF pathway inhibitor (TFPI), which is produced by endothelial cells, inhibits TF-FVIIa by form ing a quaternary complex with FXa. Therefore, it is reasonable to assume that the balance between TF and TFPI acts as a regulator of blood coagulation activity. ${ }^{11}$ 
Fibrinolytic activity is modulated by the balance between tissue-type plasminogen activator (t-PA) and PAI-1. In plasma, t-PA is the most important activator of fibrinolysis because it converts the pro-enzyme plasminogen to fibrindegrading plasmin on a fibrin surface after binding to the t-PA receptor on the endothelium. ${ }^{12-14}$ Fibrin degradation products themselves inhibit further fibrin formation. ${ }^{15}$ Although the endothelium is the main production site for t-PA and PAI-1, the latter may also be released from hepatocytes, platelet $\alpha$-granules, smooth muscle cells, and adipocytes. ${ }^{13,16,17}$

\section{Endothelial function and blood flow}

Vascular endothelial cells are pivotal in the association between hypertension and vascular thrombotic complications. Vessel walls are exposed to two distinct mechanical forces: cyclic strain and shear stress. Cyclic strain results from transmural pressure and leads to dilatation and increased wall stress. The latter develops in all structural components of the vessel wall. Cyclic strain not only augments endothelium-derived NO synthase (eNOS) expression and subsequent NO production but also the production of superoxide anions. ${ }^{3,18,19}$

Shear stress, on the other hand, is a frictional force to which only endothelial cells are exposed. It is influenced by transmural pressure gradients and vessel diameter and causes cell deformation and cytoskeletal tension. Mean shear stress is highest in small arterioles and venules. Acute shear stress activates $\mathrm{Ca}^{2+}$ channels with subsequent $\mathrm{Ca}^{2+}$ mobilization. ${ }^{18}$ This leads to release of arachidonic acid and production of NO and prostaglandin $\mathrm{I}_{2}\left(\mathrm{PGI}_{2}\right)$ via cascades involving inositol 1,4,5-triphosphate, diacylglycerol, protein kinase $\mathrm{B}$, and phospholipase A2. Acute shear stress is likely to be the most important physiological regulator of $\mathrm{PGI}_{2}$ and $\mathrm{NO}^{20}$ Sustained shear stress induces cytoskeletal remodeling of endothelial cells. Cells become flatter and they align in direction of the flow to minimize shear stress. Cell differentiation increases and cells become hypertrophic. ${ }^{18}$ Activation of nuclear factor $\kappa \mathrm{B}(\mathrm{NF}-\mathrm{\kappa B})$ may lead to enhanced transcriptional stimulation of a wide variety of factors such as platelet-derived growth factor- $\beta$, transforming growth factor- $\beta 1$, t-PA, cyclooxygenase, eNOS, prostacyclin synthase, and TF.21 Thus, whereas acute shear stress enhances vasodilation and fibrinolysis, chronic shear may favor thrombus formation by increased TF expression (Figure 1).

\section{Role of the renin-angiotensin system}

Angiotensin II (Ang II) and, to some extent, Ang III, are the natural agonists for the AT1 and AT2 receptors. Both receptor types are found on the endothelium. Ang II may be degraded to angiotensin(1-7) (Ang(1-7)) by angiotensin-converting enzyme 2 (ACE2) as well as by the endothelial enzyme prolylcarboxypeptidase (PRCP). ${ }^{22}$ However, ACE2 
Figure 1. Endothelial responses to shear stress.

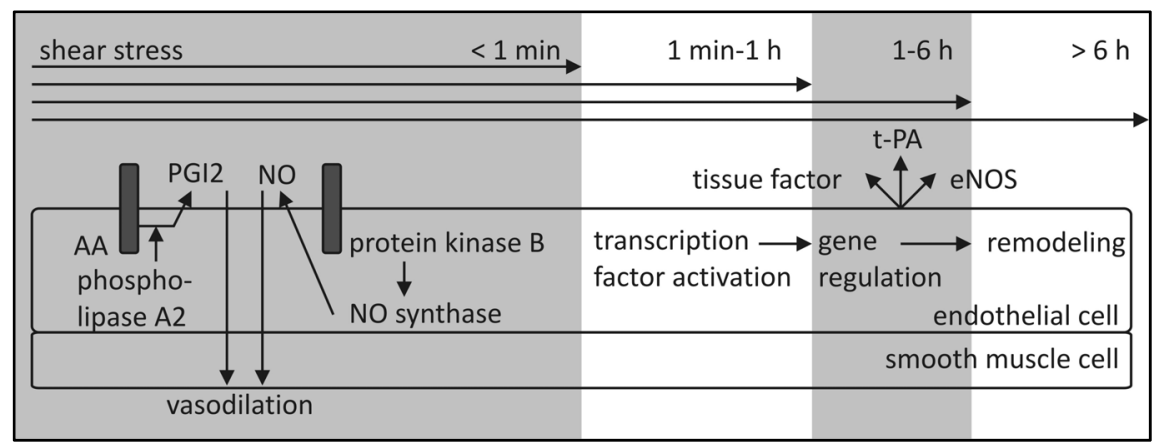

AA indicates arachidonic acid.

is the preferred angiotensinase in heart, kidney, and testes. The degradation product has vasodilator properties because it induces the release of $\mathrm{NO}$ and $\mathrm{PGI}_{2}$ after stimulation of the endothelial AT2 receptor. Recent data indicate that in the presence of Ang II, the vasodepressor effect of Ang(1-7) can only be demonstrated when the AT1 receptor is blocked. ${ }^{23}$ This suggests that the vasodilator effect of Ang(1-7) is not as potent as the vasoconstrictor effect of Ang II. In addition, the expression of the AT2 receptor is normally far less than that of the AT1 receptor. ${ }^{24}$

Ang I, Ang II, and Ang III all induce expression of TF mRNA in cultured rat endothelial cells via stimulation of the AT1 receptor and subsequent intracellular activation of transcription factors NF- $\kappa \mathrm{B}$ and activator protein-1.8,9,25,26 As a result, TF becomes predominant over TFPI, thereby rendering the endothelium prothrombotic. Ang II also stimulates the expression of PAI-1 mRNA in endothelial cells and increases plasma PAI-1 levels in a dose-dependent manner. ${ }^{26-28}$ The mechanism of this effect is still unclear. Possible explanations include increased PAI-1 expression by direct stimulation of AT1 or AT2 receptors and stimulation of the angiotensin subtype-4 (AT4) receptor after conversion of Ang I or II into Ang IV. There is conflicting data as to whether agonists of AT1 and AT2 receptor subtypes influence PAI-1 expression in endothelial cells. ${ }^{29-31}$ In cultured cells, Ang I and Ang II seem to be able to induce increased expression of PAI-1 mRNA levels, but this may also be attributable to conversion of these peptides into Ang IV.8,16,29,31 This conversion involves aminopeptidases A and M, membrane proteins of vascular endothelial cells. Antagonism of the AT4 receptor indeed reduces PAI-1 antigen levels ${ }^{28,31}$ (Figure 2). Thus, apart from shifting the balance between procoagulant and anticoagulant factors into the direction of the former, the renin-angiotensin system favors reduced fibrinolysis by increasing PAI-1. ${ }^{8}$ In addition, aldosterone has been found to increase PAI-1 expression. ${ }^{27}$ Hence, activation of the renin-angiotensin system, which may occur in various conditions such as hypertension or heart failure, can contribute considerably to a prothrombotic state. Ang II has also 
been found to increase t-PA mRNA expression, but so far, it cannot be excluded that this is attributable to t-PA autoregulation in response to increased PAI-1 levels. ${ }^{28}$

\section{Role of the kallikrein-kinin system}

The kallikrein-kinin system, in part, counteracts the effects of the renin-angiotensin system. ${ }^{22}$ Under physiological conditions, endothelial cells and their matrix provide the serine protease PRCP that activates prekallikrein (PK) to kallikrein. Next, kallikrein activates FXII. ${ }^{32-34}$ Inactive prekallikrein is converted to kallikrein after binding to kininogen, the precursor of bradykinin. In turn, PRCP-mediated conversion to kallikrein generates bradykinin from kininogen. ${ }^{33}$ In addition, PRCP also degrades Ang II. The vasodilator peptide bradykinin acts on the endothelial B2 receptor to stimulate intracellular $\mathrm{Ca}^{2+}$ mobilization and subsequent release of NO and prostaglandins. Through the same receptor, bradykinin also enhances the release of endothelial storage pool-derived t-PA, the aforementioned activator of fibrinolysis.11,12,35,36 Receptor blockade reduces t-PA release but to a lesser extent than the reduction of the vasodilator response. ${ }^{35}$

In addition to activating the kinin system, kallikrein could theoretically stimulate intrinsic coagulation through the formation of FXIIa. However, in current models of blood coagulation, this reaction is not regarded as important, an idea that is based mainly on the lack of any haemostatic consequences of the absence of FXII, PK, or high molecular weight kininogen (HMWK) in humans. ${ }^{37}$ In fact, only in conditions of sepsis or exposure to artificial surfaces (e.g. during cardiopulmonary bypass), FXII-dependent activation of the intrinsic route of coagulation may be observed. Of interest, recent studies suggest that elevated concentrations of FXIIa are associated with an increased risk of cardiovascular complications including myocardial infarction, ${ }^{38-40}$ but the pathophysiological mechanisms remain to be established. The generation of kallikrein is associated with increased bradykinin and t-PA antigen production, ${ }^{41}$ and there are convincing data to suggest that FXIIa is a weak activator of plasminogen and, hence, fibrinolysis. ${ }^{42,43}$

In addition to their respective direct roles in coagulation and fibrinolysis, the reninangiotensin and kallikrein-kinin systems interact with each other at 3 additional levels (Figure 3). First, the enzyme PRCP, which is expressed on endothelial cell membranes, is involved in the conversion of prekallikrein to kallikrein and the degradation of Ang II to Ang(1-7). Thus, PRCP activity results in vasodilation. Second, ACE degrades bradykinin to the degradation product bradykinin(1-5) and converts Ang I to Ang II. As a result, ACE activity leads to enhanced vasoconstriction and inhibition of fibrinolysis through both systems. ${ }^{44}$ Interestingly, bradykinin(1-5) is not an inert degradation product, but it inhibits thrombin-induced platelet aggregation through binding to the thrombin cleavage site on protease activated receptors 1 and 4.45,46 Finally, stimulation of AT2 
Figure 2. Angiotensin II-induced PAI-1 expression.

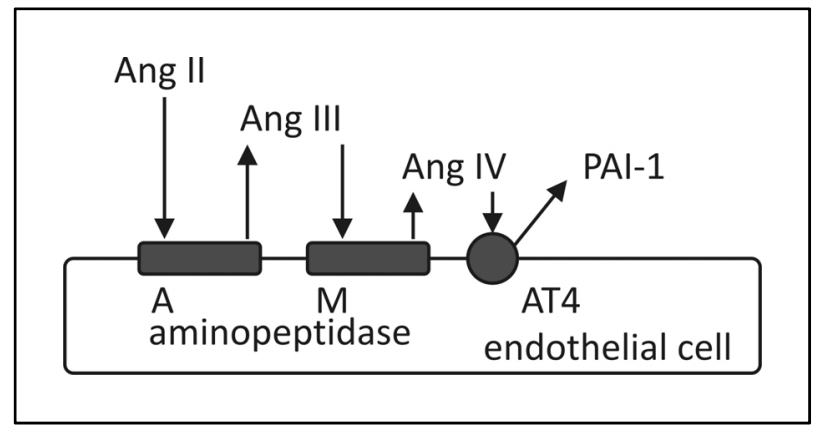

Figure 3. Interactions between the renin-angiotensin and kallikrein-kinin systems.

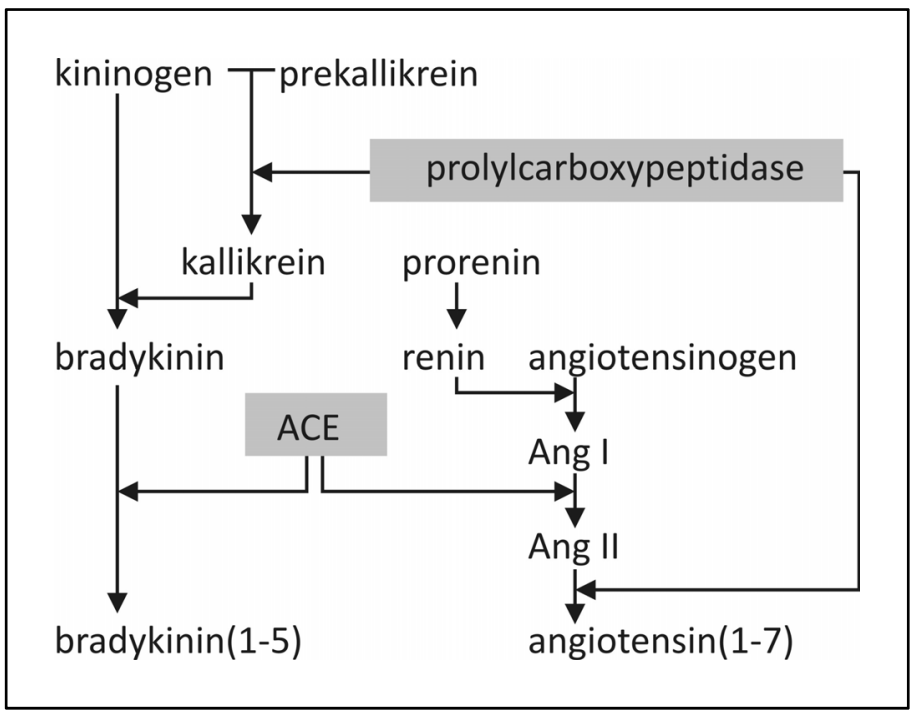

receptors enhances bradykinin formation through an yet unknown pathway. ${ }^{22,44}$ In the past, an additional interaction has been proposed in the sense that kallikrein would act as a physiological activator of prorenin, ${ }^{47,48}$ but recent data have negated that hypothesis. ${ }^{49}$

A summary of the biological actions of the renin-angiotensin system and kallikreinkinin systems on vascular functions, coagulation, and fibrinolysis is given in Table 1. 
Table 1. Biological actions of the renin-angiotensin and kallikrein-kinin systems on vascular functions, coagulation, and fibrinolysis.

\begin{tabular}{|c|c|c|c|}
\hline Effector system & Endothelial function & Fibrinolysis & Coagulation \\
\hline Renin-angiotensin system & $\begin{array}{l}\text { Vasoconstriction } \\
\text { Ang II via AT1 receptor } \\
\text { (human) }\end{array}$ & $\begin{array}{l}\text { Activation } \\
\text { Ang II via AT1 receptor: } \\
\text { increased t-PA mRNA } \\
\text { (human) }\end{array}$ & $\begin{array}{l}\text { Activation } \\
\text { Ang I/II/III via AT1 } \\
\text { receptor: TF } \\
\text { mRNA } \\
\text { (mouse) }\end{array}$ \\
\hline & $\begin{array}{l}\text { Vasodilation } \\
\text { Ang(1-7) via AT1 } \\
\text { receptor: production } \\
\text { of } \mathrm{NO} \text { and } \mathrm{PGI}_{2} \\
\text { (human) }\end{array}$ & $\begin{array}{l}\text { Inhibition } \\
\text { Ang II via AT1 receptor: } \\
\text { increased plasma PAI-1 } \\
\text { (human) }\end{array}$ & \\
\hline Kallikrein-kinin system & $\begin{array}{l}\text { Vasodilation } \\
\text { Bradykinin via } \mathrm{BKB} 2 \mathrm{R} \text { : } \\
\text { release of } \mathrm{NO} \text { and } \mathrm{PGI}_{2} \\
\text { (human) }\end{array}$ & $\begin{array}{l}\text { Activation } \\
\text { Bradykinin via BKB2R: } \\
\text { release of t-PA } \\
\text { (human) }\end{array}$ & $\begin{array}{l}\text { Activation } \\
\text { Kallikrein activates } \\
\text { FXII (theoretically) } \\
\text { Inhibition } \\
\text { Bradykinin(1-5) } \\
\text { inhibits platelet } \\
\text { aggregation by } \\
\text { thrombin }\end{array}$ \\
\hline
\end{tabular}

BKB2R indicates bradykinin B2 receptor.

\section{Clinical implications}

Essential hypertension causes an earlier onset of the age-related decline in endothelial function. ${ }^{21,50}$ Because this abnormality also occurs in subjects with a positive family history of hypertension, it seems to be, at least partially, genetically determined. Endothelial dysfunction does not only occur in normal aging and hypertension, but also in atherosclerosis, diabetes mellitus, chronic heart failure, menopause, vasospasm, and coronary artery disease, each of which is frequently coexisting in hypertension. A continuously elevated blood pressure increases shear stress and hence causes morphological alterations of vessels, so-called vascular remodeling with hypertrophic endothelial cells, and an increased media-to-lumen ratio, with further loss of normal 
endothelial function and a further rise in blood pressure. ${ }^{51}$

The terms "endothelial dysfunction" and "vascular disease" are generally used to describe deterioration of vasodilator function and subsequent changes in the vessel wall.11,19,52 By and large, vasoconstrictor responses are not impaired in endothelial dysfunction. Thus, mechanisms resulting in endothelial dysfunction include decreased secretion of or sensitivity to vasodilator agents and increased production of or sensitivity to vasoconstrictor agents.3,19,21,52 However, remarkably, disturbances in coagulation and fibrinolysis are not often considered when dealing with endothelial dysfunction. Nevertheless, several lines of evidence indicate that regardless of plasma levels, the renin-angiotensin system is activated in a considerable number of patients with essential hypertension. Indeed, experiments with inhibitors of the reninangiotensin system have made it clear that this system is critically involved in the regulation of resting vascular tone. In addition, reduced responsiveness to vasodilator prostaglandins may result in a greater sensitivity to Ang II, at least in the kidney. ${ }^{53}$ However, whether the kallikrein-kinin system plays any role in the regulation of basal vascular tone remains open to debate. Under a variety of circumstances, blockade of bradykinin receptors has no or only minimal effects, and it seems quite possible that increased activity of the kallikrein-kinin system stems from its interaction with the renin-angiotensin system. At any rate, the apparent predominance of the effects of angiotensin is likely to shift the coagulation-fibrinolysis balance toward an unfavorable position.

Cardiovascular and cerebrovascular complications of hypertension like myocardial infarction, cardiac arrhythmias, sudden cardiac death, and stroke appear to have a peak incidence between $6 \mathrm{AM}$ and noon, with a lower incidence at night. ${ }^{13}$ Although this rhythm coincides with morning peaks in blood pressure and higher urinary output of epinephrine, norepinephrine, aldosterone, and cortisol, PAI-1 and t-PA plasma levels also vary during the day. ${ }^{13,14,29} \mathrm{PAI}-1$ levels peak at $3 \mathrm{AM}$, have a nadir at $5 \mathrm{PM}$ to $11 \mathrm{PM}$, and fall by $50 \%$ between $10 \mathrm{AM}$ and 4 PM. t-PA levels show an opposite pattern with a peak at 6 PM and a nadir at 3 AM.13,14,29,36 These variations in fibrinolytic activity favor thrombus formation in the early morning and might reflect a hypercoagulable state in hypertension (Figure 4). Interestingly, elevated t-PA antigen levels but not activity are associated with an increased risk for myocardial infarction and stroke, although high t-PA levels would protect against coronary events. ${ }^{54,55}$ This merely reflects t-PA/PAI-1 complex formation. In fluid phase, PAI-1 forms a complex with t-PA, causing a slower clearance of t-PA and an elevation of t-PA antigen levels. ${ }^{11,30,54}$ Furthermore, hyperaggregability of platelets is also associated with hypertension, especially in established cardiovascular disease with fatty streaks and plaques. ${ }^{56}$ 


\section{Effect of interference with the renin-angiotensin system}

The rationale of antihypertensive treatment with ACE inhibitors (ACEIs) and AT1 receptor antagonists is to establish a decrease in the activity of the renin-angiotensin system and to diminish the number of atherosclerotic complications. ACEIs have been shown to lower the risk of reinfarction and to decrease overall mortality and cardiovascular mortality in hypertension by $16 \%$ to $27 \%$ and $18 \%$ to $21 \%$, respectively. ${ }^{14,22,27}$ Myocardial infarction and stroke are reduced by $20 \%$ during ACE inhibition. ${ }^{22}$ ACEIs ameliorate all three components of Virchow's triad through the renin-angiotensin and kallikrein-kinin systems. Endothelial function, for instance, is improved by the reduction in Ang II levels as well as by the rise in bradykinin and Ang(1-7). Inhibition of ACE further leads to an improved fibrinolytic balance. Ang I- and Ang II-mediated PAI-1 expression and activity as well as antigen levels are blocked by ACEIs. Ang IV-mediated PAI-1 expression on the other hand is not influenced by ACEIs. ${ }^{14,27,30,31,44}$ Endothelial t-PA release is potentiated, which is thought to be the result of increased availability of bradykinin. ${ }^{16,35}$ Women are more sensitive to bradykinin-mediated effects of ACEIs because estrogen upregulates bradykinin receptors and sensitizes coronary arteries to bradykinin-mediated vasodilation. ${ }^{35}$ However, ACEIs do not block the renin-angiotensin system completely because the Ang II producing enzyme chymase is not inhibited. ${ }^{8}$ Furthermore, the ACEI ramipril has been found to reduce thrombin- antithrombin complex formation, an indicator of coagulation activation. ${ }^{15,57}$ Regarding hyperaggregability of platelets, ACE inhibition lowers platelet activation markers because of platelet-inhibiting $\mathrm{PGI}_{2}$ and $\mathrm{NO}$, resulting in diminished adhesion and aggregation.56 More related to atherosclerosis, ACEIs downregulate TF synthesis in monocytes, a mechanism possibly reflected in the preventive effect on thrombotic complications. ${ }^{58}$

Figure 4. Plasma levels of t-PA and PAI-1 during the day.

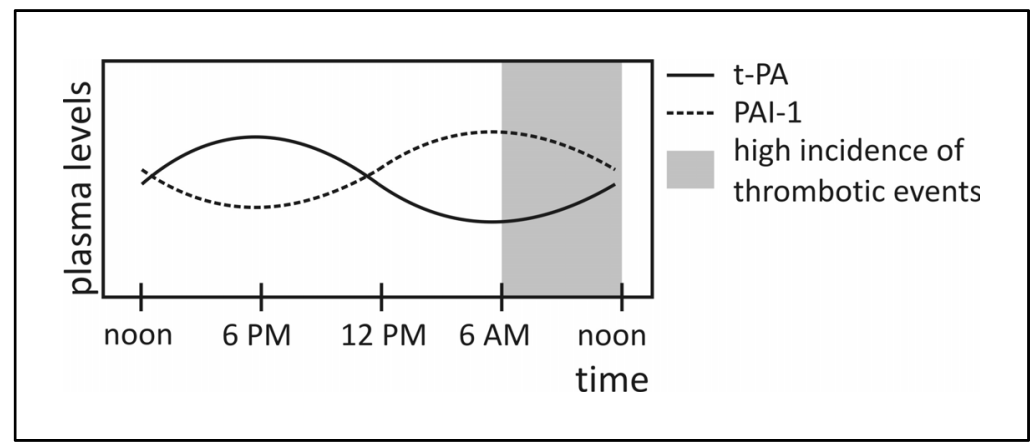


AT1 receptor antagonists also lower the incidence of hypertension-related complications. Because Ang II concentrations increase during AT1 receptor antagonism, one may expect that PAI-1 would increase via stimulation of the AT4 receptor because there is more substrate for aminopeptidases A and M if this pathway is of importance. Yet, in human as well as in rat smooth muscle cells, AT1 receptor inhibition decreased PAI-1 activity and antigen levels in vascular smooth muscle cells. Remarkably, though, this effect is not found in vivo in salt-depleted normotensive subjects and postmenopausal women (normotensive and hypertensive). ${ }^{29,30,44,54,59}$ Data concerning patients with essential hypertension are conflicting. The AT1 receptor antagonists losartan and irbesartan have been found to achieve a significant lowering of PAI-1 levels compared with the ACEI perindopril and the $\beta$-blocker atenolol. ${ }^{44,55}$ Other results show no decrease of PAI-1 antigen after losartan treatment. ${ }^{60}$ Moreover, the PAI-1 antigenlowering effect of losartan is not sustained beyond a period $>6$ weeks.9,54 AT1 receptor upregulation could account for this short period of action.9,61 In addition, there are more conflicting data as to whether losartan decreases t-PA activity and antigen. ${ }^{30,60} \mathrm{~A}$ decrease in t-PA antigen could be explained by the aforementioned complex formation because reduced PAI-1 levels result in higher levels of fluid phase t-PA that is cleared faster than complex-bound t-PA. ${ }^{30}$ Others have reported that t-PA activity increases in patients with heart failure. ${ }^{54}$ Because TF mRNA expression is solely regulated via the AT1 receptor, its inhibition prevents induction of TF mRNA. This effect may translate into a normalization of the hypercoagulable state in hypertension. ${ }^{9}$ As with ACEIs, AT1 receptor antagonists are found to inhibit platelet aggregability and adhesion by stimulating NO release from platelets and endothelial cells. ${ }^{62}$ In addition, losartan is able to counteract platelet activation ex vivo independently from the AT1 receptor, probably by blocking thromboxane A2 signaling directly. ${ }^{63}$

Table 2 summarizes the observed actions of ACEIs and AT1 receptor antagonists on endothelial function, fibrinolysis, coagulation, and platelet reactivity.

\section{Future perspectives}

It is becoming increasingly clear that essential hypertension may indeed be associated with a hypercoagulable state that may contribute to arterial thrombotic complications. The renin-angiotensin and kallikrein-kinin systems probably play a key role in causing this prothrombotic state. However, more research should be directed toward the precise mechanisms by which these systems become prothrombotic. In addition, it is worthwhile to explore in greater detail to what extent modulation of the thrombotic pathways by appropriate medication can reduce the incidence of thrombotic complications in hypertension. Although much of the favorable effects of antihypertensive drugs can be attributed to the fall in blood pressure per se, additional actions, however small, should not be overlooked. 
Table 2. Summary of observed actions of ACEls and angiotensin receptor antagonists on endothelial function, fibrinolysis, and platelet activity.

\begin{tabular}{lll}
\hline Effector on & ACE inhibition & AT1 receptor antagonism \\
\hline Endothelial function & Enhancing & Enhancing \\
& Reduced Ang II & Reduced AT1 receptor stimulation \\
& Increased bradykinin, Ang(1-7) & \\
Fibrinolysis & Activating & \\
& Reduced PAI-1 activity and antigen & Uncertain \\
& (Ang l- and Ang II-mediated) & Reduced PAl-1 antigen (short-term) \\
& Increased t-PA & (conflicting data) \\
& & \\
Coagulation & Inhibitory? & Inhibitory? \\
& Reduced TAT & Reduced TF mRNA \\
& Reduced TF synthesis in monocytes & \\
Platelet adhesion and & Inhibitory & Inhibitory \\
aggregation & PGI release & TxA2 blockade \\
& NO release & NO release \\
\hline
\end{tabular}

TAT indicates thrombin-antithrombin complexes; TXA2, thromboxane A2. 


\section{References}

1. Lip GY. Hypertension and the prothrombotic state. J Hum Hypertens. 2000;14:687-690.

2. Lip GY. Hypertension, platelets, and the endothelium: the "thrombotic paradox" of hypertension (or "Birmingham paradox") revisited. Hypertension. 2003;41:199-200.

3. Bassenge E. Endothelial function in different organs. Prog Cardiovasc Dis. 1996;39:209-228.

4. Bisoendial RJ, Kastelein JJ, Levels JH, Zwaginga JJ, van den Bogaard B, Reitsma PH et al. Activation of inflammation and coagulation after infusion of $\mathrm{C}$-reactive protein in humans. Circ Res. 2005;96:714-716.

5. Wiel E, Vallet B, ten Cate H. The endothelium in intensive care. Crit Care Clin. 2005;21:403416.

6. Jaffe EA. Cell biology of endothelial cells. Hum Pathol. 1987;18:234-239.

7. Nemerson Y, Giesen PL. Some thoughts about localization and expression of tissue factor. Blood Coagul Fibrinolysis. 1998;9:S45-S47.

8. Nishimura H, Tsuji H, Masuda H, Kasahara T, Yoshizumi M, Sugano T et al. The effects of angiotensin metabolites on the regulation of coagulation and fibrinolysis in cultured rat aortic endothelial cells. Thromb Haemost. 1999;82:1516-1521.

9. Muller DN, Mervaala EM, Dechend R, Fiebeler A, Park JK, Schmidt F et al. Angiotensin II (AT(1)) receptor blockade reduces vascular tissue factor in angiotensin II-induced cardiac vasculopathy. Am J Pathol. 2000;157:111-122.

10. Bauer KA, Mannucci PM, Gringeri A, Tradati F, Barzegar S, Kass BL et al. Factor IXa-factor VIIIa-cell surface complex does not contribute to the basal activation of the coagulation mechanism in vivo. Blood. 1992;79:2039-2047.

11. Spronk HM, Govers-Riemslag JW, ten Cate H. The blood coagulation system as a molecular machine. Bioessays. 2003;25:1220-1228.

12. Berrettini M, Schleef RR, Espana F, Loskutoff DJ, Griffin JH. Interaction of type-1 plasminogen activator inhibitor with the enzymes of the contact activation system. J Biol Chem. 1989;264:11738-11743.

13. Loscalzo J, Schafer AI. Thrombosis and Hemorrhage. Boston, Mass: Blackwell Scientific Publications; 1994.

14. Vaughan DE. Angiotensin and vascular fibrinolytic balance. Am J Hypertens. 2002;15:3S-8S.

15. Gaffney PJ, Edgell TA, Whitton CM. The haemostatic balance - Astrup revisited. Haemostasis. 1999;29:58-71.

16. Vaughan DE, Lazos SA, Tong K. Angiotensin II regulates the expression of plasminogen activator inhibitor-1 in cultured endothelial cells. A potential link between the reninangiotensin system and thrombosis. J Clin Invest. 1995;95:995-1001.

17. Binder BR, Christ G, Gruber F, Grubic N, Hufnagl P, Krebs M et al. Plasminogen activator inhibitor 1: physiological and pathophysiological roles. News Physiol Sci. 2002;17:56-61.

18. Ballermann BJ, Dardik A, Eng E, Liu A. Shear stress and the endothelium. Kidney Int Suppl. 1998;67:S100-108.

19. Boulanger CM. Secondary endothelial dysfunction: hypertension and heart failure. J Mol Cell Cardiol. 1999;31:39-49.

20. Pearson JD. Endothelial cell function and thrombosis. Baillieres Best Pract Res Clin Haematol. 1999;12:329-341. 
21. Vapaatalo H, Mervaala E. Clinically important factors influencing endothelial function. Med Sci Monit. 2001;7:1075-1085.

22. Schmaier AH. The plasma kallikrein-kinin system counterbalances the renin-angiotensin system. J Clin Invest. 2002;109:1007-1009.

23. Walters PE, Gaspari TA, Widdop RE. Angiotensin-(1-7) acts as a vasodepressor agent via angiotensin II type-2 receptors in conscious rats. Hypertension. 2005;45:960-966.

24. Shanmugam S, Corvol P, Gasc JM. Angiotensin II type-2 receptor mRNA expression in the developing cardiopulmonary system of the rat. Hypertension. 1996;28:91-97.

25. Nishimura H, Tsuji H, Masuda H, Nakagawa K, Nakahara Y, Kitamura H et al. Angiotensin II increases plasminogen activator inhibitor-1 and tissue factor mRNA expression without changing that of tissue-type plasminogen activator or tissue factor pathway inhibitor in cultured rat aortic endothelial cells. Thromb Haemost. 1997;77:1189-1195.

26. Yoshizumi M, Tsuji H, Nishimura H, Masuda H, Kunieda Y, Kawano H et al. Natriuretic peptides regulate the expression of tissue factor and PAI-1 in endothelial cells. Thromb Haemost. 1999;82:1497-1503.

27. Brown NJ, Agirbasli MA, Williams GH, Litchfield WR, Vaughan DE. Effect of activation and inhibition of the renin-angiotensin system on plasma PAI-1. Hypertension. 1998;32:965-671.

28. Mehta JL, Li DY, Yang H, Raizada MK. Angiotensin II and IV stimulate expression and release of plasminogen activator inhibitor-1 in cultured human coronary artery endothelial cells. $J$ Cardiovasc Pharmacol. 2002;39:789-794.

29. Brown NJ, Agirbasli M, Vaughan DE. Comparative effect of angiotensin-converting enzyme inhibition and angiotensin II type-1 receptor antagonism on plasma fibrinolytic balance in humans. Hypertension. 1999;34:285-290.

30. Brown NJ, Kumar S, Painter CA, Vaughan DE. ACE inhibition versus angiotensin type-1 receptor antagonism: differential effects on PAI-1 over time. Hypertension. 2002;40:859865.

31. Kerins DM, Hao Q, Vaughan DE. Angiotensin induction of PAI-1 expression in endothelial cells is mediated by the hexapeptide angiotensin IV.J Clin Invest. 1995;96:2515-2520.

32. Joseph K, Tholanikunnel BG, Kaplan AP. Activation of the bradykininforming cascade on endothelial cells: a role for heat shock protein 90. Int Immunopharmacol. 2002;2:18511859.

33. Moreira CR, Schmaier AH, Mahdi F, da Motta G, Nader HB, Shariat-Madar Z. Identification of prolylcarboxypeptidase as the cell matrix-associated prekallikrein activator. FEBS Lett. 2002;523:167-170.

34. Schmaier AH. The kallikrein-kinin and the renin-angiotensin systems have a multilayered interaction. Am J Physiol Regul Integr Comp Physiol. 2003;285:R1-R13.

35. Pretorius M, Rosenbaum D, Vaughan DE, Brown NJ. Angiotensinconverting enzyme inhibition increases human vascular tissue-type plasminogen activator release through endogenous bradykinin. Circulation. 2003;107:579-585.

36. Van den Eijnden-Schrauwen Y, Kooistra T, de Vries RE, Emeis JJ. Studies on the acute release of tissue-type plasminogen activator from human endothelial cells in vitro and in rats in vivo: evidence for a dynamic storage pool. Blood. 1995;85:3510-3517.

37. Gailani D, Broze GJ Jr. Factor XI activation in a revised model of blood coagulation. Science. 1991;253:909-912. 
38. Kohler HP, Carter AM, Stickland MH, Grant PJ. Levels of activated FXII in survivors of myocardial infarction-association with circulating risk factors and extent of coronary artery disease. Thromb Haemost. 1998;79:14-18.

39. Cooper JA, Miller GJ, Bauer KA, Morrissey JH, Meade TW, Howarth DJ et al. Comparison of novel hemostatic factors and conventional risk factors for prediction of coronary heart disease. Circulation. 2000;102:2816-2822.

40. Grundt H, Nilsen DW, Hetland O, Valente E, Fagertun HE. Activated factor 12 (FXIIa) predicts recurrent coronary events after an acute myocardial infarction. Am Heart J. 2004;147:260266.

41. Hoffmeister HM, Jur M, Wendel HP, Heller W, Seipel L. Alterations of coagulation and fibrinolytic and kallikrein-kinin systems in the acute and postacute phases in patients with unstable angina pectoris. Circulation. 1995;91:2520-2527.

42. Schousboe I. Factor XIIa activation of plasminogen is enhanced by contact activating surfaces and Zn2. Blood Coagul Fibrinolysis. 1997;8:97-104.

43. Braat EA, Dooijewaard G, Rijken DC. Fibrinolytic properties of activated FXII. Eur J Biochem. 1999;263:904-911.

44. Erdem Y, Usalan C, Haznedaroglu IC, Altun B, Arici M, Yasavul U et al. Effects of angiotensin converting enzyme and angiotensin II receptor inhibition on impaired fibrinolysis in systemic hypertension. Am J Hypertens. 1999;12:1071-1076.

45. Hasan AA, Amenta S, Schmaier AH. Bradykinin and its metabolite, Arg-Pro-Pro-Gly-Phe, are selective inhibitors of alpha-thrombin-induced platelet activation. Circulation. 1996;94:517528.

46. Nieman MT, Pagan-Ramos E, Warnock M, Krijanovski Y, Hasan AA, Schmaier AH. Mapping the interaction of bradykinin 1-5 with the exodomain of human protease activated receptor 4. FEBS Lett. 2005;579:25-29.

47. Sealey JE, Atlas SA, Laragh JH, Oza NB, Ryan JW. Human urinary kallikrein converts inactive to active renin and is a possible physiological activator of renin. Nature.1978;275:144-145.

48. Sealey JE, Atlas SA, Laragh JH. Linking the kallikrein and renin systems via activation of inactive renin: new data and a hypothesis. Am J Med. 1978;65:994-1000.

49. Azizi M, Guyene TT, Chatellier G, Wargon M, Menard J. Additive effects of losartan and enalapril on blood pressure and plasma active renin. Hypertension. 1997;29:634-640.

50. Taddei S, Virdis A, Ghiadoni L, Salvetti G, Salvetti A. Endothelial dysfunction in hypertension. J Nephrol. 2000;13:205-210.

51. Staessen JA, Wang J, Bianchi G, Birkenhager WH. Essential hypertension. Lancet. 2003;361:1629-1641.

52. Walters J, Skene D, Hampton SM, Ferns GA. Biological rhythms, endothelial health and cardiovascular disease. Med Sci Monit. 2003;9:RA1-RA8.

53. Palmgren E, Widgren B, Aurell M, Herlitz $H$. Increased renal vascular sensitivity to angiotensin II in hypertension is due to decreased response to prostaglandins. J Hypertens. 2003;21:969-976.

54. Goodfield NE, Newby DE, Ludlam CA, Flapan AD. Effects of acute angiotensin II type-1 receptor antagonism and angiotensin converting enzyme inhibition on plasma fibrinolytic parameters in patients with heart failure. Circulation. 1999;99:2983-2985.

55. Makris TK, Stavroulakis GA, Krespi PG, Hatzizacharias AN, Triposkiadis FK, Tsoukala CG et 
al. Fibrinolytic/hemostatic variables in arterial hypertension: response to treatment with irbesartan or atenolol. Am J Hypertens. 2000;13:783-788.

56. Willoughby S, Holmes A, Loscalzo J. Platelets and cardiovascular disease. Eur J Cardiovasc Nurs. 2002;1:273-288.

57. Ekholm M, Wallen NH, Johnsson $\mathrm{H}$, Eliasson K, Kahan T. Long-term angiotensin-converting enzyme inhibition with ramipril reduces thrombin generation in human hypertension. Clin Sci (Lond). 2002;103:151-155.

58. Napoleone E, Di Santo A, Camera M, Tremoli E, Lorenzet R. Angiotensin-converting enzyme inhibitors downregulate tissue factor synthesis in monocytes. Circ Res. 2000;86:139-143.

59. Fogari R, Zoppi A, Preti P, Fogari E, Malamani G, Mugellini A. Differential effects of ACEinhibition and angiotensin II antagonism on fibrinolysis and insulin sensitivity in hypertensive postmenopausal women. Am J Hypertens. 2001;14:921-926.

60. Seljeflot I, Moan A, Kjeldsen S, Sandvik E, Arnesen H. Effect of angiotensin II receptor blockade on fibrinolysis during acute hyperinsulinemia in patients with essential hypertension. Hypertension. 1996;27:1299-1304.

61. Sawathiparnich P, Murphey LJ, Kumar S, Vaughan DE, Brown NJ. Effect of combined AT1 receptor and aldosterone receptor antagonism on plasminogen activator inhibitor-1. J Clin Endocrinol Metab. 2003;88:3867-3873.

62. Kalinowski L, Matys T, Chabielska E, Buczko W, Malinski T. Angiotensin II AT1 receptor antagonists inhibit platelet adhesion and aggregation by nitric oxide release. Hypertension. 2002;40:521-527.

63. Schwemmer M, Sommer 0, Bassenge E. Angiotensin receptor blocker losartan suppresses platelet activity by interfering with thromboxane signaling. Cardiovasc Drugs Ther. 2001;15:301-307. 
Chapter 5.2

\section{Correction of the hypertension-induced hypercoagulable state}

Changes in fibrinolytic activity after angiotensin II receptor blockade in therapy-resistant hypertensive patients.

Dielis AWJH ${ }^{1}$, Smid $\mathrm{M}^{1}$, Spronk HMH ${ }^{1}$, Houben AJHMㄹ, Hamulyák $\mathrm{K}^{3}$, Kroon $\mathrm{AA}^{2}$, ten Cate $\mathrm{H}^{1}$, de Leeuw $\mathrm{PW}^{2}$.

1 Department of Internal Medicine, Laboratory for Clinical Thrombosis and Haemostasis, Cardiovascular Research Institute Maastricht, Maastricht University Medical Center, Maastricht, The Netherlands;

2 Department of Internal Medicine, Maastricht University Medical Center, Maastricht, The Netherlands;

3 Department of Internal Medicine, Division of Haematology, Maastricht University Medical Center, Maastricht, The Netherlands.

Journal of Thrombosis and Haemostasis. 2007;5:509-515. 


\section{Summary}

Background: In hypertensive patients, the activated renin-angiotensin system induces a prothrombotic state resulting from imbalance between coagulation and fibrinolysis. Although blood pressure cannot be regulated in therapyresistant hypertensive patients, they may still be responsive to medication that attenuates the renin-angiotensin system.

Objective: Our objective was to study possible attenuating properties of angiotensin II type-1 receptor blockers (AT1RBs) on the prothrombotic state in therapy-resistant hypertensive patients, focusing on parameters of fibrinolysis and coagulation.

Methods: Fourteen therapy-resistant hypertensive patients received AT1RB eprosartan infusion (45 and $150 \mu \mathrm{g} \mathrm{kg}-1$ ) (study group), and 33 therapy-resistant hypertensive patients received saline (0.9\%) infusion (control group) prior to renal angiography. Baseline values of parameters of coagulation and fibrinolysis were set at 1.00 , and relative changes were calculated.

Results: Plasminogen activator inhibitor type-1 (PAI-1) antigen showed nonsignificant decreases in both the study group (arterial 1.00-0.45, venous 1.00-0.42) and control group (arterial 1.00-0.84, venous 1.00-0.88). PAI-1 activity significantly decreased in the study group (arterial 1.00-0.72, venous 1.00-0.71) and control group (arterial 1.00-0.83, venous 1.00-0.94). In the study group, tissue-type plasminogen activator (t-PA) antigen decreased significantly (arterial 1.00-0.62, venous 1.00-0.67), whereas t-PA activity significantly increased (arterial 1.00-6.15, venous 1.00-2.66). In the control group, t-PA antigen remained unchanged. No changes were observed in blood pressure during and after infusion of eprosartan.

Conclusion: Therapy-resistant hypertensive patients show beneficial changes in fibrinolytic activity after infusion of a non-pressor dose of AT1RB. 


\section{Introduction}

Hypertension is a major risk factor for thrombotic events such as myocardial infarction and stroke, reflecting a "prothrombotic state" that is present in hypertensive patients. ${ }^{1}$ This prothrombotic state represents a shift in the balance between fibrinolysis and coagulation (Chapter 5.1).1,2

Fibrinolysis is the degradation of fibrin by plasmin upon the activation of plasminogen into plasmin by tissue-type plasminogen activator ( $t-P A$ ), the physiological activator of fibrinolysis. Fibrinolytic activity is determined by the balance between t-PA and plasminogen activator inhibitor type-1 (PAI-1). ${ }^{3}$ PAI-1/t-PA complex formation reduces fibrinolytic activity through inhibition of plasminogen activation. ${ }^{3}$ Tissue factor (TF) is an important physiological initiatior of coagulation. Upon exposure to circulating factor VIIa, the TF pathway leads to thrombin generation, which in turn converts fibrinogen into fibrin. ${ }^{4}$

In hypertension, activation of the vascular renin-angiotensin system is more pronounced, and this system influences not only vascular tone, but also fibrinolysis and coagulation (Chapter 5.1). ${ }^{1,5,6}$ Angiotensin II (Ang II) exerts its effect via the Ang II type-1 (AT1) receptor in the vascular bed. Stimulation of the AT1 receptor results in an increase in PAI-1 release fromendothelial cells and nuclear transcription factor $\kappa B-$ induced TF synthesis, thereby modifying the balance between fibrinolysis and coagulation to a procoagulant state.7,8

Antihypertensive agents targeting the renin-angiotensin system decrease blood pressure and, in addition, reduce the incidence of thrombotic events and cardiovascular mortality.9,10 Angiotensin-converting enzyme inhibitors (ACEIs) and AT1 receptor blockers (AT1RBs), which are widely used antihypertensive medications, may reverse the balance between coagulation and fibrinolysis, via either decreased production of Ang II or interference with the AT1 receptor. In animal, human and cell culture studies, AT1RBs have been found to reduce PAI-1 activity (PAI-1:act) and TF activity. ${ }^{5,6}$ In patients, however, ACEIs do not block the renin-angiotensin system completely, as there is another Ang II-producing enzyme: chymase. As a result, there will still be a certain amount of Ang II to induce effects via the AT1 receptor. ${ }^{11}$

Therapy-resistant hypertensive patients are not or less susceptible to blood pressure-lowering effects of antihypertensive agents, as they fail to show a desired decrease in blood pressure. We hypothesize that therapy-resistant hypertensive patients, regardless of smaller or no noticeable effects on blood pressure, are still responsive to AT1 receptor-mediated effects on fibrinolysis, and benefit from treatment with AT1RB by showing ameliorating changes in their prothrombotic state.

The aim of our study was to investigate changes in parameters of coagulation and fibrinolysis after administration of AT1RB in therapy-resistant hypertensive patients. 


\section{Methods}

\section{Study population}

Hypertensive patients were recruited from the Vascular Center of the Departments of Internal Medicine and Cardiology at the University Hospital Maastricht, The Netherlands. This facility is a referral center for evaluation of therapy-resistant hypertension. In the Vascular Center, these patients undergo a standard work-up, including laboratory tests and medical investigations that include renal artery angiography to exclude renal artery stenosis as the cause of (secondary) therapyresistant hypertension. Hypertension was defined as systolic blood pressure $>140 \mathrm{mmHg}$ or diastolic blood pressure $>90 \mathrm{mmHg}$ on at least three occasions. Patients had an indication for renal angiography when one or more of the following criteria were fulfilled: persistent elevation of blood pressure despite the use of two or more antihypertensive drugs, accelerated hypertension, documented atherosclerotic vascular disease in two or more vascular beds, the presence of abdominal bruit, or unexplained impairment of renal function in response to antihypertensive treatment.

At the time of angiography, all antihypertensive treatment and statins had been withdrawn for 3 weeks. The study protocol was approved by the local medical ethics committee and all subjects gave informed consent.

\section{Study design}

Prior to the administration of contrast agents for the actual angiography, indwelling femoral catheters were placed and located in the aorta and right renal vein, and blood samples were taken for baseline measurements. Next, the arterial catheter was relocated in the right renal artery. Through the arterial catheter, patients received infusion of either the AT1RB eprosartan (Solvay Pharma BV, Weesp, The Netherlands) (study group), or saline $[0.9 \%(\mathrm{w} / \mathrm{v}) \mathrm{NaCl}]$ (control group). After infusion, blood was sampled through both the arterial and venous catheters. This design with both arterial and venous catheters enables local administration of AT1RB to the renal vascular bed, and caters for comparison between arterial and venous samples, and investigation of local renal vascular endothelial influences of the renin-angiotensin system on fibrinolysis parameters.

Eprosartan was infused in two cumulative doses of $45 \mu \mathrm{g} \mathrm{kg}^{-1}$ (low dose) and $150 \mu \mathrm{g}$ $\mathrm{kg}^{-1}$ (high dose) in a total time of 30 minutes. Saline was also infused for 30 minutes. Samples were taken according to the following time path: at baseline (T0), after lowdose eprosartan infusion (T1), and after high-dose eprosartan or saline infusion (T2). Blood was drawn in 3.2\% (w/v) citrated tubes (Greiner Bio-One AG, Kremsmuenster, Austria) and Stabilyte tubes (Biopool, Umea, Sweden). At the start of infusion, blood 
pressure was measured oscillometrically using a Dinamap (Critikon; GE Healthcare, Hoevelaken, The Netherlands). After the infusions, the renal angiography was performed. All procedures were performed between 9.00 AM and 11.30 AM.

Initial analysis of changes in parameters of fibrinolysis consisted of measurements of PAI-1:act, t-PA antigen (t-PA:ag) and plasmin-antiplasmin complex (PAP). To determine changes in parameters of coagulation, D-dimer, thrombin-antithrombin complex (TAT) and activated FXII (FXIIa) were included. Endothelial cell activation was assessed using a von Willebrand factor antigen (VWF:ag) assay. These assays were initially performed on 14 patients in the study group and 13 patients in the control group. The results for the fibrinolysis parameters in the study group warranted extension of measurements with PAI-1 antigen (PAI-1:ag) and t-PA activity (t-PA:act). For this purpose, the control group was extended by 20 subjects to a total of 33 subjects.

\section{Laboratory methods}

Platelet-poor plasma samples were prepared by two-step centrifugation at $2000 \mathrm{~g}$ for five minutes at room temperature and at $11000 \mathrm{~g}$ for 10 minutes at $18^{\circ} \mathrm{C}$, and aliquots were stored at $-80^{\circ} \mathrm{C}$ until analysis.

Measurements of t-PA:act (Chromolize, Trinity Biotech, Bray, Ireland), t-PA:ag (Imulyse, Trinity Biotech), PAI-1:act (Chromolize, Trinity Biotech), PAI-1:ag (Technoclone GmbH, Vienna, Austria), TAT (Enzygnost, Dade Behring Inc., Liederbach,Germany), D-dimer (D-Dimer Plus, Dade Behring Inc.), FXIIa (Axis-Shield, Dundee, United Kingdom) and VWF:ag (Dade Behring Inc.) were performed according to the manufacturer's instructions.

\section{Statistical analysis}

Data are presented and depicted as median (interquartile range), with the $95 \%$ confidence interval (CI) being reported for the difference between T0 and T2 (95\% CI $\Delta$ ) for statistical tests in the tables. Because measured parameters are known to show wide interindividual variation, relative changes were calculated for the effects of eprosartan and saline infusion. Therefore, baseline measurements are reported as 1.00 and depicted as 1 in the figures. The effect of treatment on parameters of coagulation and fibrinolysis and differences between arterial and venous samples were analyzed using the non-parametric Wilcoxon's signed ranks test. Differences between samples from the study group and the control group were analyzed using the Mann-Whitney U-test. The influence of serum creatinine and lipid profile [total cholesterol, highdensity lipoprotein (HDL), low-density lipoprotein (LDL) and triglycerides] on parameters of fibrinolysis was studied using multiple regression analysis. A two-tailed probability value of $P<0.05$ was considered to be statistically significant. 
Chapter 5.2

Statistics were computed using SPSS version 12 for Windows (SPSS Inc., Chicago, IL, USA). 


\section{Results}

\section{Study population}

In total, 47 patients were included in the study, of whom 14 received eprosartan infusion and 33 subjects received saline infusion. The mean age of the study group was 62 years (range $40-76$ years), and $43 \%(n=6)$ of the patients were male. For the control group, the mean age was 53 years (range 28-75 years), and $42 \%(n=13)$ of the patients were male. The serum creatinine levels and lipid profiles of both groups were similar and within reference ranges, although in the study group more patients were treated with statins. Baseline blood pressure measurements, serum creatinine level, lipid profile and drug therapy are presented in Table 1.

\section{Blood pressure management and measurement}

All patients in our study except three were treated with one or more antihypertensive medications prior to cessation of these drugs. The average number of medications used was 2.2. In the study group, $38.5 \%$ of patients were treated with an ACEI and $30.8 \%$ with an AT1RB, whereas all of these patients received treatment with at least one other antihypertensive (diuretic, $\beta$-blocker, calcium antagonist). In the control group, 32.3\% received treatment with an ACEI and $38.7 \%$ with an AT1RB. Among the control patients, $77.4 \%$ were treated with at least one other antihypertensive.

During and after infusion of eprosartan, no changes were observed in blood pressure and heart rate (data not shown), indicating the absence of a systemic haemodynamic influence of the local renal infusion.

\section{Fibrinolysis}

Table 2 provides baseline characteristics for both the study and the control group regarding markers of fibrinolysis. At baseline, groups were comparable except for PAP, which was significantly higher in the control group than in the study group. PAI-1:ag ranges were wide, but did not differ significantly between groups.

Table 3 gives the results after eprosartan and saline infusion. After eprosartan and saline infusion, PAI-1:ag tended to decrease in both the study group (arterial 1.00-0.45, venous 1.00-0.42) and the control group (arterial 1.00-0.84, venous 1.00-0.88), although the data were not statistically significant. In the study group, all subjects showed a decrease of 0.5 or more (which was not observed in the control group), in contrast to four patients who showed an increase in PAI-1:ag. PAI-1:act decreased in both groups (study group, arterial 1.00-0.72, venous 1.00-0.71; control group, arterial 
Table 1. Baseline characteristics of study populations.

\begin{tabular}{|c|c|c|c|c|}
\hline \multirow{2}{*}{$\bar{n}$} & \multicolumn{2}{|c|}{ Study group (eprosartan) } & \multicolumn{2}{|c|}{ Control group (saline) } \\
\hline & 14 & & 33 & \\
\hline Mean age (years) & 62 & $(40-76)$ & $53^{*}$ & $(28-75)$ \\
\hline \multicolumn{5}{|l|}{ Sex } \\
\hline Male (\%) & 42.9 & & 42.4 & \\
\hline Female (\%) & 57.1 & & 57.6 & \\
\hline \multicolumn{5}{|l|}{ Blood pressure } \\
\hline Systolic (mmHg) & 193 & $(166-214)$ & 192 & $(161-211)$ \\
\hline Diastolic (mmHg) & 101 & $(86-117)$ & 101 & $(87-108)$ \\
\hline Serum creatinine $\left(\mu \mathrm{mol} \mathrm{L}^{-1}\right)$ & 88.0 & $(76.0-118.0)$ & 86.5 & $(70.5-118.0)$ \\
\hline \multicolumn{5}{|l|}{ Lipid profile } \\
\hline Total cholesterol $\left(\mathrm{mmol} \mathrm{L}^{-1}\right)$ & 5.0 & $(4.2-6.2)$ & 4.6 & $(4.0-5.8)$ \\
\hline $\mathrm{HDL}\left(\mathrm{mmol} \mathrm{L}^{-1}\right)$ & 1.1 & $(0.8-1.3)$ & 1.3 & $(1.1-1.6)$ \\
\hline $\mathrm{LDL}\left(\mathrm{mmol} \mathrm{L}^{-1}\right)$ & 3.4 & $(2.7-4.1)$ & 2.4 & $(2.0-3.7)$ \\
\hline Triglycerides $\left(\mathrm{mmol} \mathrm{L}^{-1}\right)$ & 1.7 & $(1.3-2.4)$ & 1.3 & $(1.0-2.2)$ \\
\hline \multicolumn{5}{|l|}{ Drug therapy } \\
\hline \multicolumn{5}{|c|}{ Number of antihypertensive medications } \\
\hline $0-2(\%)$ & 61.5 & & 64.5 & \\
\hline 3 or more (\%) & 38.5 & & 35.5 & \\
\hline \multicolumn{5}{|c|}{ Specific antihypertensive medication } \\
\hline ACEI (\%) & 38.5 & & 32.3 & \\
\hline AT1RB (\%) & 30.8 & & 38.7 & \\
\hline Other (\%) & 100.0 & & 77.4 & \\
\hline \multicolumn{5}{|l|}{ Other medication } \\
\hline Statin (\%) & 69.2 & & $35.5^{*}$ & \\
\hline Thiazolidinediones (\%) & 0.0 & & 0.0 & \\
\hline
\end{tabular}

HDL, high-density lipoprotein; LDL, low-density lipoprotein; ACEl, angiotensin-converting enzyme inhibitor; AT1RBs, AT1 receptor blockers. Data are presented as mean (range) for age, and as median (interquartile range) for other parameters, unless otherwise stated. * denotes $P<0.05$ compared with study group.

$1.00-0.83$, venous $1.00-0.94)$, with a more pronounced decrease being seen in the study group ( $P$ for the difference between study group and control group: arterial $P=0.05$, venous $P=0.02$ ). t-PA:ag decreased after eprosartan infusion (arterial 1.00-0.62, venous 1.00-0.67), whereas no difference was noted after saline infusion. To study the effect of decreased t-PA:ag on fibrinolytic activity in the study group following eprosartan infusion, t-PA:act was measured. t-PA:act was found to increase (arterial 1.00-6.15, venous 1.00-2.66) (Figure 1A, B). 
Table 2. Baseline measurements of markers of coagulation, vascular endothelial cell activation and fibrinolysis.

\begin{tabular}{|c|c|c|c|c|}
\hline \multirow{2}{*}{$\overline{F X I l a ~}\left(\mu \mathrm{g} L^{-1}\right)$} & \multicolumn{2}{|c|}{ Study group (eprosartan) } & \multicolumn{2}{|c|}{ Control group (saline) } \\
\hline & & & & \\
\hline$n$ & 14 & & 13 & \\
\hline \multirow{2}{*}{$\begin{array}{l}\text { T0 art } \\
\text { ven }\end{array}$} & 0.6 & $(0.4-0.7)$ & 0.7 & $(06 .-0.9)$ \\
\hline & 0.5 & $(0.4-0.6)$ & 0.7 & $(0.5-1.0)$ \\
\hline \multicolumn{5}{|c|}{$D-\operatorname{dimer}\left(\mu g \mathrm{~L}^{-1}\right)$} \\
\hline$n$ & 14 & & 13 & \\
\hline \multirow{2}{*}{$\begin{array}{l}\text { TO art } \\
\text { ven }\end{array}$} & 165.5 & $(104.0-205.5)$ & 151.0 & $(103.0-220.0)$ \\
\hline & 164.0 & $(101.0-204.0)$ & 138.0 & $(96.0-218.0)$ \\
\hline \multicolumn{5}{|l|}{ TAT $\left(\mu g \mathrm{~L}^{-1}\right)$} \\
\hline$n$ & 14 & & 13 & \\
\hline \multirow{2}{*}{$\begin{array}{l}\text { TO art } \\
\text { ven }\end{array}$} & 12.6 & (8.2-21.9) & $5.0^{*}$ & $(3.6-10.2)$ \\
\hline & 16.3 & (7.1-37.9) & $3.5^{*}$ & $(2.7-14.7)$ \\
\hline \multicolumn{5}{|l|}{ VWF:ag (\%) } \\
\hline$n$ & 14 & & 13 & \\
\hline \multirow{2}{*}{$\begin{array}{l}\text { TO art } \\
\text { ven }\end{array}$} & 160.5 & $(119.8-177.8)$ & 128.0 & $(102.0-171.0)$ \\
\hline & 145.5 & $(126.5-178.5)$ & 131.0 & $(103.0-171.0)$ \\
\hline \multicolumn{5}{|l|}{$\operatorname{PAP}\left(\mu \mathrm{g}^{-1}\right)$} \\
\hline$n$ & 14 & & 20 & \\
\hline \multirow{2}{*}{$\begin{array}{l}\text { TO art } \\
\text { ven }\end{array}$} & 13.3 & $(9.7-22.3)$ & $29.1^{*}$ & $(21.0-41.4)$ \\
\hline & 17.5 & $(12.1-31.7)$ & $29.7^{*}$ & $(22.2-43.5)$ \\
\hline \multicolumn{5}{|c|}{ PAl-1:ag $\left(\mu g \mathrm{~L}^{-1}\right)$} \\
\hline$n$ & 14 & & 20 & \\
\hline \multirow{2}{*}{$\begin{array}{l}\text { TO art } \\
\text { ven }\end{array}$} & 18.7 & $(5.3-28.4)$ & 19.7 & $(8.5-46.6)$ \\
\hline & 8.6 & $(4.2-22.6)$ & 27.2 & $(12.7-50.6)$ \\
\hline \multicolumn{5}{|c|}{ PAI-1:act $\left(\mathrm{U} \mathrm{mL}^{-1}\right)$} \\
\hline$n$ & 14 & & 13 & \\
\hline \multirow{2}{*}{$\begin{array}{l}\text { T0 art } \\
\text { ven }\end{array}$} & 7.1 & (3.9-15.1) & 4.9 & $(2.0-8.3)$ \\
\hline & 6.6 & $(3.2-15.3)$ & 4.2 & $(1.6-7.2)$ \\
\hline \multicolumn{5}{|c|}{ t-PA:ag $\left(\mu \mathrm{g} \mathrm{L}^{-1}\right)$} \\
\hline$n$ & 14 & & 13 & \\
\hline \multirow{2}{*}{$\begin{array}{l}\text { TO art } \\
\text { ven }\end{array}$} & 10.5 & (8.8-11.0) & 8.9 & $(7.8-10.9)$ \\
\hline & 10.8 & $(8.7-11.6)$ & 10.0 & $(7.3-11.5)$ \\
\hline \multicolumn{5}{|c|}{ t-PA:act $\left(\mathrm{U} \mathrm{mL}^{-1}\right)$} \\
\hline$n$ & 14 & & - & \\
\hline \multirow{2}{*}{$\begin{array}{l}\text { TO art } \\
\text { ven }\end{array}$} & 1.9 & $(0.3-7.4)$ & - & \\
\hline & 4.9 & $(0.6-30.8)$ & - & \\
\hline
\end{tabular}

art, arterial; ven, venous; TAT, thrombin-antithrombin complex; VWF:ag, von Willebrand factor antigen; PAP, plasmin-antiplasmin complex; PAI-1:ag, plasminogen activator inhibitor type-1 antigen; PAl-1:act, plasminogen activator inhibitor type-1 activity; t-PA:ag, tissue-type plasminogen activator antigen; t-PA:act, tissue-type plasminogen activator activity. Data are presented as median (interquartile range). * denotes $P<0.05$ compared with study group; reference ranges are not available for renal artery and renal vein blood samples. 
No changes were observed in PAP levels after infusion of either eprosartan or saline. For all parameters of fibrinolysis, ratios were calculated for arterial and venous samples, and are reported as art/ven in Table 3. Except for PAP and t-PA:act, with arterial samples lower than venous samples at T0 and increasing towards 1.00 at T2, all art/ven were approximately 1.00 .

To assess a possible effect of antihypertensive treatments and the use of statins prior to the 3-week wash-out period, parameters of fibrinolysis were compared between patients who received either statins, ACEIs, AT1RBs, $\beta$-blockers, calcium antagonists or thiazides, and patients who did not, but no differences were observed.

Multiple linear regression analysis revealed LDL and triglycerides as predictors of baseline PAI-1:ag in the control group, but they did not influence changes in time. None of the other variables (creatinine, total cholesterol and HDL) were predictors of other fibrinolysis parameters in any group at any time point (data not shown).

\section{Coagulation and endothelial cell activation}

Table 2 provides baseline subject characteristics for both study and control groups regarding markers of coagulation and endothelial cell activation. At baseline, groups were comparable except for TAT, which was significantly higher in the study group than in the control group.

Table 4 shows the results after eprosartan and saline infusion. FXIIa increased in both the study group (arterial 1.00-1.50, venous 1.00-1.55) and the control group(arterial 1.00-1.29, venous 1.00-1.25). TAT tended to decrease after infusion of eprosartan (arterial 1.00-0.48, venous 1.00-0.30) and saline (arterial 1.00-0.76, venous 1.00-0.69), although the data were not significant.

No changes were observed in either group for D-dimer and VWF:ag. Calculated ratios for arterial and venous samples were approximately 1.00, with no changes between T0 and $\mathrm{T} 2$. 
Figure 1. Effect of the angiotensin II type-1 receptor blocker eprosartan on tissue-type plasminogen activator (t-PA). (A) t-PA antigen (t-PA:ag) in the study group. (B) t-PA activity (t-PA:act) in the study group. Data at T2 are depicted relative to T0 (set at 1).

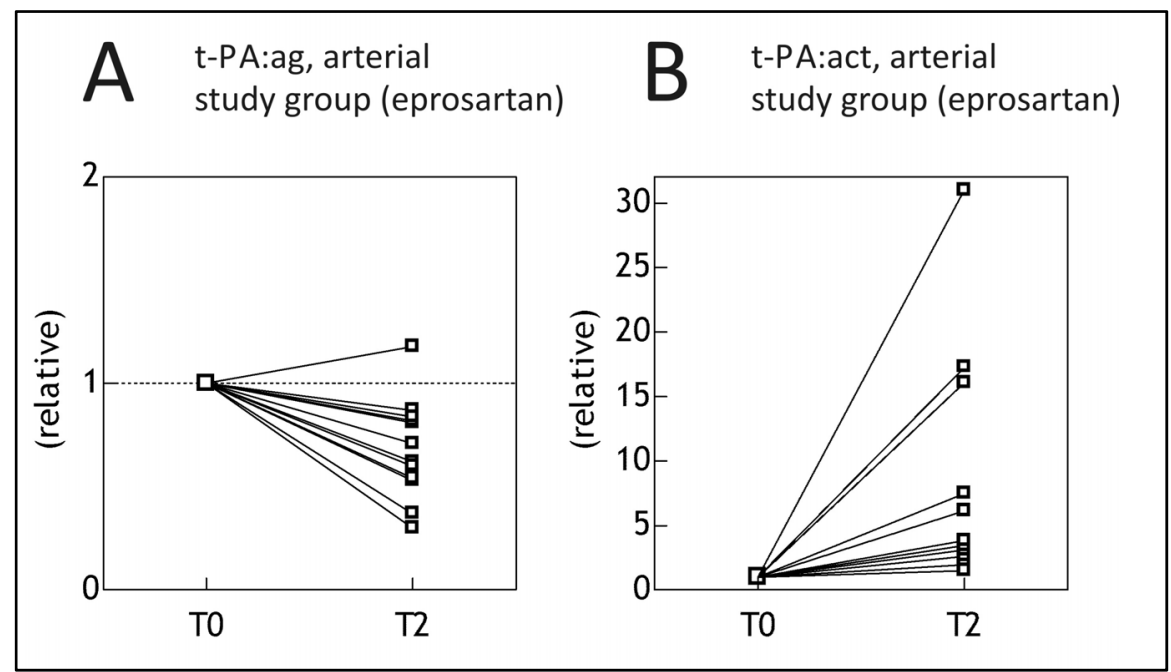


Table 3. Effect of the angiotensin II type-1 receptor blocker eprosartan on markers of fibrinolysis.

\begin{tabular}{|c|c|c|c|c|}
\hline & \multicolumn{2}{|c|}{ Study group (eprosartan) } & \multicolumn{2}{|c|}{ Control group (saline) } \\
\hline & relative & art/ven & relative & art/ven \\
\hline \multicolumn{5}{|l|}{ PAP } \\
\hline \multirow{2}{*}{$\begin{array}{r}\text { T0 art } \\
\text { ver }\end{array}$} & 1.00 & 0.72 & 1.00 & 1.02 \\
\hline & 1.00 & - & 1.00 & - \\
\hline \multirow{2}{*}{$\begin{array}{l}\text { T2 art } \\
\text { ven }\end{array}$} & $1.30(1.17-1.39)$ & $1.07^{*}$ & $0.96(0.91-1.06)$ & 0.99 \\
\hline & $0.92(0.64-1.26)$ & - & $0.99(0.93-1.04)$ & - \\
\hline \multicolumn{5}{|l|}{$95 \% \mathrm{Cl} \Delta$} \\
\hline art & $-0.08-0.48$ & $0.02-0.61$ & $-0.06-0.02$ & $-0.06-0.06$ \\
\hline ven & $-0.41-0.31$ & - & $-0.07-0.03$ & - \\
\hline \multicolumn{5}{|l|}{ PAI-1:ag } \\
\hline \multirow{2}{*}{$\begin{array}{r}\text { T0 art } \\
\text { ven }\end{array}$} & 1.00 & 1.03 & 1.00 & 1.12 \\
\hline & 1.00 & - & 1.00 & - \\
\hline \multirow{2}{*}{$\begin{array}{l}\text { T2 art } \\
\text { ven }\end{array}$} & $0.45(0.17-6.49)$ & 1.10 & $0.84(0.61-1.28)$ & 0.96 \\
\hline & $0.42(0.12-5.99)$ & - & $0.88(0.63-1.66)$ & - \\
\hline \multicolumn{5}{|l|}{$95 \% \mathrm{Cl} \Delta$} \\
\hline art & $-0.61-7.61$ & $-0.10-0.53$ & $-1.54-4.52$ & $-0.43-0.07$ \\
\hline ven & $-0.30-6.70$ & - & $-1.96-6.74$ & - \\
\hline \multicolumn{5}{|l|}{ PAI-1:act } \\
\hline \multirow{2}{*}{$\begin{array}{l}\text { T0 art } \\
\text { ven }\end{array}$} & 1.00 & 1.05 & 1.00 & 1.13 \\
\hline & 1.00 & - & 1.00 & - \\
\hline \multirow{2}{*}{$\begin{array}{l}\text { T2 art } \\
\text { ven }\end{array}$} & $0.72 *(0.44-0.77)$ & 1.04 & $0.83 *(0.71-0.89)$ & 1.02 \\
\hline & $0.71 *(0.48-0.83)$ & - & $0.94 *(0.75-1.00)$ & - \\
\hline \multicolumn{5}{|l|}{$95 \% \mathrm{Cl} \Delta$} \\
\hline art & $-0.47--0.23$ & $-0.08-0.06$ & $-0.27--0.12$ & $-0.22-0.14$ \\
\hline ven & $-0.45--0.22$ & - & $-0.28--0.01$ & - \\
\hline \multicolumn{5}{|l|}{ t-PA:ag } \\
\hline \multirow{2}{*}{$\begin{array}{l}\text { T0 art } \\
\text { ven }\end{array}$} & 1.00 & 0.97 & 1.00 & 0.94 \\
\hline & 1.00 & - & 1.00 & - \\
\hline \multirow{2}{*}{$\begin{array}{l}\text { T2 art } \\
\text { ven }\end{array}$} & $0.62 *(0.54-0.82)$ & 0.94 & $0.95(0.83-1.06)$ & 0.95 \\
\hline & $0.67 *(0.56-0.81)$ & - & $0.97(0.84-1.07)$ & - \\
\hline \multicolumn{5}{|l|}{$95 \% \mathrm{Cl} \Delta$} \\
\hline art & $-0.46--0.18$ & $-0.09-0.02$ & $-0.18-0.05$ & $-0.09-0.08$ \\
\hline ven & $-0.48--0.21$ & - & $-0.20-0.08$ & - \\
\hline \multicolumn{5}{|l|}{ t-PA:act } \\
\hline \multirow{2}{*}{$\begin{array}{l}\text { T0 art } \\
\text { ven }\end{array}$} & 1.00 & 0.43 & - & - \\
\hline & 1.00 & - & - & - \\
\hline \multirow{2}{*}{$\begin{array}{l}\text { T2 art } \\
\text { ven }\end{array}$} & $6.15^{*}(3.10-17.3)$ & $0.70^{*}$ & - & - \\
\hline & $2.66 *(1.89-9.78)$ & - & - & - \\
\hline \multicolumn{5}{|l|}{$95 \% \mathrm{Cl} \Delta$} \\
\hline art & $2.49-25.2$ & $0.18-0.46$ & - & - \\
\hline ven & $2.54-21.8$ & - & - & - \\
\hline
\end{tabular}

PAP, plasmin-antiplasmin complex; PAl-1:ag, plasminogen activator inhibitor type-1 antigen; PAl-1:act, plasminogen activator inhibitor type-1 activity; t-PA:ag, tissue-type plasminogen activator antigen; t-PA:act, tissue-type plasminogen activator activity. Data are presented relative to T0 (set at 1.00) as median (interquartile range). $95 \%$ Confidence intervals $(95 \% \mathrm{CI} \Delta)$ are given for differences between T0 and T2 for arterial samples, venous samples and ratios of arterial and venous measurements (art/ven). ${ }^{*}$ denotes $P<0.05$ compared with TO. 
Table 4. Effect of the angiotensin II type-1 receptor blocker eprosartan on markers of coagulation and vascular endothelial cell activation.

\begin{tabular}{|c|c|c|c|c|}
\hline & \multicolumn{2}{|c|}{ Study group (eprosartan) } & \multicolumn{2}{|c|}{ Control group (saline) } \\
\hline & relative & art/ven & relative & art/ven \\
\hline \multicolumn{5}{|l|}{ FXIlla } \\
\hline \multirow{2}{*}{ TO at } & 1.00 & 1.05 & 1.00 & 1.00 \\
\hline & 1.00 & - & 1.00 & - \\
\hline \multirow{2}{*}{$\begin{array}{l}\text { T2 art } \\
\text { ven }\end{array}$} & $1.50 *(1.00-1.63)$ & 1.00 & $1.29 *(1.14-1.50)$ & 1.00 \\
\hline & $1.55 *(1.10-1.77)$ & - & $1.25 *(1.14-1.33)$ & - \\
\hline \multicolumn{5}{|l|}{$95 \% \mathrm{Cl} \Delta$} \\
\hline art & $0.05-0.79$ & $-0.20-0.27$ & $0.11-0.81$ & $-0.20-0.06$ \\
\hline ven & $0.17-0.81$ & - & $0.04-0.87$ & - \\
\hline \multicolumn{5}{|l|}{ D-dimer } \\
\hline \multirow{2}{*}{$\begin{array}{l}\text { T0 art } \\
\text { ven }\end{array}$} & 1.00 & 1.03 & 1.00 & 1.01 \\
\hline & 1.00 & - & 1.00 & - \\
\hline \multirow{2}{*}{$\begin{array}{l}\text { T2 art } \\
\text { ven }\end{array}$} & $1.03(0.88-1.09)$ & 0.99 & $0.97(0.93-1.02)$ & 0.99 \\
\hline & $0.99(0.92-1.12)$ & - & $0.97(0.94-1.09)$ & - \\
\hline \multicolumn{5}{|l|}{$95 \% \mathrm{Cl} \Delta$} \\
\hline art & $-0.12-0.10$ & $-0.06-0.02$ & $-0.09-0.10$ & $-0.20-0.08$ \\
\hline ven & $-0.11-0.14$ & - & $-0.05-0.14$ & - \\
\hline \multicolumn{5}{|l|}{ VWF:ag } \\
\hline \multirow{2}{*}{$\begin{array}{r}\text { TO art } \\
\text { ven }\end{array}$} & 1.00 & 1.01 & 1.00 & 1.00 \\
\hline & 1.00 & - & 1.00 & - \\
\hline \multirow{2}{*}{$\begin{array}{l}\text { T2 art } \\
\text { ven }\end{array}$} & $1.01(0.98-1.07)$ & 1.01 & $1.01(0.98-1.05)$ & 1.00 \\
\hline & $1.00(0.98-1.04)$ & - & $1.01(0.97-1.10)$ & - \\
\hline \multicolumn{5}{|l|}{$95 \% \mathrm{Cl} \Delta$} \\
\hline art & $-0.02-0.07$ & $-0.04-0.05$ & $-0.02-0.10$ & $-0.04-0.04$ \\
\hline ven & $-0.03-0.06$ & - & $-0.01-0.08$ & - \\
\hline \multicolumn{5}{|l|}{ TAT } \\
\hline \multirow{2}{*}{$\begin{array}{l}\text { T0 art } \\
\text { ven }\end{array}$} & 1.00 & 0.79 & 1.00 & 0.99 \\
\hline & 1.00 & - & 1.00 & - \\
\hline \multirow{2}{*}{$\begin{array}{l}\text { T2 art } \\
\text { ven }\end{array}$} & $0.48(0.26-0.84)$ & 1.03 & $0.76(0.45-1.61)$ & 1.05 \\
\hline & $0.30(0.15-0.58)$ & - & $0.69(0.39-1.60)$ & - \\
\hline \multicolumn{5}{|l|}{$95 \% \mathrm{Cl} \Delta$} \\
\hline art & $-1.13-1.46$ & $-0.25-0.50$ & $-0.48-0.89$ & $-0.22-1.34$ \\
\hline ven & $-0.91-0.40$ & - & $-0.63-1.03$ & - \\
\hline
\end{tabular}

VWF:ag, von Willebrand factor antigen; TAT, thrombin-antithrombin complex. Data are presented relative to T0 (set at 1.00) as median (interquartile range). $95 \%$ Confidence intervals $(95 \% \mathrm{CI} \Delta)$ are given for differences between $\mathrm{T} 0$ and $\mathrm{T} 2$ for arterial samples, venous samples and ratios of arterial and venous measurements (art/ven). * denotes $P<0.05$ compared with T0. 


\section{Discussion}

The present study provides evidence that therapy-resistant hypertensive patients are responsive to the immediate effects of a non-pressor dose of the AT1RB eprosartan, showing changes in parameters of fibrinolytic function as reflected by decreased PAI-1:ag, PAI-1:act and t-PA:ag.

Several aspects of our observations need further comment. First, decreased t-PA:ag is known to correlate with a reduced incidence of atherothrombotic complications. ${ }^{12-14}$ This apparent paradox has been discussed extensively, and is thought to reflect decreased PAI-1/t-PA complex formation following decreased PAI-1 release from the endothelium.5,13,15 t-PA is cleared from the body faster when not complexed to PAI-1, and analysis of t-PA:ag includes both free and complexed t-PA. Therefore, t-PA:ag is expected to decrease with a concomitant increase in t-PA:act when less PAI- 1 is released. In the present study, we were able to confirm this increased fibrinolytic activity, as t-PA:act increased after eprosartan infusion. PAI-1:act was found to decrease in both the study group and the control group; however, the decrease was more pronounced after eprosartan infusion (arterial $-28 \%$ and venous $-29 \%$ after eprosartan infusion, and arterial $-6 \%$ and venous $-17 \%$ after saline infusion).

Second, PAI-1 and t-PA are known to have a circadian rhythm, with a decrease in PAI-1 levels and an increase in t-PA activity during the morning (Chapter 5.1). ${ }^{1}$ This circadian rhythm of PAI-1 and t-PA may explain the slight decrease that we found in t-PA:ag, PAI-1:ag and PAI-1:act in the control group, but these changes were only small $(-1 \%$ to $-17 \%)$ in comparison to the decreases in the study group $(-28 \%$ to $-58 \%)$. Therefore, it is not likely that the changes in PAI-1 and t-PA after the infusion of eprosartan in our study group are attributable to circadian variations of PAI-1 and t-PA. Moreover, infusions lasted for 30 minutes only, and all patients received the infusions within a relatively narrow time frame.

One may argue that the observed changes in PAI-1 and consequent changes in t-PA are the result of endothelial cell activation associated with the invasive procedure. The latter cannot be excluded completely, however, as we did not observe changes in VWF:ag as a marker of endothelial cell activation, the changes in PAI-1 and t-PA are most likely the result of blockade of the AT1 receptor-mediated pathways rather than endothelial cell activation.

Analysis of parameters that may influence fibrinolysis [specifically, lipid profile, lipid-lowering medication (statins) and antihypertensive medication] did not show involvement of these in the observed changes after AT1RB infusion, although we found a correlation between LDL and triglycerides with baseline PAI-1:ag in the control group. The increase in FXIIa may be attributed to the procedure of angiography and blood sampling. As the procedures followed include indwelling catheters, contact activation cannot be excluded, and this might be reflected in the FXIIa elevation, as both the study 
group and the control group showed the same changes. Although a marker of contact activation, FXIIa has been thought to be able to inhibit PAI-1:act through activation of FXI. FXIa, in turn, is able to form complexeswith PAI-1. ${ }^{16}$ Whether this causes the change in PAI-1:act in the control group could not be established in this study. We found no evidence of overt coagulation activity in the absence of any changes in D-dimer after the sampling procedure. TAT did not show a significant decrease, although there was a marked difference between the study group and the control group ( $-52 \%$ and $-70 \%$ compared to $-24 \%$ and $-31 \%$, respectively). A decrease in TAT after interference with the renin-angiotensin system through ACEIs has been described previously. ${ }^{17}$

Our study design focused on local renal infusion of low-dose AT1RB, to exclude systemic haemodynamic changes, and to possibly study the local renal influence on parameters of fibrinolysis and coagulation. To determine whether our measurements reflect local renal changes or systemic effects, we calculated ratios from arterial and venous data. As the ratios did not follow changes in PAI-1 and t-PA, we were not able to establish that the observed changes resulted from local effects solely. Therefore, a local contribution of the kidney on fibrinolysis in this experimental setup seems to be excluded.

In conclusion, this study shows a beneficial effect of AT1RB eprosartan on the balance between coagulation and fibrinolysis, because of improvement of the latter. This supports the view that, although blood pressure does not improve, AT1RB treatment in therapy-resistant hypertensive patients may still be beneficial, with favorable changes in fibrinolysis. Future studies in larger patient groups should investigate whether this results in a decreased risk of atherothrombotic complications. Importantly, the observed changes in fibrinolysis in the present study are short-term. As there are conflicting data on fibrinolytic changes in the long term, studies of a longterm character should be performed. ${ }^{8,18}$

To our knowledge, this is the first study to focus on acute AT1RB effects in therapyresistant hypertensive patients. The question of whether effects in therapy-resistant hypertensive patients are comparable to effects in patients sensitive to AT1RB-induced decreases in blood pressure is a subject of our future studies.

\section{Acknowledgements}

We would like to thank R. van Oerle, J.W.P. Govers-Riemslag and D. van der Voort for their expert technical assistance.

\section{Disclosure of conflict of interests}

A.W.J.H. Dielis is a Kootstra fellow from Maastricht University. M. Smid, H.M.H. Spronk, A.J.H.M. Houben, K. Hamulyák, A.A. Kroon, H. ten Cate and P.W. de Leeuw state that they have no conflict of interest. 


\section{References}

1. Dielis AW, Smid M, Spronk HM, Hamulyak K, Kroon AA, ten Cate H et al. The prothrombotic paradox of hypertension. Role of the renin-angiotensin and kallikrein-kinin systems. Hypertension. 2005;46:1236-1242.

2. Spronk HM, van der Voort D, ten Cate H. Blood coagulation and the risk of atherothrombosis: a complex relationship. Thromb J. 2004;2:12.

3. Hamsten A, Wiman B, de Faire U, Blomback M. Increased plasma levels of a rapid inhibitor of tissue plasminogen activator in young survivors of myocardial infarction. $N$ Engl J Med. 1985;313:1557-1563.

4. Spronk HM, Govers-Riemslag JW, ten Cate H. The blood coagulation system as a molecular machine. Bioessays. 2003;25:1220-1228.

5. Brown NJ, Kumar S, Painter CA, Vaughan DE. ACE inhibition versus angiotensin type-1 receptor antagonism: differential effects on PAI-1 over time. Hypertension. 2002;40:859865.

6. Brown NJ, Agirbasli MA, Williams GH, Litchfield WR, Vaughan DE. Effect of activation and inhibition of the renin-angiotensin system on plasma PAI-1. Hypertension. 1998;32:965-971.

7. Nishimura H, Tsuji H, Masuda H, Kasahara T, Yoshizumi M, Sugano T et al. The effects of angiotensin metabolites on the regulation of coagulation and fibrinolysis in cultured rat aortic endothelial cells. Thromb Haemost. 1999;82:1516-1521.

8. Muller DN, Mervaala EM, Dechend R, Fiebeler A, Park JK, Schmidt F et al. Angiotensin II (AT(1)) receptor blockade reduces vascular tissue factor in angiotensin II-induced cardiac vasculopathy. Am J Pathol. 2000;157:111-122.

9. Al-Mallah MH, Tleyjeh IM, Abdel-Latif AA, Weaver WD. Angiotensin-converting enzyme inhibitors in coronary artery disease and preserved left ventricular systolic function: a systematic review and meta-analysis of randomized controlled trials. J Am Coll Cardiol. 2006; 47:1576-1583.

10. Kjeldsen SE, Julius S. Hypertension mega-trials with cardiovascular end points: effect of angiotensin-converting enzyme inhibitors and angiotensin receptor blockers. Am Heart J. 2004;148:747-754.

11. Weber MA. Interrupting the renin-angiotensin system: the role of angiotensin-converting enzyme inhibitors and angiotensin II receptor antagonists in the treatment of hypertension. Am J Hypertens. 1999;12:189S-194S.

12. Johansson L, Jansson JH, Boman K, Nilsson TK, Stegmayr B, Hallmans G. Tissue plasminogen activator, plasminogen activator inhibitor-1, and tissue plasminogen activator/plasminogen activator inhibitor-1 complex as risk factors for the development of a first stroke. Stroke. 2000;31:26-32.

13. Jansson JH, Olofsson BO, Nilsson TK. Predictive value of tissue plasminogen activator mass concentration on long-term mortality in patients with coronary artery disease. A 7-year follow-up. Circulation. 1993;88:2030-2034.

14. Thompson SG, Kienast J, Pyke SD, Haverkate F, van de Loo JC. Hemostatic factors and the risk of myocardial infarction or sudden death in patients with angina pectoris. European Concerted Action on Thrombosis and Disabilities Angina Pectoris Study Group. N Engl J Med. 1995;332:635-641. 
15. De Bono D. Significance of raised plasma concentrations of tissue-type plasminogen activator and plasminogen activator inhibitor in patients at risk from ischaemic heart disease. Br Heart J. 1994;71:504-507.

16. Berrettini M, Schleef RR, Espana F, Loskutoff DJ, Griffin JH. Interaction of type-1 plasminogen activator inhibitor with the enzymes of the contact activation system. J Biol Chem. 1989;264:11738-11743.

17. Ekholm M, Wallen NH, Johnsson H, Eliasson K, Kahan T. Long-term angiotensin-converting enzyme inhibition with ramipril reduces thrombin generation in human hypertension. Clin Sci (Lond). 2002;103:151-155.

18. Goodfield NE, Newby DE, Ludlam CA, Flapan AD. Effects of acute angiotensin II type-1 receptor antagonism and angiotensin converting enzyme inhibition on plasma fibrinolytic parameters in patients with heart failure. Circulation. 1999;99:2983-2985. 



\section{Chapter 6}

\section{Thrombin generation as a tool to assess prohaemostatic treatment}

Thrombomodulin-modified thrombin generation after in vivo recombinant factor VIII treatment in severe haemophilia A.

Dielis AWJH' $\mathrm{H}^{1}$, Balliël WMR' ${ }^{2}$, van Oerle $\mathrm{R}^{2}$, Hermens $\mathrm{WT}^{3}$, Spronk $\mathrm{HMH}^{1}$, ten Cate $\mathrm{H}^{1}$, Hamulyák $\mathrm{K}^{2}$.

1 Department of Internal Medicine, Laboratory for Clinical Thrombosis and Haemostasis, Cardiovascular Research Institute Maastricht, Maastricht University Medical Center, Maastricht, The Netherlands;

2 Department of Internal Medicine, Division of Haematology, Maastricht University Medical Center, Maastricht, The Netherlands;

3 Delbia BV, Cardiovascular Research Institute Maastricht, Maastricht University, Maastricht, The Netherlands.

Haematologica. 2008;93:1351-1357. 


\section{Abstract}

Background: Thrombin generation has been shown to reflect coagulation potential and factor VIII (FVIII) levels in patients with haemophilia A. We hypothesize that thrombin generation in the presence of thrombomodulin reflects plasma FVIII levels better.

Design and methods: Plasma FVIII levels were determined chromogenically and thrombin generation was measured with and without thrombomodulin in 12 patients with severe haemophilia A. Blood was sampled at baseline and 15 minutes, 1, 3, 6, 24 and 48 hours after recombinant FVIII administration.

Results: FVIII administration restored the decreased baseline thrombin generation (reflected by endogenous thrombin potential, peak height, slope and time to peak). Lag time did not change. All thrombin generation parameters except time to peak returned to baseline within 48 hours, while plasma FVIII concentration was increased and time to peak shortened. Endogenous thrombin potential and peak height showed wide interindividual variation, with strong intra-individual correlations. Addition of thrombomodulin to the assay shortened time to peak and decreased endogenous thrombin potential and peak height. The decrease in peak height was almost completely offset by FVIII administration. Multiple linear regression analysis revealed thrombomodulin-modified thrombin generation to be a moderately better predictor of plasma FVIII levels than thrombin generation in the absence of thrombomodulin (adjusted $R^{2} 0.79$ vs 0.71 ).

Conclusions: Addition of thrombomodulin has pronounced effects on all parameters of thrombin generation. This thrombomodulin-modified thrombin generation assay better reflects plasma FVIII levels than thrombin generation in the absence of thrombomodulin. 


\section{Introduction}

Haemophilia A is an inherited disorder characterized by decreased levels of coagulation factor VIII (FVIII) in the blood. Upon tissue factor-induced activation of the coagulation system, only small amounts of thrombin are initially formed following activation of FX. Activated FVIII (FVIIIa) acts as a cofactor to FIXa in the formation of the intrinsic tenase complex (FVIIIa, FIXa and FX together with calcium on negatively charged phospholipids), which enhances thrombin formation dramatically through increased formation of FXa. After binding to thrombomodulin, thrombin activates protein $\mathrm{C}$ which, together with its cofactor protein S, inactivates both FVIIIa and FVa. At low levels of FVIII or in the absence of FVIII the formation of the tenase complex is diminished and the positive feedback loop is impaired, which decreases the coagulation potential of blood, resulting in a risk of bleeding complications.

Prophylactic treatment of haemophilia A consists of replacing FVIII and nowadays recombinant products are widely used for this purpose. All registered recombinant FVIII products have been shown to be effective and safe in reducing bleeding complications in haemophilia A patients. ${ }^{1}$ Overall, bleeding risk is inversely correlated with FVIII levels, but it is well known that bleeding patterns in patients vary markedly, also at comparable FVIII levels and in the absence of additional abnormalities of haemostasis. $^{2,3}$ This raises the question of whether determinants other than FVIII levels contribute to the risk of bleeding, i.e. the total plasma coagulation potential.

Several studies employed a variety of thrombin generation assays to test the total plasma coagulation potential in haemophilic blood samples and reconstituted plasma models, showing that the endogenous thrombin potential (ETP; area under the thrombin generation curve) reflects haemorrhagic tendency ${ }^{4-9}$ and is decreased in patients with severe haemophilia $A$, while the initiation phase of coagulation is prolonged. ${ }^{10}$ The replacement of FVIII, both in vitro in FVIII-deficient plasma ${ }^{11,12}$ and in vivo in treated haemophilia A patients, ${ }^{13}$ is able to restore thrombin generation, while increased FVIII levels may reflect a procoagulant state. ${ }^{14-16}$ The lag time of the thrombin generation curve was not found to correlate with FVIII levels, and it was suggested recently that slope and time to peak are better predictors of FVIII influences on thrombin generation, ${ }^{5}$ tested in haemophilia A patients and healthy controls. Indeed, time to peak was correlated with FVIII levels. ${ }^{17}$ The only study available on thrombin generation after in vivo FVIII administration in a platelet-poor plasma assay was recently published by Lewis et al.,18 who used a 1 pM tissue factor stimulus. In this study, the ETP and peak height of the thrombin generation curve show wide inter- and intra-individual variations, indicating that other components of coagulation or inhibition thereof are involved besides FVIII. Alternatively, thrombin generation measurements have been proposed as a way to screen for the effects of inhibitors on blood coagulation in haemophilia A patients. ${ }^{19-21}$ 
Previously, we validated the Calibrated Automated Thrombogram assay in our laboratory with platelet-poor plasma activated by $1 \mathrm{pM}$ tissue factor and added thrombomodulin to the Calibrated Automated Thrombogram assay to study the influence of the protein $C$ system on the initiation and, in particular the propagation phases of coagulation (Chapter 3.2). ${ }^{22}$ Adding thrombomodulin to the Calibrated Automated Thrombogram assay decreases total thrombin generation through inhibition of FV and FVIII. Since FVIII is the varying factor in haemophilia A, the residual thrombin formation still present after addition of thrombomodulin may be a more direct reflection of FVIII levels. We, therefore, hypothesize that addition of thrombomodulin to plasma samples from haemophilia A patients after in vivo FVIII replacement therapy (with different intra-individual FVIII levels) may make the thrombin generation assay reflect FVIII levels better.

In this study, we determined thrombin generation using $1 \mathrm{pM}$ tissue factor and FVIII levels using a chromogenic assay in 12 patients before and 48 hours after administration of a recombinant FVIII product, and we assessed changes in thrombin generation upon addition of thrombomodulin. 


\section{Design and methods}

\section{Patients}

Male patients with severe haemophilia A who had a regular in vivo recovery of FVIII upon administration of this clotting factor at the Division of Haematology at the University Hospital Maastricht, The Netherlands, were asked to allow further testing of the remaining amount of their plasma. Inclusion criteria were FVIII levels below 1\%, no FVIII administration in the previous 72 hours, and no evidence of active bleeding or inhibitors. Informed consent was obtained from all patients according to our local hospital guidelines.

\section{Study design}

All patients received a fixed dose of $3000 \mathrm{U}$ of a recombinant FVIII product through infusion after a wash-out period of at least 72 hours, resulting in a mean dosage of 40.0 $\mathrm{U} \mathrm{kg}^{-1}$ [range, 39.2-43.2].

\section{Normal pooled plasma}

Normal pooled plasma was prepared at the Departments of Haematology and Clinical Chemistry of the University Hospital Maastricht, The Netherlands, by pooling plasma from 85 healthy volunteers not using any medication.

\section{Blood collection and preparation}

Venous blood $(3.2 \%$ citrate $(\mathrm{w} / \mathrm{v}))$ was collected from an antecubital vein at baseline (before infusion), and 15 minutes, 1, 3, 6, 24 and 48 hours after infusion. Platelet-poor plasma was prepared by two-step centrifugation: first at $2000 \mathrm{~g}$ for 15 minutes followed by centrifugation at $11000 \mathrm{~g}$ for five minutes. Plasma aliquots were stored at $-80^{\circ} \mathrm{C}$ until use and thawed at $37^{\circ} \mathrm{C}$ for 15 minutes before analysis.

\section{FVIII analysis}

FVIII levels were measured according to the manufacturer's instructions in a chromogenic assay on BCS (Dade Behring, Liederbach, Germany) using a chromogenic assay kit. All FVIII assays employed standard human plasma (Dade Behring), calibrated against the World Health Organization-standard. 


\section{Thrombin generation measurements}

Thrombin generation in tissue factor-triggered platelet-poor plasma was measured with the Calibrated Automated Thrombogram method (Thrombinoscope BV, Maastricht, The Netherlands).2,3 Measurements were conducted on $80 \mu \mathrm{L}$ plasma with final concentrations of $1 \mathrm{pM}$ tissue factor (PPP Reagent Low, Thrombinoscope BV) and 4 $\mu \mathrm{M}$ phospholipids in the absence and presence of $1.5 \mathrm{nM}$ recombinant soluble thrombomodulin (Asahi Kasei Pharma Corporation, Tagata, Japan). The concentration of thrombomodulin was chosen such as to inhibit thrombin generation in normal pooled plasma by $50 \%$. Thrombin Calibrator was obtained from Thrombinoscope BV. Fluorescence was read in a Fluoroskan Ascent reader (Thermo Labsystems OY, Helsinki, Finland) equipped with a 390/460 filter set and thrombin generation curves were calculated with the Thrombinoscope software (Thrombinoscope BV).

Five parameters were derived from the thrombin generation curves: lag time (initiation phase of coagulation), ETP, peak height, time to peak and slope (propagation phase of coagulation). Lag time was defined as the time to reach one-sixth of the peak height. The slope was calculated by dividing five-sixth of the peak height by the time to peak minus the lag time.

The influence of the activation of the plasma kallikrein-kinin system in conditions of a low tissue factor stimulus (1 pM) was assessed in a separate experiment in which thrombin generation was recorded with and without corn trypsin inhibitor at a final concentration of $40 \mu \mathrm{g} \mathrm{mL}-1$ (Haematologic Technologies Inc, Essex, VT, USA). No differences were observed between the two thrombin generation assays. Furthermore, analysis of thrombin generation without the tissue factor trigger showed no thrombin formation within one hour, thereby suggesting that the plasma kallikrein-kinin system was not activated (data not shown).

Validation of the Calibrated Automated Thrombogram method in our laboratory showed that it was essential to normalize non-time-dependent parameters in order to obtain acceptable inter-assay variations (Chapter 3.1). ${ }^{23}$ Intra-assay variations for normalized parameters are typically below $6 \%$ and inter-assay variations below $8 \%$. Each thrombin generation measurement therefore includes normal pooled plasma and both the ETP and peak height values are expressed as the ratio of value $_{\text {patient }} / v_{\text {value }}$ normal pooled plasma, as a percentage.

\section{Statistical analysis}

Data are expressed as median [interquartile range], unless otherwise specified. Differences over time in thrombin generation parameters and FVIII levels were analyzed using Wilcoxon's signed rank test. Correlations are expressed as Pearson's coefficients. To assess the relation between thrombin generation and FVIII levels, 
multiple linear regression analysis was performed with FVIII as the dependent variable and the lag time, ETP, peak height, time to peak, slope, age and product dose infused as independent variables. For each model, the adjusted $R^{2}$ and the standardized regression coefficients (beta) of the independent variables were calculated. The beta indicates the change of the dependent variable, expressed in standard deviations (SD), when the independent variable increases one SD and all other variables in the model remain unchanged.

A two-tailed probability value $P<0.05$ was considered statistically significant. Statistics were computed using SPSS for Windows, version 12.0 (SPSS Inc., Chicago, IL, USA), and Prism for Windows, version 5.00 (GraphPad Software Inc., San Diego, CA, USA). 


\section{Results}

\section{Patients}

Twelve male patients known to have severe haemophilia A formed the study group. Their median age was 34 years (range, 14-66) and their median weight was $72.5 \mathrm{~kg}$ [65.0-75.0]. None of the patients had inhibitors. Nine out of the 12 patients had normal liver function, the remaining three patients had slightly abnormal liver function (alanine aminotransferase less than $90 \mathrm{IU} \mathrm{L}^{-1}$ ), two of whom were known to be hepatitis $\mathrm{C}$ carriers. No other comorbidities were known during the period of investigation.

\section{FVIII level measurements}

FVIII level measurements are presented in Table 1(A) and depicted in Figure 1. At baseline, the median FVIII level was $0.9 \%$.

FVIII infusion significantly increased FVIII levels to a peak value of $105.0 \%$ after 15 minutes. Forty-eight hours after administration, the FVIII level was still significantly increased compared to baseline: 6.0 vs $0.9 \%$. Peak FVIII levels correlated with the administered dose, $R=0.73(P<0.01)$.

\section{Thrombin generation measurements with 1 pM tissue factor trigger in the absence of thrombomodulin}

Thrombin generation measurements in the absence of thrombomodulin are presented in Table 1(B), and the ETP and peak height are depicted in Figure 2 (panels A and B, respectively; solid lines). Correlations of the thrombin generation parameters with FVIII levels are presented in Table 2. The effects of FVIII administration and the addition of thrombomodulin on the thrombin generation curve are depicted in Figure 3.

The lag time showed no significant changes upon FVIII administration and the lag time and FVIII levels were not correlated.

The ETP increased significantly after FVIII infusion to a peak value of $114.5 \%$ after 15 minutes. Forty-eight hours after FVIII administration, the ETP returned to the baseline value of $40.0 \%$. FVIII levels correlated with the ETP in the group of patients as a whole $(R=0.79, P<0.0001)$. However, when data were analyzed per individual patient, correlations were markedly higher. Despite these correlations, there was a wide range of ETP at higher FVIII levels.

Prior to FVIII administration, the peak height was relatively low compared to the ETP (24.0 vs $40.0 \%$ ), but became greater after 15 minutes: $126.0 \%$. The peak height returned to baseline by 48 hours (29.0\%). Similar to the ETP, the peak height correlated 
Figure 1. FVIII levels at baseline and upon recombinant FVIII substitution. Data are presented as the median [interquartile range].

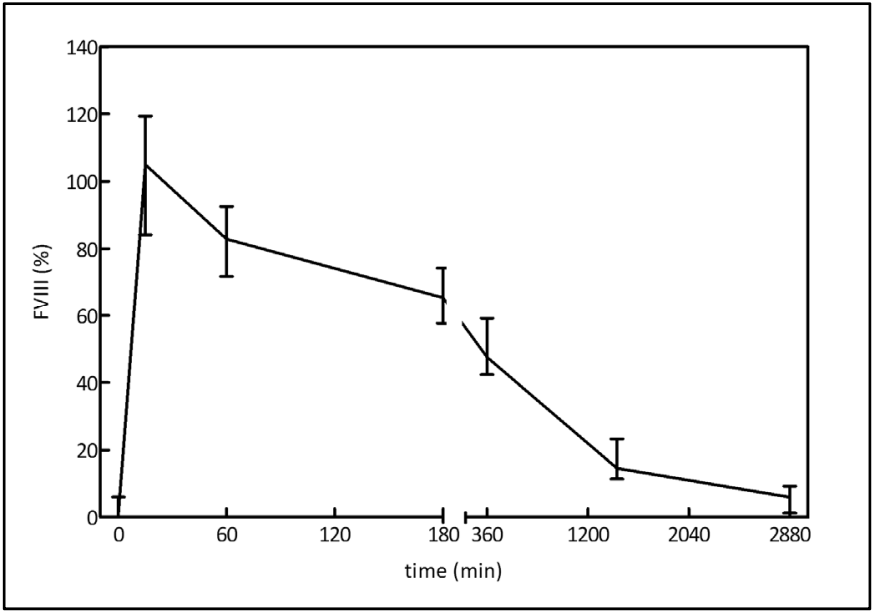

with FVIII levels in the whole group of patients $(R=0.79, P<0.0001)$, although stronger correlations were found in individual patients.

Administration of FVIII significantly shortened the time to peak (from 16.9 to 10.3 minutes after 15 minutes). The time to peak was the only thrombin generation parameter still significantly decreased after 48 hours (15.2 vs 16.9 minutes at baseline). The time to peak was inversely correlated with FVIII levels $(R=-0.75, P<0.0001)$. In contrast to the ETP and peak height, the time to peak values were within a narrow range across all FVIII levels.

The slope was calculated from non-normalized peak height data, a method that yields comparable data to the slope calculated from normalized peak height data $(R=0.997, P<0.0001$, data not shown). The slope increased upon FVIII infusion, reaching

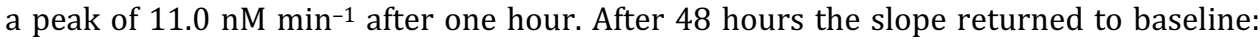

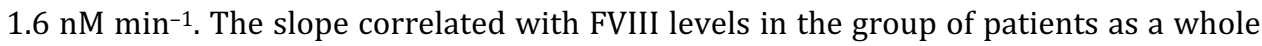
$(R=0.74, P<0.0001)$. The ETP, peak height and slope were strongly correlated in all patients.

\section{Thrombin generation measurements with 1 pM tissue factor trigger in the presence of thrombomodulin}

Thrombin generation measurements in the presence of thrombomodulin are presented in Table 1(C), and the ETP and peak height are depicted in Figure 2 (panels A and B, respectively; dashed lines). Correlations of FVIII levels with thrombin generation parameters in the presence of thrombomodulin (calculated from both absolute data and 
Figure 2. ETP (A) and peak height (B) at $1 \mathrm{pM}$ tissue factor in the absence (solid line) and presence (dashed line) of thrombomodulin at baseline and upon administration of recombinant FVIII. Data are presented as the median [interquartile range].

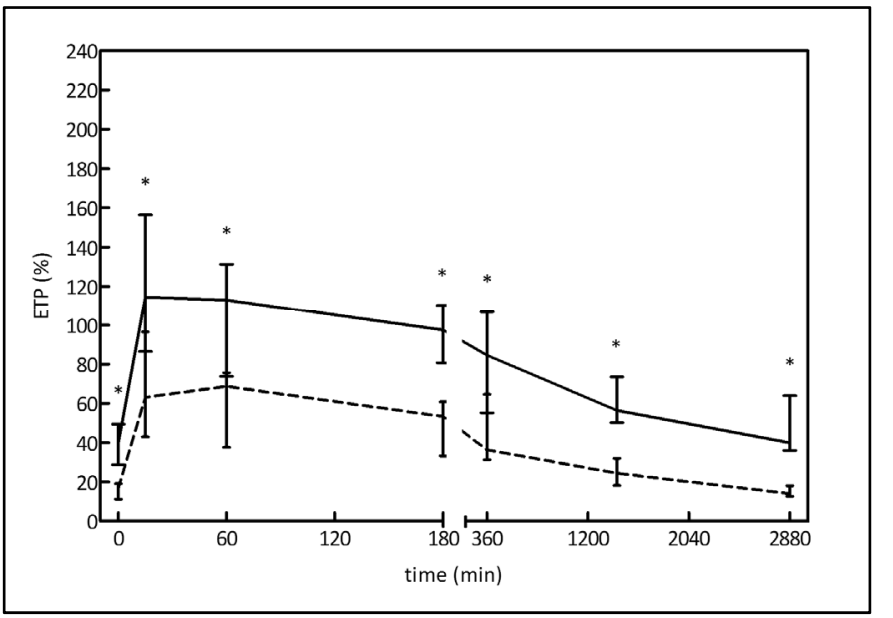

A

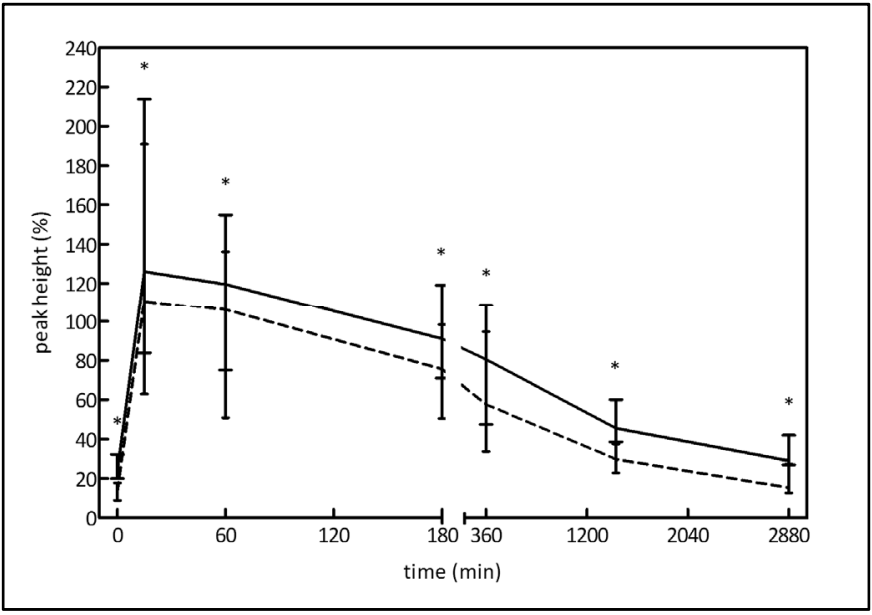

B

* denotes $P<0.05$.

relative reductions) are presented in Table 2. The effects of FVIII administration and the addition of thrombomodulin on the thrombin generation curve are depicted in Figure 3.

The lag time at low FVIII levels was significantly shorter in the presence of thrombomodulin than in its absence. At high FVIII levels, however, the addition of thrombomodulin did not influence the lag time, demonstrating that the addition of FVIII can successfully offset the effect of thrombomodulin. Unlike in the absence of 
thrombomodulin, in the presence of thrombomodulin the lag time correlated with FVIII levels $(R=0.26, P<0.05)$, with a stronger correlation between FVIII levels and the relative reduction in the lag time achieved by thrombomodulin $(R=0.71, P<0.001)$.

The ETP decreased significantly in the presence of thrombomodulin (titrated at a reduction in ETP of 50\% in normal pooled plasma), although this decrease was less pronounced at high FVIII levels (41-51\% compared to 57-60\% at low FVIII levels). FVIII levels correlated with the ETP to a similar extent with or without addition of thrombomodulin, although the relative reduction in ETP correlated less with FVIII levels.

The addition of thrombomodulin significantly decreased the peak height at low FVIII levels, although this decrease was almost completely offset by FVIII administration, resulting in a peak height comparable to that in normal pooled plasma (Figure 2B). Correlations with FVIII levels were similar to those of the ETP and FVIII.

The time to peak was significantly shorter at all time points upon addition of thrombomodulin. After FVIII infusion, the time to peak decreased significantly 9.2 minutes after 15 minutes, and returned to baseline (12.2 minutes) after 48 hours. Similar to the lag time, time to peak in the presence of thrombomodulin showed a poor inverse correlation with FVIII levels $(R=-0.56, P<0.0001)$, while the relative reduction correlated strongly with FVIII levels $(R=0.72, P<0.0001)$.

Addition of thrombomodulin to the thrombin generation assay significantly increased the slope, while recombinant FVIII infusion resulted in a maximum of $13 \mathrm{nM}$ min $^{-1}$ within 15 minutes, returning to baseline after 24 hours. The slope correlated to FVIII levels in all but one patient.

In all patients, the ETP, peak height and slope in the presence of thrombomodulin were strongly correlated.

\section{Thrombin generation and product dose}

Overall, FVIII levels correlated weakly with the dose of product infused $(R=0.25$, $P<0.05)$, although correlations between 15 minutes to six hours after infusion were markedly stronger $(R=0.73, P<0.01$ at 15 minutes decreasing to $R=0.59, P<0.05$ at six hours). The ETP and peak height at six and 24 hours after administration correlated with the FVIII dose (ETP: $R=0.58$ and $R=0.75, P<0.05$; peak height: $R=0.59$ and $R=0.81$, $P<0.05$ ), while all parameters (except the slope) of the thrombin generation curve at all other time points were significantly but weakly correlated with the dose infused.

\section{Multiple linear regression models}

Multiple linear regression models for FVIII incorporating thrombin generation parameters both in the absence and presence of thrombomodulin, age and product dose 


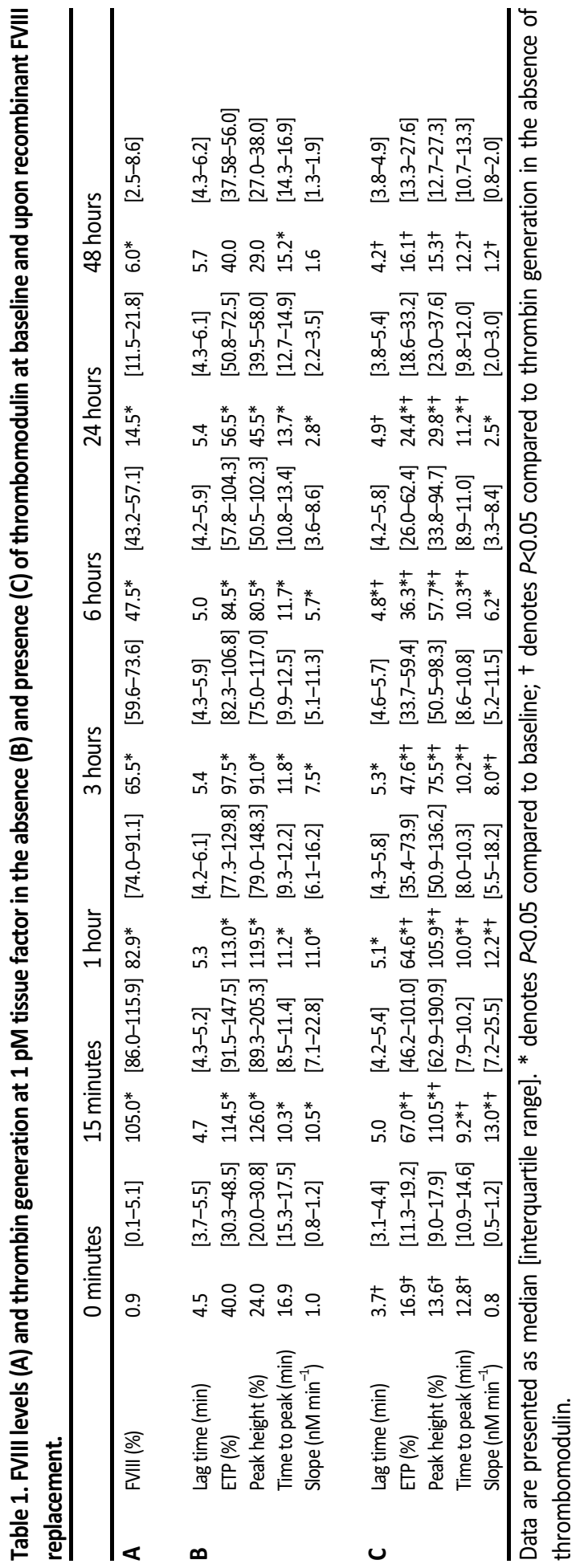


Table 2. Correlation between FVIII levels and thrombin generation at $1 \mathrm{pM}$ tissue factor in the absence of thrombomodulin (-TM) and its presence (absolute: $+\mathrm{TMa}$; relative reduction: $+\mathrm{TMr}$ ).

\begin{tabular}{|c|c|c|c|c|c|c|c|c|c|c|}
\hline \multirow[t]{2}{*}{ Patient } & \multicolumn{2}{|c|}{ Lag time } & \multicolumn{2}{|l|}{ ETP } & \multicolumn{2}{|c|}{ Peak height } & \multicolumn{2}{|c|}{ Time to peak } & \multicolumn{2}{|l|}{ Slope } \\
\hline & $-\mathrm{TM}$ & $+\mathrm{TMr}$ & $-\mathrm{TM}$ & +TMa & $-\mathrm{TM}$ & $+\mathrm{TMa}$ & $-\mathrm{TM}$ & $+\mathrm{TMa}$ & $-\mathrm{TM}$ & +TMa \\
\hline 1 & -0.46 & $0.89 *$ & $0.84^{*}$ & $0.92^{*}$ & $0.86^{*}$ & $0.92 *$ & $-0.99 *$ & $0.82 *$ & $0.82^{*}$ & $0.84^{*}$ \\
\hline 2 & 0.56 & 0.58 & $0.96 *$ & $0.94^{*}$ & $0.97^{*}$ & $0.97^{*}$ & $-0.89 *$ & $0.92 *$ & $0.97^{*}$ & $0.97^{*}$ \\
\hline 3 & -0.42 & $0.89 *$ & $0.89 *$ & $0.92^{*}$ & $0.94^{*}$ & $0.95^{*}$ & $-0.94^{*}$ & $0.85^{*}$ & $0.92^{*}$ & $0.94 *$ \\
\hline 4 & 0.17 & $0.94 *$ & $0.93 *$ & $0.94^{*}$ & $0.95^{*}$ & $0.94^{*}$ & $-0.91^{*}$ & $0.94 *$ & $0.96 *$ & $0.95^{*}$ \\
\hline 5 & 0.62 & 0.49 & 0.72 & 0.75 & 0.73 & $0.78^{*}$ & $-0.79 *$ & 0.29 & 0.75 & $0.78^{*}$ \\
\hline 6 & 0.46 & $0.76 *$ & $0.99 *$ & $0.96 *$ & $0.98^{*}$ & $0.95 *$ & $-0.95^{*}$ & $0.94 *$ & $0.96 *$ & $0.94^{*}$ \\
\hline 7 & 0.49 & $0.76^{*}$ & $0.96 *$ & $0.97 *$ & $0.99 *$ & $0.99 *$ & $-0.87^{*}$ & $0.94 *$ & $0.99 *$ & $0.99 *$ \\
\hline 8 & -0.02 & $0.84^{*}$ & $0.93 *$ & $0.95^{*}$ & $0.97^{*}$ & $0.97 *$ & $-0.84^{*}$ & 0.64 & $0.99 *$ & $0.97^{*}$ \\
\hline 9 & 0.13 & $0.90 *$ & $0.94 *$ & $0.90^{*}$ & $0.97^{*}$ & $0.92 *$ & $-0.92 *$ & $0.94 *$ & $0.97^{*}$ & $0.92^{*}$ \\
\hline 10 & $0.82 *$ & 0.59 & $0.90^{*}$ & $0.94^{*}$ & $0.91^{*}$ & $0.94^{*}$ & $-0.88^{*}$ & 0.74 & $0.85^{*}$ & $0.90 *$ \\
\hline 11 & -0.69 & $0.94 *$ & 0.72 & 0.58 & 0.70 & 0.61 & -0.78 & $0.92 *$ & 0.63 & 0.61 \\
\hline 12 & -0.26 & $0.88^{*}$ & $0.80 *$ & $0.90^{*}$ & $0.84^{*}$ & $0.89 *$ & $-0.96 *$ & $0.86^{*}$ & $0.85^{*}$ & $0.91^{*}$ \\
\hline Total group & -0.06 & $0.71^{*}$ & $0.79 *$ & $0.78^{*}$ & $0.79 *$ & $0.78^{*}$ & $-0.75^{*}$ & $0.72 *$ & $0.74^{*}$ & $0.74 *$ \\
\hline
\end{tabular}

Data are presented as Pearson's $R .^{*}$ denotes $P<0.05$.

Table 3. Multiple linear regression models for FVIII, incorporating thrombin generation parameters at $1 \mathrm{pM}$ tissue factor in the absence (A) and presence (B) of thrombomodulin, age and dose of product infused.

\begin{tabular}{|c|c|c|c|c|}
\hline Dependent variable: FVIII & A & & B & \\
\hline Independent variable & Beta & Adjusted $R^{2}$ & Beta & Adjusted $R^{2}$ \\
\hline Product dose infused & 0.06 & 0.71 & 0.58 & 0.79 \\
\hline Age & $0.16^{*}$ & & $0.22 *$ & \\
\hline Lag time & $0.22 *$ & & $-0.29 *$ & \\
\hline ETP & -0.31 & & $-1.45^{*}$ & \\
\hline Peak height & 1.13 & & $3.37^{*}$ & \\
\hline Time to peak & $-0.47^{*}$ & & $-0.16^{*}$ & \\
\hline Slope & -0.40 & & $-1.44^{*}$ & \\
\hline
\end{tabular}

* denotes $P<0.05$.

infused are presented in Table 3.

Inclusion of age and parameters of thrombin generation in the absence of thrombomodulin in a regression model resulted in a high adjusted $R^{2}$ of 0.71 . Determinants in this model were age, the lag time and time to peak, while the ETP and 
peak height were not significant predictors of FVIII levels. Inclusion of parameters of thrombin generation in the presence of thrombomodulin in a regression model resulted in a higher adjusted $R^{2}$ of 0.79 , with all thrombin generation parameters and age as significant predictors. Instead of including the absolute parameters, inclusion of the relative reduction in the lag time and time to peak increased linear regression results due to better correlations with FVIII (Table 2). In this model, the peak height showed a very strong positive association, while the ETP and slope were strong negative predictors, contrary to their positive correlation with FVIII levels. This effect is likely due to very strong correlations between the ETP, peak height and slope. The inclusion of only one of these three parameters in the model together with the lag time, time to peak and age did not result in a change of the adjusted $R^{2}$, and the included parameter had a positive beta between 0.45 and 0.50 (data not shown). 
Figure 3. Thrombin generation curves at baseline (solid lines) and after 15 minutes (dashed lines), in the absence (black line) and presence (gray line) of thrombomodulin. Gray areas represent the $95 \%$ confidence intervals.

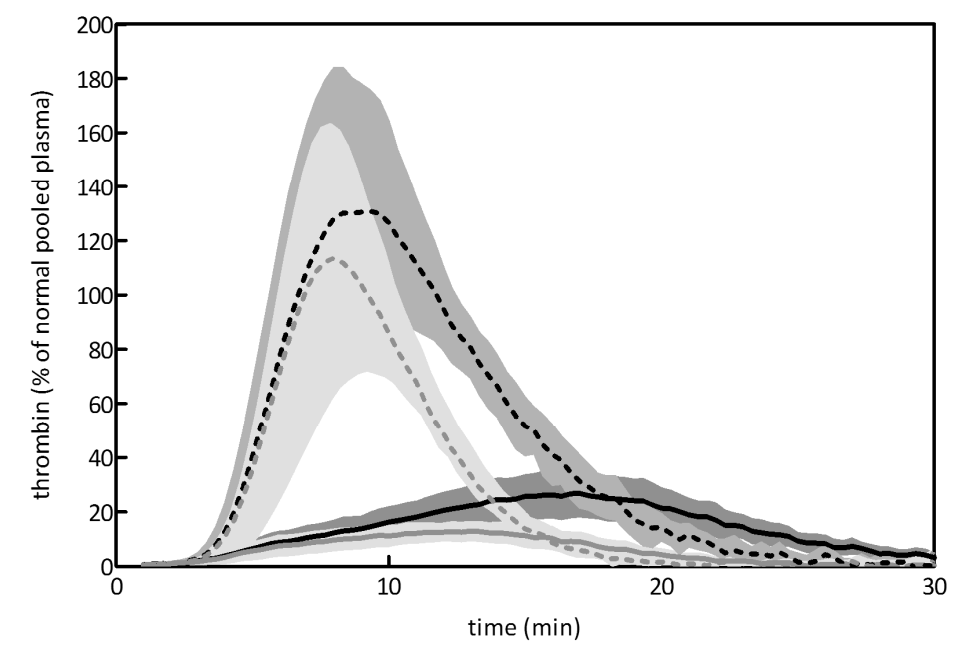

Figure 4. Thrombin generation curves at baseline in the absence (solid line) and presence (dashed line) of thrombomodulin. Horizontal lines indicate the peak height and one-sixth of the peak height of their respective curves.

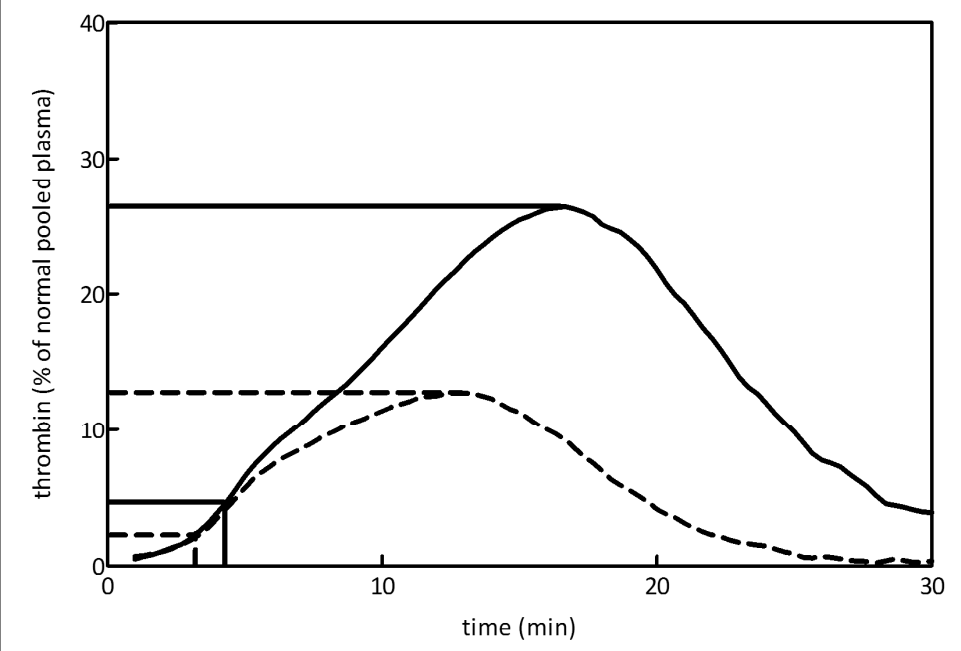




\section{Discussion}

In this study we compared thrombin generation parameters at $1 \mathrm{pM}$ tissue factor in the Calibrated Automated Thrombogram assay with chromogenically determined FVIII levels during 48 hours after FVIII administration in patients with severe heamophilia A. In addition, we studied whether a modification of the Calibrated Automated Thrombogram (by adding thrombomodulin, a component of the activated protein $\mathrm{C}$ pathway, inhibiting FVIIIa and FVa) results in a thrombin generation assay that reflects FVIII levels better.

FVIII levels increased to normal after administration, then declined by approximately $40 \%$ within the first three hours, followed by a more gradual decay up to 48 hours, when the FVIII levels were still higher than at baseline. All assessed thrombin generation parameters (the ETP, peak height, time to peak and slope), except lag time, showed concomitant changes towards an increased coagulation potential, i.e. shorter times and higher total thrombin. The lack of shortening of the lag time emphasizes the importance of FVIII in the propagation rather than in the initiation phase of coagulation. Unlike all other parameters the time to peak was still shortened by 1.7 minutes after 48 hours, indicating that, although the total amount of thrombin formed was comparable to that at baseline, the propagation phase of coagulation was still enhanced.

Although the ETP and peak height generally correlated with FVIII levels, ${ }^{17}$ there was a very large variation in these parameters at higher FVIII levels, with ETP ranging from 50 to $160 \%$ at FVIII levels of approximately $100 \%$. While correlations were around $R=0.79$ for the group as a whole, patients showed much narrower intra-individual variation with very high correlations when studied individually. Theoretically, this may coincide with the known inter-individual variations of bleeding risk, but this study was not designed to assess this relationship. In our assay, the slope of the thrombin generation curve strongly correlated with the ETP and peak height, but correlated less well with the other parameters it is calculated from (the lag time and time to peak). In contrast to the results of Dargaud et al., ${ }^{6}$ in our 1 pM tissue factor setup, calculation of the slope does not seem to reveal information additional to that yielded by either the ETP or peak height, although the actual calculation methods may differ. This was confirmed in the multiple linear regression analysis, in which the inclusion of either the slope, ETP or peak height as an independent variable alongside the lag time, time to peak and age did not change the adjusted $R^{2}$ of the model.

Addition of thrombomodulin to the thrombin generation assay reduced the coagulation potential at baseline, reflected by the lower ETP and peak height. The significant shortening of the time to peak compared to that in the assay conducted in the absence of thrombomodulin may seem in contradiction to the overall decreased thrombin generation, but this is probably due to the decreased feedback loop involving FVIII. In the presence of thrombomodulin, the first thrombin that is generated is unable 
to activate FVIII and promote further thrombin generation over a prolonged period. This results in a decreased thrombin generation curve in which the peak (although lower) is reached earlier. This effect is illustrated in Figure 3, where the grey curves (in the presence of thrombomodulin) reflect lower thrombin generation with shorter time parameters.

At low FVIII, addition of thrombomodulin to the thrombin generation assay resulted in a shortening of the lag time. This effect may seem paradoxical since no change in lag time was described by Dargaud et al. in a 5 pM tissue factor thrombin generation assay upon addition of thrombomodulin ${ }^{24}$ and even a prolongation at low FVIII levels could be expected. However, the observed effect is due to the calculation method used by the Thrombinoscope software to define lag time (i.e. the time to reach one-sixth of the peak height). Thrombin generation curves at low FVIII levels have a distinctive form in which one-sixth of the peak height is reached at an earlier time in the presence of thrombomodulin. This effect is illustrated in Figure 4. In this figure it can be appreciated that addition of thrombomodulin (dashed line) shortens the lag time compared to that of thrombin generation in the absence of thrombomodulin (solid line). Although this paradoxical effect may be regarded as a technical artifact, we show that the reduction in lag time achieved by addition of thrombomodulin does correlate with FVIII levels $(R=0.71, P<0.001)$ and may, therefore, be a useful variable of the thrombin generation curve.

The relative reductions in both the lag time and time to peak that are achieved by addition of thrombomodulin correlated well with FVIII levels, and the fact that the ETP, peak height and slope were interchangeable in the multiple regression analysis, indicate that the focus should not be on a single thrombin generation parameter. Instead, the total curve should be regarded as a measure of (FVIII-dependent) coagulation potential (the effects on all parameters of the thrombin generation curve are especially clear in Figure 3). Taking all thrombin generation parameters into account, modification of the thrombin generation assay by addition of thrombomodulin results in measurements that better reflect FVIII status in patients with haemophilia A.

\section{Acknowledgements}

The authors reported no potential conflicts of interest. A.W.J.H. Dielis is a Kootstra fellow from Maastricht University. 


\section{References}

1. Lusher JM. First and second generation recombinant factor VIII concentrates in previously untreated patients: recovery, safety, efficacy, and inhibitor development. Semin Thromb Hemost. 2002;28:273-276.

2. Hemker HC, Giesen P, Al Dieri R, Regnault V, de Smedt E, Wagenvoord R et al. The Calibrated Automated Thrombogram (CAT): a universal routine test for hyper- and hypocoagulability. Pathophysiol Haemost Thromb. 2002;32:249-253.

3. Hemker HC, Giesen P, Al Dieri R, Regnault V, de Smedt E, Wagenvoord R et al. Calibrated automated thrombin generation measurement in clotting plasma. Pathophysiol Haemost Thromb. 2003;33:4-15.

4. Beltran-Miranda CP, Khan A, Jaloma-Cruz AR, Laffan MA. Thrombin generation and phenotypic correlation in haemophilia A. Haemophilia. 2005;11:326-334.

5. Dargaud Y, Bordet JC, Francillon S, Negrier C. Haemophilia patients exhibit prolonged coagulation time but normal lag time of thrombin generation test: Are these results really discordant? Thromb Haemost. 2007;97:675-676.

6. Dargaud Y, Béguin S, Lienhart A, Al Dieri R, Trzeciak C, Bordet JC et al. Evaluation of thrombin generation capacity in plasma from patients with haemophilia A and B. Thromb Haemost. 2005;93:475-480.

7. Trossaert M, Regnault V, Sigaud M, Boisseau P, Fressinaud E, Lecompte T. Mild haemophilia A with factor VIII assay discrepancy: using thrombin generation assay to assess the bleeding phenotype. J Thromb Haemost. 2008;6:486-493.

8. Barrowcliffe TW. Monitoring haemophilia severity and treatment: new or old laboratory tests? Haemophilia. 2004;10:109-114.

9. Siegemund T, Petros S, Siegemund A, Scholz U, Engelmann L. Thrombin generation in severe haemophilia A and B: the endogenous thrombin potential in platelet-rich plasma. Thromb Haemost. 2003;90:781-786.

10. Butenas S, van 't Veer C, Mann KG. "Normal” thrombin generation. Blood. 1999;94:21692178.

11. Radtke KP, Griffin JH, Riceberg J, Gale AJ. Disulfide bond-stabilized factor VIII has prolonged factor VIIIa activity and improved potency in whole blood clotting assays. J Thromb Haemost. 2007;5:102-108.

12. Rugeri L, Béguin S, Hemker C, Bordet JC, Fleury R, Chatard B et al. Thrombin-generating capacity in patients with von Willebrand's disease. Haematologica. 2007;92:1639-1646.

13. Bassus S, Wegert W, Krause M, Escuriola-Ettinghausen C, Siegemund A, Petros S et al. Platelet-dependent coagulation assays for factor VIII efficacy measurement after substitution therapy in patients with haemophilia A. Platelets. 2006;17:378-384.

14. Brummel-Ziedins K, Undas A, Orfeo T, Gissel M, Butenas S, Zmudka K et al. Thrombin generation in acute coronary syndrome and stable coronary artery disease: dependence on plasma factor composition. J Thromb Haemost. 2008;6:104-110.

15. Siegemund A, Petros S, Siegemund T, Scholz U, Seyfarth HJ, Engelmann J. The endogenous thrombin potential and high levels of coagulation factor VIII, factor IX and factor XI. Blood Coagul Fibrinolysis. 2004;15:241-244.

16. Regnault V, Béguin S, Lecompte T. Calibrated automated thrombin generation in frozen- 
thawed platelet-rich plasma to detect hypercoagulability. Pathophysiol Haemost Thromb. 2003;33:23-29.

17. Matsumoto T, Shima M, Takeyama M, Yoshida K, Tanaka I, Sakurai Y et al. The measurement of low levels of factor VIII or factor IX in hemophilia A and hemophilia B plasma by clot waveform analysis and thrombin generation assay. J Thromb Haemost. 2006;4:377-384.

18. Lewis SJ, Stephens E, Florou G, Macartney NJ, Hathaway LS, Knipping J et al. Measurement of global haemostasis in severe haemophilia A following factor VIII infusion. Br J Haematol. 2007;138:775-782.

19. Dargaud Y, Lienhart A, Meunier S, Hequet O, Chavanne H, Chamouard V et al. Major surgery in a severe haemophilia A patient with high titre inhibitor: use of the thrombin generation test in the therapeutic decision. Haemophilia. 2005;11:552-558.

20. Salvagno GL, Astermark J, Ekman M, Franchini M, Guidi GC, Lippi G et al. Impact of different inhibitor reactivities with commercial factor VIII concentrates on thrombin generation. Haemophilia. 2007;13:51-56.

21. Varadi K, Turecek PL, Schwarz HP. Thrombin generation assay and other universal tests for monitoring haemophilia therapy. Haemophilia. 2004;10:17-21.

22. Dielis AW, Castoldi E, Spronk HM, van Oerle R, Hamulyák K, ten Cate H et al. Coagulation factors and the protein $\mathrm{C}$ system as determinants of thrombin generation in a normal population. J Thromb Haemost. 2008;6:125-131.

23. Spronk HM, Dielis AW, de Smedt E, van Oerle R, Fens D, Prins MH et al. Assessment of thrombin generation II: Validation of the Calibrated Automated Thrombogram in plateletpoor plasma in a clinical laboratory. Thromb Haemost. 2008;100:362-364.

24. Dargaud Y, Trzeciak MC, Bordet JC, Ninet J, Negrier C. Use of calibrated automated thrombinography +/- thrombomodulin to recognise the prothrombotic phenotype. Thromb Haemost. 2006;96:562-567. 



\section{Chapter 7}

General discussion, summary and conclusions 
Chapter 7 
Chapter 7.1

General discussion, summary and conclusions 
Chapter 7.1 


\section{Coagulation- versus fibrinolysis-dependent hypercoagulability}

Thrombosis is an important cause of morbidity and mortality worldwide, with an increasing incidence of (especially) arterial thrombotic disease. ${ }^{1}$ Whether venous or arterial, thrombosis is characterized by, and results from an underlying hypercoagulable state. Although the contributing risk factors may differ between the different thrombotic disorders (acute myocardial infarction, cerebrovascular accident, deep venous thrombosis, pulmonary embolism), they all result in blood that is more prone to excessive thrombus formation, also known as the hypercoagulable state of blood. ${ }^{2,3}$ Essentially, a dysbalance between coagulation and fibrinolysis is created. ${ }^{4}$

In the last decades, many studies have been conducted to characterize factors (both biochemical and lifestyle-related) ${ }^{5,6}$ that contribute to hypercoagulability. Besides wellknown risk factors such as smoking, age and body weight, arterial and venous thrombosis are mainly associated with changes in coagulation-related biochemical markers (including soluble plasma tissue factor, ${ }^{7}$ antithrombin, ${ }^{8,9}$ prothrombin, ${ }^{10}$ FVIII ${ }^{11-13}$ ) that enhance coagulation activity. In contrast to a hypercoagulable state that results from an increased coagulation potential, hypercoagulability may also arise from a decrease in fibrinolytic activity. ${ }^{14}$ Hypertension is an example of such fibrinolysisdependent hypercoagulability. ${ }^{15}$ These differences in underlying mechanisms of hypercoagulability warrant different, specific screening methods and treatments that are focused on restoring the dysbalance between coagulation and fibrinolysis. In this thesis we therefore make a clear distinction between 1. Coagulation-dependent hypercoagulabilty and 2. Fibrinolysis-dependent hypercoagulability, and the presentation of studies in this thesis is structured accordingly.

\section{Optimization and validation of the thrombin generation technique}

The main part of this thesis focuses on thrombin generation as a tool to probe the coagulation potential in plasma samples from several patients with thrombotic disease. In Chapter 3 we present studies on the validation of the Calibrated Automated Thrombogram in our laboratory. Many studies have been published on establishing normal ranges of thrombin generation parameters, but these studies are difficult to compare because of the different test systems used, with different initiator sources and concentrations, the variety in phospholipids used and variations in plasma preparation. ${ }^{16-22}$ In addition, several software packages available to calculate thrombin generation parameters use different definitions for these parameters. Recent papers by Van Veen et al. ${ }^{19}$ and Dargaud et al. ${ }^{20}$ confirm the poor comparability of thrombin generation in identical samples between institutes, with variances reaching almost $40 \%$ (for endogenous thrombin potential).

For our patient studies we chose a commercially available technique ${ }^{23}$ and we used 
the accompanying reagents to ensure optimal comparability. To establish a reference range and inter- and intra-assay variations of the Calibrated Automated Thrombogram in our laboratory we studied plasma samples from 139 healthy volunteers. Furthermore, we repeatedly sampled plasma from 33 healthy individuals with intervals of six weeks, 12 weeks and one year. Thrombin generation analyses were repeated after five and nine months. To our surprise the thrombin generation assay did not provide stable results over time (showing a decrease in endogenous thrombin potential after five months, only to restore after nine months). Because the pre-analytical conditions did not change, differences were likely to result from unstable reagents. A similar shift in thrombin generation parameters was observed in pooled normal plasma that was included in all analyses as an internal control. If thrombin generation parameters were expressed as percentages relative to pooled normal plasma (set at $100 \%$ ) rather than as $\mathrm{nM}$ of thrombin production, the observed temporal changes were eliminated. With this normalization intra- and inter-assay variations were acceptable at values below $8 \%$ for the latter. The results presented in Chapter 3.1 therefore advocate the necessity of normalization of thrombin generation results. A similar recommendation was given by Dargaud et $a l^{20}$ in the aforementioned paper.

Thrombin generation does not only provide an overall measure of coagulation potential, but analysis of the individual parameters that can be derived from the thrombin generation curve can provide information on specific phases of coagulation. Lag time reflects the initiation phase, while the peak height, time to peak and slope represent the propagation phase of coagulation. The termination phase is represented by the time to the start of the tail. The endogenous thrombin potential corresponds to the total amount of thrombin formed and incorporates all of the aforementioned phases. During these phases, pro- and anticoagulant proteins have differential activities and their relative contributions to the corresponding thrombin generation parameters were studied in healthy individuals as described in Chapter 3.2. We measured coagulation factors and factors of the protein $\mathrm{C}$ system and employed multiple regression analysis to establish the determinants of thrombin generation. In order to achieve a more specific reflection of the activity of the protein $\mathrm{C}$ system we primed the assays by adding thrombomodulin and activated protein C. Major contributors to the lag time were plasma levels of fibrinogen, FVII, free protein $\mathrm{S}$ and free tissue factor pathway inhibitor. Main determinants of the endogenous thrombin potential and peak height were fibrinogen, free tissue factor pathway inhibitor and antithrombin. At high tissue factor concentrations FV was an additional determinant, and FXII at low tissue factor concentrations.

These results, however, should be cautiously approached because our study group consisted of healthy individuals with normal coagulation factor levels and relatively narrow variations. Moreover, the statistical method used (multiple linear regression analysis) does not allow direct extrapolation to patients with (an increased risk for) thrombotic disease. A similar approach of exploration of the determinants in plasma 
samples from several patient groups would provide valuable information and would help putting these results in perspective.

A hot topic in the field of research involving thrombin generation is the contribution of the intrinsic coagulation or contact activation system. ${ }^{24,25}$ Indeed, plasma assayed in the absence of an initiator of the extrinsic pathway, but in the presence of calcium and phospholipids, can display generation of thrombin after incubation for approximately 20 minutes. In the presence of a sufficient tissue factor concentration contact activation is less likely to have pronounced effects but its role at low concentrations of tissue factor is controversial. In our determinants study FXII was found to be significantly associated with the endogenous thrombin potential and peak height in the $1 \mathrm{pM}$ tissue factor assay but this effect was absent at the (much) higher tissue factor concentration of $13.6 \mathrm{pM}$. Others have reported moderate to pronounced effects of the intrinsic pathway. It was unclear whether FXII activation occurred during the measurements, or resulted from blood sampling that generated trace amounts of activated FXII. Although FXIIa is rapidly bound to its major inhibitor C1-esterase inhibitor, downstream activation of FXI could already have occurred.

The influence of contact activation may be overcome by the addition of corn trypsin inhibitor to the plasma, ${ }^{26}$ but the question remained if it should be added to the blood drawing tubes prior to sampling, or during plasma preparation or the actual thrombin generation measurement. In Chapter 3.3 we explored this topic by sampling blood from healthy individuals and we varied blood drawing techniques, adding corn trypsin inhibitor during different stages, and we measured thrombin generation at varying amounts of tissue factor and kaolin concentrations. In thrombin generation assays that were triggered with $0.5 \mathrm{pM}$ tissue factor or higher the addition of corn trypsin inhibitor to plasma did not significantly influence thrombin generation measurements. Addition of corn trypsin inhibitor in blood collection tubes prior to sampling did not influence measurements triggered with $1 \mathrm{pM}$ tissue factor or higher. Although peak height in the presence of corn trypsin inhibitor was lower, the observed differences were within the inter-assay variations. Given these results and practical considerations (including additional costs of more than $€ 15$ per tube), we recommend no addition of corn trypsin inhibitor in thrombin generation assays with $1 \mathrm{pM}$ tissue factor initiation or higher.

In conclusion, our recommendations to ensure optimal reproducibility and comparability within and between study centers are:

1. No addition of corn trypsin inhibitor to thrombin generation assays triggered with tissue factor in a concentration of $1 \mathrm{pM}$ or higher;

2. Standardized blood collection and plasma preparation, including two-step centrifugation to remove microparticles from the plasma;

3. Use of commercially available and standardized reagents (including phospholipids and thrombin generation initiator);

4. Normalization of non-time dependent thrombin generation parameters (endogenous thrombin potential and peak height) against pooled normal plasma. 


\section{Coagulation-dependent hypercoagulability - the clinical application of thrombin generation}

Representation of coagulation activity or potential would be useful in patients with thrombotic disease to get a general overview of their current state of coagulability and could possibly be translated in an actual risk predictor. In this respect, several studies have attempted to estimate coagulation activity in patient plasma samples. Initial studies focused on measurements of prothrombin fragment $1+2$ as a marker of the conversion of prothrombin to thrombin, ${ }^{28-31}$ and complexes of thrombin and antithrombin. ${ }^{28,32,33}$ Likewise, D-dimer levels reflect ongoing fibrinolysis following the formation of thrombi. ${ }^{28,32,33}$

In patient studies, risks for acute myocardial infarction, cerebrovascular accident and deep venous thrombosis were (generally) positively associated with the aforementioned laboratory markers, although some studies showed conflicting data.9,2834 A limitation of most studies is their retrospective nature, that they did not take outcome parameters into account, and that it is difficult to distinguish whether the observed changes in coagulability are either a cause or an effect of the thrombotic disease. More recently, D-dimer levels have been studied prospectively in deep venous thrombosis patients and several authors provided evidence that patients with persistently increased D-dimer levels are at higher risk for recurrent disease. ${ }^{35,36}$

Application of the thrombin generation technique to reflect overall coagulation in these patients was the inevitable next step, but there is a subtle yet very important difference from the aforementioned markers of coagulation. While prothrombin fragment $1+2$, thrombin-antithrombin complexes and D-dimer reflect actual ongoing coagulation, thrombin generation provides an indication of the activity that could potentially occur should the coagulation cascade be activated. In fact, endogenous thrombin potential (as the most intensively studied thrombin generation parameter) was found to be negatively correlated with prothrombin fragment $1+2$ (albeit in pediatric patients with congenital heart disease), ${ }^{37}$ but was increased in patients after acute myocardial infarction. ${ }^{38}$

Our study in patients with acute myocardial infarction (Chapter 4.1) was conducted to utilize the thrombin generation assay as a risk predictor of outcome. Plasma samples were drawn during the acute phase of the infarction (before initiation of therapy) and patients were followed-up for 12 months and relevant clinical outcome was recorded. In agreement with previous studies overall thrombin generating potential was increased during the infarction, and was persistently increased six months later. Endogenous thrombin potential measured on admission was, surprisingly, significantly associated with outcome in an inverse manner. Patients with low thrombin generation were at 
higher risk to develop a recurrent infarction or stroke, and at a higher risk of cardiovascular death.

We hypothesized three opposing mechanisms explaining this finding: 1 . consumption of thrombin resulting in a decreased thrombin generation potential; 2. low thrombin generation response (together with decreased thrombomodulin in atherosclerosis) causing insufficient activation of the protein $\mathrm{C}$ system; 3 . upregulation of antithrombotic proteins. Consumption of thrombin, however, is not very likely because of the relatively small and acute thrombotic process in comparison to deep venous thrombosis, for example. Although thrombin generation in general was increased in these patients compared to healthy individuals (Chapter 4.2), due to the study design we did not have samples to confirm the absence of thrombin consumption in the acute phase of thrombosis. In acute myocardial infarction patients, in addition, thrombin generation was not correlated with prothrombin fragment $1+2$, and thus does not provide a direct link between actual prothrombin activation and thrombin potential. Lastly, thrombin generation may actually be increased, but upregulation of antithrombotic proteins could influence the test results. From the determinants study (Chapter 3.2) it can be appreciated that tissue factor pathway inhibitor is a particular strong suppressor of the thrombin generation parameters and it has been published (although in vitro) that endothelial cells release tissue factor pathway inhibitor in the presence of thrombin. ${ }^{39}$ A repetition of the determinants study presented in Chapter 3.2 in patients with acute myocardial infarction could shed light on this suprising, but interesting, data.

In contrast to the results obtained in patients with acute myocardial infarction, increased thrombin generation was associated with recurrence of deep venous thrombosis (Chapter 4.3). Interestingly, while thrombin generation was persistently increased during follow-up for a total of two years, the last plasma sample taken before the recurrence showed a further increase. When the plasma was assayed in the presence of thrombomodulin, the reduction in thrombin generation that could be achieved was significantly less in patients with a recurrence during follow-up, suggesting resistance to thrombomodulin in these plasmas. While thrombin generation in the absence of thrombomodulin was associated with known risk factors such as residual thrombosis, ${ }^{40}$ previous thrombosis, age ${ }^{41}$ and FV Leiden, ${ }^{42}$ addition of thrombomodulin removed such associations and could therefore serve as an additional risk factor besides these known risk factors.

\section{Fibrinolysis-dependent hypercoagulability - targeting the renin- angiotensin system}

The fibrinolysis-dependent hypercoagulability that is present in hypertension is presented in Chapter 5.1. The renin-angiotensin system is the predominantly involved 
system that links blood pressure and fibrinolysis, or rather the inhibition of fibrinolysis. ${ }^{43}$ Increased angiotensin II induces plasminogen activator inhibitor type-1 release upon stimulation of the angiotensin II receptor type-1, and this results in hypofibrinolysis - and thus relative hypercoagulability. ${ }^{43,44}$ In addition, there is evidence (in vitro) that tissue factor is upregulated and expressed on the endothelial surface, ${ }^{45}$ further disturbing the balance between coagulation and fibrinolysis. In apparent contradiction is the finding that high tissue-type plasminogen activator antigen is associated with an increased risk for arterial thrombotic disease, ${ }^{46}$ but this effect is most likely the result of increased complex formation with the upregulated plasminogen activator inhibitor type- 1 because this complex has a slower clearance than free (active) tissue-type plasminogen activator. ${ }^{47}$

From this, it can be hypothesized that administration of antihypertensive medication that influences the renin-angiotensin system may ameliorate the level of fibrinolytic activity, and this effect may be present regardless of changes in blood pressure. We tested this hypothesis by administering the angiotensin II receptor blocker eprosartan in a non-pressor dose to therapy-resistant hypertensive patients undergoing renal artery angiography (Chapter 5.2). Indeed, eprosartan resulted in a sharp decrease in plasminogen activator inhibitor type- 1 activity and tissue-type plasminogen activator antigen, with a concomitant increase in activity of the latter. Although these effects of angiotensin II receptor blockers have been described before, we were able to demonstrate that this effect also occurs in therapy-resistant hypertension in the absence of changes in blood pressure. Given these results it is tempting to recommend this class of medication to all hypertensive patients, but because our study only focused on short-term effects, the effects on restoration of fibrinolytic activity on the longer term should be investigated. In addition, it is unclear whether these effects translate into a decreased incidence of thrombotic complications of hypertension.

\section{Coagulation-modifying medication and the effects on thrombin generation}

While thrombin generation measurements are useful to determine the potential activity of coagulation in patients, treatment that influences this coagulation activity obviously also alters thrombin generation. Examples of anticoagulant treatment that influence thrombin generation are low molecular weight heparin (as described in Chapter 4.1) and vitamin $\mathrm{K}$ antagonists (Chapter 4.2). A study focusing on the effects of procoagulant treatment (FVIII administration in haemophilia A patients) is presented in Chapter 6.

Haemophilia A is characterized by decreased levels of FVIII and this results in a bleeding tendency. Thrombin generation has been shown to reflect this haemorrhagic tendency in patients, ${ }^{48,49}$ while increased FVIII levels reflect a procoagulant state. ${ }^{50}$ Administration of (procoagulant) recombinant FVIII to haemophilia A patients restores 
this hypocoagulability and this is reflected in normalization of thrombin generation measurements upon FVIII infusion. Although FVIII levels in plasma are correlated with the incidence of bleedings, there is a wide inter-individual variation indicating that other components of coagulation are involved besides FVIII. In agreement with this observation are previously published studies in which parameters of thrombin generation and FVIII were correlated. These studies again showed wide inter-individual variations in thrombin generation parameters at comparable FVIII plasma levels. ${ }^{51}$

We studied thrombin generation during 48 hours after recombinant FVIII administration and we were able to confirm the aforementioned findings. In addition, we hypothesized that addition of thrombomodulin to the Calibrated Automated Thrombogram results in an assay that may better reflect FVIII levels because thrombomodulin-induced reduction of thrombin generation is dependent on plasma levels of FV and FVIII. Since FV levels are not expected to show significant changes during the 48 hours of the study protocol, changes in the observed reductions in the presence of thrombomodulin are expected to be predominantly dependent on FVIII levels. Multiple linear regression analysis incorporating thrombin generation parameters measured in the presence of thrombomodulin indeed resulted in a moderately better reflection of plasma FVIII levels. Whether this results in a clinically relevant method for screening bleeding tendency remains to be established in a prospective study. 


\section{Relevance for thrombin generation measurements in a laboratory setting}

This thesis provides results from studies on optimization, standardization and sensitivity for coagulation-influencing therapy of the Calibrated Automated Thrombogram as a technique to measure thrombin generation. Subsequent recommendations on plasma sample collection and preparation, use of reagents and expression of thrombin generation results are given. In addition, the contribution of pro- and anticoagulant proteins on parameters of the thrombin generation curve are explored. These results and recommendations are a first effort to standardize thrombin generation measurements to be able to compare results between laboratories and promote (international) cooperation on thrombin generation research.

\section{Relevance of determining (hyper)coagulability for clinical practice}

This thesis presents studies in patients with coagulation- and fibrinolysis-dependent hypercoagulability in whom parameters that reflect activity of either coagulation or fibrinolysis were determined, including measurements of thrombin generation. The results of the presented studies on associations between thrombin generation and clinical outcome after arterial and venous thrombosis provide a starting point for further research focusing on the use of thrombin generation measurements on actual clinical decision making, based on a patient's state of hypercoagulability. Likewise, the presented study on the renin-angiotensin system as a target to reduce hypercoagulability in therapy-resistant hypertension serves as a basis for prospective intervention studies looking into possible benefits from a more hypercoagulabilityspecific approach. 


\section{References}

1. Rosamond W, Flegal K, Furie K, Go A, Greenlund K, Haase N et al.; American Heart Association Statistics Committee and Stroke Statistics Subcomittee. Heart disease and stroke statistics: 2008 update: a report from the American Heart Association Statistics Committee and Stroke Statistics Subcommittee. Circulation. 2008;117:e25-e146.

2. Nachman RL, Silverstein R. Hypercoagulable states. Ann Intern Med. 1993;119:819-827.

3. Schafer AI, Levine MN, Konkle BA, Kearon C. Thrombotic disorders: diagnosis and treatment. Hematology Am Soc Hematol Educ Program. 2003:520-539.

4. Gaffney PJ, Edgell TA, Whitton CM. The haemostatic balance - Astrup revisited. Haemostasis. 1999;29:58-71.

5. Chiuve SE, McCullough ML, Sacks FM, Rimm EB. Healthy lifestyle factors in the primary prevention of coronary heart disease among men. Circulation. 2006;114:160-167.

6. Stampfer MJ, Hu FB, Manson JE, Rimm EB, Willett WC. Primary prevention of coronary heart disease in women through diet and lifestyle. N Engl J Med. 2000;343:16-22.

7. Seljeflot I, Hurlen M, Hole T, Arnesen H. Soluble tissue factor as predictor of future events in patients with acute myocardial infarction. Thromb Res. 2003;111:369-372.

8. Van der Putten RF, Glatz JF, Hermens WT. Plasma markers of activated hemostasis in the early diagnosis of acute coronary syndromes. Clin Chim Acta. 2006;371:37-54.

9. Dahlbäck B. Advances in understanding pathogenic mechanisms of thrombophilic disorders. Blood. 2008;112:19-27.

10. Chinthammitr Y, Vos HL, Rosendaal FR, Doggen CJ. The association of prothrombin A19911G polymorphism with plasma prothrombin activity and venous thrombosis: results of the MEGA study, a large population-based case-control study. J Thromb Haemost. 2006;4:25872592.

11. Kyrle PA, Minar E, Hirschl M, Bialonczyk C, Stain M, Schneider B et al. High plasma levels of factor VIII and the risk of recurrent venous thromboembolism. N Engl J Med. 2000;343:457462.

12. Legnani C, Cini M, Cosmi B, Poggi M, Boggian O, Palareti G. Risk of deep venous thrombosis: interaction between oral contraceptives and high factor VIII levels. Haematologica. 2004;89:1347-1351.

13. Bank I, Libourel EJ, Middeldorp S, Hamulyák K, van Pampus EC, Koopman MM et al. Elevated levels of FVIII:C within families are associated with an increased risk for venous and arterial thrombosis. J Thromb Haemost. 2005;3:97-84.

14. Spronk HM, Govers-Riemslag JW, ten Cate H. The blood coagulation system as a molecular machine. Bioessays. 2003;25:1220-1228.

15. Fogari R, Zoppi A. Antihypertensive drugs and fibrinolytic function. Am J Hypertens. 2006;19:1293-1299.

16. De Smedt E, Al Dieri R, Spronk HM, Hamulyák K, ten Cate H, Hemker HC. The technique of measuring thrombin generation with fluorogenic substrates: 1. Necessity of adequate calibration. Thromb Haemost. 2008;100:343-349.

17. Duchemin J, Pan-Petesch B, Arnaud B, Blouch MT, Abgrall JF. Influence of the coagulation factors and tissue factor concentration on the thrombin generation test in plasma. Thromb Haemost. 2008;99:767-773. 
18. Van Veen JJ, Gatt A, Cooper PC, Kitchen S, Makris M. Between-batch variation of calibrator activity can significantly influence fluorogenic measurement of thrombin generation. $J$ Thromb Haemost. 2006;4:2514-2516.

19. Van Veen JJ, Gatt A, Makris M. Thrombin generation testing in routine clinical practice: are we there yet? BrJ Haematol. 2008;142:889-903.

20. Dargaud Y, Luddington R, Gray E, Negrier C, Lecompte T, Petros S et al. Effect of standardization and normalization on imprecision of calibrated automated thrombography: an international multicentre study. Br J Haematol. 2007;139:303-309.

21. Devreese K, Wijns W, Combes I, Van Kerckhoven S, Hoylaerts MF. Thrombin generation in plasma of healthy adults and children: chromogenic versus fluorogenic thrombogram analysis. Thromb Haemost. 2007;98:600-613.

22. Haidl H, Cimenti C, Leschnik B, Zach D, Muntean W. Age-dependency of thrombin generation measured by means of calibrated automated thrombography (CAT). Thromb Haemost. 2006;95:772-775.

23. Hemker HC, Giesen P, Al Dieri R, Regnault V, de Smedt E, Wagenvoord R et al. The Calibrated Automated Thrombogram (CAT): a universal routine test for hyper- and hypocoagulability. Pathophysiol Haemost Thromb. 2002;32:249-253.

24. Luddington R, Baglin T. Clinical measurement of thrombin generation by calibrated automated thrombography requires contact factor inhibition. J Thromb Haemost. 2004;2:1954-1959.

25. Van Veen JJ, Gatt A, Cooper PC, Kitchen S, Bowyer AE, Makris M. Corn trypsin inhibitor in fluorogenic thrombin-generation measurements is only necessary at low tissue factor concentrations and influences the relationship between factor VIII coagulant activity and thrombogram parameters. Blood Coagul Fibrinolysis. 2008;19:183-189.

26. Ramström S. Clotting time analysis of citrated blood samples is strongly affected by the tube used for blood sampling. Blood Coagul Fibrinolysis. 2005;16:447-452.

27. Ota S, Wada H, Abe Y, Yamada E, Sakaguchi A, Nishioka J et al. Elevated levels of prothrombin fragment 1+2 indicate high risk of thrombosis. Clin Appl Thromb Hemost. 2008;14:279-285.

28. Agewall S, Wikstrand J, Fagerberg B. Prothrombin fragment $1+2$ is a risk factor for myocardial infarction in treated hypertensive men. J Hypertens. 1998;16:537-541.

29. Cooper JA, Miller GJ, Bauer KA, Morrissey JH, Meade TW, Howarth DJ et al. Comparison of novel hemostatic factors and conventional risk factors for prediction of coronary heart disease. Circulation. 2000;102:2816-2822.

30. Côté R, Wolfson C, Solymoss S, Mackey A, Leclerc JR, Simard D et al. Hemostatic markers in patients at risk of cerebral ischemia. Stroke. 2000;31:1856-1862.

31. Kyrle PA, Eichinger S, Pabinger I, Stümpflen A, Hirschl M, Bialonczyk C et al. Prothrombin fragment $\mathrm{F} 1+2$ is not predictive for recurrent venous thromboembolism. Thromb Haemost. 1997;77:829-833.

32. Lowe GD, Rumley A, Sweetnam PM, Yarnell JW, Rumley J. Fibrin D-dimer, markers of coagulation activation and the risk of major ischaemic heart disease in the Caerphilly study. Thromb Haemost. 2001;86:822-827.

33. Oldgren J, Linder R, Grip L, Siegbahn A, Wallentin L. Coagulation activity and clinical outcome in unstable coronary artery disease. Arterioscler Thromb Vasc Biol. 2001;21:10591064 . 
34. Palareti G, Legnani C, Cosmi B, Valdre L, Lunghi B, Bernardi F et al. Predictive value of Ddimer test for recurrent venous thromboembolism after anticoagulation withdrawal in subjects with a previous idiopathic event and in carriers of congenital thrombophilia. Circulation. 2003;108:313-318.

35. Palareti G, Legnani C, Cosmi B, Guazzaloca G, Pancani C, Coccheri S. Risk of venous thromboembolism recurrence: high negative predictive value of $\mathrm{D}$-dimer performed after oral anticoagulation is stopped. Thromb Haemost. 2002;87:7-12.

36. Legnani C, Palareti G, Cosmi B, Cini M, Tosetto A, Tripodi A; PROLONG Investigators (FCSA and Italian Federation of Thrombosis Centers). Different cut-off values of quantitative Ddimer methods to predict the risk of venous thromboembolism recurrence: a post-hoc analysis of the PROLONG study. Haematologica. 2008;93:900-907.

37. Koestenberger M, Cvirn G, Nagel B, Rosenkranz A, Leschnik B, Gamillscheg A et al. Thrombin generation determined by calibrated automated thrombography (CAT) in pediatric patients with congenital heart disease. Thromb Res. 2008;122:13-19.

38. Van der Putten RF, Glatz JF, Hermens WT. Plasma markers of activated hemostasis in the early diagnosis of acute coronary syndromes. Clin Chim Acta. 2006;371:37-54.

39. Crawley JT, Lane DA. The haemostatic role of tissue factor pathway inhibitor. Arterioscler Thromb Vasc Biol. 2008;28:233-242.

40. Young L, Ockelford P, Milne D, Rolfe-Vyson V, Mckelvie S et al. Post-treatment residual thrombosis increases the risk of recurrent deep vein thrombosis and mortality. J Thromb Haemost. 2006;4:1919-1924.

41. Baglin T, Palmer CR, Luddington R, Baglin C. Unprovoked recurrent venous thrombosis: prediction by D-dimer and clinical risk factors. J Thromb Haemost. 2008;6:577-582.

42. Marchiori A, Mosena L, Prins MH, Prandoni P. The risk of recurrent venous thromboembolism among heterozygous carriers of factor $\mathrm{V}$ Leiden or prothrombin G20210A mutation. A systematic review of prospective studies. Haematologica. 2007;92:1107-1114.

43. Brown NJ, Agirbasli MA, Williams GH, Litchfield WR, Vaughan DE. Effect of activation and inhibition of the renin-angiotensin system on plasma PAI-1. Hypertension. 1998:32:965-971.

44. Lip GY. Hypertension and the prothrombotic state. J Hum Hypertens. 2000;14:687-690.

45. Mehta JL, Li DY, Yang H, Raizada MK. Angiotensin II and IV stimulate expression and release of plasminogen activator inhibitor-1 in cultured human coronary artery endothelial cells. $J$ Cardiovasc Pharmacol. 2002;39:789-794.

46. Goodfield NE, Newby DE, Ludlam CA, Flapan AD. Effects of acute angiotensin II type-1 receptor antagonism and angiotensin converting enzyme inhibition on plasma fibrinolytic parameters in patients with heart failure. Circulation. 1999;99:2983-2985.

47. Brown NJ, Kumar S, Painter CA, Vaughan DE. ACE inhibition versus angiotensin type-1 receptor antagonism: differential effects on PAI-1 over time. Hypertension. 2002;40:859865.

48. Beltran-Miranda CP, Khan A, Jaloma-Cruz AR, Laffan MA. Thrombin generation and phenotypic correlation in haemophilia A. Haemophilia. 2005;11:326-334.

49. Trossaert M, Regnault V, Sigaud M, Boisseau P, Fressinaud E, Lecompte T. Mild haemophilia A with factor VIII assay discrepancy: using thrombin generation assay to assess the bleeding phenotype. J Thromb Haemost. 2008;6:486-493. 


\section{Chapter 7.1}

50. Siegemund A, Petros S, Siegemund T, Scholz U, Seyfarth HJ, Engelmann J. The endogenous thrombin potential and high levels of coagulation factor VIII, factor IX and factor XI. Blood Coagul Fibrinolysis. 2004;15:241-244.

51. Lewis SJ, Stephens E, Florou G, Macartney NJ, Hathaway LS, Knipping J et al. Measurement of global haemostasis in severe haemophilia A following factor VIII infusion. Br J Hematol. 2007;138:775-782. 
Chapter 7.2

Algemene discussie, samenvatting en conclusies 
Chapter 7.2 


\section{Stollings- versus fibrinolysegerelateerde verhoogde stollingsneiging}

Trombose is een belangrijke oorzaak van ziekte en sterfte, en wereldwijd is er een toenemende incidentie van (met name) arteriële trombose. ${ }^{1}$ Zowel veneuze als arteriële trombose gaat gepaard met, en ontstaat door een toestand van verhoogde stollingsneiging (hypercoagulabiliteit). Hoewel verschillende vormen van trombose (acuut myocardinfarct, herseninfarct, diepveneuze trombose, longembolie) verschillende risicofactoren kunnen hebben, leiden deze in meer of mindere mate tot bloed met een verhoogde neiging tot het vormen van bloedstolsels. ${ }^{2,3}$ Feitelijk raakt het evenwicht tussen stolling en stollingsafbraak (fibrinolyse) hierdoor verstoord. ${ }^{4}$

De laatste jaren is uitgebreid onderzoek verricht om zowel biochemische als levensstijlfactoren aan te duiden die bijdragen aan deze verhoogde stollingsneiging.5,6 Naast bekende risicofactoren als roken, leeftijd en overgewicht blijken arteriële en veneuze trombose voornamelijk geassocieerd met biochemische factoren die de activiteit van de stolling beïnvloeden (verhogen) of reflecteren, waaronder plasmaoplosbaar weefselfactor, ${ }^{7}$ antitrombine, ${ }^{8,9}$ protrombine $^{10}$ en FVIII.11-13 Naast hypercoagulabiliteit die wordt veroorzaakt door een verhoogde activiteit van stolling kan een verhoogde stollingsneiging ook ontstaan door een afname in de acitiviteit van de fibrinolyse, ${ }^{14}$ zoals bij hoge bloeddruk (hypertensie) het geval is. ${ }^{15}$ Deze verschillende mechanismen vragen om specifieke tests en behandelingen die erop gericht zijn het verstoorde evenwicht tussen stolling en fibrinolyse te herstellen. In dit proefschrift wordt dan ook een onderscheid gemaakt tussen 1. Stollingsgerelateerde hypercoagulabiliteit enerzijds, en 2. Fibrinolysegerelateerde hypercoagulabiliteit anderzijds.

\section{Optimalisatie en validatie van de trombinegeneratietest}

Een groot deel van dit proefschrift richt zich op de mogelijkheid om potentiële stollingsactiviteit te meten met behulp van de trombinegeneratietest in plasmasamples van patiënten met diverse vormen van trombose. In Hoofdstuk 3 worden studies besproken die zijn uitgevoerd om de Calibrated Automated Thrombogram techniek voor het meten van trombinegeneratie in ons laboratorium te valideren. Er zijn reeds vele studies verschenen om normaalwaarden voor trombinegeneratie vast te stellen, maar door de uiteenlopende technieken met verschillende initiatoren in verschillende concentraties en de grote diversiteit in gebruikte fosfolipiden en plasmabereiding zijn deze studies moeilijk onderling te vergelijken. ${ }^{16-22}$ Bovendien gebruiken de beschikbare softwarepakketten uiteenlopende definities voor parameters die de trombinecurve beschrijven. Recentelijk bevestigden Van Veen et al. ${ }^{19}$ en Dargaud et al. ${ }^{20}$ de slechte onderlinge vergelijkbaarheid door identieke plasmasamples door verschillende instituten te laten meten. Dit resulteerde in variatiecoefficiënten tot $40 \%$ (voor de 
endogene trombinepotentiaal).

Om optimale vergelijkbaarheid te bewerkstelligen kozen we voor onze patiëntenstudies een commercieel verkrijgbare techniek ${ }^{23}$ met de bijbehorende reagentia. We gebruikten plasmasamples van 139 gezonde vrijwilligers om referentiewaarden en variatie (zowel inter- als intra-assay) van de Calibrated Automated Thrombogram techniek vast te stellen. Daarnaast werden bloedafnames herhaald bij 33 gezonde personen na zes weken, 12 weken en één jaar. Trombinegeneratiemetingen werden herhaald na vijf en negen maanden. De trombinegeneratietest bleek, geheel onverwacht, niet stabiel in de tijd: er was sprake van een afname in trombinegeneratie na vijf maanden, terwijl de meting na negen maanden vergelijkbaar was met de eerste meting. Omdat pre-analytische omstandigheden onveranderd waren, was instabiliteit van de gebruikte reagentia de waarschijnlijkste oorzaak. Dezelfde verschuiving in trombinegeneratie trad op in het normaalplasma dat bij elke meting als interne controle werd meegenomen. Wanneer trombinegeneratie van geteste samples niet in $\mathrm{nM}$ trombine werd uitgedrukt, maar als percentage van normaalplasma (per definitie 100\%) verdween de tijdelijke variatie. Deze 'normalisatie' resulteerde in acceptabele variaties (zowel inter- als intra-assay) van minder dan 8\%. Deze resultaten, besproken in Hoofdstuk 3.1, tonen de noodzaak van het normaliseren van resultaten van de trombinegeneratietest. Dargaud et al. ${ }^{20}$ kwamen tot een vergelijkbare aanbeveling.

Trombinegeneratie geeft niet alleen een algemeen beeld van potentiële stollingsactiviteit, maar de afzonderlijke parameters die de trombinecurve beschrijven reflecteren specifieke fasen van de stolling. De lag time beschrijft de initiatiefase, de piekhoogte (peak height), time to peak, en steilheid (slope) geven de propagatiefase weer, en de time to the start of the tail beschrijft de terminatiefase. De endogene trombinepotentiaal komt overeen met de totale hoeveelheid gegenereerd trombine en is afhankelijk van de hierboven genoemde fasen. Tijdens deze fasen spelen stollingsactiverende en -remmende eiwitten een rol, afhankelijk van de mate van activatie. Hun relatieve bijdrage aan trombinegeneratie werd bestudeerd in gezonde vrijwilligers zoals beschreven in Hoofdstuk 3.2. Om de determinanten van de trombinegeneratie vast te stellen werden stolfactoren en factoren van het proteïne $C$ systeem gemeten en geanalyseerd met behulp van multivariate regressie. Om de test gevoeliger te maken voor de activiteit van het proteïne $\mathrm{C}$ systeem werden trombomoduline en geactiveerd proteïne $\mathrm{C}$ toegevoegd. In de analyse bleken fibrinogeen, FVII, vrij proteïne S en vrij tissue factor pathway inhibitor de grootste bijdragen te leveren aan de lag time. De endogene trombinepotentiaal en piekhoogte werden met name bepaald door fibrinogeen, vrij tissue factor pathway inhibitor en antitrombine. Bij hoge weefselfactorconcentraties was FV een extra determinant, en FXII bij lage weefselfactorconcentraties.

Deze resultaten moeten zorgvuldig worden geïnterpreteerd omdat onze studiegroep uit gezonde vrijwilligers bestond met normale plasmaspiegels van stolfactoren, en 
relatief kleine onderlinge variaties. Mede door de gebruikte statistische methode (multivariate regressieanalyse) kunnen de gevonden resultaten niet direct worden geëxtrapoleerd naar patiënten met (een verhoogd risico op) trombose. Een herhaling van deze studie in diverse groepen patiënten zou de beschreven resultaten in perspectief kunnen plaatsen.

Een veelbesproken onderwerp is de invloed van het intrinsieke stollingssysteem, of contactactivatie, op trombinegeneratie. ${ }^{24,25}$ Wanneer plasma wordt geïncubeerd in aanwezigheid van calcium en fosfolipiden, maar zonder initiator van de intrinsieke stolling, kan na ongeveer 20 minuten generatie van trombine worden waargenomen. In de aanwezigheid van een voldoende hoge concentratie weefselfactor speelt contactactivatie waarschijnlijk een minder belangrijke rol, maar het effect van contactactivatie bij lage concentraties weefselfactor is controversieel. In onze determinantenstudie was FXII significant geassocieerd met de endogene trombinepotentiaal en de piekhoogte bij stimulatie met $1 \mathrm{pM}$ weefselfactor, maar niet bij 13,6 pM. Het is echter onduidelijk of er sprake is van FXII activatie tijdens de trombinegeneratiemetingen, of dat kleine hoeveelheden FXII reeds tijdens de bloedafname worden geactiveerd. Hoewel FXIIa snel wordt gebonden aan C1esteraseremmer zou FXI al geactiveerd kunnen zijn.

Door corn trypsin inhibitor aan plasma toe te voegen kan beïnvloeding van de trombinegeneratie door contactactivatie worden vermeden, ${ }^{26}$ maar het was onduidelijk of het vóór de bloedafname (in de bloedafnamebuizen), tijdens de bewerking van plasma of tijdens de daadwerkelijke meting moest worden toegevoegd. Hoofdstuk 3.3 beschrijft een studie bij gezonde vrijwilligers waarin we bloedafnamemethoden varieerden en corn trypsin inhibitor op verschillende momenten vóór en tijdens de metingen toevoegden. Bovendien varieerden we de concentraties van de intitiatoren weefselfactor en kaoline. Aan plasma toegevoegde corn trypsin inhibitor had alleen een significant effect op de metingen bij weefselfactor concentraties onder 0,5 pM. Wanneer corn trypsin inhibitor werd toegevoegd aan de afnamebuizen had het alleen een significant effect op metingen bij weefselfactor concentraties onder 1 pM. Hoewel de piekhoogte lager was in de aanwezigheid van corn trypsin inhibitor viel het verschil binnen de inter-assay variatie. Gezien deze resultaten en uit praktische overwegingen (waaronder de kosten van de aangepaste afnamebuizen, €15 per buis) raden we aan geen corn trypsin inhibitor te gebruiken wanneer de trombinegeneratietest wordt geactiveerd met $1 \mathrm{pM}$ weefselfactor of meer.

Concluderend geven de de volgende aanbevelingen om te komen tot een optimale reproduceerbaarheid en vergelijkbaarheid tussen studiecentra:

1. Geen toevoeging van corn trypsin inhibitor aan trombinegeneratietests die worden geactiveerd met 1 pM weefselfactor of meer;

2. Gestandaardiseerde bloedafname en -bewerking, waaronder centrifugatie in twee stappen om microparticles uit het plasma te verwijderen; 
3. Gebruik van commercieel verkrijgbare en gestandaardiseerde reagentia (waaronder fosfolipiden en initiatoren);

4. Normalisatie van tijdsonafhankelijke trombinegeneratieparameters (endogene trombinepotentiaal en piekhoogte) tegen normaalplasma.

\section{Stollingsgerelateerde hypercoagulabiliteit - klinische toepassing van trombinegeneratie}

Trombinegeneratie zou een bruikbare en waardevolle methode kunnen zijn om een algemeen beeld te krijgen van de mate van stollingsactivatie in patiënten met trombose, en zou mogelijk zelfs dienst kunnen doen als risicovoorspeller. Stollingsactiviteit in plasma van patiënten is in vele studies beschreven door middel van het meten van ondere andere protrombine fragment 1+2 (als een marker van de conversie van protrombine naar trombine), ${ }^{28-31}$ trombine-antitrombine complexen ${ }^{28,32,33}$ en Ddimeren (als een marker van de fibrinolyse volgend op trombose). ${ }^{28,32,33}$

Deze biochemische markers zijn in patiëntenstudies (over het algemeen) positief geassocieerd met het risico op myocardinfarct, herseninfarct en diepveneuze trombose, hoewel sommige studies tegenstrijdige resultaten lieten zien.9,28-34 Beperkingen van deze studies zijn onder andere het retrospectieve design, het gebrek aan uitkomstparameters en de onduidelijkheid of de verhoogde stollingsactiviteit een oorzaak of gevolg is van de trombose. Onlangs verschenen enkele studies waarin spiegels van D-dimeren prospectief werden vervolgd in patiënten met diepveneuze trombose. Uit de resultaten bleek dat patiënten met voortdurend verhoogde D-dimeren een grotere kans hebben op het krijgen van een recidief. ${ }^{35,36}$

Toepassing van de trombinegeneratietest in deze patiënten was de logische volgende stap, maar er is een subtiel, maar belangrijk verschil met de bovengenoemde stollingsmarkers. Terwijl protrombine fragment $1+2$, trombine-antitrombine complexen en D-dimeren werkelijk aanwezige stolling weerspiegelen, geeft trombinegeneratie een indicatie van de stollingsactiviteit die mogelijk kan ontstaan als de stollingscascade geactiveerd wordt. De endogene trombinepotentiaal correleerde zelfs omgekeerd met protrombine fragment $1+2$ (in pediatrische patiënten met aangeboren hartafwijkingen), ${ }^{37}$ hoewel protrombine fragment $1+2$ verhoogd was in patiënten met een acuut myocardinfarct. ${ }^{38}$

In Hoofdstuk 4.1 presenteren we een studie in patiënten met een eerste acuut myocardinfarct waarbij we de waarde van de trombinegeneratietest als risicovoorspeller van het klinisch beloop beschrijven. Tijdens de acute fase van het infarct (vóór start van de behandeling) werd bloed afgenomen, en patiënten werden gevolgd gedurende een periode van 12 maanden waarbij het klinisch beloop werd vastgelegd. In overeenstemming met eerdere studies bleek het niveau van trombinegeneratie verhoogd tijdens het infarct, met een persisterend verhoogde 
trombinegenratie na zes maanden. De endogene trombinepotentiaal gemeten bij presentatie was verrassend genoeg omgekeerd geassocieerd met klinische uitkomst. Patiënten met een lage endogene trombinepotentiaal hadden een grotere kans op het doormaken van een recidief infarct (myocard- en herseninfarct) en cardiovasculaire sterfte.

Deze resultaten leidden tot drie tegenstrijdige hypothesen: 1 . consumptie van trombine resulterend in een verlaagde trombinegeneratiepotentieel; 2 . een lage trombinegeneratierespons en een verminderde hoeveelheid trombomoduline (ten gevolge van atherosclerose) resulterend in onvoldoende activatie van het proteïne $C$ systeem; 3. een toegenomen activiteit van eiwitten met een antistollend effect. Consumptie van trombine is echter niet erg waarschijnlijk aangezien de arteriële trombose een relatief klein en acuut proces is, in tegenstelling tot bijvoorbeeld diepveneuze trombose. Hoewel trombinegeneratie over het algemeen verhoogd was in patiënten met diepveneuze trombose in vergelijking met gezonde individuen (Hoofdstuk 4.2) zijn er geen bloedsamples afgenomen tijdens de acute fase van de trombose om consumptie van trombine aan te tonen danwel uit te sluiten. In patiënten met een acuut myocardinfarct correleerde trombinegeneratie bovendien niet met protrombine fragment $1+2$, waardoor een directe link tussen werkelijke activatie van protrombine en mogelijke stollingsactiviteit niet kon worden aangetoond. Tenslotte is het mogelijk dat de trombinegeneratie verhoogd is, maar dat ook eiwitten met een antistollend effect in aantal of activiteit zijn toegenomen. Uit de determinantenstudie (Hoofdstuk 3.2) kan worden afgeleid dat met name tissue factor pathway inhibitor een sterk negatief (remmend) effect heeft op parameters van de trombinegeneratie. In vitro is aangetoond dat endotheelcellen tissue factor pathway inhibitor vrijmaken in de aanwezigheid van trombine. ${ }^{39}$ Een herhaling van de determinantenstudie zoals beschreven in Hoofdstuk 3.2 in patiënten met een acuut myocardinfarct zou bij kunnen dragen aan een beter begrip van deze verrassende, maar interessante, resultaten.

In tegenstelling tot de resultaten verkregen in de myocardinfarctpatiënten was verhoogde trombinegeneratie geassocieerd met recidiverende diepveneuze trombose (Hoofdstuk 4.3). Hoewel de trombinegeneratie blijvend verhoogd was tijdens follow-up gedurende twee jaar, liet de laatste sample vóór het optreden van het recidief een verdere stijging zien. De toevoeging van trombomoduline aan de trombinegeneratietest resulteerde in een afgenomen reductie in plasmasamples van patiënten met een trombose in het beloop, suggestief voor trombomodulineresistentie. Terwijl trombinegeneratie in afwezigheid van trombomoduline geassocieerd was met bekende risicofactoren als resttrombose, ${ }^{40}$ eerdere episode van trombose, leeftijd, ${ }^{41}$ en FV Leiden, ${ }^{42}$ leidde de toevoeging van trombomoduline aan de test tot een verlies van deze associaties. Trombinegeneratie met trombomoduline zou daarom een nieuwe risicofactor kunnen zijn naast deze bekende factoren. 


\section{Fibrinolysegerelateerde hypercoagulabiliteit - beïnvloeding van het renine-angiotensinesysteem}

Fibrinolysegerelateerde hypercoagulabiliteit in hypertensie wordt beschreven in Hoofdstuk 5.1. Het renine-angiotensinesysteem vormt de belangrijkste link tussen bloeddruk en fibrinolyse, of liever remming van de fibrinolyse. ${ }^{43}$ Stimulatie van de angiotensine II receptor type-1 door angiotensine II resulteert in het vrijkomen van plasminogen activator inhibitor type-1, wat vervolgens leidt tot hypofibrinolyse - en een relatief verhoogde stollingsneiging. ${ }^{43,44}$ Daarnaast zijn er aanwijzingen (in vitro) dat weefselfactor wordt opgereguleerd en tot expressie komt op het endotheeloppervlak; ${ }^{45}$ dit leidt tot een verdere verstoring van het evenwicht tussen stolling en fibrinolyse. In schijnbare tegenstelling is het gegeven dat een hoge tissue-type plasminogen activator spiegel is geassocieerd met een verhoogd risico op arteriële trombose. ${ }^{46}$ Dit is waarschijnlijk een weerspiegeling van verhoogde complexvorming door de aanwezigheid van meer plasminogen activator inhibitor type-1 omdat het complex trager wordt geklaard dan vrij (actief) tissue-type plasminogen activator. ${ }^{47}$

Behandeling met bloeddrukverlagende medicatie die zijn werking ontleent aan beïnvloeding van het renine-angiotensinesysteem zou een positief effect kunnen hebben op de mate van activiteit van de fibrinolyse, en dit effect zou zelfs op kunnen treden in afwezigheid van veranderingen in de bloeddruk. Deze hypothese leidde tot een onderzoek waarin we de angiotensine II receptorantagonist eprosartan toedienden aan therapieresistente patiënten met hypertensie, in een zodanig lage dosis dat er geen bloeddrukveranderingen optraden. Deze toediening vond plaats tijdens een angiografie van de nierarterie (Hoofdstuk 5.2). Toediening van eprosartan zorgde inderdaad voor een aanzienlijke daling in plasminogen activator inhibitor type-1 activiteit en tissue-type plasminogen activator antigeen, en een stijging in de activiteit van tissue-type plasminogen activator. Hoewel deze resultaten eerder zijn beschreven toont deze studie aan dat dit effect ook kan optreden in therapieresistente hypertensie, zonder veranderingen in de bloeddruk. Gezien deze resultaten is het verleidelijk dit type medicatie breder toe te passen bij patiënten met hoge bloeddruk, maar deze studie kijkt alleen naar effecten op de korte termijn. Bovendien is het nog onduidelijk of deze effecten zich vertalen naar een daling in de incidentie van trombotische complicaties van hoge bloeddruk.

\section{Stollingsmediërende medicatie en de effecten op trombine- generatie}

Trombinegeneratie lijkt dus een bruikbare methode om potentiële stollingsactivatie te meten in patiënten, maar het is vanzelfsprekend ook gevoelig voor stollingsmediërende 
medicatie. Voorbeelden hiervan zijn laag moleculair gewicht heparine (zoals beschreven in Hoofdstuk 4.1) en vitamine $\mathrm{K}$ antagonisten (Hoofdstuk 4.2). Een studie gericht op het in kaart brengen van stollingsbevorderende medicatie (de toediening van FVIII aan hemofilie A patiënten) wordt beschreven in Hoofdstuk 6.

Hemofilie A wordt gekarakteriseerd door verlaagde plasmaspiegels van FVIII en dit leidt tot een bloedingsneiging bij hemofilie A patiënten. Deze bloedingsneiging wordt weerspiegeld in trombinegeneratiemetingen, ${ }^{48,49}$ terwijl verhoogde plasmaspiegels van FVIII een staat van verhoogde stolbaarheid aangeven. ${ }^{50}$ De toediening van (procoagulant) recombinant FVIII via infusie aan hemofiliepatiënten corrigeert de verlaagde stollingsactiviteit en veroorzaakt een normalisatie van de trombinegeneratie. Het optreden van bloedingen in hemofilie A correleert met FVIII plasmaspiegels, maar er is een grote variatie tussen individuen wat er op kan wijzen dat naast FVIII nog andere componenten van de stolling van invloed zijn op het klinisch beeld. Deze observatie werd onlangs bevestigd in een aantal studies die de onderlinge relatie tussen FVIII en trombinegeneratie beschreven, waarin een grote interindividuele spreiding van de trombinegeneratie werd gevonden bij vergelijkbare FVIII plasmaspiegels. ${ }^{51}$

Onze studie waarin we trombinegeneratieparameters in kaart brachten gedurende 48 uur na toediening van recombinant FVIII bevestigde deze resultaten. Daarnaast onderzochten we de hypothese dat toevoeging van trombomoduline aan de Calibrated Automated Thrombogram de test gevoeliger zou maken voor FVIII, aangezien het remmende effect van trombomoduline afhankelijk is van de plasmaspiegels van $\mathrm{FV}$ en FVIII. Omdat het onwaarschijnlijk is dat FV grote schommelingen vertoonde tijdens de 48 uur dat het studieprotocol duurde, zou het waargenomen effect van trombomoduline voornamelijk veroorzaakt worden door verschillen in de concentratie FVIII. Multivariate regressieanalyse toonde dat de parameters die de trombinegeneratiecurve beschrijven beter de hoeveelheid FVIII weergeven wanneer trombomoduline aan de assay werd toegevoegd. Of deze techniek geschikt is om bloedingsrisico's in patiënten te schatten zal moeten blijken uit prospectieve studies. 


\section{Relevantie voor het meten van trombinegeneratie in een laboratoriumsetting}

Dit proefschrift beschrijft de optimalisatie, standaardisatie en medicatiegevoeligheid van de Calibrated Automated Thrombogram, een techniek voor het meten van trombinegeneratie, en daaruit voortvloeiende aanbevelingen ten aanzien van het afnemen en bewerken van bloedplasma, het gebruik van reagentia en het uitdrukken van de resultaten van trombinegeneratie. Daarnaast wordt de bijdrage aan trombinegeneratie van zowel pro- als anticoagulante factoren beschreven. Deze resultaten en aanbevelingen zijn een eerste aanzet tot het standaardiseren van trombinegeneratiemetingen, om zo de resultaten van verschillende laboratoria te kunnen vergelijken en (internationale) samenwerking op het gebied van trombinegeneratieonderzoek te stimuleren.

\section{Relevantie van het meten van (verhoogde) stolbaarheid in de kliniek}

Dit proefschrift presenteert studies in patiënten met stollings- en fibrinolysegerelateerde verhoogde stolbaarheid, waarbij parameters van stolling en fibrinolyse werden gemeten, waaronder trombinegeneratie. De gevonden associaties tussen trombinegeneratie en klinisch beloop na arteriële en veneuze trombose dienen als een startpunt voor toekomstig onderzoek gericht op de waarde van de trombinegeneratietest voor het maken van klinische beslissingen op geleide van de individuele stolbaarheid van een patiënt. Het onderzoek gericht op beïnvloeding van het renine-angiotensinesysteem vormt een basis voor prospectieve interventiestudies die de waarde in kaart moeten brengen van een behandeling die meer gericht is op de hypercoagulabiliteit waarmee therapieresistente hypertensie gepaard gaat. 


\section{Referenties}

1. Rosamond W, Flegal K, Furie K, Go A, Greenlund K, Haase N et al.; American Heart Association Statistics Committee and Stroke Statistics Subcomittee. Heart disease and stroke statistics: 2008 update: a report from the American Heart Association Statistics Committee and Stroke Statistics Subcommittee. Circulation. 2008;117:e25-e146.

2. Nachman RL, Silverstein R. Hypercoagulable states. Ann Intern Med. 1993;119:819-827.

3. Schafer AI, Levine MN, Konkle BA, Kearon C. Thrombotic disorders: diagnosis and treatment. Hematology Am Soc Hematol Educ Program. 2003:520-539.

4. Gaffney PJ, Edgell TA, Whitton CM. The haemostatic balance - Astrup revisited. Haemostasis. 1999;29:58-71.

5. Chiuve SE, McCullough ML, Sacks FM, Rimm EB. Healthy lifestyle factors in the primary prevention of coronary heart disease among men. Circulation. 2006;114:160-167.

6. Stampfer MJ, Hu FB, Manson JE, Rimm EB, Willett WC. Primary prevention of coronary heart disease in women through diet and lifestyle. N Engl J Med. 2000;343:16-22.

7. Seljeflot I, Hurlen M, Hole T, Arnesen H. Soluble tissue factor as predictor of future events in patients with acute myocardial infarction. Thromb Res. 2003;111:369-372.

8. Van der Putten RF, Glatz JF, Hermens WT. Plasma markers of activated hemostasis in the early diagnosis of acute coronary syndromes. Clin Chim Acta. 2006;371:37-54.

9. Dahlbäck B. Advances in understanding pathogenic mechanisms of thrombophilic disorders. Blood. 2008;112:19-27.

10. Chinthammitr Y, Vos HL, Rosendaal FR, Doggen CJ. The association of prothrombin A19911G polymorphism with plasma prothrombin activity and venous thrombosis: results of the MEGA study, a large population-based case-control study. J Thromb Haemost. 2006;4:25872592.

11. Kyrle PA, Minar E, Hirschl M, Bialonczyk C, Stain M, Schneider B et al. High plasma levels of factor VIII and the risk of recurrent venous thromboembolism. N Engl J Med. 2000;343:457462.

12. Legnani C, Cini M, Cosmi B, Poggi M, Boggian O, Palareti G. Risk of deep venous thrombosis: interaction between oral contraceptives and high factor VIII levels. Haematologica. 2004;89:1347-1351.

13. Bank I, Libourel EJ, Middeldorp S, Hamulyák K, van Pampus EC, Koopman MM et al. Elevated levels of FVIII:C within families are associated with an increased risk for venous and arterial thrombosis. J Thromb Haemost. 2005;3:97-84.

14. Spronk HM, Govers-Riemslag JW, ten Cate H. The blood coagulation system as a molecular machine. Bioessays. 2003;25:1220-1228.

15. Fogari R, Zoppi A. Antihypertensive drugs and fibrinolytic function. Am J Hypertens. 2006;19:1293-1299.

16. De Smedt E, Al Dieri R, Spronk HM, Hamulyák K, ten Cate H, Hemker HC. The technique of measuring thrombin generation with fluorogenic substrates: 1 . Necessity of adequate calibration. Thromb Haemost. 2008;100:343-349.

17. Duchemin J, Pan-Petesch B, Arnaud B, Blouch MT, Abgrall JF. Influence of the coagulation factors and tissue factor concentration on the thrombin generation test in plasma. Thromb Haemost. 2008;99:767-773. 
18. Van Veen JJ, Gatt A, Cooper PC, Kitchen S, Makris M. Between-batch variation of calibrator activity can significantly influence fluorogenic measurement of thrombin generation. $J$ Thromb Haemost. 2006;4:2514-2516.

19. Van Veen JJ, Gatt A, Makris M. Thrombin generation testing in routine clinical practice: are we there yet? BrJ Haematol. 2008;142:889-903.

20. Dargaud Y, Luddington R, Gray E, Negrier C, Lecompte T, Petros S et al. Effect of standardization and normalization on imprecision of calibrated automated thrombography: an international multicentre study. Br J Haematol. 2007;139:303-309.

21. Devreese K, Wijns W, Combes I, Van Kerckhoven S, Hoylaerts MF. Thrombin generation in plasma of healthy adults and children: chromogenic versus fluorogenic thrombogram analysis. Thromb Haemost. 2007;98:600-613.

22. Haidl H, Cimenti C, Leschnik B, Zach D, Muntean W. Age-dependency of thrombin generation measured by means of calibrated automated thrombography (CAT). Thromb Haemost. 2006;95:772-775.

23. Hemker HC, Giesen P, Al Dieri R, Regnault V, de Smedt E, Wagenvoord R et al. The Calibrated Automated Thrombogram (CAT): a universal routine test for hyper- and hypocoagulability. Pathophysiol Haemost Thromb. 2002;32:249-253.

24. Luddington R, Baglin T. Clinical measurement of thrombin generation by calibrated automated thrombography requires contact factor inhibition. J Thromb Haemost. 2004;2:1954-1959.

25. Van Veen JJ, Gatt A, Cooper PC, Kitchen S, Bowyer AE, Makris M. Corn trypsin inhibitor in fluorogenic thrombin-generation measurements is only necessary at low tissue factor concentrations and influences the relationship between factor VIII coagulant activity and thrombogram parameters. Blood Coagul Fibrinolysis. 2008;19:183-189.

26. Ramström S. Clotting time analysis of citrated blood samples is strongly affected by the tube used for blood sampling. Blood Coagul Fibrinolysis. 2005;16:447-452.

27. Ota S, Wada H, Abe Y, Yamada E, Sakaguchi A, Nishioka J et al. Elevated levels of prothrombin fragment 1+2 indicate high risk of thrombosis. Clin Appl Thromb Hemost. 2008;14:279-285.

28. Agewall S, Wikstrand J, Fagerberg B. Prothrombin fragment $1+2$ is a risk factor for myocardial infarction in treated hypertensive men. J Hypertens. 1998;16:537-541.

29. Cooper JA, Miller GJ, Bauer KA, Morrissey JH, Meade TW, Howarth DJ et al. Comparison of novel hemostatic factors and conventional risk factors for prediction of coronary heart disease. Circulation. 2000;102:2816-2822.

30. Côté R, Wolfson C, Solymoss S, Mackey A, Leclerc JR, Simard D et al. Hemostatic markers in patients at risk of cerebral ischemia. Stroke. 2000;31:1856-1862.

31. Kyrle PA, Eichinger S, Pabinger I, Stümpflen A, Hirschl M, Bialonczyk C et al. Prothrombin fragment $\mathrm{F} 1+2$ is not predictive for recurrent venous thromboembolism. Thromb Haemost. 1997;77:829-833.

32. Lowe GD, Rumley A, Sweetnam PM, Yarnell JW, Rumley J. Fibrin D-dimer, markers of coagulation activation and the risk of major ischaemic heart disease in the Caerphilly study. Thromb Haemost. 2001;86:822-827.

33. Oldgren J, Linder R, Grip L, Siegbahn A, Wallentin L. Coagulation activity and clinical outcome in unstable coronary artery disease. Arterioscler Thromb Vasc Biol. 2001;21:10591064 . 
34. Palareti G, Legnani C, Cosmi B, Valdre L, Lunghi B, Bernardi F et al. Predictive value of Ddimer test for recurrent venous thromboembolism after anticoagulation withdrawal in subjects with a previous idiopathic event and in carriers of congenital thrombophilia. Circulation. 2003;108:313-318.

35. Palareti G, Legnani C, Cosmi B, Guazzaloca G, Pancani C, Coccheri S. Risk of venous thromboembolism recurrence: high negative predictive value of D-dimer performed after oral anticoagulation is stopped. Thromb Haemost. 2002;87:7-12.

36. Legnani C, Palareti G, Cosmi B, Cini M, Tosetto A, Tripodi A; PROLONG Investigators (FCSA and Italian Federation of Thrombosis Centers). Different cut-off values of quantitative Ddimer methods to predict the risk of venous thromboembolism recurrence: a post-hoc analysis of the PROLONG study. Haematologica. 2008;93:900-907.

37. Koestenberger M, Cvirn G, Nagel B, Rosenkranz A, Leschnik B, Gamillscheg A et al. Thrombin generation determined by calibrated automated thrombography (CAT) in pediatric patients with congenital heart disease. Thromb Res. 2008;122:13-19.

38. Van der Putten RF, Glatz JF, Hermens WT. Plasma markers of activated hemostasis in the early diagnosis of acute coronary syndromes. Clin Chim Acta. 2006;371:37-54.

39. Crawley JT, Lane DA. The haemostatic role of tissue factor pathway inhibitor. Arterioscler Thromb Vasc Biol. 2008;28:233-242.

40. Young L, Ockelford P, Milne D, Rolfe-Vyson V, Mckelvie S et al. Post-treatment residual thrombosis increases the risk of recurrent deep vein thrombosis and mortality. J Thromb Haemost. 2006;4:1919-1924.

41. Baglin T, Palmer CR, Luddington R, Baglin C. Unprovoked recurrent venous thrombosis: prediction by D-dimer and clinical risk factors. J Thromb Haemost. 2008;6:577-582.

42. Marchiori A, Mosena L, Prins MH, Prandoni P. The risk of recurrent venous thromboembolism among heterozygous carriers of factor $\mathrm{V}$ Leiden or prothrombin G20210A mutation. A systematic review of prospective studies. Haematologica. 2007;92:1107-1114.

43. Brown NJ, Agirbasli MA, Williams GH, Litchfield WR, Vaughan DE. Effect of activation and inhibition of the renin-angiotensin system on plasma PAI-1. Hypertension. 1998:32:965-971.

44. Lip GY. Hypertension and the prothrombotic state. J Hum Hypertens. 2000;14:687-690.

45. Mehta JL, Li DY, Yang H, Raizada MK. Angiotensin II and IV stimulate expression and release of plasminogen activator inhibitor-1 in cultured human coronary artery endothelial cells. $J$ Cardiovasc Pharmacol. 2002;39:789-794.

46. Goodfield NE, Newby DE, Ludlam CA, Flapan AD. Effects of acute angiotensin II type-1 receptor antagonism and angiotensin converting enzyme inhibition on plasma fibrinolytic parameters in patients with heart failure. Circulation. 1999;99:2983-2985.

47. Brown NJ, Kumar S, Painter CA, Vaughan DE. ACE inhibition versus angiotensin type-1 receptor antagonism: differential effects on PAI-1 over time. Hypertension. 2002;40:859865.

48. Beltran-Miranda CP, Khan A, Jaloma-Cruz AR, Laffan MA. Thrombin generation and phenotypic correlation in haemophilia A. Haemophilia. 2005;11:326-334.

49. Trossaert M, Regnault V, Sigaud M, Boisseau P, Fressinaud E, Lecompte T. Mild haemophilia A with factor VIII assay discrepancy: using thrombin generation assay to assess the bleeding phenotype. J Thromb Haemost. 2008;6:486-493. 


\section{Chapter 7.2}

50. Siegemund A, Petros S, Siegemund T, Scholz U, Seyfarth HJ, Engelmann J. The endogenous thrombin potential and high levels of coagulation factor VIII, factor IX and factor XI. Blood Coagul Fibrinolysis. 2004;15:241-244.

51. Lewis SJ, Stephens E, Florou G, Macartney NJ, Hathaway LS, Knipping J et al. Measurement of global haemostasis in severe haemophilia A following factor VIII infusion. Br J Hematol. 2007;138:775-782. 


\section{Curriculum vitae}

Arne Dielis was born on the $15^{\text {th }}$ of January 1980 in Valkenswaard. After graduating high school (VWO Gymnasium) at Scholengemeenschap Were Di Valkenswaard in 1998, he started his Medicine study at Maastricht University. His interest in scientific research was instigated in 2002 during one of his first internships, a science program at Sanquin Blood Bank Maastricht under supervision of Joyce Curvers, PhD. Soon after, Arne was introduced to prof. Hugo ten Cate, $\mathrm{PhD}, \mathrm{MD}$, and prof. Peter de Leeuw, PhD, MD, and he applied for a position as PhD student. Between 2003 and 2005, Arne alternated between clinical internships and his work as a PhD student, and received a Kootstra fellowship research grant from the Faculty of Medicine, Maastricht University, in 2005. He obtained his MD degree at Maastricht University on the $26^{\text {th }}$ of September 2005.

To stay involved in clinical work, Arne combined his research with a position as dosing physician (doseerarts) at the Trombosedienst Maastricht, and as physician at the Venous Thrombosis outpatient department of the Academic Hospital Maastricht under supervision of Hugo ten Cate en Karly Hamulyák, PhD, MD.

In October 2008 Arne became a resident in Internal Medicine at Orbis Medisch Centrum in Sittard, and in March 2009 he started his specialization in Internal Medicine at VieCuri in Venlo, under supervision of Ton Luik, PhD, MD. 



\section{Publications}

\section{Papers}

Spronk HMH, Dielis AWJH, Panova-Noeva M, van Oerle R, Govers-Riemslag JWP, Hamulyák K, Falanga A, ten Cate H. Monitoring thrombin generation: Is addition of corn trypsin inhibitor needed? Thrombosis and Haemostasis. Accepted for publication, 2009.

Spronk HMH, ten Cate-Hoek AJ, Dielis AWJH, Hamulyák K, ten Cate H. Bepaling van trombinegeneratie in plasma: Een zinvolle stollingstest? Nederlands Tijdschrift voor Hematologie. 2009;6:22-27.

Löwenberg EC, Dielis AWJH, Meijers JC, ten Cate H, Levi M. Voortschrijdend inzicht in de werking van de bloedstolling in vivo. Nederlands Tijdschrift voor Geneeskunde. 2009;153:30-37.

Dielis AWJH, Balliël WMR, van Oerle R, Hermens WT, Spronk HMH, ten Cate H, Hamulyák K. Thrombomodulin-modified thrombin generation after in vivo recombinant factor VIII treatment in severe haemophilia A. Haematologica. 2008;93:1351-1357.

Ten Cate-Hoek AJ, Dielis AWJH, Spronk HMH, van Oerle R, Hamulyák K, Prins MH, ten Cate H. Thrombin generation in patients after acute deep-vein thrombosis. Thrombosis and Haemostasis. 2008;100:240-245.

Spronk HMH, Dielis AWJH, de Smedt E, van Oerle R, Fens D, Prins MH, Hamulyák K, ten Cate H. Assessment of thrombin generation II: Validation of the Calibrated Automated Thrombogram in platelet-poor plasma in a clinical laboratory. Thrombosis and Haemostasis. 2008;100:362-364.

Dielis AWJH, Castoldi E, Spronk HMH, van Oerle R, Hamulyák K, ten Cate H, Rosing J. Coagulation factors and the protein $\mathrm{C}$ system as determinants of thrombin generation in a normal population. Journal of Thrombosis and Haemostasis. 2008;6:125-131.

Dielis AWJH, Smid M, Spronk HMH, Houben AJHM, Hamulyák K, Kroon AA, ten Cate H, de Leeuw PW. Changes in fibrinolytic activity after angiotensin II receptor blockade in therapy-resistant hypertensive patients. Journal of Thrombosis and Haemostasis. 2007;5:509-515. 
Curvers J, Dielis AWJH, Heeremans J, van Wersch JWJ. Platelet function in whole blood donors is impaired: the effect of painkillers. Transfusion. 2007;47:67-73.

Dielis AWJH, Smid M, Spronk HMH, Hamulyák K, Kroon AA, ten Cate H, de Leeuw PW. The prothrombotic paradox of hypertension. Role of the renin-angiotensin and kallikrein-kinin systems. Hypertension. 2005;46:1236-1242.

\section{Oral presentations}

Dielis AWJH, Govers-Riemslag JWP, Winkens M, Wijers-Holys P, Hamulyák K, Spronk $\mathrm{HMH}$, Waltenberger J, ten Cate $\mathrm{H}$. The contact activation coagulation pathway is involved in (recurrent) coronary disease. 49 $9^{\text {th }}$ American Society of Hematology Annual Meeting, Atlanta, GA, 2007.

Dielis AWJH, Smid M, Spronk HMH, van Oerle R, Govers-Riemslag JWP, van der Voort D, Houben B, Hamulyák K, Kroon AA, de Leeuw PW, ten Cate H. Changes in fibrinolysis activity after angiotensin II receptor blockade in therapy resistant hypertensive patients. 18 ${ }^{\text {th }}$ Dutch Internal Medicine Meeting, Maastricht, The Netherlands, 2006.

\section{Abstracts}

Spronk HMH, Dielis AWJH, van Oerle R, Hamulyák K, ten Cate H. Monitoring thrombin generation: Do we need addition of corn trypsin inhibitor? 54 th Annual Meeting of the Scientific and Standardization Committee of the ISTH, Vienna, Austria, 2008.

Dielis AWJH, Balliël WMR, van Oerle R, Hermens WT, ten Cate H, Hamulyák K. Comparison of thrombin generation and FVIII level measurements in haemophilia patients after recombinant FVIII treatment. XXVIII th World Federation of Hemophilia International Congress, Istanbul, Turkey, 2008.

Balliël WMR, Dielis AWJH, van Oerle R, Hermens WT, ten Cate H, Hamulyák K. In vivo availability of two recombinant factor VIII products. XXVIIIth World Federation of Hemophilia International Congress, Istanbul, Turkey, 2008.

Dielis AWJH, Spronk HMH, van Oerle R, Winkens M, Wijers-Holys P, Hamulyák K, Rosing J, Waltenberger J, ten Cate $\mathrm{H}$. Thrombin generation is a marker of clinical outcome after acute myocardial infarction. Arteriosclerosis, Thrombosis and Vascular Biology Annual Conference, Atlanta, GA, 2008.

Dielis AWJH, Govers-Riemslag J, Winkens M, Wijers-Holys P, Spronk HMH, 
Waltenberger J, ten Cate $\mathrm{H}$, Hamulyák K. The contact activation system (through coagulation factors XII and XI) is a marker of outcome after acute myocardial infarction. Arteriosclerosis, Thrombosis and Vascular Biology Annual Conference, Atlanta, GA, 2008.

Balliël WMR, Dielis AWJH, van Oerle R, Hermens WT, ten Cate H, Hamulyák K. In vivo availability of two recombinant factor VIII products. XXI ${ }^{\text {th }}$ International Society on Thrombosis and Haemostasis Congress, Geneva, Switzerland, 2007.

Dielis AWJH, Balliël WMR, van Oerle R, Hermens WT, ten Cate H, Hamulyák K. Comparison of thrombin generation and FVIII level measurements in haemophilia patients after recombinant FVIII treatment. XXI ${ }^{\text {th }}$ International Society on Thrombosis and Haemostasis Congress, Geneva, Switzerland, 2007.

Dielis AWJH, Castoldi E, Spronk HMH, van Oerle R, Hamulyák K, Rosing J, ten Cate H. Coagulation factors and the protein $\mathrm{C}$ system as determinants of thrombin generation. $\mathrm{XXI}^{\text {th }}$ International Society on Thrombosis and Haemostasis Congress, Geneva, Switzerland, 2007.

Dielis AWJH, Winkens MHM, Spronk HMH, Wijers-Holys PA, van Oerle R, Hamulyák K, Waltenberger JL, ten Cate H. Thrombin generation and coagulation markers in patients with a first acute myocardial infarction. XXIth International Society on Thrombosis and Haemostasis Congress, Geneva, Switzerland, 2007.

Dielis AWJH, Winkens MHM, Spronk HMH, Wijers-Holys PA, van Oerle R, Hamulyák K, Waltenberger JL, ten Cate H. Thromboxane B2 in patients with a first acute myocardial infarction: The influence of treatment with acetylsalicylic acid. XXI ${ }^{\text {th }}$ International Society on Thrombosis and Haemostasis Congress, Geneva, Switzerland, 2007.

Ten Cate AJ, Dielis AWJH, Spronk HMH, van Oerle R, Hamulyák K, Prins MH, ten Cate H. Levels of factor VIII, D-dimer and thrombin generation in patients after acute deep vein thrombosis. XXIth International Society on Thrombosis and Haemostasis Congress, Geneva, Switzerland, 2007.

Ten Cate AJ, Dielis AWJH, Spronk HMH, van Oerle R, Hamulyák K, Prins MH, ten Cate H. Thrombin generation in patients after recent deep vein thrombosis versus healthy controls. XXIth International Society on Thrombosis and Haemostasis Congress, Geneva, Switzerland, 2007.

Dielis AWJH, Smid M, Spronk HMH, van Oerle R, Govers-Riemslag JWP, van der Voort D, Houben B, Hamulyák K, Kroon AA, ten Cate H, de Leeuw PW. Changes in fibrinolytic 
activity after angiotensin II receptor blockade in therapy-resistant hypertensive patients. $16^{\text {th }}$ European Meeting on Hypertension, Madrid, Spain, 2006.

Dielis AWJH, Spronk HMH, van Oerle R, Fens D, Prins M, Rosing J, Ruiters L, Waltenberger J, Hamulyák $\mathrm{K}$, ten Cate $\mathrm{H}$. Monitoring endogenous thrombin generation in healthy individuals and patients after a first acute myocardial infarction. $46^{\text {th }}$ Annual Scientific Meeting incorporating The Netherlands and British Haemostasis Societies, Edinburgh, Scotland, 2006.

Dielis AWJH. Referaat: Rokers met periodontitis hebben vaker coronarialijden. Nederlands Tijdschrift voor Geneeskunde. 2005;149:2587-2588 [RF].

Dielis AWJH, Smid M, Spronk HMH, van Oerle R, Govers-Riemslag JWP, van der Voort D, Houben B, Hamulyák K, Kroon AA, de Leeuw PW, ten Cate H. Changes in fibrinolytic activity after angiotensin II receptor blockade in therapy-resistant hypertensive patients. XXth International Society on Thrombosis and Haemostasis Congress, Sydney, Australia, 2005.

Curvers J, Dielis AWJH, van Wersch JWJ. High intake of pain killers in whole blood donors. 56 th $^{\text {th }}$ American Association of Blood Banks Annual Meeting, San Diego, CA, 2003.

\section{Awards}

Travel award. 49 $9^{\text {th }}$ American Society of Hematology Annual Meeting, Atlanta, GA, 2007.

Poster award. 46 th Annual Scientific Meeting incorporating The Netherlands and British Haemostasis Societies, Edinburgh, Scotland, 2006.

Kootstra fellowship research grant. Faculty of Medicine, Maastricht University, Maastricht, The Netherlands, 2005. 


\section{Dankwoord}

En als alles dan zo goed als achter de rug is rest er nog maar één, heel belangrijke, taak. Dus voor iedereen die me, op verschillende en geheel eigen wijze, heeft gesteund, geholpen en bijgestaan: bedankt! En in het bijzonder:

Prof. dr. ten Cate, of liever: Hugo. Onze eerste ontmoeting was in een kamertje op de uni dat, op twee stoelen en een tafel na, helemaal kaal was. De kantoren en het lab van Klinische Trombose en Haemostase moesten nog ingericht worden. Hoewel ik dacht dat het een leuk kennismakingsgesprek was, was jij in de veronderstelling dat ik kwam solliciteren en was ik meteen welkom om als promovendus te beginnen. En die directe en spontane manier van werken heb ik de afgelopen jaren erg gewaardeerd. Als clinicus wist je me een goede balans te geven tussen wetenschappelijke kansen (en congressen!) en klinische taken (bij de Trombosedienst en de DVT-poli), net zoals je het lab een fijne balans hebt gegeven tussen basaal en klinisch onderzoek. Zoals je weet zal ik niet geheel uit de onderzoeksgroep verdwijnen, en hoewel mijn opleiding in eerste instantie veel energie van me zal vergen verheug ik me op onze samenwerking na mijn promotie. Nogmaals, bedankt!

Prof. dr. de Leeuw, beste Peter, hoewel het onderwerp van mijn promotie langzaam is verschoven van hypertensie-gerelateerde problemen naar een algemenere benadering van verhoogde stollingsneiging, ligt de eerste aanzet in onze prettige samenwerking. Onder jouw en Hugo's leiding kreeg ik de kans om redelijk vanaf nul een weg voor het onderzoek uit te stippelen en dat heeft uiteindelijk geleid tot dit boekje. Helaas was het niet mogelijk om alle ideeën daadwerkelijk uit te voeren, maar ze liggen nog klaar. Dus misschien voor de toekomst? Bedankt voor het delen van je enorme kennis en ervaring met alles wat met hypertensie samenhangt.

Dr. Spronk. Maar ik geloof niet dat ik je ooit zo heb genoemd, Henri. Net zoals je mij mijn weg hebt zien vinden in het onderzoek, zo heb ik jou ook zien veranderen van de (soms iets te) eerlijke Henri naar een (soms iets te) eerlijke Henri met twee heel schattige ventjes. Het is ongelooflijk om zo veel taken op je te nemen en die vervolgens zo goed uit te voeren: promovenus-coach, ICT-manager, criticus, grappenmaker en "dagelijks leider". Ik vond het heel prettig om samen te werken met iemand die altijd zegt wat-ie denkt. Maar bovenal supergezellig. Veel geluk met Jessica en de ventjes. En in de toekomst blijf ik je gewoon lastig vallen met alle vragen die me binnenvallen...

Dr. Hamulyák, beste Karly, bedankt voor je altijd kritische, maar ook bemoedigende commentaren. Je kon er altijd goed op toezien dat, als er weer nieuwe resultaten te bespreken waren, de relevantie voor de kliniek niet uit het oog werd verloren. Met name het laatste jaar heb je ook regelmatig als supervisor van de poli opgetreden, en ik kan alleen maar hopen dat ik tijdens mijn verdere klinische werk dezelfde fijne 
ondersteuning mag tegenkomen.

Dr. Rosing, beste Jan, ondanks dat we niet tijdens veel projecten hebben samengewerkt was het fijn dat er op de achtergrond kritisch werd meegekeken met wat ik nu eigenlijk deed. Bovendien was er op de woensdagochtendbespreking altijd nog wel een vraag te vinden waarover ik nog niet zo had nagedacht. Ondanks dat ik door mijn verschillende aanstellingen dan wel, en dan weer niet officieel deel uitmaakte van de vakgroep Biochemie heb ik me altijd thuisgevoeld op "jouw" afdeling.

Machiel, oh sorry, dokter Smid, we zijn als partners in crime op hetzelfde project begonnen, maar na een tijdje begonnen onze boekjes en schema's een eigen richting te krijgen. Maar met jou samenwerken (en congressen en cursussen bezoeken, inclusief de bijbehorende feestjes) was superleuk. Ik ken niemand met zo veel talent voor fantasietaal uitkramen, youtube-filmpjes zoeken en (héél veel) dochters opvoeden. Succes met je laatste jaartje onderzoek, gaat zeker lukken, en misschien tot in de kliniek. Veel geluk met Rachel en de andere dames.

Sarah, het eerste jaar hebben we elkaar een beetje misgelopen en ik vroeg me dan ook serieus af wie die blonde Belgische was daar verderop in de gang. Maar gelukkig zijn we de afgelopen tijd echte maatjes geworden en ik zal je als collega dan ook erg missen, maar ik ben er van overtuigd dat we elkaar buiten het werk om nog blijven zien. Veel succes zul je niet nodig hebben om je eigen boekje af te ronden, en voorlopig blijf je nog op het schip dat Klinische Trombose en Haemostase heet. En geef Guy nou eindelijk eens zijn champagne met aardbeien!

Kim, de charmante Vlaamse met een echte "Hollandse" grote mond. We hebben ontelbare leuke (en slechte) dingen gedaan, van feestjes in Houthalen tot karaokeachtergrondkoor in Sydney, en van Daan tot quiznight. Maar het mooiste was wel temidden van een groepje dieractivisten terechtkomen op Pukkelpop, haha. Veel plezier met Dan en jullie eigen huisje. En voor je Luikse collega's hoop ik dat je geen spat bent veranderd...

Arina, we hebben heel wat uurtjes achter de pc doorgebracht op zoek naar $P$ waarden, en we hebben er ook een heel stel gevonden. Genoeg om te promoveren op een heel mooi proefschrift! "Jouw" DVT-poli gaf mij de mogelijkheid klinische taken naast het onderzoek te blijven houden en daar heb ik veel aan gehad. Ik heb onze samenwerking erg fijn gevonden en ik wens je veel succes met je nieuwe opleiding.

René, de duizendpoot van het lab. Voor een stapel metingen (én humor) draaide jij je hand niet om. En als we eens wilde plannen aan het maken waren kon je ons met een praktisch antwoord weer terug op aarde zetten. En da's maar goed ook. Maar ik ben nog wel heel erg benieuwd naar dat ene, prachtige uitzicht over Genève, Bertje.

José, onze "ambassadrice" van de contactactivatie. Al die jaren hebben we (met anderen) een kantoor gedeeld, en dat was erg gezellig. Net als ons tripje naar Atlanta en New York, waar we met een goede combinatie van onze onderzoeken terecht zijn gekomen. Bedankt!

Diane, onze buikdansende technisch expert op het gebied van trombinegeneratie. 
Als ik voor elke sample die je voor me hebt gemeten "Bedankt" zou moeten schrijven, dan was dit boekje minstens dubbel zo dik geworden. Gelukkig heb ik nog een prachtige foto van jou achter de Fluoroskan waarop je laat zien dat laboratoriumonderzoek gecombineerd kan worden met modellenwerk. Bedankt. Bedankt. Bedankt. Bedankt etc.

Carina, als ik je belde was dat bijna altijd om door te geven dat ik veel werk voor je had. Heel veel werk. En je was altijd bereid om bloed af te nemen voor de hypertensiestudie als ik er eens niet was. Kortom, je hebt me enorm geholpen. Bedankt voor de koffie en veel geluk voor je hele gezin in jullie nieuwe huis.

Marina, the femme fatale from Bergamo. As a true Italian, you were able to make a perfect balance between lunch, work, lunch, coffee breaks and lunch. Oh, and wearing sunglasses indoors. It was very nice to have a hint of Mediterranean atmosphere in our room. Besides all this, you truly are an assistant professor. Ciao bella!

Julian, you and your humour too brought atmosphere into our room, but more in a Bulgarian-Chinese kind of way... I'm convinced that your persistence and hard work will bring you very far. For the last time I will repeat what I said almost every day: "Have a nice evening, and greetings to Geri".

Evren, you are the living evidence that the Dutch language is not too hard to learn in quite a short time. The next step is getting all that particulate matter behaving like it should. Good luck with your thesis, and you may even be able to write it in Dutch!

In het bijzonder wil ik Kristien succes wensen die, alsof ze het nog niet druk genoeg zal krijgen met haar eigen promotieonderzoek bij Tilman, een hele stapel klinische taken van me zal overnemen. Maar op de voortvarende manier waarop jij te werk gaat zal dat geen enkel probleem worden. Als je je auto tenminste met vier wielen op de grond geparkeerd krijgt...

Hjalmar, waar je ook uithangt (Nepal, Thailand, Amsterdam), groeten uit Maastricht!

Veerle, bedankt voor al je uren data verwerken. Ik weet niet hoe je het naast je coschappen voor elkaar kreeg, maar je was een grote hulp. Succes in het buitenland.

Daniëlle, misschien tot in Sittard, Patricia, welkom terug op het lab, Iris, succes met je jaartje onderzoek en Bianca, bedankt voor je labwerk en succes in het azM.

Een bedankje voor de hele gang voor de gezelligheid bij de koffieautomaat en de kritische noot op woensdagochtend: Chris, Connie, Elke, Gerry, Guido, Heidi, Hugo, Imke, Jeroen, Judith, Kees, Kenneth, Kirsten, Kristof, Leo, Leon, Lisbeth, Marijke, Marion, Menno, Nico, Olivier, Paola, Rory, Sandra, Saskia, Simone, Stella, Svetlana, Theo, en Tilman.

Trees, dé secretaresse en zowat moeder van de afdeling, die me door haar verhalen over reizen altijd zin in vakantie liet krijgen. Bedankt voor je wijze raad en hulp bij al die vervelende formulieren. Wat zou Biochemie zonder jou moeten?

In het azM heb ik regelmatig samengewerkt met Patricia, Wolfgang, en Daniëlle, en dat was altijd even aangenaam. Met name Patricia zorgde voor heel wat afleiding, en dat vond ik eigenlijk wel heel leuk. Jammer dat je het azM gaat verlaten, maar veel succes 
met alles wat er komen gaat (en met kleine Koen).

De afdelingen Speciële stolling en Haematologie van het azM zagen me elke maandagochtend heen-en-weer sjouwen met patiënten en bloedbuizen, en hielpen me waar nodig zonder problemen. Met name Paul, Daniëlle, Carol en Mariëlle.

De dames van het Hart- en Vaatcentrum zorgden er elke week weer voor dat de (onderwijs)poli zo soepel mogelijk verliep. En het Hypertensieteam op het Hart- en Vaatcentrum regelde een continue stroom patiënten voor onze hypertensiestudie en ik wil hen dan ook bedanken voor hun eindeloze inzet.

Bram en Boy van Interne Geneeskunde, Mark en Professor Waltenberger van Cardiologie, Elisabetta, Prof. Hemker, Wim van Delbia BV, Peter en Tim van Thrombinoscope BV, Marcel, Joost en Ester van het AMC, en Martin ben ik dankbaar voor hun bijdragen.

De Stichting Trombosedienst Maastricht die me onderdak verleende gedurende de laatste anderhalf jaar heeft ervoor gezorgd dat ik dit project tot een goed einde kon brengen. En de dames van de Trombosedienst zorgden ervoor dat er nooit een tekort aan thee, koekjes, spekken en chocolade was tijdens het doseren. In het bijzonder, Jolanda, Loes en Marie-José, bedankt voor de gezellige samenwerking.

Als Koosje (reisgenoot exceptionelle) me niet aan Joyce (stagebegeleidster exceptionelle) had voorgesteld toen ik nog geen zin had om een wetenschapsstage te regelen was ik waarschijnlijk nooit zo enthousiast geraakt over onderzoek. Ik kan jullie dus niet dankbaar genoeg zijn.

The Coca-Cola Company krijgt een compliment voor het maken van het lekkerste drankje ter wereld, waarvan ik enkele badkuipen vol nodig heb gehad tijdens de afgelopen jaren. En dat heeft Hugo heel wat tijd gekost (één of twee keer per dag op en neer naar de automaat), jammer dus dat ze geen sponsorverzoek konden inwilligen...

En waar zou ik zijn zonder mijn familie en vrienden? Mijn ouders verdienen een enorm dankjewel voor alle ondersteuning in de afgelopen, zeg 29, jaren en voor alle kansen die ik mocht benutten. Pap, mam: bedankt! En ook Eva en Birgit (én Joeri en Niek) verdienen een pluim voor hun interesse en gezelligheid, maar vooral voor hun enorme doorzettingsvermogen.

En last but not least, lieve Steffie. Niemand ter wereld kan zo overtuigend zeggen dat het allemaal goed komt, en de laatste paar maanden heb je dat wat vaker moeten zeggen dan voorheen. Maar je hebt gelijk gekregen, alles is inderdaad goed gekomen. Bedankt voor je steun en hulp, ik hou van je.

\section{Arne}

